\title{
GEOTECHNICAL PROPERTIES AND FLOW BEHAVIOR OF COAL REFUSE \\ UNDER STATIC AND IMPACT LOADING
}

\author{
by \\ HAO YU \\ Submitted in partial fulfillment of the requirements \\ For the degree of Doctor of Philosophy

\section{Dissertation Advisor:} \\ Professor Xiangwu Zeng \\ Department of Civil Engineering \\ CASE WESTERN RESERVE UNIVERSITY
}

January, 2015 


\title{
CASE WESTERN RESERVE UNIVERSITY SCHOOL OF GRADUATE STUDIES
}

\author{
We hereby approve the thesis/dissertation of \\ Hao Yu \\ candidate for the degree of Ph.D.*. \\ Committee Chair \\ Xiangwu Zeng
}

Committee Member

Adel Saada

Committee Member

Xiong Yu

Committee Member

Weihong Guo

Date of Dense

$11 / 19 / 2014$

*We also certify that written approval has been obtained for any proprietary material contained therein. 


\section{TABLE OF CONTENTS}

NOTATION ............................................................................................................................................ V

LIST OF TABLES................................................................................................ VIII

LIST OF FIGURES.........................................................................................................................X

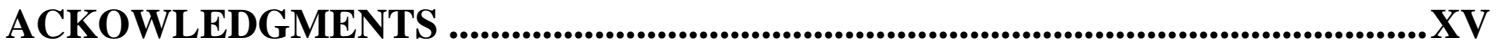

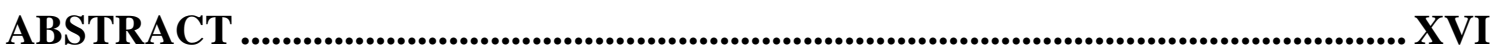

Chapter 1 INTRODUCTION......................................................................................................1

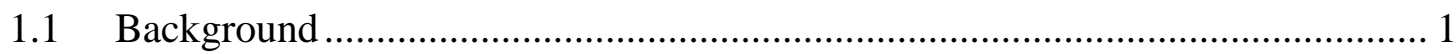

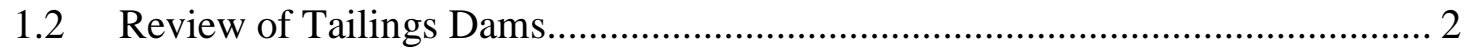

1.2.1 Construction of Tailings Dams ............................................................. 4

1.2.2 Disposal of Fine Refuse in Impoundments ............................................. 8

1.3 Review of Flow Failure of Tailings Dams...................................................... 9

1.4 Review of Breakthrough of Impounded Coal Refuse into Underground Mine. 13

1.5 Review of Flow Failure Mitigation for Tailings Dams .................................... 16

1.6 Motivation and Research Objectives ............................................................. 19

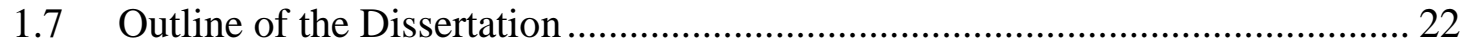

Chapter 2 GEOTECHNICAL PROPERTIES OF COAL REFUSE ..........................24

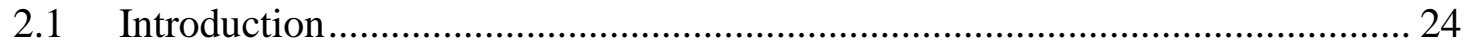

2.2 Sample Collection and Preparation............................................................ 24

2.3 Geotechnical Properties of Coal Refuse …………………………............... 25

2.3.1 Particle Size Distribution ................................................................. 26 


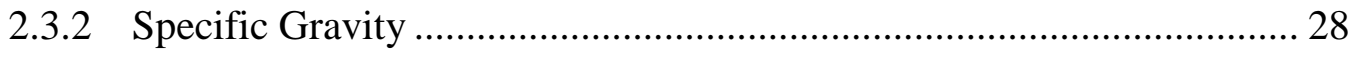

2.3.3 Atterberg Limits Tests ...................................................................... 30

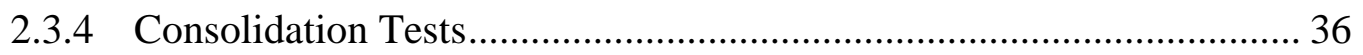

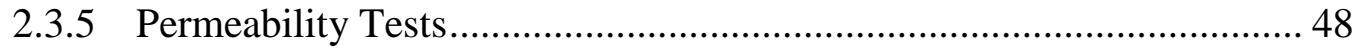

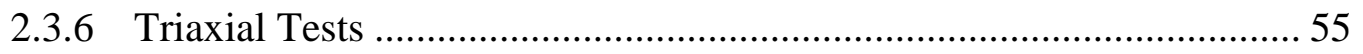

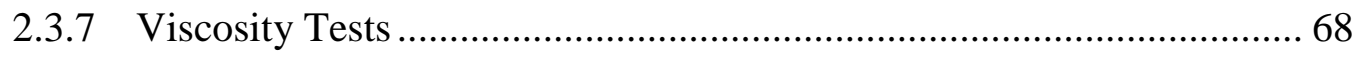

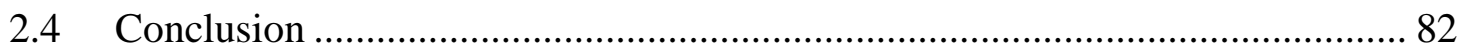

Chapter 3 ANALYSIS OF FLOW BEHAVIOR OF COAL REFUSE BY SMALL

SCALE MODEL TESTS...........................................................................86

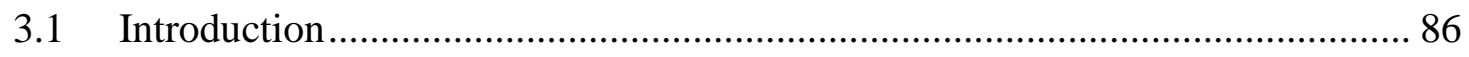

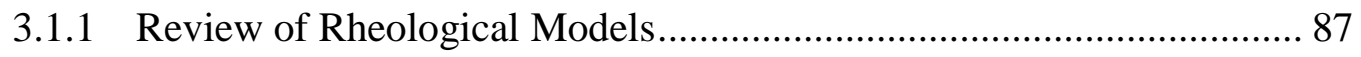

3.1.2 Determine Rheological Parameters of Bingham Plastic Flow ............... 91

3.2 Model Preparations and Test Procedures............................................................. 93

3.2.1 Flume Tests under Static Loading …………………........................... 93

3.2.2 Flume Test under Impact Loading ................................................... 95

3.3 Test Results and Analysis under Static Loading............................................... 98

3.3.1 Representation of Coal Refuse by Bingham Plastic Model................. 106

3.3.2 Estimation of Flow Regime ………………….................................. 115

3.3.3 Velocity Profile ................................................................................ 119

3.3.4 Relationship between Flow Velocity and Viscosity …….................... 122

3.4 Test Results and Analysis under Impact Loading......................................... 125

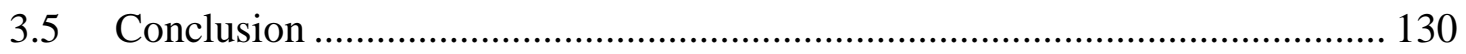




\section{Chapter 4 ANALYSIS OF FLOW BEHAVIOR OF COAL REFUSE BY CENTRIFUGE MODEL TESTS ................................................................133}

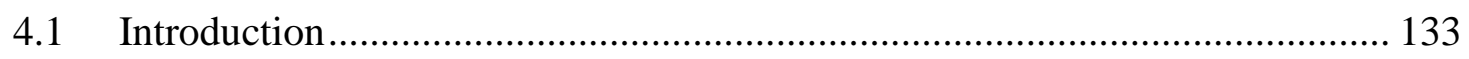

4.1.1 Review of Geotechnical Centrifuge Test ............................................. 134

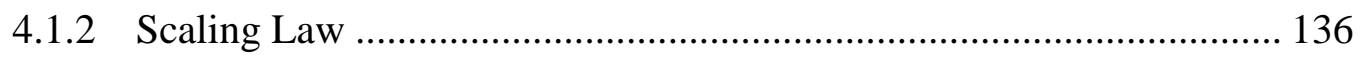

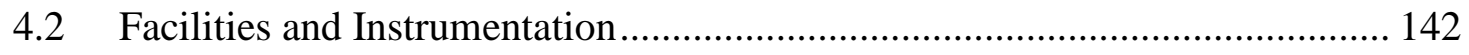

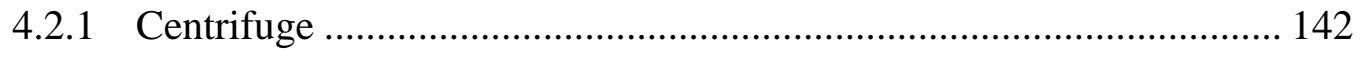

4.2.2 Pore Pressure Transducers ................................................................. 144

4.2.3 Flow Container for Centrifuge Test ................................................. 145

4.3 Model Preparations and Test Procedures........................................................ 149

4.4 Test Results and Analysis under Static Loading ............................................. 151

4.5 Test Results and Analysis under Impact Loading.......................................... 156

4.6 Evaluation of Slurry Cell as a Countermeasure ……..................................... 163

4.6.1 Review of Coal Refuse Slurry Cells .................................................... 163

4.6.2 Centrifuge Model Preparations ........................................................... 165

4.6.3 Test Results and Analysis .................................................................. 166

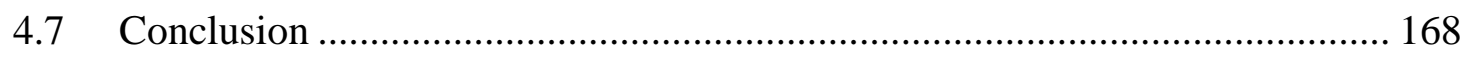

Chapter 5 CONCLUSIONS AND RECOMMENDATIONS .......................................170

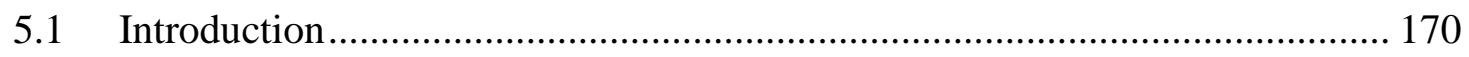

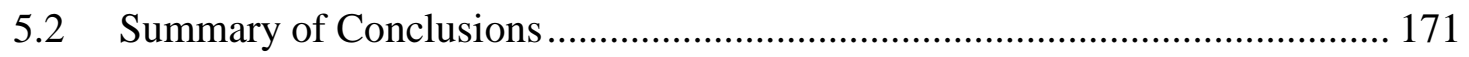

5.2.1 Geotechnical Properties of Impounded Coal Refuse ............................ 171

5.2.2 Flow Behavior of Impounded Coal Refuse under Static Loading ....... 174 
5.2.3 Flow Behavior of Impounded Coal Refuse under Impact Loading ..... 176

5.2.4 Effectiveness of Slurry Cells as a Countermeasure .......................... 177

5.3 Recommendations for Future Study ................................................ 178

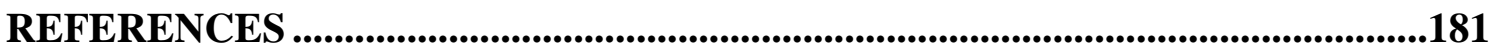




\section{NOTATION}

a cross-sectional area of standpipe

A cross-sectional area of soil mass through which flow q takes place

B Skempton's pore pressure parameter

c cohesion of soil

$c_{s} \quad$ shape factor

$c_{u} \quad$ undrained shear strength

$C_{c} \quad$ compression index

$C_{s} \quad$ swelling index

$C_{v} \quad$ coefficient of consolidation

d hydraulic radius in the open channel

$D_{s} \quad$ effective grain diameter

e void ratio

$e_{0} \quad$ initial void ratio

$F_{f} \quad$ flow factor

$\mathrm{G}_{s} \quad$ specific gravity

h total head difference across the flow path of length $\mathrm{L}$

$\mathrm{H}_{\mathrm{dr}} \quad$ maximum drainage path

He Hedstrom number

$h_{1} \quad$ hydraulic head across soil sample at the begin of test $(\mathrm{t}=0)$ 
$h_{2} \quad$ hydraulic head across soil sample at the end of test

i hydraulic gradient

$I_{p} \quad$ plasticity index

$k \quad$ hydraulic conductivity

KY coal refuse sample collected from Kentucky

L length of sample or flow path that produces the head difference $h$

$m_{v} \quad$ coefficient of volume change

$\mathrm{N} \quad$ scaling factor

q quantity of fluid flow in a unit time

$\bar{q} \quad$ deviator stress

Re Reynolds number

$\operatorname{Re}_{c} \quad$ critical Reynolds number

$\mathrm{t} \quad$ time required to get $\mathrm{V}$ volume

$t_{50} \quad$ time elapsed at 50 percent consolidation

$T_{v} \quad$ time factor

$\mathrm{u} \quad$ excessive pore water pressure

v flow velocity

V collected volume of water

WV coal refuse sample collected from West Virginia

$W_{n} \quad$ water content

$w_{L} \quad$ liquid limit

$w_{p} \quad$ plastic limit 


\begin{tabular}{ll}
$\alpha$ & slope angle \\
$\sigma$ & normal stress on the plane of shearing \\
$\sigma_{3}$ & confining pressure \\
$\sigma_{t}$ & total vertical stress \\
$\tau$ & shear stress \\
$\tau_{f}$ & shear strength at failure \\
$\tau_{y}$ & yield stress \\
$\phi$ & friction angle of soil \\
$\gamma_{w}$ & unit weight of pore fluid \\
$\gamma_{\gamma}$ & shear rate or velocity gradient \\
$\eta$ & viscosity of fluid \\
$\eta_{p}$ & plastic viscosity \\
& \\
\hline &
\end{tabular}




\section{LIST OF TABLES}

Table 2-1 Summary of laboratory tests conducted on coal refuse ................................... 26

Table 2-2 Summarized results of specific gravity test................................................ 29

Table 2-3 Summarized results of Atterberg limit tests ..................................................... 34

Table 2-4 Comparison of Compression Index $C_{c}$ and Swelling Index $C_{s} \ldots \ldots \ldots \ldots \ldots \ldots \ldots \ldots . . . . . . . .44$

Table 2-5 Compression index $C_{c}$ for different types of soils (Widodo and Ibrahim, 2012) 45

Table 2-6 Typical ranges of permeability for various soils ............................................ 54

Table 2-7 Typical cohesion value for different soil groups (after Lindeburg, 2003) ....... 67

Table 2-8 Typical viscosity values of various materials (after Mezger, 2002) ................ 70

Table 2-9 Range table of each spindle under different velocities (unit: $\mathrm{cp}$ ) .................... 76

Table 2-10 Recorded viscosities of KY samples with different water content (unit: cp). 79

Table 2-11 Recorded viscosities of WV samples with different water content (unit: cp) 81

Table 3-1 Reference summary of published researches on the impact loading (after Charlie, 1988) 97

Table 3-2 Variation of flow velocities of KY sample with water content and slope angle (Unit: $\mathrm{m} / \mathrm{sec}$ ) 100

Table 3-3 Variation of flow velocities of WV sample with water content and slope angle (Unit: $\mathrm{m} / \mathrm{sec}$ ) 100

Table 3-4 Recorded travel distance and flow depth in the midstream of KY sample .... 101

Table 3-5 Recorded travel distance and flow depth in the midstream of WV sample ... 101

Table 3-6 Determination of shear rate from rotational speed 108 
Table 3-7 Recorded viscosities of KY sample at different water content and shear rate 109

Table 3-8 Recorded viscosities of WV samples at different water content and shear rate 110

Table 3-9 Determination of critical Reynolds number for KY sample 117

Table 3-10 Determination of critical Reynolds number for WV sample. 117

Table 3-11 Determination of flow regime for KY sample 118

Table 3-12 Determination of flow regime for WV sample. 118

Table 3-13 The summarized test results of KY sample under impact loading $\left(\alpha=30^{\circ}\right) 126$ Table 3-14 The summarized test results of WV sample under impact loading $\left(\alpha=30^{\circ}\right)$ 127

Table 4-1 Scaling relationship for centrifuge test (N: scaling factor) 138

Table 4-2 Pore Pressure Transducer PDCR81 (Source: GE Sensing). 144

Table 4-3 Comparison of liquid limit with critical water content in centrifuge tests ..... 152 Table 4-4 Recorded travel distance and flow depth of two samples in the centrifuge tests 153

Table 4-5 Determination of flow regime in the centrifuge tests 156

Table 4-6 The summarized results of centrifuge tests under impact loading $\left(\alpha=30^{\circ}\right) . .159$

Table 4-7 The summarized results of centrifuge tests with slurry cells ( $\alpha=30^{\circ}$ ) 167 


\section{LIST OF FIGURES}

Figure 1-1 Overview of a typical coal waste tailings dams (Michael et al., 2013) ........... 3

Figure 1-2 Construction of starter dike (after Volpe, 1979) .......................................... 4

Figure 1-3 Three construction methods for embankment (after Zeng, 2003)................... 5

Figure 1-4 Disposal of fine refuse in impoundment (after Zeng, 2003) ......................... 8

Figure 1-5 Failure of impoundment in Buffalo Creek area ........................................ 12

Figure 1-6 Slurry impoundment basin and adjacent coal mine workings (after NRC, 2002)

Figure 1-7 Breakthrough failure occurred at the Big Branch slurry impoundment in Martin

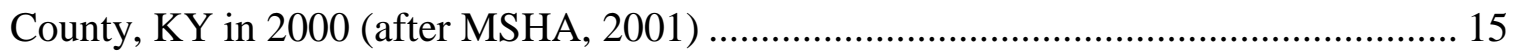

Figure 2-1 Collected sample from coal preparation plant ........................................ 25

Figure 2-2 Particle size distribution curve for KY sample and WV sample .................. 28

Figure 2-3 Liquid limit test on coal refuse sample (the groove has closed $12.7 \mathrm{~mm}$ )...... 31

Figure 2-4 Relationship between water content and blow number $\mathrm{N}$ for KY sample (Liquid

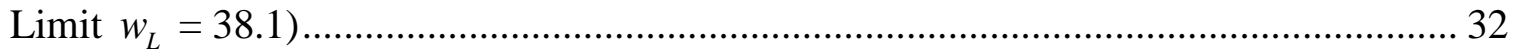

Figure 2-5 Relationship between water content and blow number $\mathrm{N}$ for WV sample (Liquid

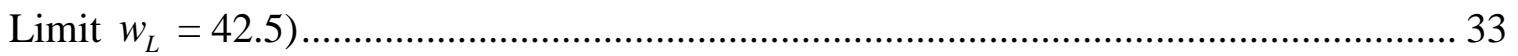

Figure 2-6 Plastic limit test on coal refuse sample .................................................. 33

Figure 2-7 Plasticity chart to use for the Unified Soil Classification System ................. 35

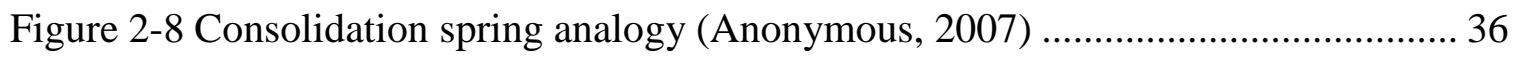

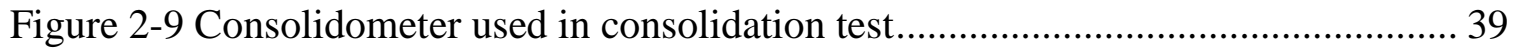

Figure 2-10 An example plot of dial reading vs. log time in minute............................. 39 
Figure 2-11Summarized results of coefficients of consolidation $C_{v}$ for KY sample ...... 41 Figure 2-12 Summarized results of coefficients of consolidation $C_{v}$ of WV Sample ...... 42 Figure 2-13 Void ratio vs. pressure for KY samples with different initial water content 43 Figure 2-14 Void ratio vs. pressure for WV samples with different initial water content 44 Figure 2-15 Compressibility of mine tailings as a function of void ratio (Qiu and Sego, 1998) 46

Figure 2-16 A schematic diagram of constant-head permeability test (after Hanson et al., 2013) 49

Figure 2-17 A schematic diagram of constant-head permeability test (after Chang et al., 2013) 50

Figure 2-18 Falling-head permeability test apparatus 52

Figure 2-19 Comparison of permeability test results of two samples .......................... 53

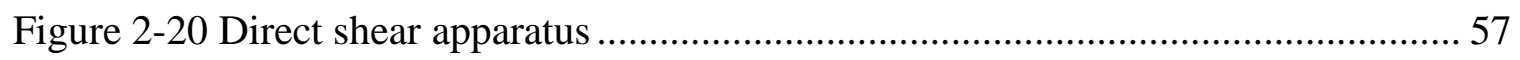

Figure 2-21 Triaxial chamber with external LVDT and load cell (FHWA, 2007).......... 58

Figure 2-22 Mohr stress circles and developed strength envelope.............................. 59

Figure 2-23 Prepared test sample and triaxial chamber for triaxial tests....................... 61

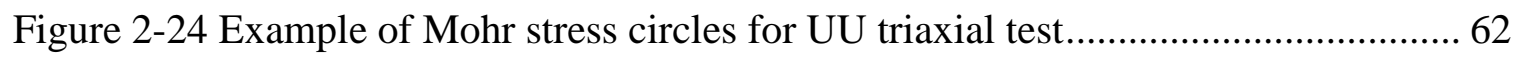

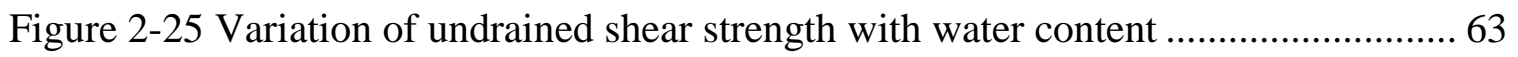

Figure 2-26 Results of consolidated-drained (CD) tests for KY sample ....................... 65

Figure 2-27 Results of consolidated-drained (CD) tests for WV sample ........................ 65

Figure 2-28 Variation of $\Phi$ ' with water content for two samples................................ 66

Figure 2-29 Shear flow by using Two-Plates-Model (after Vlachopoulos, 2003) .......... 69

Figure 2-30 a) U-tube viscometer; b) Falling sphere viscosity ................................. 72 
Figure 2-31 Schematic diagram of rotational viscometer (after Anonymous, 2012) ...... 73

Figure 2-32 Structure of NDJ-8S digital rotary viscometer: (1) Level indicator (2) LCD (3)

Housing (4) Protection bracket (5) Base (6) Operation key (7) Rotor connector (8) Rotor

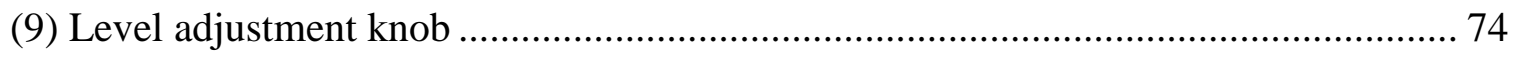

Figure 2-33 Four types of spindles of NDJ-8S digital rotary viscometer....................... 75

Figure 2-34 Example plot of viscosity vs. time (water content $=40 \%$, rotational speed=6rpm) 78

Figure 2-35 Water content vs. viscosity of KY sample under different rotational speeds 80 Figure 2-36 Water content vs. viscosity of WV sample under different rotational speeds 81

Figure 3-1 Basic models of rheological behavior (after Kawatra et al., 1995) ................ 89

Figure 3-2 Pseudo-Bingham Plastic Model (after Krizek, 2004) ................................. 92

Figure 3-3 Small-scale model for flow study under static loading .............................. 94

Figure 3-4 Small-scale model test for flow study under impact loading ....................... 96

Figure 3-5 Example of the variation of flow velocity with distance for KY sample at initial

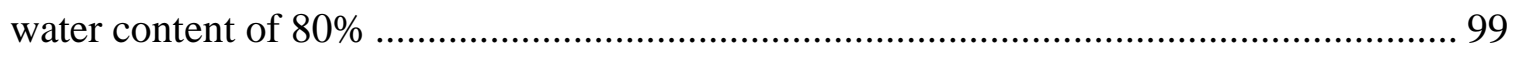

Figure 3-6 The flows of KY sample at different water content (w) and slope angle ( $\alpha$ ) 102 Figure 3-7 The flows of WV sample at different water content (w) and slope angle $(\alpha) 103$ Figure 3-8 Comparison of variations of viscosities with rotational speed at $50 \%$ and $80 \%$

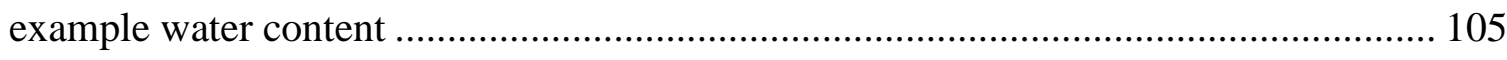

Figure 3-9 Comparison of flow velocity of two coal refuse samples varying with initial

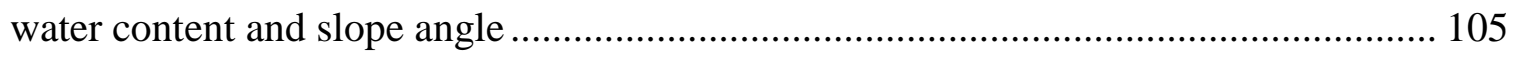

Figure 3-10 Sketch of cylindrical spindle rotating in the tested fluid......................... 107 
Figure 3-11 Variation of viscosity with shear rate for $\mathrm{KY}$ coal refuse sample $\left(23^{\circ} \mathrm{C}\right) .110$ Figure 3-12 Variation of viscosity with shear rate for WV coal refuse sample $\left(23^{\circ} \mathrm{C}\right) . .111$ Figure 3-13 Determination of flow parameters of Bingham Plastic model (KY coal refuse sample, $\mathrm{w}=80 \%$ ) 112

Figure 3-14 Bingham Plastic model for KY samples at different water content 113

Figure 3-15 Bingham Plastic model for WV samples at different water content 113

Figure 3-16 Schematic of flow configuration (De Kee et al., 1990) 120

Figure 3-17 Comparison of flow profile at different water content (WV sample)......... 121

Figure 3-18 The relationship between flow velocity and viscosity of KY sample........ 123

Figure 3-19 The relationship between flow velocity and viscosity of WV sample........ 123

Figure 3-20 Results of impact loading tests on KY sample under different compressive

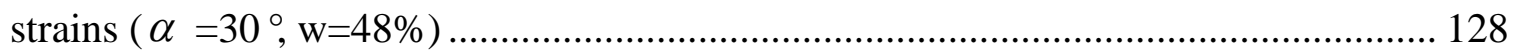

Figure 3-21 Results of impact loading tests on WV sample under different compressive

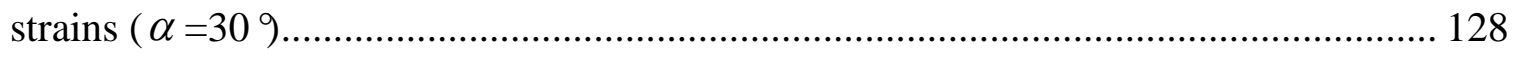

Figure 4-1 Gravity effects in prototype and model (after Schofield, 1980) .................. 137

Figure 4-2 CWRU geotechnical centrifuge ......................................................... 143

Figure 4-3 Cross-sectional view of CWRU centrifuge (after Figueroa et al., 1998) ..... 143

Figure 4-4 Rigid box on the CWRU geotechnical centrifuge .................................... 144

Figure 4-5 The design drawing of model container for centrifuge test (unit: $\mathrm{cm}$ ) ......... 145

Figure 4-6 The flow container in the centrifuge test.............................................. 146

Figure 4-7 Actuator used in the centrifuge test.................................................... 147

Figure 4-8 Design of centrifuge model test under impact loading ............................. 149

Figure 4-9 Centrifuge test results for two coal slurry samples ................................. 152 
Figure 4-10 Flow of KY coal refuse sample in the centrifuge tests

Figure 4-11 The centrifuge model test under impact loading.

Figure 4-12 Flow of coal refuse in the centrifuge tests under impact loading $\left(\alpha=30^{\circ}\right) 161$

Figure 4-13 Recorded pore water pressure under impact loading 162

Figure 4-14 Coal refuse slurry cells (after Wu et al., 2003; and Michael et al. 2010) ... 164

Figure 4-15 Centrifuge model with coarse refuse build cells 165

Figure 4-16 Recorded pore water pressure under impact loading by using slurry cells . 168 


\section{ACKOWLEDGMENTS}

I would like to express my deep gratitude to my advisor, Professor Xiangwu Zeng,

for his guidance and support during my graduate study. He has given me opportunities to be involved in many prominent projects. He is also a great mentor who always encourages me to keep a proactive attitude in my study and a positive faith in my life.

I am grateful to Professor Adel S. Saada and Professor Xiong Yu for their guidance, encouragement, and dedication in the years of my study at CWRU.

I also want to sincerely thank Professor Weihong Guo for her extraordinary teaching and for being a member of the graduate committee.

I appreciate the assistance and support from Mr. Jim Berilla in regards to experiment preparation and data acquisition.

This work is funded by U.S. Department of Interior Office of Surface Mining Reclamation and Enforcement. I am grateful for the financial support throughout this project.

Many thanks are extended to all faculty members, staffs, and my fellow graduate students in the Department of Civil Engineering for their consistent support over the years.

Last, but most importantly, I would like to thank my wife Xiang Li for her understanding and love during the past years. Her support and encouragement was in the end what made this dissertation possible. My appreciation is also conveyed to my parents, parents-in-law, and all the members in my big family for their everlasting support and love. 


\title{
Geotechnical Properties and Flow Behavior of Coal Refuse under Static and Impact Loading
}

\author{
ABSTRACT \\ By \\ HAO YU
}

Millions of tons of coal refuse are produced every year and need to be stored in the coal waste tailings dams. Since the impounded fine coal refuse has high water content and low shear strength, the tailings dams is susceptible to the flow failure under static and dynamic impact loading. In some other cases, the coal slurry might break through into the adjacent or underground mines and thereafter flow into the groundwater resources and river ecosystems. It has been known that flow failure of coal waste tailings dams would cause severe property damage, loss of human lives, and environmental issues. Without adequate information and measurement techniques, there is no comprehensive study reported on the properties and flow behavior of impounded coal refuse as well as the failure mechanism.

In this study, a comprehensive investigation was carried out on the geotechnical properties and flow behavior of impounded coal refuse under static and impact loading by using a range of laboratory tests, small-scale model tests, and centrifuge model tests. The combined results would help to better understand the flowability of coal refuse and the failure potential of tailings dams. In addition, a potential countermeasure was proposed by using slurry cells. Its effectiveness in reducing the risk of flow failure was evaluated in centrifuge model tests. 


\section{Chapter 1 INTRODUCTION}

\subsection{Background}

With the continuous increasing of oil price in recent years, coal still plays an important role as the largest energy source for domestic energy consumption. In the U.S., nearly 90 percent of the produced coal is used in the power plant and accounted for more than 50 percent of electric power generation in 2000 (Freme and Hong, 2000).

In order to comply with the government air quality regulations in the U.S., coal is often processed near coal mines to remove some impurities before the coal is transported to power plants. Every year, millions of tons of coal refuse are produced in the U.S. and stored in the coal producing regions such as Alabama, Illinois, Indiana, Kentucky, Ohio, Pennsylvania, and West Virginia. Hundreds of coal waste tailings dams have been built in the past few decades to store coal refuse materials.

Tailings dam is a common infrastructure in the coal mining field and is characterized by hydraulically placed fills held in place by a coarse refuse build embankment. Fine refuse from coal processing is in general too wet to be used as construction material for embankment and is disposed as slurry in an impoundment. The fine refuse with particle size similar to silt has quite low strength and permeability. The consolidation of the coal waste impoundment may take many years to finish. The adverse properties of fine refuse as well as some particular construction method result in high potential of flow failure of coal waste tailings dams under static loading and dynamic disturbance. 
Flow failure of tailings dams has been reported many times in the past few decades in the form of overall slope failure or breakthrough of impounded coal slurry into underground mine under static and/or dynamic impact loading. The failed tailings dams would release huge amount of tailing waste causing not only property damage and loss of lives, but also significant environmental problems as the waste material it supports can be hazardous.

There is not enough information about the mechanical properties of the impounded coal-waste fine refuse especially the flow behavior of the material. In addition, there is lack of clear criteria determining if the tailings dam has adequate stability under static and impact loading. In this research, a comprehensive study was performed on the geotechnical properties and flow behavior of coal refuse under static and dynamic impact loading. The mechanism of response was evaluated using laboratory tests, small-scale model tests, and centrifuge model tests.

\subsection{Review of Tailings Dams}

Tailings, also called refuse or mine dumps, are a waste byproduct of mining. They are in general uneconomic fraction of the run-of-mine coal and are often left over after purification of coal. The composition of tailings is primarily dependent on the composition of the coal and the process of mineral extraction. The processing typically includes: removing extraneous materials, crushing and grinding, sizing, blending coal from several locations, and mineral concentration (Committee on Coal Waste Impoundments, 2002). As described by Jeyapalan (1980), the mineral concentration is as low as $0.4 \%$ of the total 
weight of the ore body. The vast majority proportion of the ore body is disposed in the form of tailings.

The crushed tailings are either spigotted or cyclone to separate the coarse refuse (with the grain size ranging from $0.1 \mathrm{~mm}$ to $70 \mathrm{~mm}$ ) and fine refuses (with the grain size ranging from $0.001 \mathrm{~mm}$ or less to $20 \mathrm{~mm}$ ). A typical coal-waste tailings dam includes an embankment made of relatively dry coarse refuse and impoundment slurry of fine refuse. An overview of a tailings dam was shown in Figure 1-1. The characteristics of this distinct infrastructure in the coal mining regions were introduced as the following.

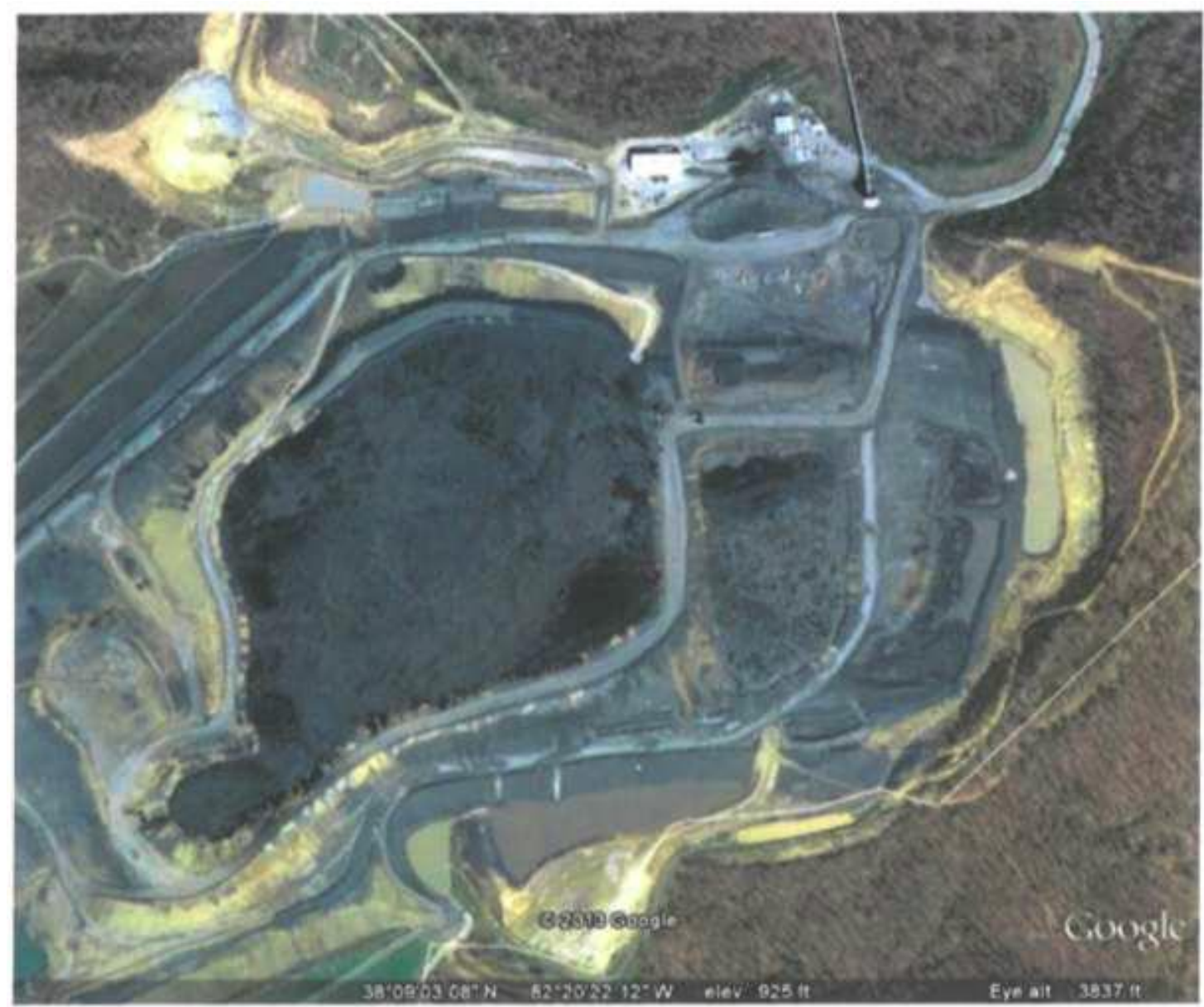

Figure 1-1 Overview of a typical coal waste tailings dams (Michael et al., 2013) 


\subsubsection{Construction of Tailings Dams}

In the initial period, the tailings after processing are too wet to be used in constructing a dike. Considering this reason, it is common to construct a "starter dike" or "starter embankment" as shown in Figure 1-2. The starter dike would provide a safe reservoir in the initial stage of construction. With the increasing volume of disposed coal slurry into impoundment, the embankment is constructed in several stages by continuously stacking new dikes. The height of a tailings dam could be more than three hundred meters.

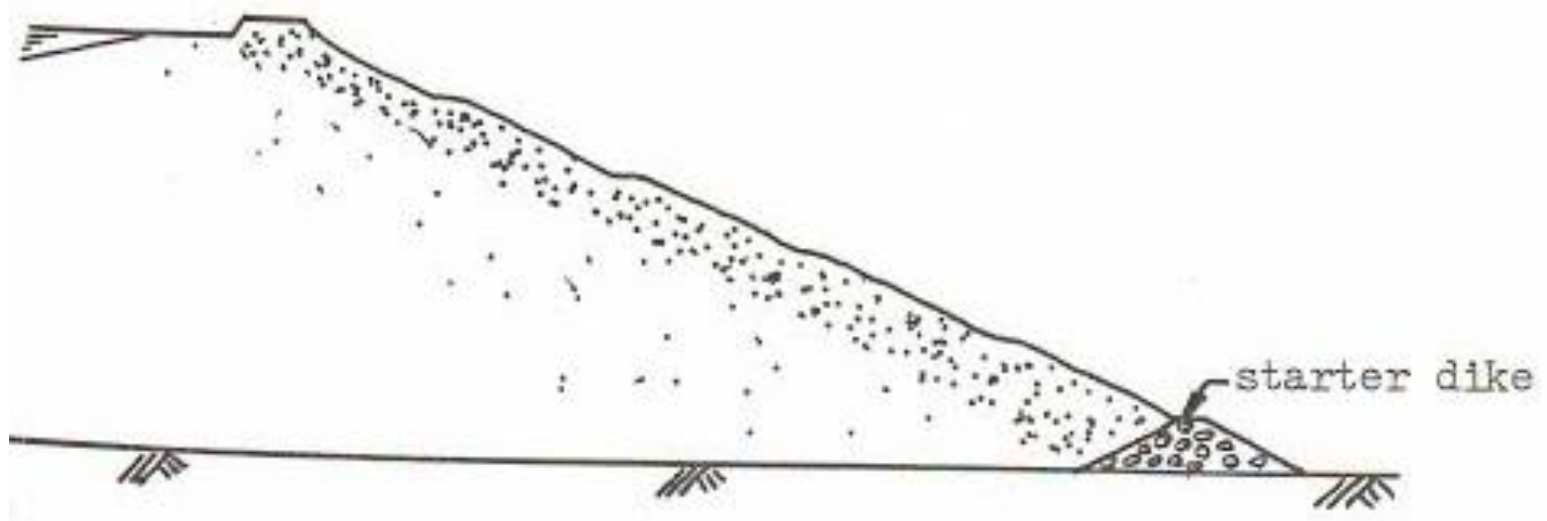

Figure 1-2 Construction of starter dike (after Volpe, 1979)

Following the completion of a starter embankment on initial stage, there are three different construction methods for tailings dams used in the field. As shown in Figure 1-3, these are:

- Downstream method

- Upstream method

- Centerline method 


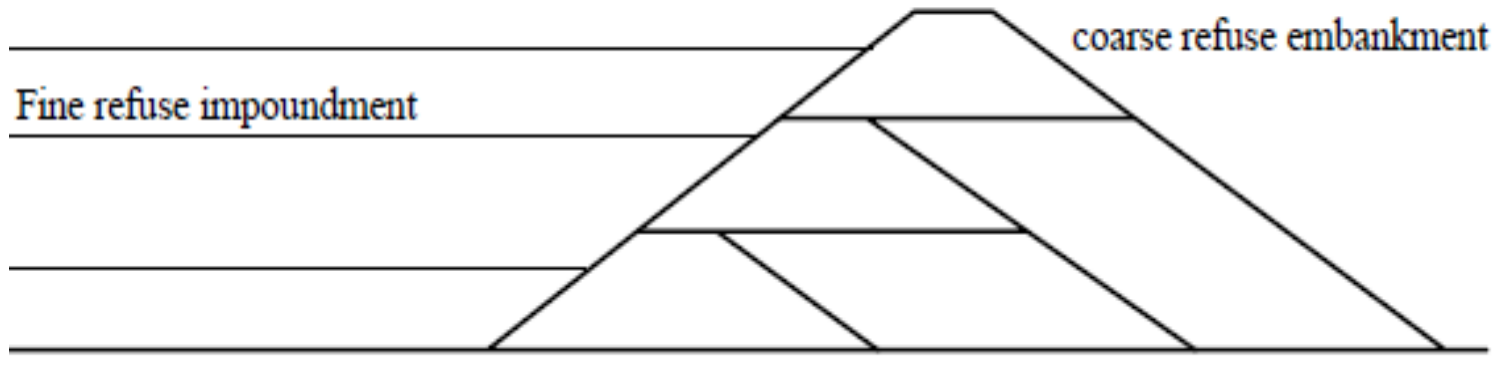

Downstream construction

Fine refuse impoundment

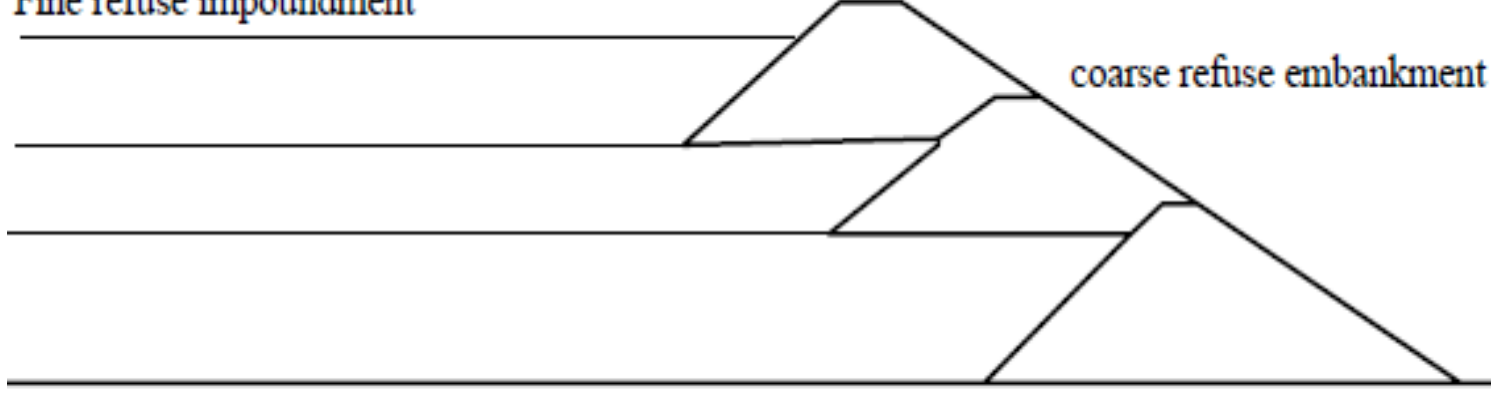

Upstream construction

Fine refuse impoundment

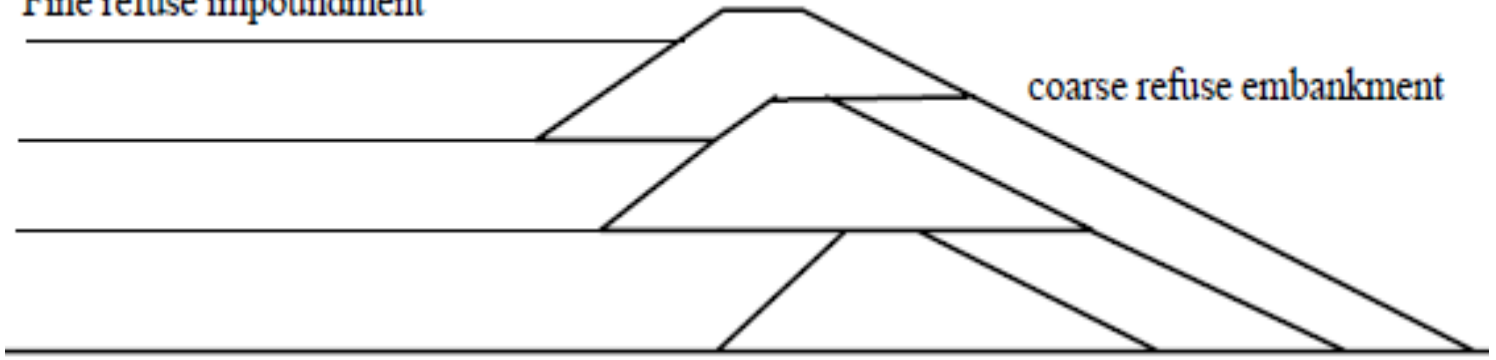

Centerline construction

Figure 1-3 Three construction methods for embankment (after Zeng, 2003)

The performance and stability of a tailings dam is primarily dependent on the construction method of embankment. The characteristics of three construction methods were introduced as the following:

\section{Downstream Method}


Downstream method is the least common used for the construction of tailings dam embankment. In this type of construction method, the newly built dike is not placed on the previous discharged fine refuse. The centerline of the embankment is moved downstream with subsequent raises. Since the embankment is not underlain by poorly draining and weak fine refuse, the downstream method is generally more stable than upstream and centerline methods. However, downstream method requires quite a large volume of construction materials with subsequent embankment raises. In addition, the facilities downstream of the embankment including sedimentation ponds, pump stations, and others may cause confliction with future structural fill and construction.

\section{Upstream Method}

Upstream method is the oldest and most commonly used tailings dam construction method. In the initial stage of this construction method, the fine refuse is hydraulically discharged from the crest of the starter dike to form a beach. The fine refuse in the edge of the impoundment is used as foundation for a second embankment raise. Construction continues in this manner as the height of embankment keeps increasing. Opposite to the downstream method, the embankment centerline is moved upstream with sequential raises. The advantages of the upstream construction method include its simplicity and economicalefficiency. Also, it will not conflict with the construction of downstream facilities. However, the prominent limitation of the upstream method is related to its inherent weakness and is due to the fact that embankment is sitting on foundation which is partially formed by the low-strength and low-permeability fine refuse. As stated by Committee on Coal Waste Impoundments in 2002: "Under static loading conditions, the ultimate 
embankment height will depend on the strength of the consolidated fine refuse within the zone of shearing, the steepness of the downstream slope of the embankment, and the location of the phreatic surface within the embankment. Under seismic loading, the stability of the embankment depends on the potential of the consolidated fine refuse to liquefy". Therefore, the upstream embankment has the least stability and is only suitable to the site with low seismic hazard.

\section{Centerline Method}

Centerline method of tailings dam construction is a compromise between the upstream method and downstream method, and is limited to cases where cyclones are used to separate the coarse and fine fractions (Jeyapalan, 1980). As seen from Figure 1-3, the embankment is raised by filling materials on both sides of the previous dike with the crest of embankment raised nearly vertically. The centerline embankment is between the upstream and downstream embankment regarding to the quality, stability and requirement of construction materials.

The selection and construction of tailings dams are dependent on the topographical

and geological condition, project budget, supply of construction material, and potential geological/geotechnical hazards in the project site. The stability of coal waste tailings dams is evaluated with the identical procedures and criteria used for the water dams (Wilson and Marsal, 1979; and U.S. Army Corps of Engineers, 1982). However, the average unit weight of liquefied fine coal refuse is nearly twice of that of water. Therefore, it should be noted that tailings dams retaining saturated materials (especially those constructed by upstream 
method) has less stability than conventional water dams and deserve more careful engineering attentions.

\subsubsection{Disposal of Fine Refuse in Impoundments}

With the completion of certain stage of embankment, the fine refuse is thereafter mixed with water and pumped as slurry into the impoundment (see Figure 1-4). Huge amount of water is required to transport fine refuses in pipe from processing plant to the impoundment in case the viscous materials stick in the pipelines. Therefore, the impounded fine refuse is typically too wet to be placed in the fills. The fine particles settle (consolidate) under gravity. Due to the high percent of fine particles and thereby low permeability, consolidation process may take quite a long time ranging from several months to a few years. It would result in significant instability of tailings dams when used as foundation of the embankment.

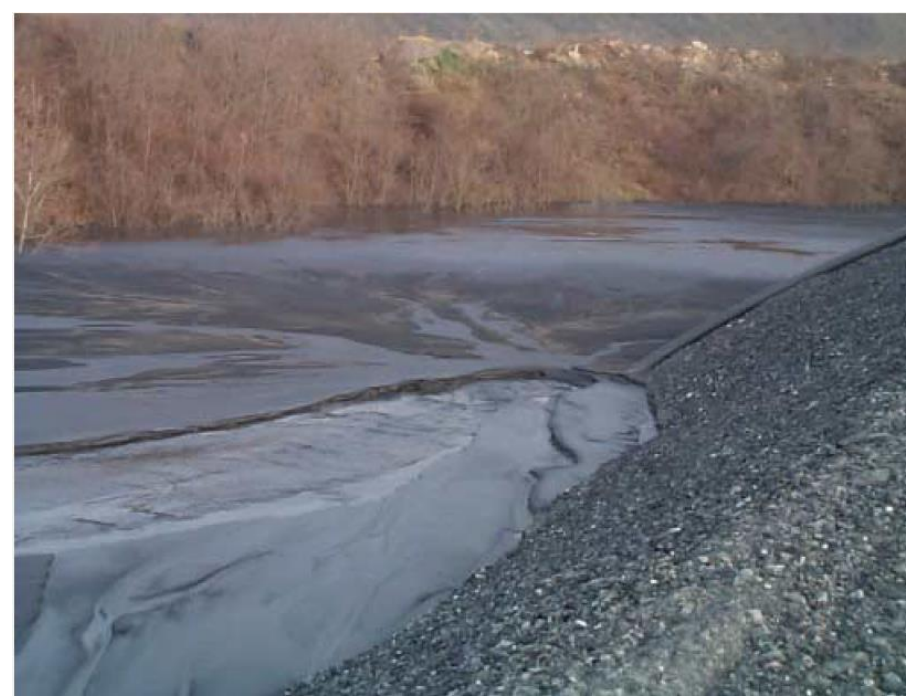

Figure 1-4 Disposal of fine refuse in impoundment (after Zeng, 2003) 


\subsection{Review of Flow Failure of Tailings Dams}

According to the statement from National Inventory of Dams, there are more than 700 coal waste tailings dams in the U.S. 241 of them are classified as having high hazard potential (facilities whose failure could reasonably be expected to cause loss of human life, serious damage to houses, industrial and commercial buildings, important utilities, highways, and railroads) by FEMA hazard rating system. Government regulatory agencies such as the Office of Surface Mining (OSM) and the Mine Safety and Health Administration (MSHA) require comprehensive stability analysis in the design of new tailings dams, which creates unique challenges to geotechnical engineers.

The major design calculation is a slope stability analysis under the static loading and dynamic loading which evaluates the possibility of sliding of a segment of the embankment together with the fine refuse in the impoundment. One of the critical issues in the stability analysis is the flowability of impounded fine refuse at high water content. Fine coal refuse has quite different properties from natural soil in terms of fabric, structure, unit weight, and composition. According to experiments on fine refuse at a number of sites in the field (Huang and $\mathrm{Li}, 1987$ ), the non-plastic fine particles make up more than 50\% of the fine refuse. The flow failure of fine refuse in an impoundment can be triggered by static loading or dynamic impact loading.

The problem of instability of mining waste was first realized by Casagrande (1950) as early as 1950 . He concluded after studying several case histories of such failure that: "chemical and mining wastes consisting of flour-sized material are usually deposited hydraulically in very loose condition. Although they may appear stable behind some of the flimsiest dikes and in some cases supported only by a thin wall of the same material which 
has dried along the slopes, they are extremely sensitive to disturbance and constitutes treacherous conditions which in some instances have caused disastrous flow slides with much loss of life and property."

Once flow failure of tailings dam occurs, it can cause significant property damage, loss of lives and environmental issues as the waste material can be hazardous. The most well-known flow failure of coal-waste tailings dam in the U.S. occurred in the Appalachian coal field at Buffalo Creek in West Virginia on February 26, 1972. As shown in Figure 15 , the tailings dam was built on a thick layer of wet, loose sludge making it highly susceptible to flow failure. It collapsed suddenly during a rainstorm which filled in the pond. The resulting flood released $500,000 \mathrm{~m}^{3}$ of black refuse and water into the valley below. 117 people were confirmed dead and 7 were reported missing. In addition, 1121 were injured and over 4000 were left homeless (Anonymous, 2014).

The flow failure of tailings dams during dynamic impact loading and earthquake loading has been reported many times in seismic active area. A similar failure of tailings dam to that in Buffalo Creek occurred at Ages Creek in Kentucky in 1981. According to the report from Office of Surface Mining, at mid-night prior to the failure, some new coalwaste slurry was dumped into the pond. As reported by an eye witness, when the new material was dumped into the pond, a significant stress wave was felt which might consequently trigger the flow failure. The International Workshop on Seismic Stability of Tailings Dams sponsored by NSF and MSHA and organized by Prof. Zeng was held at Case Western Reserve University in 2003. Prof. Idriss (2003) presented a keynote lecture in the workshop and indicated that there have been more than 15 cases of liquefactioninduced failure of tailings dams in the past 40 years. Dobry and Alvarez (1967) reported 
widespread tailings dam failures during earthquakes in Chile. For instance, the EL Cobre dams were almost completely destroyed during the 1965 earthquake. More than 2 million tons of tailings flowed into the valley, traveled $12 \mathrm{~km}$ in a few minutes, destroyed part of the town of EL Cobre, and killed more than 200 people. The major cause of the failures was believed to be the overall slope stability failure as a result of soil liquefaction. Similar type of failure was repeated during the Central Chile Earthquake of March 3, 1985. Failures with similar patterns were also reported in Japan by Ishihara (1992).

The seismic stability of tailings dams have been studied in the past few years. Thacker et al. (1988) and Zeng (2003) conducted an experimental study on the mechanical properties of coal refuse and concluded that excess pore water pressure could build up in fine refuse under cyclic shear stress. Jayapalan et al. (1983a, 1983b) studied the failure mechanism and the resulting displacement of tailings dams due to the liquefaction of tailings material using theoretical analysis and small-scale model tests at 1-g condition. The liquefied coal refuse was treated as a highly viscous fluid. Zeng et al. (1998a, 1998b, 1998c) studied the seismic stability of tailings dam by using centrifuge model tests and found the downstream embankment has the least deformation and the highest stability under earthquake loading. In addition, they performed a number of SPT tests and laboratory tests on fine refuse collected from a tailings dam in eastern Kentucky. It was found that the fine refuse was a silt-like powder with low plasticity and high potential to be liquefied under earthquake. Al-Hussaini et al. (1981) performed centrifuge model tests with varying geometrics and properties of coal refuse and confirmed that positive seepage control can be beneficial to tailings dams. 

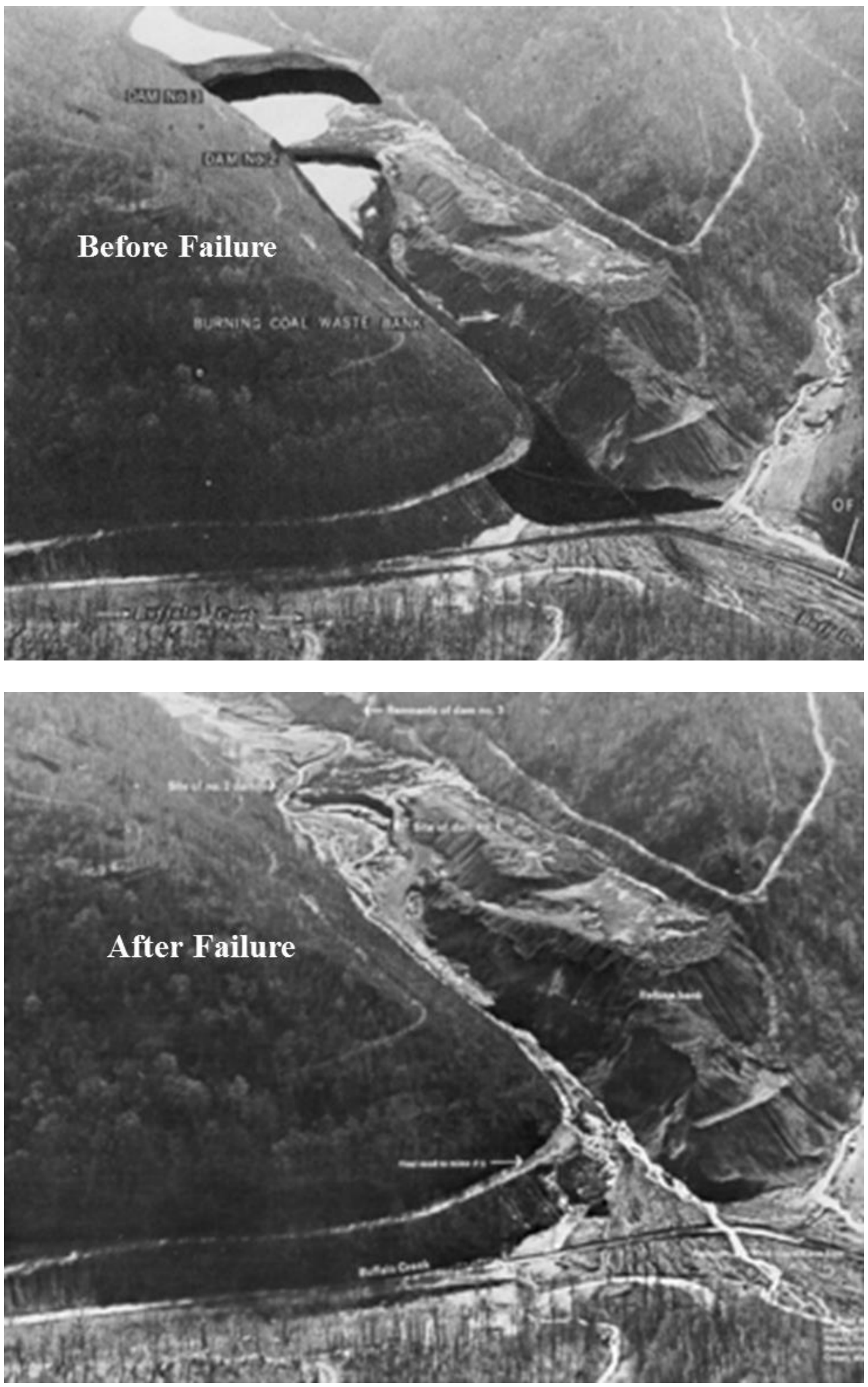

Figure 1-5 Failure of impoundment in Buffalo Creek area 


\subsection{Review of Breakthrough of Impounded Coal Refuse into Underground Mine}

In addition to the failure of embankment, the other thorny issue that has concerned OSM and MSHA for many years is the potential of breakthrough of impounded coal slurry into underground mines. There are no appropriate methods or available techniques that could accurately locate the underground mines and determine if they are adjacent to or underlying coal waste impoundment. There are no regulation and design criteria either to evaluate the breakthrough potential of impoundments.

For some coal waste impoundment located adjacent or right above the underground mines (see Figure 1-6), the breakthroughs of coal refuse would endanger the lives of mine workers and downstream inhabitants. In addition, the breakthroughs of coal refuse would result in significant environmental problems as the coal waste contaminant may flow into the groundwater resources and river ecosystems.

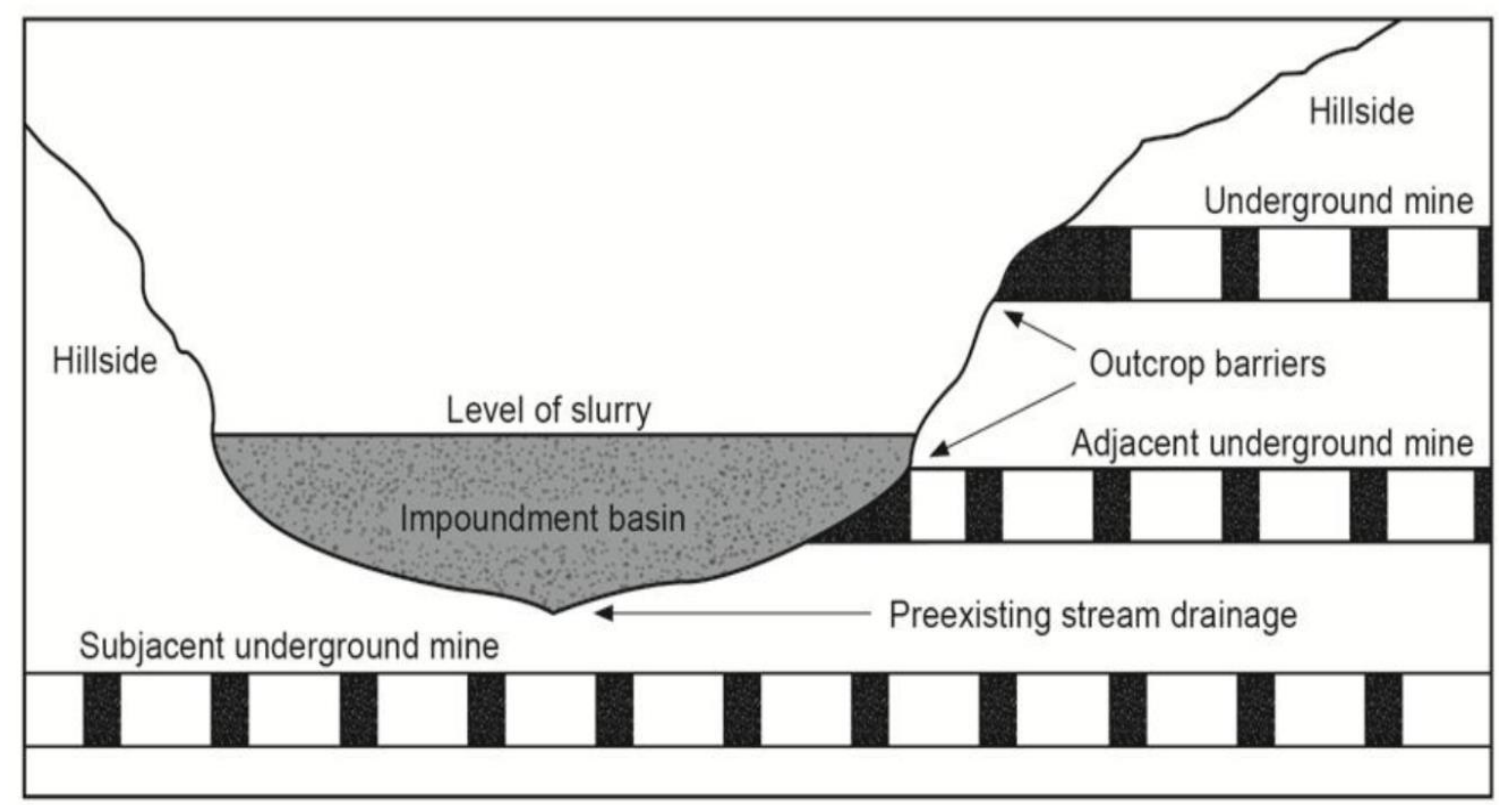

Figure 1-6 Slurry impoundment basin and adjacent coal mine workings (after NRC, 2002) 
In 1996, there was a breakthrough at Miller Cove slurry impoundment. According to the report, approximately 2.75 inches of rain had fallen into the pond about one and a half hours before the failure of impoundment. Approximately 1 million gallons of coal waste materials were released into Gin Creek through an abandoned mine (Michalek et al., 1996). According to the further exploration by excavating breach, it was found that the leak occurred in an area where existing mine maps indicated a barrier of at least 25 feet of solid coal between the outcrop and the underground mine workings. The hydrostatic pressure from the slurry was believed to expand cracks in the coal seam and initiated a piping-type failure.

A similar breakthrough of Big Branch slurry impoundment occurred in Martin County, Kentucky in 2000. As shown in Figure 1-7, more than 250 million gallons of coal slurry was released into a nearby underground coal mine and thereafter flowed into nearby creeks and rivers causing tremendous environmental damages. No loss of lives was reported in this accident. However, "the release killed aquatic life along the Tug Fork of the Big Sandy River and its tributaries. Public water supplies were disrupted when communities along the rivers in both Kentucky and West Virginia shut down water plants to prevent contamination with black water. American Electric Power had to close its massive generating plant, and numerous properties and residences were damaged." - stated by Committee on Coal Waste Impoundments (2002). Congress also paid high attention on this incident and requested National Research Council to evaluate the breakthrough failure and find some ways to reduce the potential for similar accident in the future. 


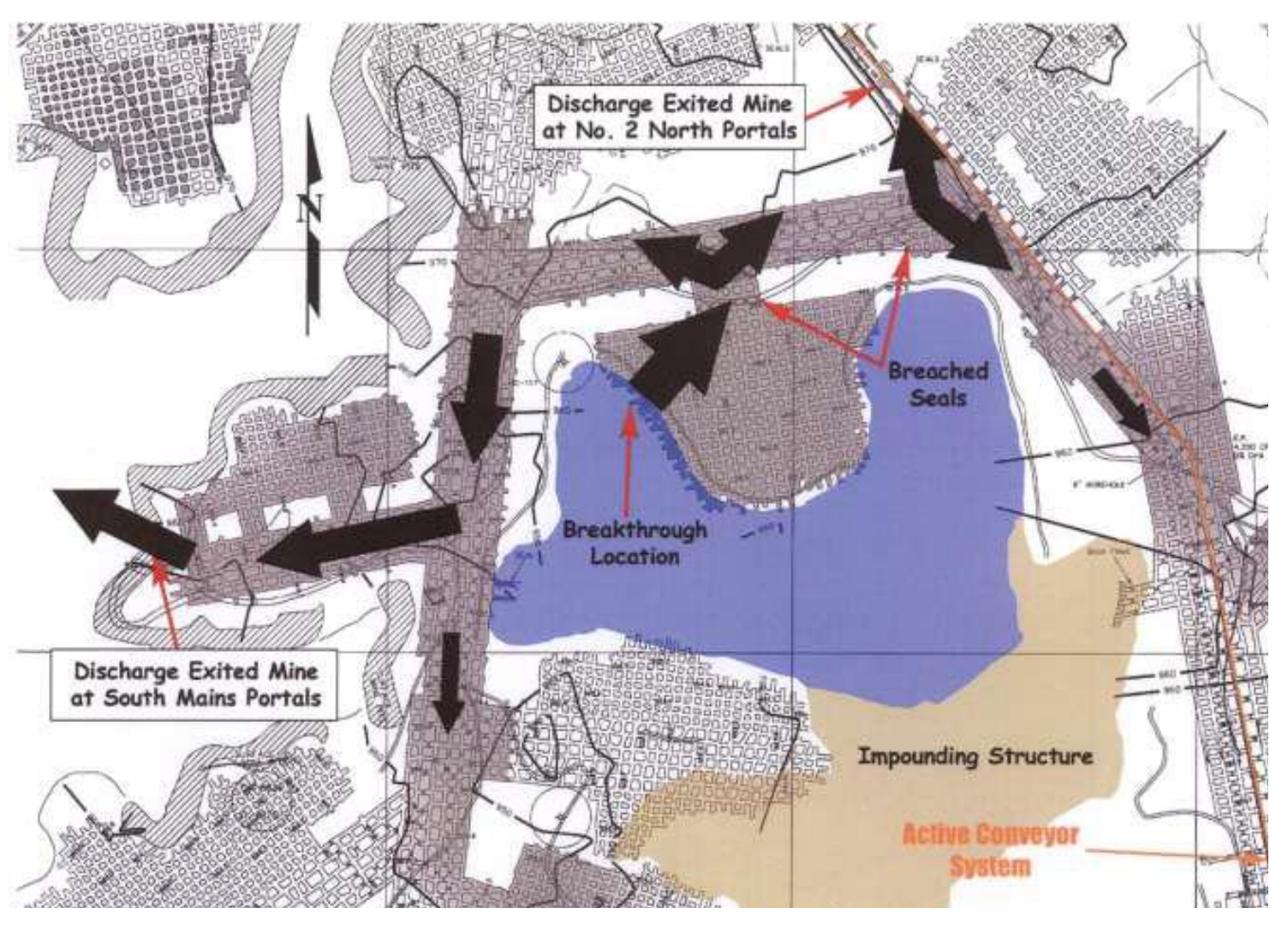

Figure 1-7 Breakthrough failure occurred at the Big Branch slurry impoundment in Martin County, KY in 2000 (after MSHA, 2001)

National Research Council (NRC) (2002) performed a prominent investigation on the coal waste impoundment and also examined current specifications, regulations, and engineering practices intending to find effective measures to improve underground mine locations relative to the impoundment as well as evaluate available techniques that could maximize utilization and therefore reduce the amount of produced coal refuse. Michael et al. (2010) performed comprehensive literature review on the case histories of the breakthrough failure of coal waste impoundment. In addition, they carried out thorough investigation to assess the potential of the breakthrough failure, the cause and mechanism of the event, and the applicable techniques and mitigations to prevent flow failures. 
According to their investigations, two of the most significant concerns are related to: (1) it is difficult to find a criterion to determine the occurrence of breakthrough failure; (2) the flow behavior of impounded coal refuse has not been well studied in the past years so that the damage caused by flow failure can not be accurately predicted.

\subsection{Review of Flow Failure Mitigation for Tailings Dams}

Engineering recommendations and in-depth investigations on the mitigation measures have been proposed in the past few decades regarding to the failures of embankment and breakthroughs of impounded slurry into underground mines.

Al-Hussaini et al. (1981) verified the geometrics and properties of coal refuse in the centrifuge model tests and confirmed the positive effect of seepage control on the stability of tailings dams. Zeng (2003) studied the dynamic properties of coarse refuse and fine refuse by performing a range of laboratory tests. He also built centrifuge models to compare the seismic behaviors of tailings dams with different construction methods of embankments (Zeng et al., 1998). The results demonstrated that the hydraulically placed fine coal refuse remained as a loose viscous material with high void ratio and little shear resistance even after a long period of consolidation. Under seismic loading, the downstream exhibited the greatest stability in retaining the softened fine refuse in terms of the least subsidence and sliding. However, the downstream embankment would not commonly used in the field due to the excessive requirement of construction material and confliction with downstream facilities.

In the case of less stable upstream embankment, dewatering and densification of impounded fine refuse were suggested by Committee on Coal Waste Impoundments (2002), 
Shinavski (2006), and Michael et al. (2010). It might take long time for wet fine refuse to be consolidated into a statically and dynamically stable material. Decant system and spillways (principal, auxiliary, and emergency) were recommended by MSHA (2009) in order to control direct runoff at the slurry impoundment. Michael and Chavel (2008) assessed the effect of reclamation of fine coal refuse impoundment on the breakthrough potential and derived positive conclusion. They found that the reclamation process would remove water from above the slurry and decrease surface water and groundwater infiltration into the reservoir, and consequently reduce the hydrostatic pressure on mine barriers and the flowability of coal refuse.

In addition to the cross-valley and diked impoundments, some impoundment alternatives are available by reducing the storage capacity of coal slurry and thereafter the potential of flow failure risk.

\section{Incised Pond}

Incised pond is a small size impoundment used for the disposal of fine coal refuse. It has been widely used in the Midwest regions where surface mining is primarily conducted on flat topography. Incised ponds has no embankment but are designed to impound any form of coal refuse including slurry. The water table in an incised pond is typically below the ground surface. The flow failure or breakthrough failure of impoundment would not be a major issue as a result of the reduced reserve of coal slurry. 


\section{Slurry Cells}

The concept of slurry cell is to reduce the total capacity of flowable material to a level that is consistent with a low-hazard-potential classification for the facilities. The impoundment is constructed with a number of individual cells with the designed slurry storage capacity of less than 20 acre-feet. Each cell is small and self-contained and can be designed according to the strength properties of the coarse refuse (Committee on Coal Waste Impoundments, 2002). The slurry cells were found to work effectively when act as drainages of impounded coal slurry. MSHA (2009) demonstrated that slurry cells are preferable for impoundment with relatively shallow depth of slurry in the cells. The flowability of fine coal refuse would be less significant after dewatering and capping. However, the construction of slurry cells, like cross-valley and diked embankment, are also dependent on the topographical condition in the vicinity of the coal mine, which is more applicable to the site with flat terrain.

\section{Combined Refuse Piles}

Combined refuse piles are non-impounding facility and in general consist of fine coal refuse that has been dewatered away from the site and combined with coarse refuse. Providing the small size and low moisture content, the flow failure of this type of facility is not the major concern in the design. However, the control of water content is a common issue in the process of dewatering. In addition, it is difficult to handle and compact the dewatered material. Regarding these limitations, the combined refuse pile is typically an expensive solution in mitigating flow failure of coal waste impoundment. 
One of the most effective methods to reduce the volume of material in constructed or abandoned impoundments is to recover the fine coal refuse. Old impoundment has tremendous amount of refuse material with recoverable energy value. At the same time, it is necessary to improve the processing techniques to reduce the production of coal refuse with high energy value being deposited in the impoundment. Other innovative technologies should be investigated to reduce the need for coal refuse impoundments. Stout et al. (2004) summarized the technology innovations to improve the safety of coal waste tailings dams and divided them into three categories:

- Technologies to improve safety of existing impoundments

- Technologies to reduce the volume of impoundments by dewatering the slurry or by extracting more amounts of valuable components from the slurry during coal processing.

- Technologies to detect/identify underground mine void (i.e. ground penetration radar)

\subsection{Motivation and Research Objectives}

It has been recognized for a long time that flow failure of tailings dams would result in significant property damage, loss of lives and environmental issues. Due to the extremely low permeability of impounded fine coal refuse, consolidation of the material may take a long time. It could be expected that high void ratio and large amount of pore water exist in the fine refuse for months or years after initial placement, which would significantly reduce the shear strength of the material. In the event of dynamic impact loading, excess pore water pressure in the coal refuse can quickly build up and cause a significant reduction in 
the strength of materials. In the worst scenario, liquefaction of the fine refuse would change the solid refuse into a heavy viscous fluid producing a large pressure increase on the embankment. Therefore, tailings dams are quite susceptible to the flow failure.

Without available data and applicable measurements, the flow failure of tailings dams has not been well studied. There is neither enough information about the mechanical properties of coal - waste refuse especially the flow behavior of the material under static and dynamic impact loading. The proposed research will fill the gap in the current stateof-the-art and state-of-the-practice knowledge in evaluating the failure mechanism and flow behavior of coal refuse.

In this study, a comprehensive investigation was performed on geotechnical properties and flow behavior of impounded coal refuse under static and impact loading using laboratory tests, small-scale model tests, and centrifuge model tests. A thorough literature review has been performed in the previous sections. The potential of flow failure as well as the remediation measures were found to be, to a great extent, related to the water content of impounded coal refuse. Therefore, it is reasonable to propose a hypothesis that flow behavior of coal refuse is critically dominated by water content and the consolidation of fine refuse. The measures by accelerating de-watering and controlling the construction speed based on field monitoring of consolidation and water content would prevent flow failure. The relationships have been established between water content of fine coal refuse and its geotechnical and rheological parameters in order to evaluate the effects of water content on these important design parameters of tailings dams.

A potential countermeasure of using slurry cells was proposed in this study. Its effectiveness in resisting dynamic impact loading was evaluated in the centrifuge model 
tests. The coal waste impoundment could be reinforced by the coarse refuse built cells since they have higher strength than fine refuse. Also, the coarse refuse in general has higher permeability and could therefore be used as drains to speed up consolidation process and dissipation of excess pore water pressure induced by impact loading. Since coarse refuse is a by-product of coal mining, the adequate supply of construction material is considered as another advantage of slurry cells.

Regarding the definition of liquid limit as the water content at which the behavior of soil changes from plastic to liquid, the other important hypothesis proposed in this study is to treat liquid limit of fine coal refuse as the critical water content above which the flow of slurry would be triggered. In the experiments, the coal refuse samples were prepared with different water content (mostly above liquid limit and several below liquid limit). The test results would help to validate the flowability, strength, and dynamic resistance of impounded coal refuse under static and impact loading when initial water content drops below liquid limit.

The objectives of this study also include but not limit to:

- To better understand the mechanism of flow failure of tailings dams and the most influential factors

- To investigate geotechnical properties and flow behavior of coal refuse under static and impact loading

- To explore applicable flow models to represent flow characteristics of fine coal refuse

- To evaluate a potential countermeasure to reduce the risk of flow failure 
- To establish a database about geotechnical properties and flow behavior of coal refuse for future studies and researches

- To provide engineering recommendation on the design and construction of tailings dams so as to prevent flow failure

\subsection{Outline of the Dissertation}

Chapter 1 introduces different types of tailings dams and coal waste impoundment. A thorough literature review is also performed on the case histories of flow failure of tailings dams and potential measures and techniques to mitigate the risk of flow failure.

Chapter 2 studies geotechnical properties of impounded coal refuse by performing a range of laboratory tests. The measured soil properties include particle size distribution, Atterberg limits, specific gravity, coefficient of consolidation, compression index, hydraulic conductivity, shear strength, and viscosity. The variations of these parameters with initial water content are investigated.

Chapter 3 performs comprehensive investigation on the flow behavior of coal refuse by small-scale model tests. The flow characteristics of coal slurry with different water content are analyzed under static loading and impact loading. Appropriate flow model is proposed in terms of the flow behavior of coal refuse which would help to better understand the properties of coal refuse flow and its failure mechanism.

Chapter 4 reports a group of centrifuge tests used to analyze flow behavior of coal refuse in the high stress field as well as to validate the measured results from small-scale model tests. The proposed countermeasure by using slurry cells is evaluated in the centrifuge model tests. 
Chapter 5 summarizes the significant findings and conclusions of this research, along with plans and recommendations for future work. 


\section{Chapter 2 GEOTECHNICAL PROPERTIES OF COAL REFUSE}

\section{$2.1 \quad$ Introduction}

The understanding of geotechnical properties of coal refuse is of fundamental importance and necessity for the investigation of flow behavior of coal refuse as well as the engineering design and construction of tailings dams. In essence, the coal refuse is a mixture of many different substances including coal, waste, middlings and many other impurities (Osborne, 1988). The physical properties of coal refuse may be quite variable due to the mineralogy of the coal and the coal preparation process. One of the most important objectives of this project is to comprehensively study the geotechnical properties of the fine coal refuse which might influence its flow behavior under static and impact loading.

\subsection{Sample Collection and Preparation}

The coal slurry refuse samples used in this research project were collected from two representative tailings dams in the Appalachian region (located in Kentucky and West Virginia, respectively). In order to simplify the expression, the coal slurry samples obtained from Kentucky and West Virginia was designated as "KY" sample and "WV" samples.

Both samples of fine refuse were collected directly from the coal preparation plant located near the entrance of the mine. The sample collected at the processing facility is the same material that is pumped up the mountain and hydraulically placed in the impoundment.

As shown in Figure 2-1, the coal slurry samples were taken directly from the pipeline by catching the slurry in the buckets as it was been discharged. The initial water 
content was extremely high which was too wet to be tested. The slurry suspension was placed at rest for some time varying from a couple of days to half month before starting laboratory experiments. The consolidated refuse samples could then be prepared with different initial water content (or initial void ratio). In order to prepare samples with relatively lower water content, the consolidation process could be speeded up by spinning coal slurry samples in the centrifuge. The variations of some of the geotechnical properties of fine coal refuse were thereafter established with initial water content.

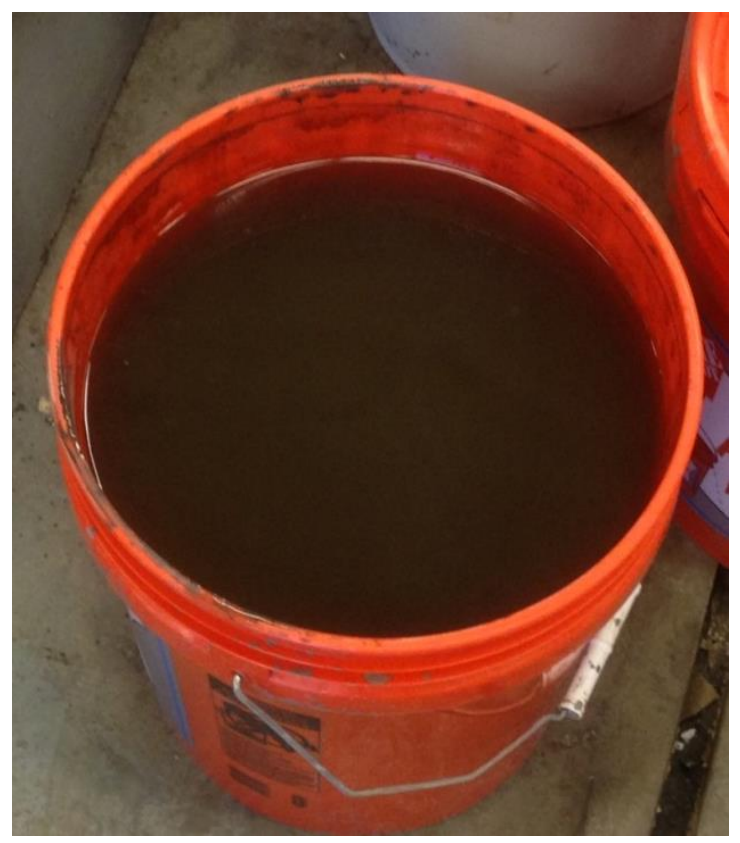

Figure 2-1 Collected sample from coal preparation plant

\subsection{Geotechnical Properties of Coal Refuse}

The geotechnical properties of coal refuse were determined by a group of laboratory tests performed in the Department of Civil Engineering at Case Western Reserve University, Cleveland, $\mathrm{OH}$. The proposed tests included particle size analysis by using 
mechanical method and hydrometer method, index property tests, specific gravity tests, consolidation tests, permeability tests, triaxial tests, and viscosity tests. A summary of the tests conducted is shown in Table 2-1. All the laboratory tests strictly followed the standards specified by ASTM, which are the standards commonly used by the geotechnical engineering community, so as to ensure the consistency and comparability of the results. Some of the tests were repeated multiple times in order to check the repeatability. Each type of test has its purpose, advantages and limitations. Combining the capability of these tests, the established database would help to investigate the flowability of coal refuse.

Table 2-1 Summary of laboratory tests conducted on coal refuse

\begin{tabular}{|c|c|c|}
\hline Lab. Tests & ASTM Standard & Soil Properties Measured \\
\hline $\begin{array}{c}\text { Sieve Test \& Hydrometer } \\
\text { Tests }\end{array}$ & D421; D422; D423 & Particle size distribution \\
\hline Specific Gravity Tests & D854 & Specific gravity $G_{s}$ \\
\hline Atterberg Limits Tests & D4318 & $\begin{array}{l}\text { Liquid limit; Plastic limit; } \\
\text { Plastic index }\end{array}$ \\
\hline Consolidation Tests & D2435 & $\begin{array}{c}\text { Coefficient of } \\
\text { consolidation; } \\
\text { Compressive index; }\end{array}$ \\
\hline Permeability Tests & D2434; D5084 & Coefficient of permeability \\
\hline Triaxial Tests & D7181; D2850 & $\begin{array}{l}\text { Cohesion; Internal friction } \\
\text { angle }\end{array}$ \\
\hline Viscosity Tests & $\begin{array}{c}\text { D1084; D2556; D4402; } \\
\text { D5018 }\end{array}$ & $\begin{array}{l}\text { Relationship between water } \\
\text { content and viscosity }\end{array}$ \\
\hline
\end{tabular}

\subsubsection{Particle Size Distribution}

\section{$\underline{\text { Introduction }}$}

The particle size distribution is one of the most significant properties which has great impact on the strength, compressibility, and seismic resistance of the impounded coal refuse. Wakeley and Peterson (2004) indicated that the geological setting of the mine 
substance is attributed by mineralogy, grain size, grain shape and other physical characteristice of mine waste. Coal refuse derived from cyclothem sedmentary rock is relatively rich in clay minerals and clay sized particles. Justice (1997) performed the particle size analysis of coal slurry and found that more than $70 \%$ of fine refuse particles were within the silt size range with the coefficient of uniformity $C_{u}$ between 11 and 34 . The values of $C_{u}$ indicated that the slurry is composed of a moderate to narrow range of particle size. Ferrrini et al. (1984), Round and Hessari, Logos and Nguyen (1996), and Boylu et al. (2004) pointed out the rheological behavior of coal-water slurry had close relationship to particle size, particle size distribution and particle shape.

The particle size distribution of fine coal refuse was determined by following ASTM standard for sample preparation (D421), sieve analysis for coarse particles (D422), and hydrometer tests for fine particles (D422). About 300g oven-dried coal refuse sample was washed under tap water through No. 200 sieve $(0.075 \mathrm{~mm})$ until the wash water was clear. The sieve analysis was performed on the coarse fraction retained on the No. 200 sieve while hydrometer analysis on the fine particles passed the No. 200 sieve. The hydrometer method is based on Stoke's law which governs the velocity at which the spherical particles settle in a suspension. No repeating tests were conducted duo to the limited quantity of coal refuse sample and the time-consuming hydrometer test.

\section{$\underline{\text { Test Results }}$}

The results of the measurements are shown in Figure 2-2. It was found that, for both KY and WV sample, the percent finer than No. 200 was higher than $80 \%$. The WV sample has finer particle size and wider size range than KY sample. In addition to the particle size distribution analyis, Atterberg limit tests were also performed to determin the liquid limits, 
plastic limit, and plasticity index of the coal refuse samples. The details of test procedures will be introduced in the section 2.3.3. The tests showed that the coal refuse has quite slight plasticity. Based upon the measured particle size distribution and index properties, both KY sample and WV sample were classified as a low-plasticity silt (ML) using the Unified Soil Classification System.

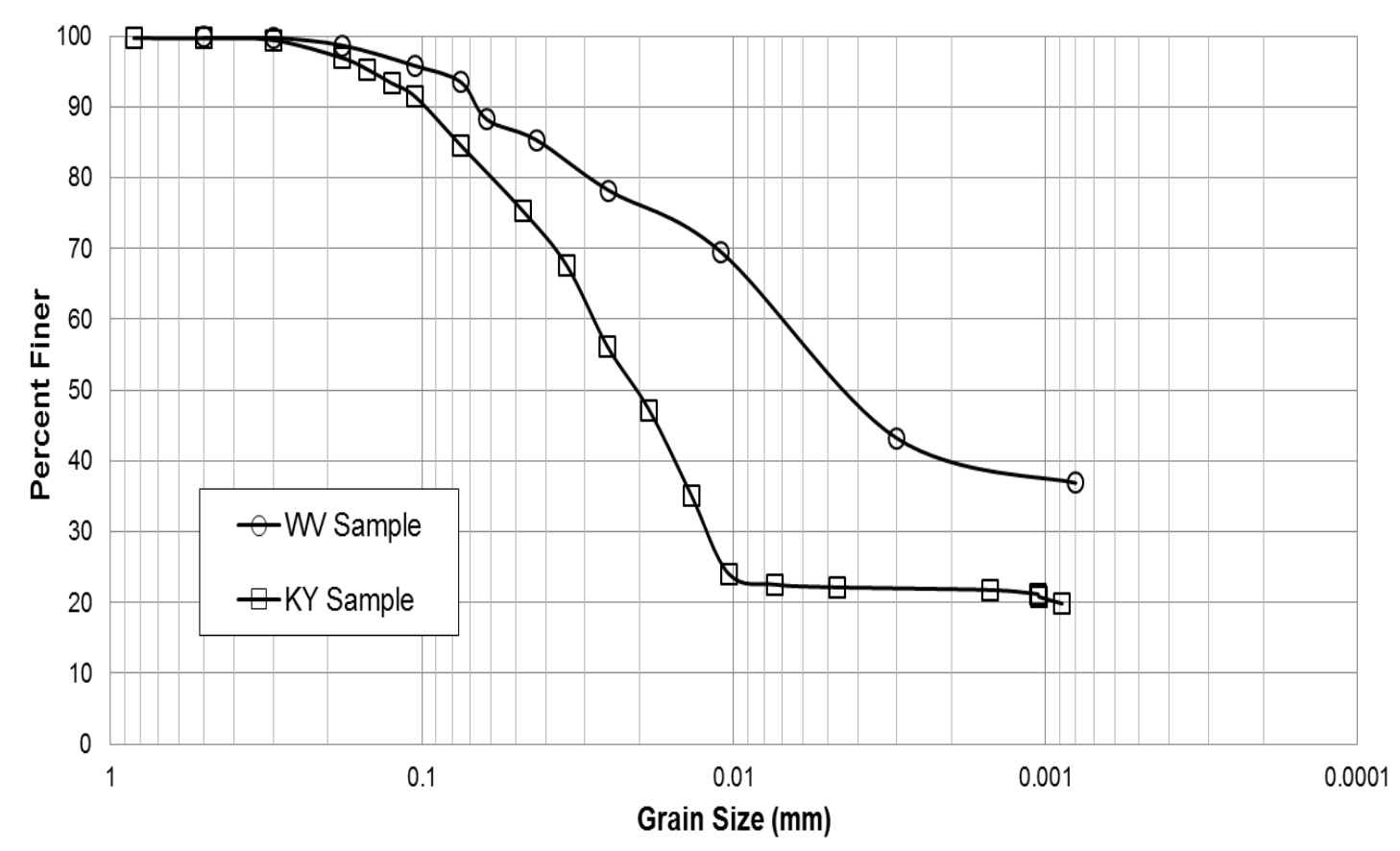

Figure 2-2 Particle size distribution curve for KY sample and WV sample

\subsubsection{Specific Gravity}

\section{Introduction}

The specific gravity of any substance is defined as the density of the material divided by the density of distilled water at $4^{\circ} \mathrm{C}$. Specific gravity is one of the most significant geotechnical parameters. A value of specific gravity is necessary to computer the void ratio of a soil and the soil density. Occasionally, the specific gravity may be used in soil mineral classification. 
The measurements of specific gravity of coal refuse were suggested by ASTM (D854) which involved procedures that determined the weight of coal refuse particles and the weight of the equivalent volume of water occupied by the sample particles at the temperature of $23^{\circ} \mathrm{C}$. These procedures were repeated three times for each coal refuse sample and the average was recorded as the $\mathrm{G}_{s}$ value.

\section{$\underline{\text { Test Results }}$}

As shown in Table 2-2, the recorded average specific gravity was 2.03 for KY sample and 2.14 for WV sample, respectively. The typical values of specific gravity for soil forming minerals are on the order of 2.5-2.8. It should note that the specific gravity of coal refuse is smaller than other soils. Busch et al. (1975) performed laboratory tests on the undisturbed Shelby tube fine coal refuse samples. The specific gravity of the high coal content samples is in the range of 1.25 to 1.70 . The low value of specific gravity creates a lower level of effective stress and hence lower shear strength. It also can cause an initially loose structure after consolidation, making the impoundment more susceptible to disturbance by impact loading.

Table 2-2 Summarized results of specific gravity test

\begin{tabular}{|c|c|c|}
\hline Test Sample & KY & WV \\
\hline Volume of flask at $20^{\circ} \mathrm{C}$ & $500 \mathrm{ml}$ & $500 \mathrm{ml}$ \\
\hline Method of air removal & Vacuum & Vacuum \\
\hline Temperature & $23^{\circ} \mathrm{C}$ & $23^{\circ} \mathrm{C}$ \\
\hline $\begin{array}{c}\text { Temperature correction coefficient } \\
\alpha=\frac{\rho_{t}}{\rho_{20^{\circ} \mathrm{C}}}\end{array}$ & 0.9993 & 0.9993 \\
\hline
\end{tabular}




\section{Average Specific gravity}

$$
G_{s}=\alpha \frac{M_{s}}{M_{w}}
$$

\subsubsection{Atterberg Limits Tests}

\section{$\underline{\text { Introduction }}$}

Atterberg limit tests measured the liquid limit, plastic limit, and plasticity index of the coal refuse. The liquid limit and plastic limit are primarily used by civil and geotechnical engineers for soil identification, classification and for strength correlations (Bowles, 1992). The liquid limit (LL) $w_{L}$ is often conceptually defined as the minimum water content at which the behavior of a clayed soil changes from plastic to liquid or the soil will transform into a viscous fluid upon application of a very small shearing force i.e. under self-weight or small amount of energy input. The plastic limit is the water content at which a soil exhibits plasticity. These upper and lower limits of water content create the range over which a soil exhibited plastic behavior.

\section{Testing Facilities and Procedures}

In the laboratory test, the liquid limit could be arbitrarily defined as the water content at which a pat of soil sample placed in a brass cup, cut with a standard groove, and then dropped from a constant height of $10 \mathrm{~mm}$ will undergo a groove closure of $12.7 \mathrm{~mm}$ when the cup of soil is dropped 25 times at the rate of 120 drops/minute. The liquid limit tests by using Casagrande's liquid device (ASTM, D4318) were illustrated in Figure 2-3. The test is normally run at several moisture contents, and the water content is plotted 
against the logarithm of the number of blows and the best straight line fitting the scattered points is drawn. The moisture content which requires 25 blows to close the groove is interpolated as the liquid limit.
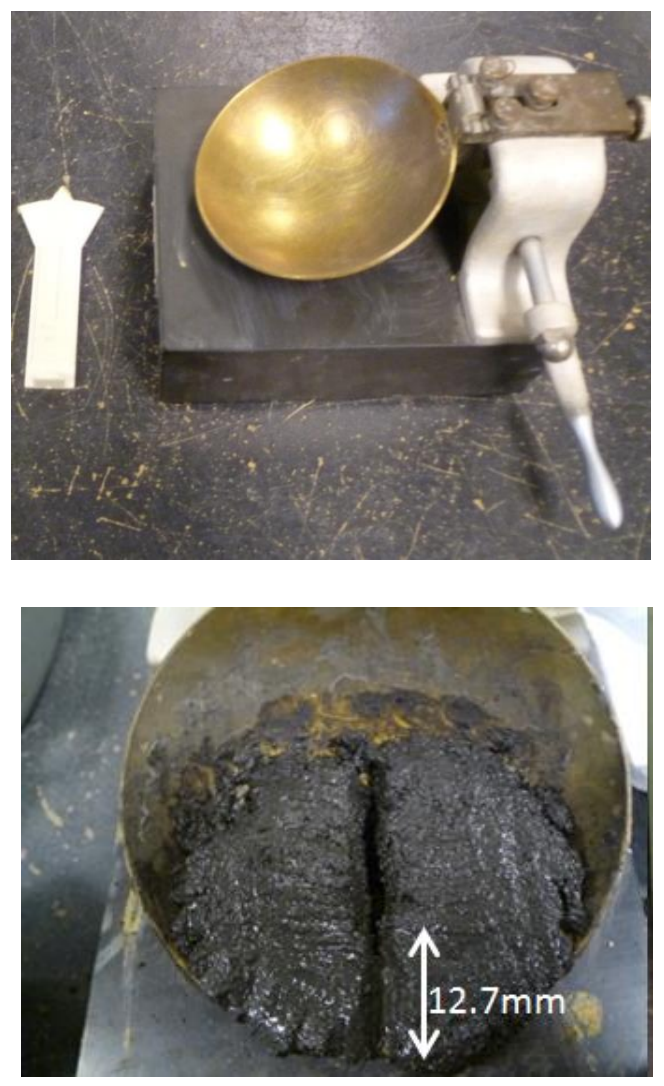

Figure 2-3 Liquid limit test on coal refuse sample (the groove has closed $12.7 \mathrm{~mm}$ )

\section{$\underline{\text { Test Results }}$}

The results of liquid limit tests for the two samples were shown in Figure 2-4 and 2-5. The liquid limits corresponding to 25 blow count were 38.1 for KY sample and 42.5 for WV sample.

The plastic limit $w_{p}$ is arbitrarily defined as the water content at which a soil thread just crumbles when it is rolled down to a diameter of $3 \mathrm{~mm}$. Figure 2-6 exhibited the 
measurement of plastic limit. The recorded plastic limits were 28.3 for KY sample and 27.8 for WV sample, respectively.

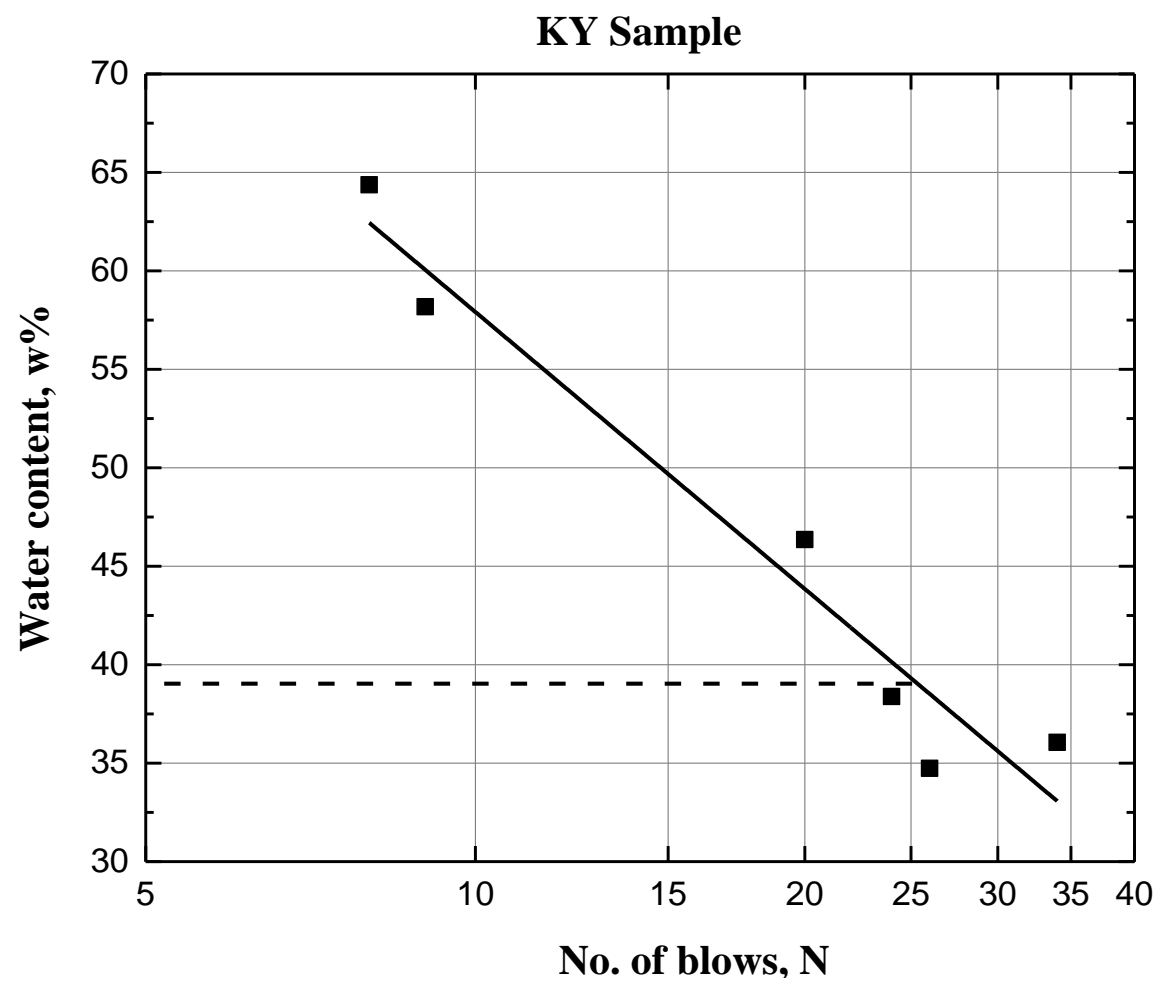

Figure 2-4 Relationship between water content and blow number N for KY sample

(Liquid Limit $w_{L}=38.1$ ) 


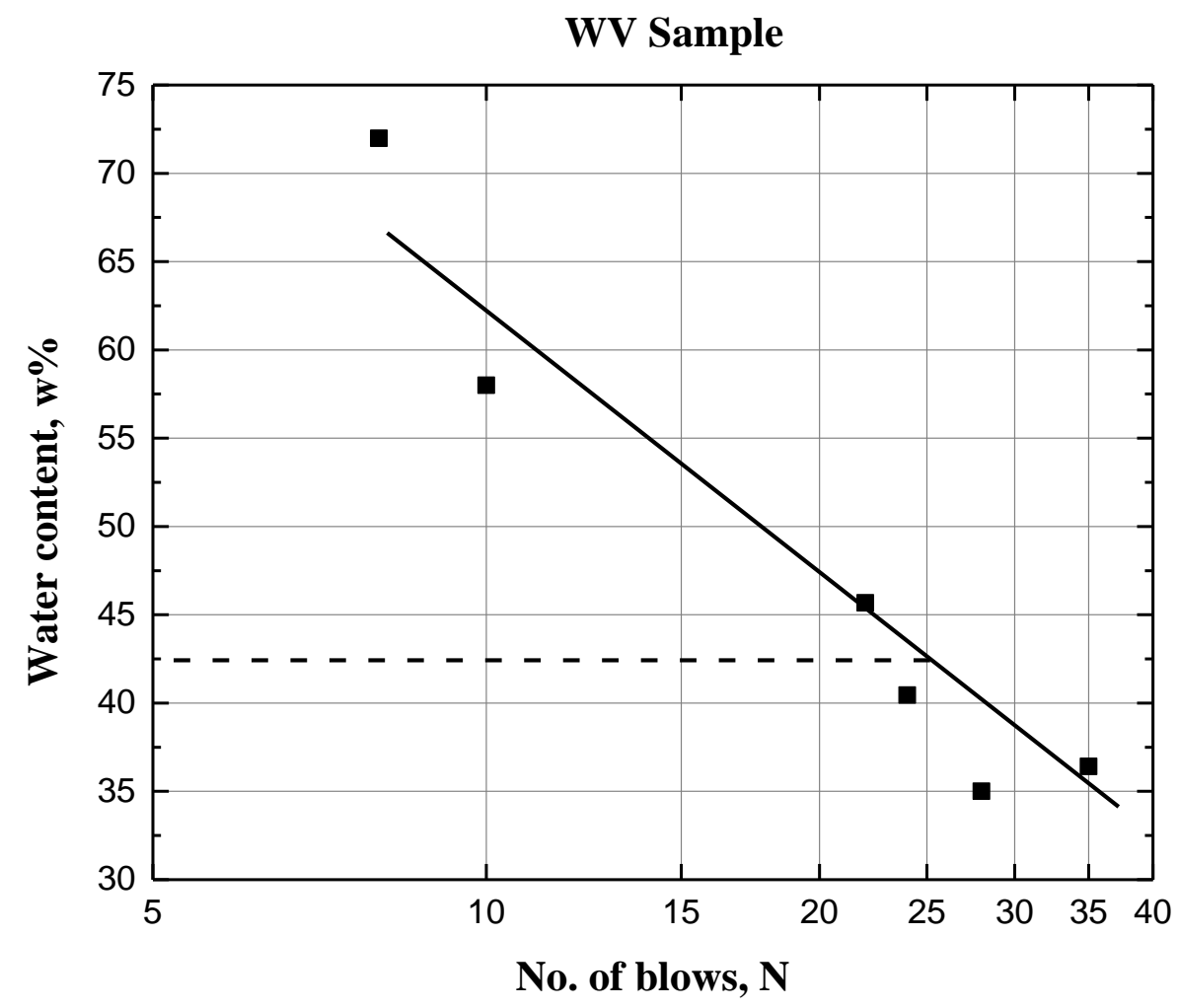

Figure 2-5 Relationship between water content and blow number N for WV sample

(Liquid Limit $w_{L}=42.5$ )

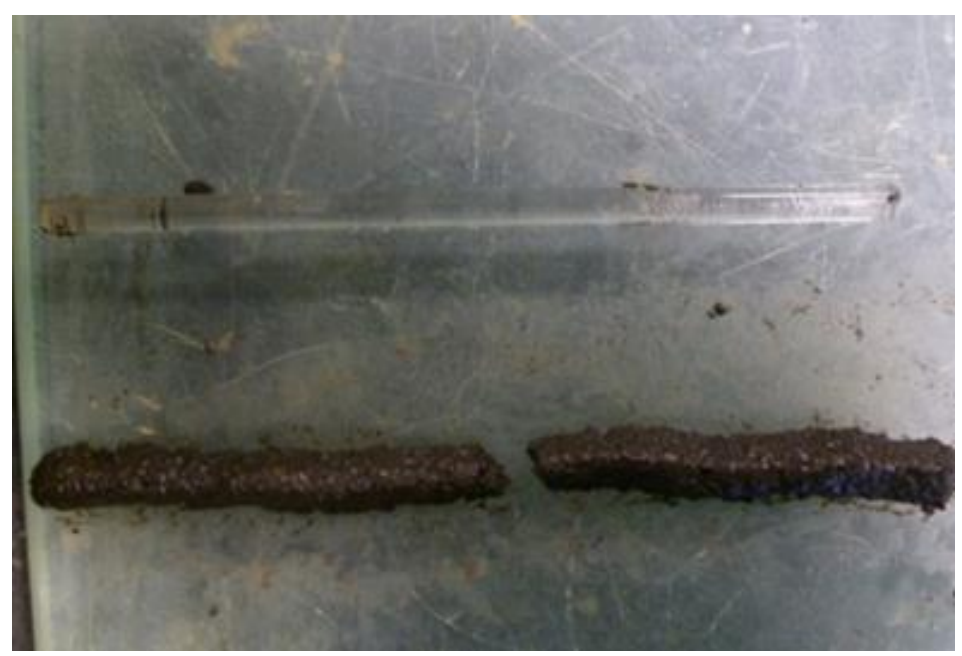

Figure 2-6 Plastic limit test on coal refuse sample 
The plasticity index $I_{p}$ is a range of moisture in which a soil remains in a plastic state while passing from a semisolid state to liquid state. The plasticity index can be obtained from the difference between the liquid limit and the plastic limit $\left(I_{p}=w_{L}-w_{p}\right)$. The plasticity index was 9.8 and 14.7 for KY sample and WV sample, respectively. The values of plasticity index were divided by Sower (1979) as:

- (0-3)- Nonplastic

- (3-15) - Slightly plastic

- $\quad$ (15-30) - Medium plastic

- $\quad$ >30 - Highly plastic

It was noted that both samples behaved slight plastic which indicated that coal refuse has low response to change in the water content. The summarized results of Atterberg limit tests were listed in Table 2-3. With the known liquid limit and plasticity index, the soil could be classified as a low-plasticity silt (ML) by using the Unified Soil Classification System (Figure 2-7).

Table 2-3 Summarized results of Atterberg limit tests

\begin{tabular}{|c|c|c|}
\hline Property & KY Sample & WV Sample \\
\hline Liquid Limit $w_{L}$ & 38.1 & 42.5 \\
\hline Plastic Limit $w_{p}$ & 28.3 & 27.8 \\
\hline Plasticity Index $I_{p}$ & 9.8 & 14.7 \\
\hline
\end{tabular}




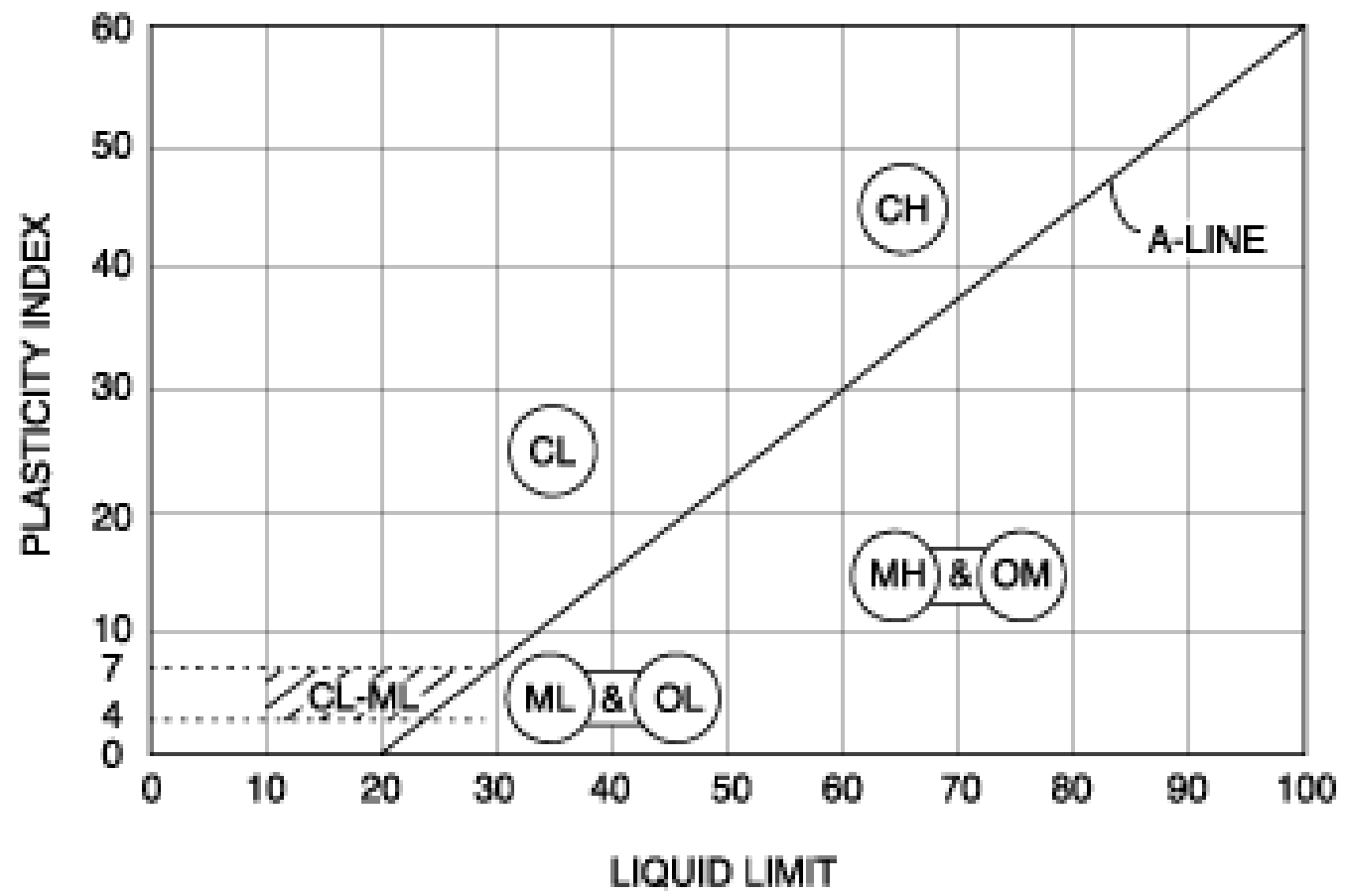

Figure 2-7 Plasticity chart to use for the Unified Soil Classification System

Theoretically speaking, the flow of coal refuse would take place under static loading only when the water content is above the liquid limit. Therefore, one of the most important hypotheses in this research considers the liquid limit as the critical water content at which the coal refuse flow will be triggered. Based on such hypothesis, the samples were prepared with initial water content higher than liquid limit for static loading tests. However, under the impact loading, excess pore water pressure might be generated to increase the flowability of coal refuse even if the initial water content is below liquid limit. Therefore, in tests on impact loading, some samples were prepared with initial water content lower than liquid limit. 


\subsubsection{Consolidation Tests}

\section{$\underline{\text { Introduction }}$}

Consolidation is a process by which the volume of soil decreases under certain load application. For a fully saturated soil sample, the reduction in volume results from the drainage of pore water. As shown in Figure 2-8, the consolidation process for fully saturated soil could be interpreted by using an idealized system which composes of a spring and a water container with a valve in its top plate and four stages listed as following:

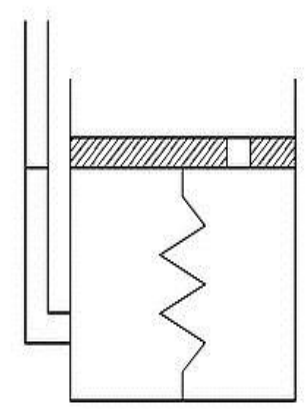

(1)

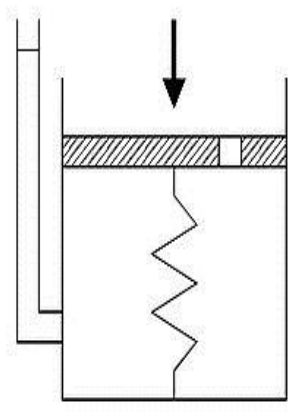

(2)

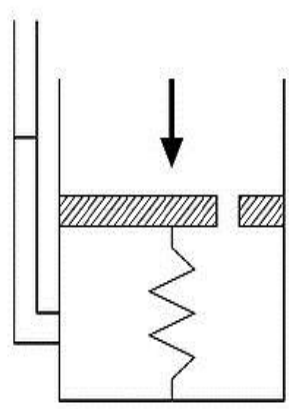

(3)

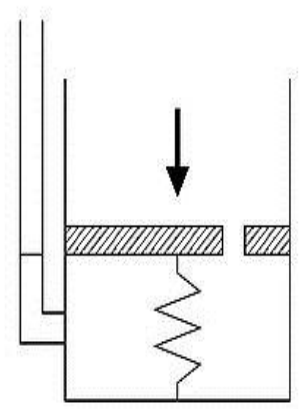

(4)

Figure 2-8 Consolidation spring analogy (Anonymous, 2007)

1. The water container is completely full of water with the top plate valve closed.

2. A load is applied on the top plate with the valve is still closed. At this time, only the water undertakes the applied load with the excess pore water pressure built up. (The spring keeps the same length as that in \#1)

3. The drainage occurs as soon as the valve is open. At this time, excess pore water pressure starts to dissipate. (The spring is gradually shorten) 
4. As the drainage of water finish, all built-up excess pore water pressure in \#2 dissipates. At this time, all applied load is undertook by the spring alone. (The spring has stable and shortest length)

When any soil subjected to a load which is larger than the resistance, the soil skeleton will be broken and rearranged. This process will be considered as the plastic deformation with a corresponding reduction in void ratio e. Although a small amount of elastic deformation may also take place, it could be neglected due to the magnitude of applied load and small modulus of elasticity of the soil particles on the order of $20 \mathrm{MPa}$ (Bowles, 1992).

The results of consolidation test which include coefficient of consolidation $C_{v}$, compression index $C_{c}$, and swelling index $C_{s}$ will help to address two important engineering issues:

a. How much settlement will the foundation take place under the designed loads?

b. How fast will the process of consolidation finish?

\section{$\underline{\text { Testing Procedures }}$}

The soil consolidation parameters could be obtained through consolidometer (or sometimes called oedometer) test. The detailed procedures and measurements are included in ASTM D 2435. As shown in Figure 2-9, the prepared soil sample is placed in the consolidometer and subjected to a series of one-dimensional compressive load with the load increment ratio $\Delta p / p=1$. A dial gauge is used to take deformation readings at the specific elapsed times. Typically, the duration of each load is 24 hours or when the difference of deformation between two successive readings is sufficiently small. For each 
load increment, the results will be graphically displayed as a semilog plot of consolidation dial readings versus the log time so as to determine $t_{50}$ which is the time at 50 percent consolidation and most commonly used in the Casangrade's method to estimate the coefficient of consolidation from a test $C_{v}$. Olson (1985) concluded that the only rational way to estimate the $C_{v}$ value is based on the coefficient of volume compressibility and the coefficient of permeability. Therefore, the coefficient of consolidation $C_{v}\left(\right.$ in $\left.\mathrm{m}^{2} / \mathrm{s}\right)$ can be expressed as:

$$
C_{v}=\frac{k}{m_{v} \gamma_{w}}
$$

Where

$$
\begin{aligned}
& k=\text { hydraulic conductivity }(\mathrm{m} / \mathrm{s}) \\
& m_{v}=\text { coefficient of volume change }\left(\mathrm{m}^{2} / \mathrm{kN}\right) \\
& \gamma_{w}=\text { unit weight of pore fluid }\left(\mathrm{kN} / \mathrm{m}^{3}\right)
\end{aligned}
$$

Figure 2-10 exhibited a trial test result of a saturated soil sample under certain contact pressure and $t_{50}$ was obtained by determining $D_{0}, D_{100}$ and $D_{50}$. Many other curve-fitting procedures based the Terzaghi uncoupled consolidation theory have also been proposed for determination of the laboratory coefficient of consolidation $C_{v}$, such as square root of time and its variant, inflection point, hyperbolic, and least square methods (Taylor, 1948; Sridharan and Prakash, 1985; Olson, 1986; Sridharan and Prakash, 1995; Mesri et al., 1999; and Chan, 2003). Since many factors influence the value of coefficient of consolidation, the experimental behavior of soil in the one-dimensional consolidation 
test would not completely match with the theoretical relationship of consolidation as obtained by Terzaghi’s equation.

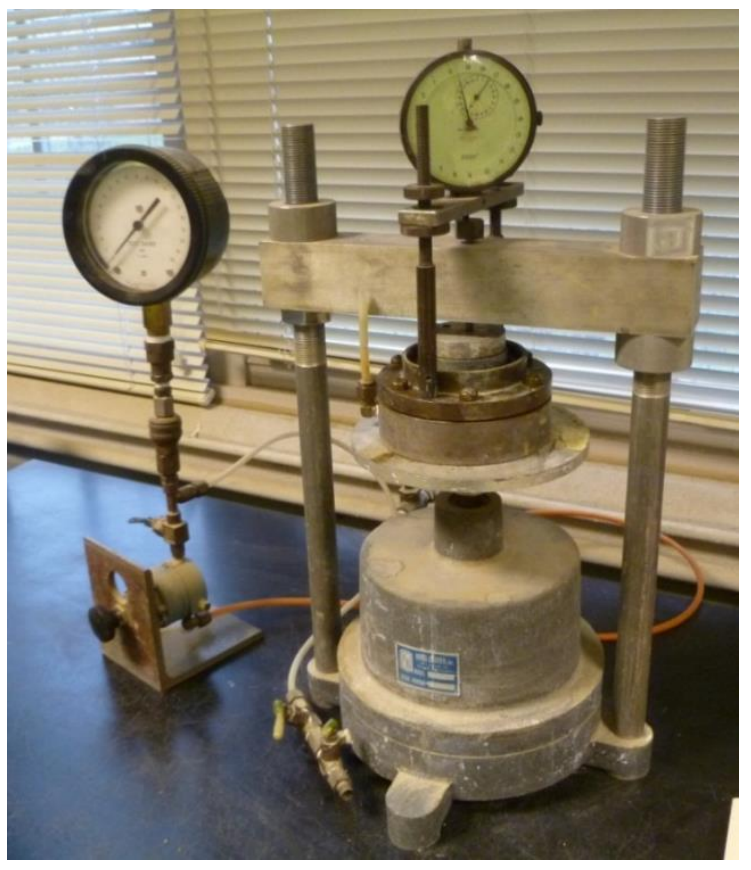

Figure 2-9 Consolidometer used in consolidation test

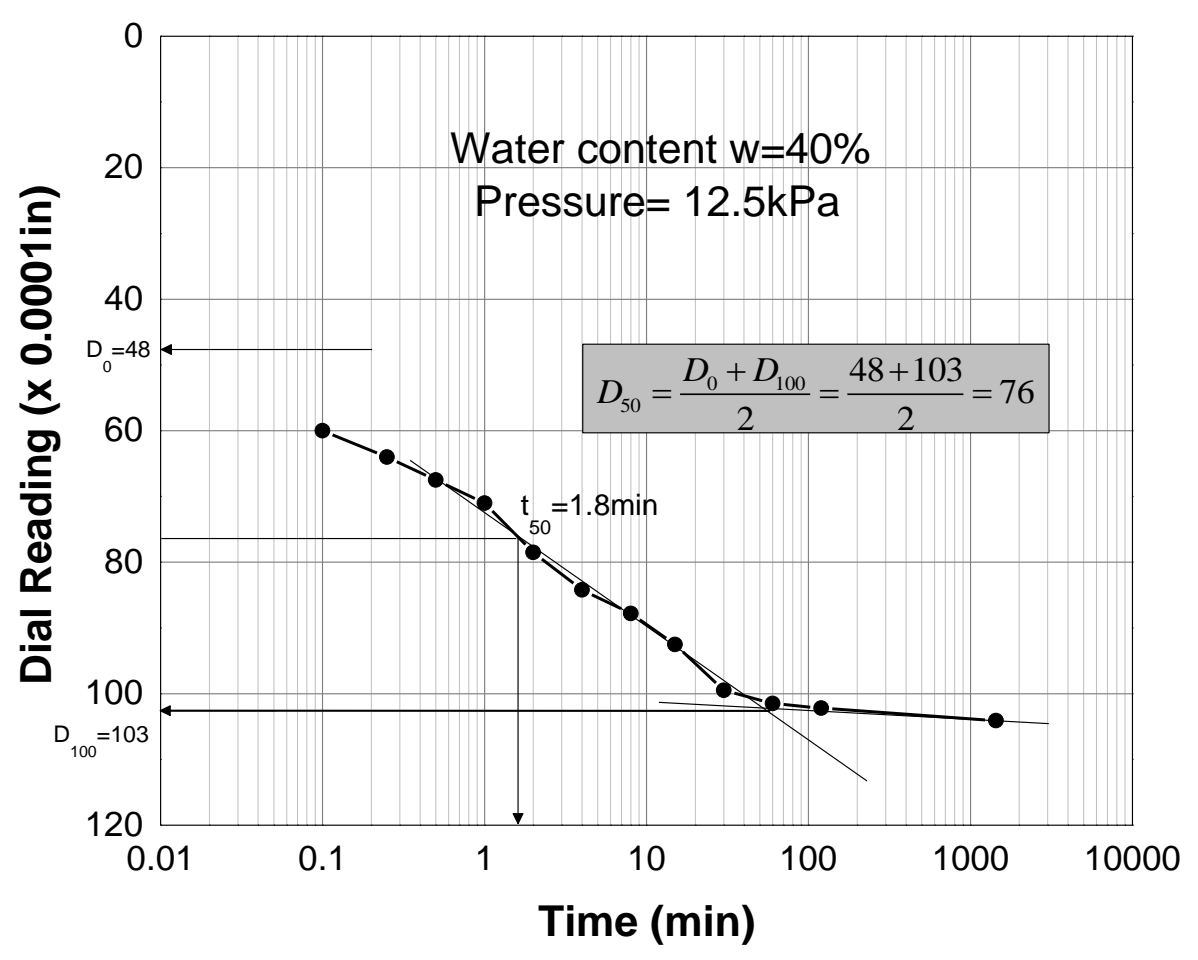

Figure 2-10 An example plot of dial reading vs. log time in minute 
In the meantime, the void ratio at the end of primary consolidation for each load increment was calculated. The results are thereafter plotted as void ratio versus log pressure. From the straight-line part of the curve, the compression index $C_{c}$ is determined as:

$$
C_{c}=\left(e_{1}-e_{2}\right) / \log \left(p_{2} / p_{1}\right)
$$

Where $e_{1}$ and $e_{2}$ are the void ratio of the fine refuse corresponding to the pressure of $p_{1}$ and $p_{2}$, respectively. After the maximum loading, the vertical loading was gradually reduced with the decrement ratio $\Delta p / p=1$ and the resulting void ratios are measured. From the recorded data on the unloading line, the swelling index of the sample $C_{s}$ is determined as:

$$
C_{s}=\left(e_{1}-e_{2}\right) / \log \left(p_{2} / p_{1}\right)
$$

In this research, the fine coal refuse samples were prepared for consolidation tests at the initial water content of $64 \%, 52 \%$ and $45 \%$ respectively (a slight variation may exist). One-dimensional axial load were applied from the top of the sample in six increments (5, $20,40,80,160,320 \mathrm{kPa}$ ). According to the recommendation in ASTM D2435, the duration of each load increment should be 24 hours. However, this time period was not sufficient for the fully primary consolidation of coal refuse based on the results of several trial tests. The difference of displacement between two successive readings was not in the negligible range after 24 hours. Therefore, the time span under each load increment was set as 72 hours in order to ensure the coal refuse sample reach the end of the primary consolidation. The unloading process would be exactly the same as the loading process. The consolidation dial readings under each load increment were recorded at the elapsed time.

\section{$\underline{\text { Test Results }}$}


As mentioned above, the coefficient of consolidation $C_{v}$ under each load increment was determined by using Casangrade's method. The summarized results of coefficient of consolidation $C_{v}$ for the two coal refuse samples were shown in Figure 2-11 and Figure 212. It was found that the coefficient of consolidation increased with the vertical consolidation pressure. More apparent increase was observed as the compressive pressure larger than $80 \mathrm{kPa}$. In addition, Both of KY sample and WV sample exhibited the same characteristic that the sample with lower water content had larger coefficient of consolidation. The larger value of $C_{v}$ therefore indicated a faster consolidation rate under the same consolidation pressure.

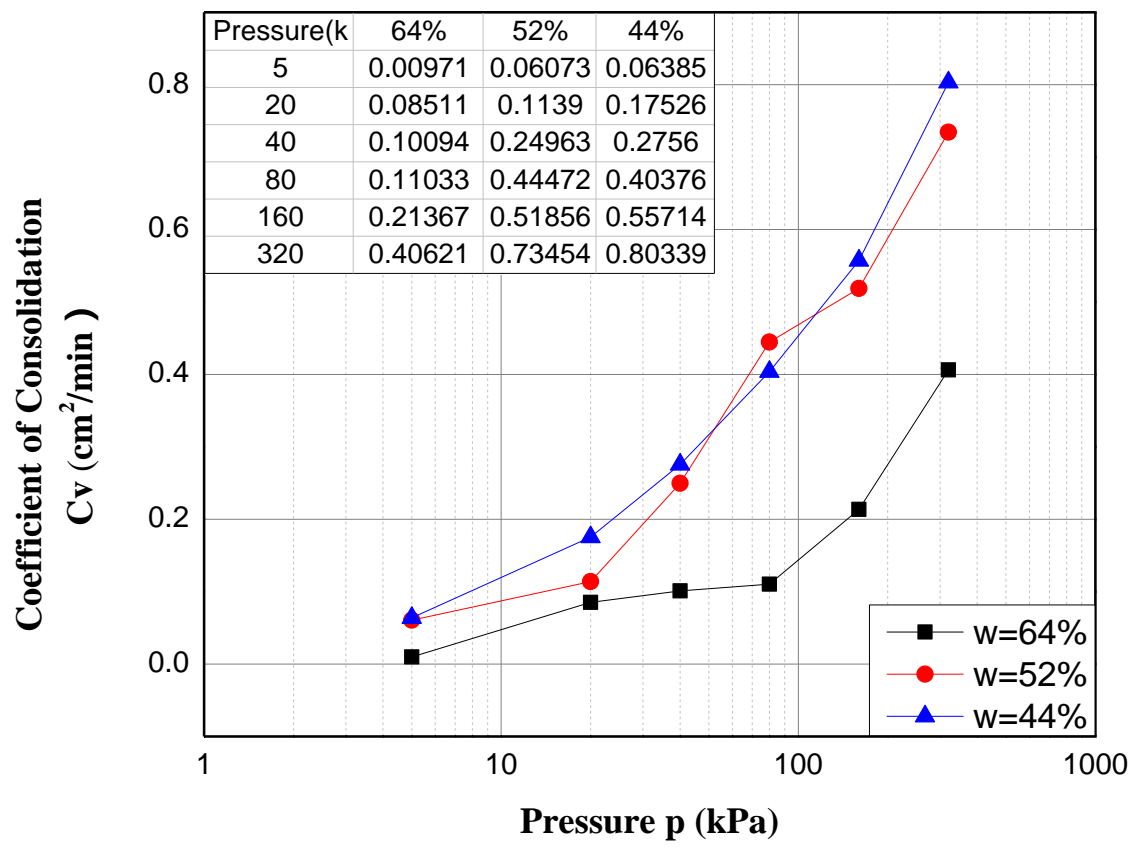

Figure 2-11Summarized results of coefficients of consolidation $\mathrm{C}_{\mathrm{v}}$ for $\mathrm{KY}$ sample 


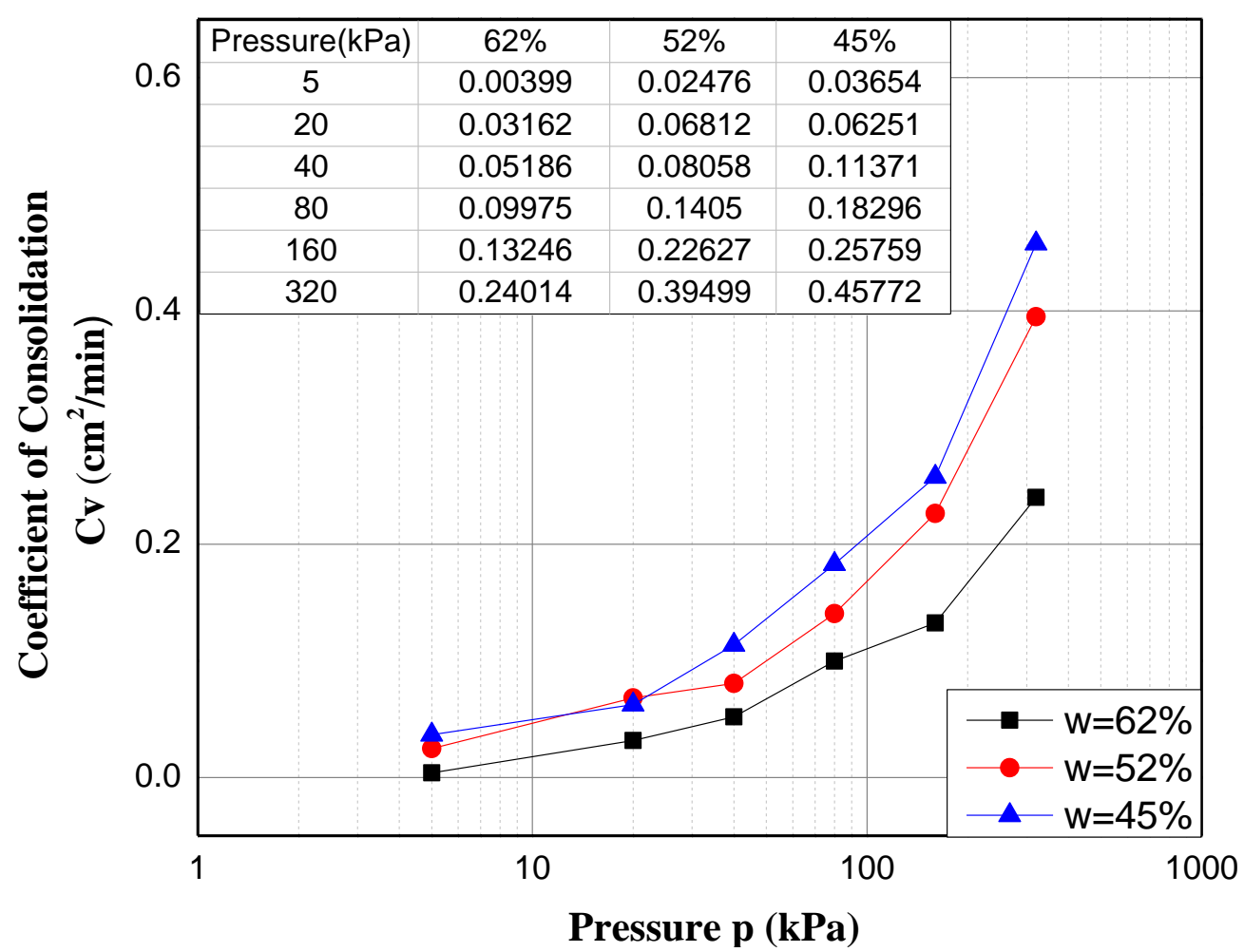

Figure 2-12 Summarized results of coefficients of consolidation $C_{v}$ of WV Sample

Referring to Equation 2-1, Terzaghi and Peck (1967) found that both of hydraulic conductivity $k$ and coefficient of volume change $m_{v}$ decrease rapidly when the effective vertical consolidation pressure applied. The ratio of $k / m_{v}$ and therefore $C_{v}$ would be a fairly constant value over a wide range of applied pressure. However, this is the general understanding of the variation of coefficient of consolidation with consolidation pressure. In reality, the coefficient of consolidation could exhibit quite significant change over the applied pressure range. This inconsistency for different soils, especially for clay soil, needs reconciliation. Recent investigations have found that the relationship between coefficient of consolidation and applied effective consolidation pressure is affected by clay mineralogy, soil type and some mechanical and physicochemical factors (Olson and Mesri, 1970; 
Sridharan and Rao, 1976; Robinson and Allam, 1998; and Sridharan and Nagaraf, 2004). A large number of laboratory test results show that the coefficient of consolidation increases with consolidation pressure for kaolinite, glacial silty clay, sand clay and kawasaki clay but decrease with consolidation for residual clay and bentonite (Leonards and Ramiah, 1959; Samarasinghe et al., 1982; and Nagase et al., 1994). Robinson and Allam (1998) compared the compressibility of three clay minerals (kaolinite, illite, and montmorillonite) and found that the variation of coefficient of consolidation with applied pressure was dependent on whether the virgin consolidation behavior was governed by mechanical properties of the solid grains and the lubricating effect of the pore fluid.

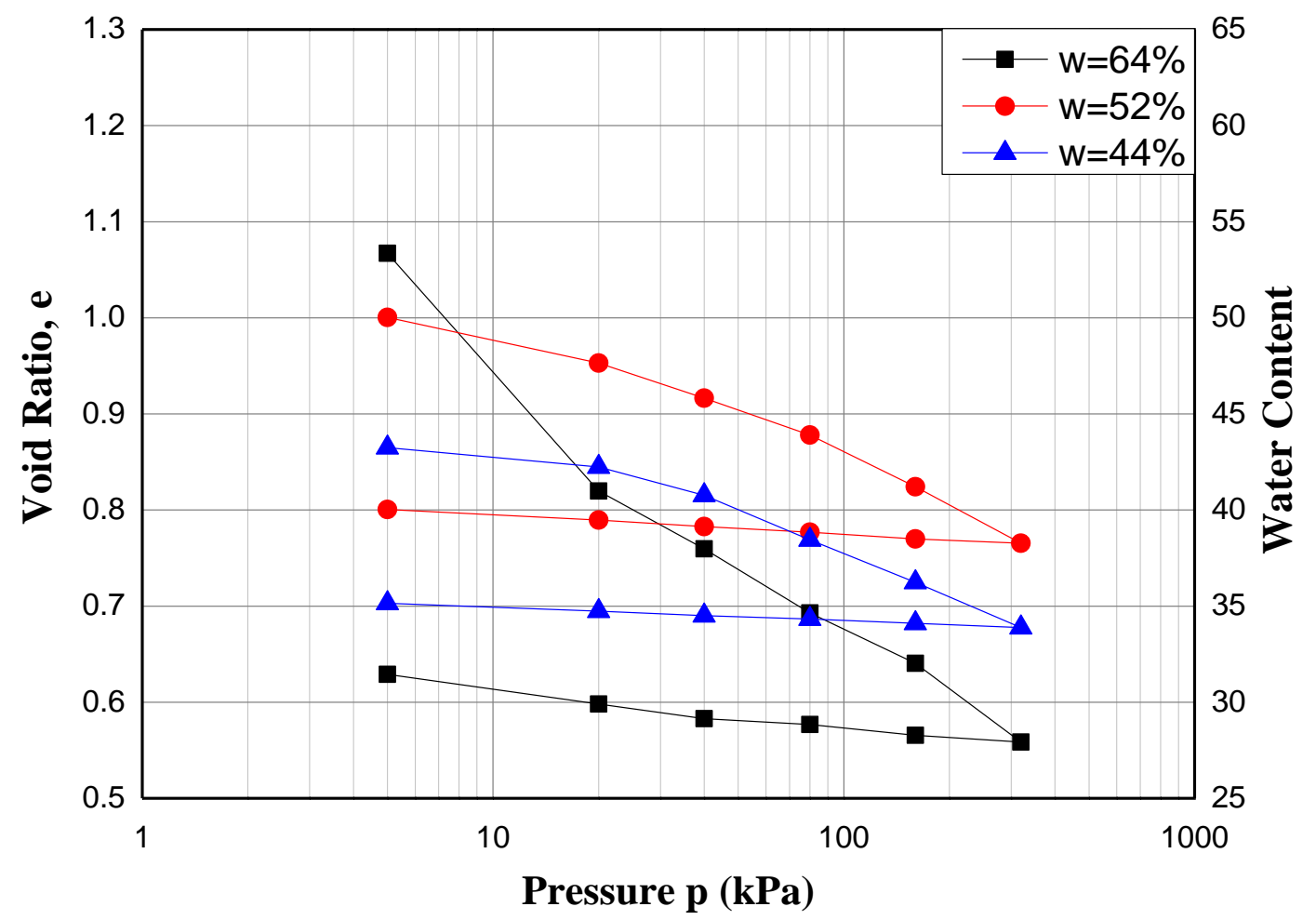

Figure 2-13 Void ratio vs. pressure for KY samples with different initial water content 


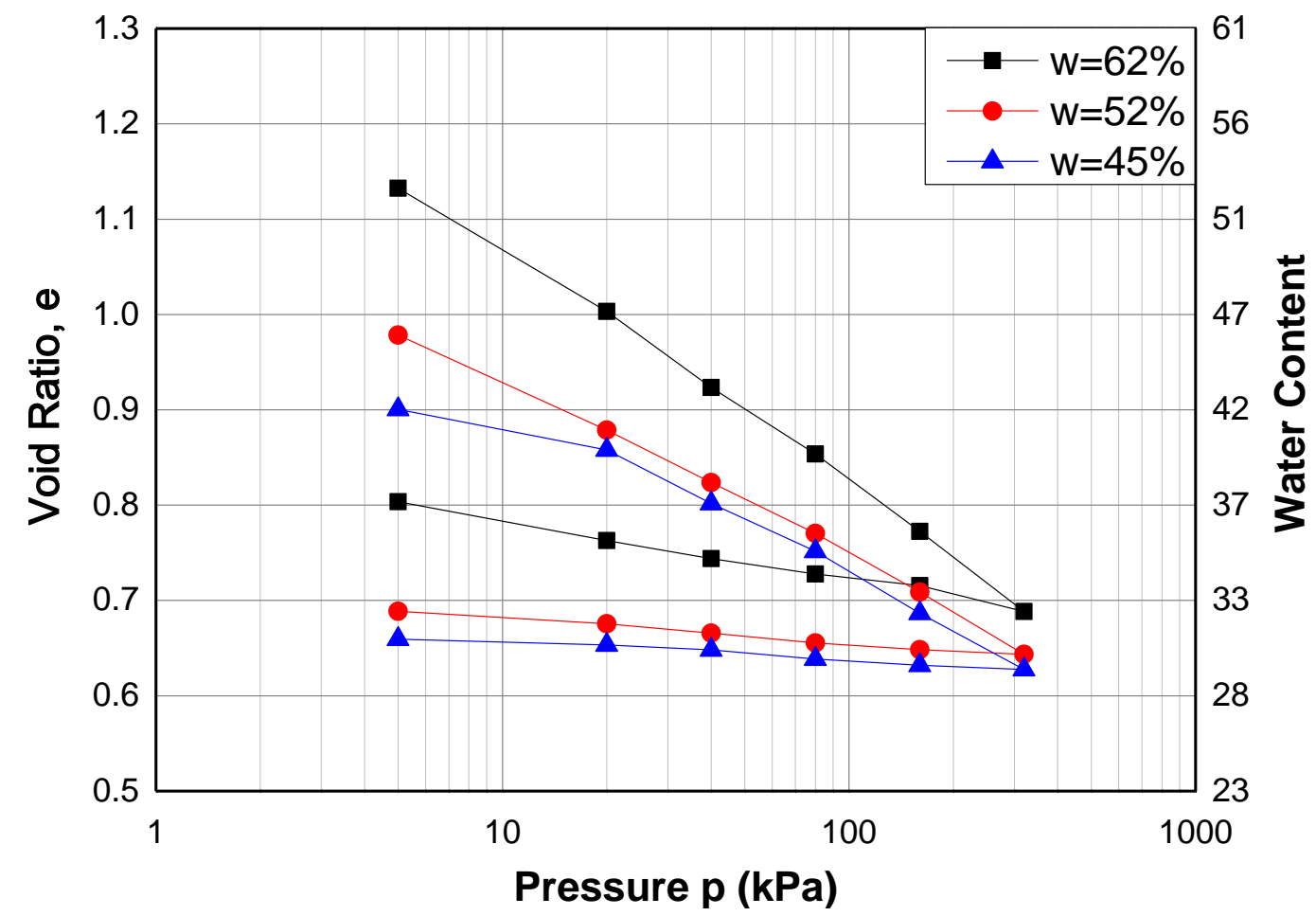

Figure 2-14 Void ratio vs. pressure for WV samples with different initial water content

Table 2-4 Comparison of Compression Index $C_{c}$ and Swelling Index $C_{s}$

\begin{tabular}{|c|c|c|c|}
\hline WV Sample & $\mathrm{w}=62 \%$ & $\mathrm{w}=52 \%$ & $\mathrm{w}=45 \%$ \\
\hline Compression Index $C_{c}$ & 0.278 & 0.205 & 0.176 \\
\hline Swelling Index $C_{s}$ & 0.056 & 0.034 & 0.015 \\
\hline \multicolumn{3}{|c|}{} \\
\hline KY Sample & $\mathrm{w}=64 \%$ & $\mathrm{w}=52 \%$ & $\mathrm{w}=44 \%$ \\
\hline Compression Index $C_{c}$ & 0.217 & 0.187 & 0.152 \\
\hline Swelling Index $C_{s}$ & 0.039 & 0.02 & 0.018 \\
\hline
\end{tabular}

The void ratio versus applied consolidation pressure of the two samples with different initial water content (or initial void ratio) was shown in Figure 2-13 and Figure 
2-14 where the consolidation pressure axis is plotted on a logarithmic scale. The compressive index $C_{c}$ was obtained from the straight-line part from the preconsolidation pressure and the swelling index $C_{s}$ was from the unloading branch. The summarized results of the two samples were listed in Table 2-4. Typically, the fine grained soils have relatively smaller capacity in bearing of applied load than the coarse grained soil. Therefore, the soils with more fine particles would have a higher degree of compressibility. The compressibility of different mine tailings were compared by Qiu and Sego (1998) and exhibited in the form of $\log \sigma^{\prime}-e$ plot. As shown in Figure 2-15, the coal wash tailings have much higher compressibility than other mine tailings. The values of compression index for different types of soil are listed in Table. 2-5. It was found that the compression index of coal refuse was quite close to that for medium-soft clay.

Table 2-5 Compression index $C_{c}$ for different types of soils (Widodo and Ibrahim, 2012)

\begin{tabular}{|c|c|}
\hline Type of Soil & Compression Index $C_{c}$ \\
\hline Dense Sand & $0.0005-0.01$ \\
Loose Sand & $0.025-0.05$ \\
\hline Firm Clay & $0.03-0.06$ \\
Stiff Clay & $0.06-0.15$ \\
\hline Medium - Soft Clay & $0.15-1.0$ \\
\hline Organic Soil & $1.0-4.5$ \\
\hline Rock & 0 \\
\hline
\end{tabular}




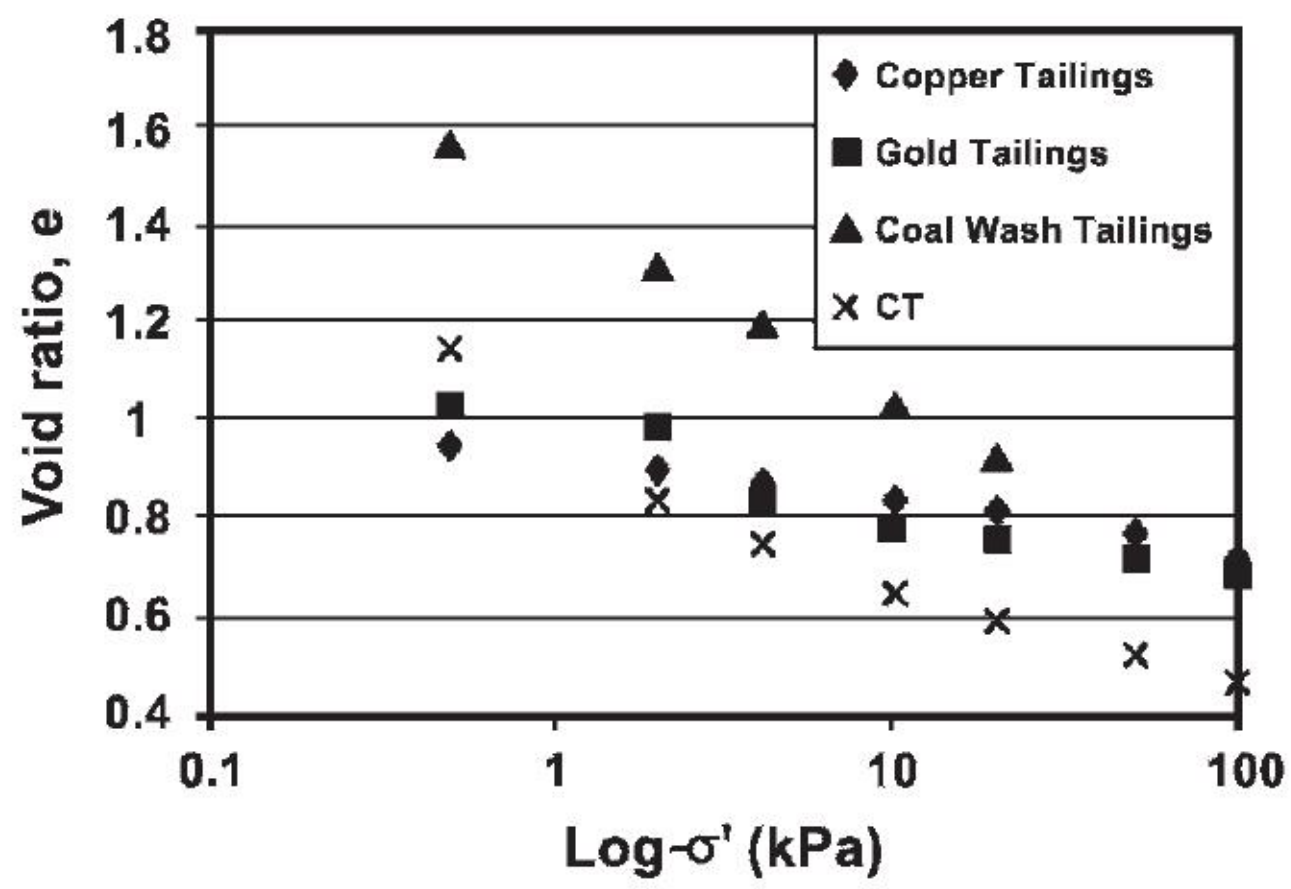

Figure 2-15 Compressibility of mine tailings as a function of void ratio (Qiu and Sego, 1998)

The compression index of soil has been investigated by many researchers and is correlated to other soil properties. Hough (1957) established the following relationship between compression index and void ratio and also water content for cohesive soil, silt, clay, silt clay and inorganic soil:

$$
\begin{gathered}
C_{c}=0.4049\left(e_{0}-0.3216\right) \\
C_{c}=0.0102\left(W_{n}-9.15\right)
\end{gathered}
$$

Terzhaghi and Peck (1967) proposed the correlation between primary compression index and the liquid limit. The equation is shown below:

$$
C_{c}=0.009\left(W_{L}-10\right)
$$


And Koppula (1981) and Worth and Wood (1978) tried to relate the compression index to the plasticity index for the remoulding clay as:

$$
C_{c}=1.325 I_{p}
$$

Quite a number of correlations have been developed between primary compression index and void ratio, water content, Atterberg limits (Skempton, 1944; Bowles, 1979; Rendon-Herrero, 1980; Sridharan and Nagaraj, 2000). However, the significant variation was observed in determining the compression index for different types of soils. Akayuli and Ofosu (2013) and Widodo and Ibrahim (2012) performed linear regression analysis on the established empirical models relating compression index and index properties of different types of soils. They found the liquid limit had the highest coefficient of determination and might be used to estimate the primary compression index in the engineering design.

As is shown in Figure 2-13 and Figure 2-14, the void became decreasing as the sample was compressed under consolidation pressure. The volume of coal refuse sample would swell a bit as the pressure gradually reduces to zero. The consistent results of both samples also indicated that the coal refuse sample with higher initial water content (or void ratio) had larger compression index and swelling index. The larger value of compression index stands for greater compressibility. Accordingly, the higher compressibility would result in lower coefficient of consolidation $C_{v}$ and more strain that is necessary for the buildup of the effective stress in the soil (Michael et al., 2010). This conclusion coincided with the represented results in Figure 2-11 and Figure 2-12.

In the practical engineering, the consolidation parameters are quite significant in the stability analysis of tailings dams and the flow behavior of coal refuse since they will 
determine the time for water content to drop below liquid limit in the field, the initial density after consolidation, the shear strength of coal refuse in a long run, and the resistance to the static and dynamic loading. The influence of consolidation on the strength of coal refuse will be introduced in the following sections.

\subsubsection{Permeability Tests}

\section{$\underline{\text { Introduction }}$}

The hydraulic conductivity (or coefficient of permeability) is defined as a constant of proportionality relating to the ease with which a fluid passes through a porous medium. Two general laboratory test methods are available to determine the hydraulic conductivity of soils, i.e., constant-head method and falling-head method. The constant-head method is suitable for the soils with higher permeability while falling-head method is for soils with relatively low permeability. Both methods are based on Darcy's law which is given as:

$$
v=k i
$$

The corresponding flow rate (or quantity per unit time) is

$$
q=k i A
$$

Where

$\mathrm{q}=$ quantity of fluid flow in a unit time, $\mathrm{m}^{3} / \mathrm{s}$

$\mathrm{k}=$ hydraulic conductivity, in velocity units

$\mathrm{i}=$ hydraulic gradient $=\mathrm{h} / \mathrm{L}=$ head loss across a flow path of length $\mathrm{L}$ (dimensionless)

$\mathrm{h}=$ total head difference across the flow path of length $\mathrm{L}$

$\mathrm{L}=$ length of sample or flow path that produces the head difference $\mathrm{h}$ 
$A=$ cross-sectional area of soil mass through which flow $q$ takes place in units consistent with $\mathrm{k}$

\section{Constant-Head Method}

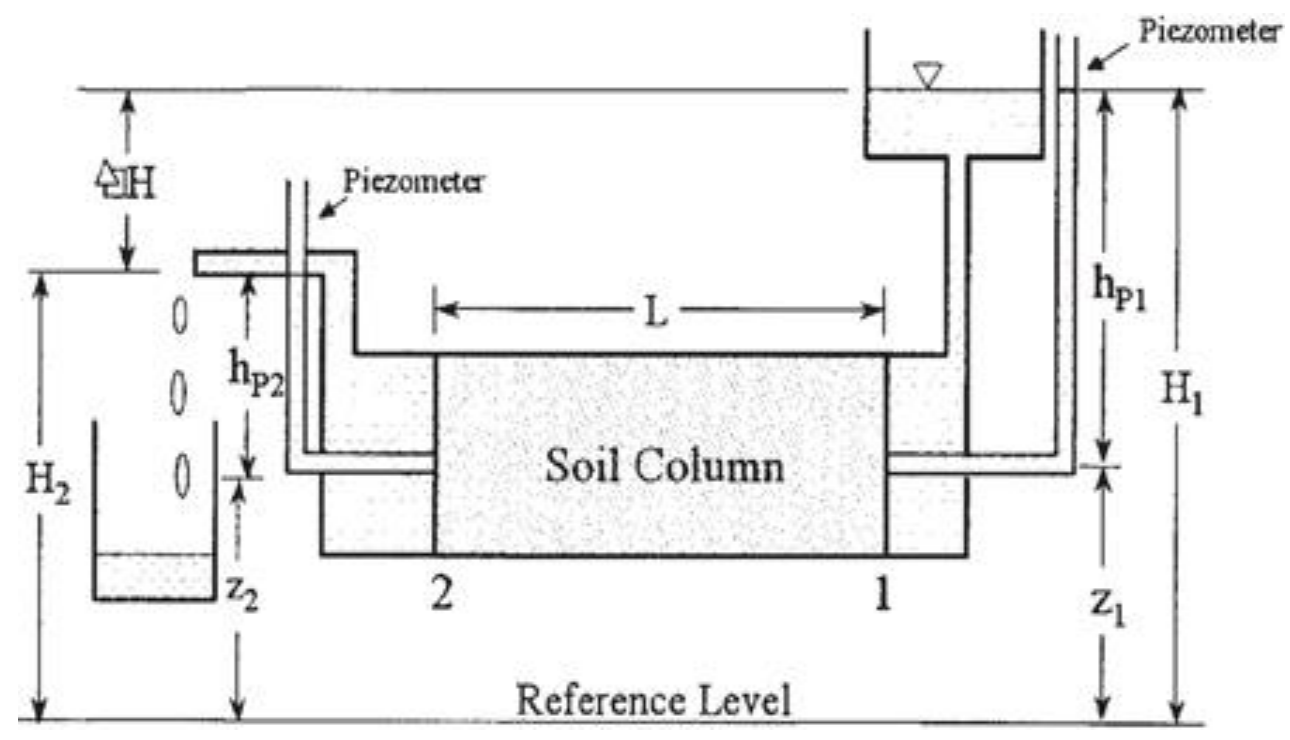

Figure 2-16 A schematic diagram of constant-head permeability test (after Hanson et al., 2013)

The constant-head test is usually used for cohesionless soil with hydraulic conductivity $k>10^{-4} \mathrm{~cm} / \mathrm{s}$ because a large amount of water is wasted into the overflow weir, which controls the constant head, unless the test is of short duration on the order of a few minutes. The schematic diagram is shown in Figure 2-16. Allow sufficient time for the flow pattern and specimen to stabilize. After equilibrium flow has been established, it could start to measure the volume of outlet water and required time to get the volume. At least 
three readings should be recorded to obtain the average value. The hydraulic conductivity can be determined by using the following equation:

$$
k=\frac{V L}{A \triangle H t}
$$

Where

$\mathrm{V}=$ collected volume of water

$\mathrm{L}=$ length of soil sample

$\mathrm{A}=$ cross-sectional area of soil sample

$\Delta H=$ head difference

$\mathrm{t}=$ time required to get $\mathrm{V}$ volume

\section{Falling-Head Method}

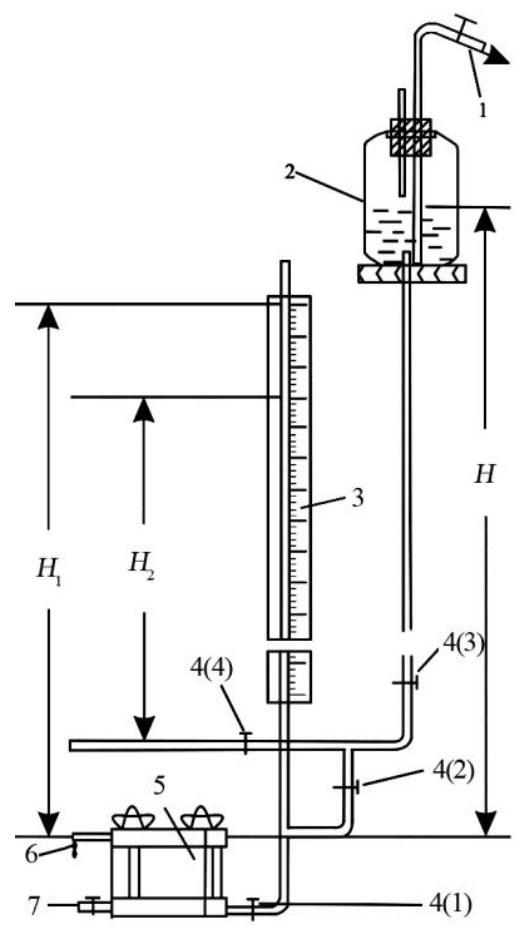

Figure 2-17 A schematic diagram of falling-head permeability test (after Chang et al., 2013) 
The falling-head permeability test typically involves flow of water through a cohesive soil sample with hydraulic conductivity $k<10^{-4} \mathrm{~cm} / \mathrm{s}$ connected to a standpipe which provides the water head and also allows measuring the volume of water passing through the sample. The test can be conducted in a falling-head permeability cell or in an odometer cell. The schematic diagram is shown in Figure 2-17. Before starting the flow measurement, the soil sample is saturated and the standpipe is filled with water to a marked level. The test then starts by allowing water flow through the soil sample within the given time period or until the water level drops down to a given lower limit. The same as the constant-head test, the process will be repeated at least three times to take the average readings. The hydraulic conductivity could be determined according to the following equation:

$$
k=\frac{a L}{A t} \ln \frac{h_{1}}{h_{2}}
$$

Where

$\mathrm{a}=$ cross-sectional area of standpipe

A $=$ cross-sectional area of soil sample

$h_{1}=$ hydraulic head across soil sample at the begin of test $(\mathrm{t}=0)$

$h_{2}=$ hydraulic head across soil sample at the end of test

\section{$\underline{\text { Testing Facilities and Procedures }}$}

Considering the relatively low permeability of fine coal refuse, a group of fallinghead permeability tests were performed following the procedures shown in ASTM D2434 and ASTM D5084. The falling-head permeability test apparatus are shown in Figure 2-18. 
The fully saturated coal refuse samples were pre-compressed in the permeability cell to reach different initial water content or void ratio. The fluid used in the permeability tests was distilled water and was de-aired prior the tests. The hydraulic gradient was controlled within $10 \mathrm{~cm}$ in order to avoid the seepage-induced consolidation during the test process.
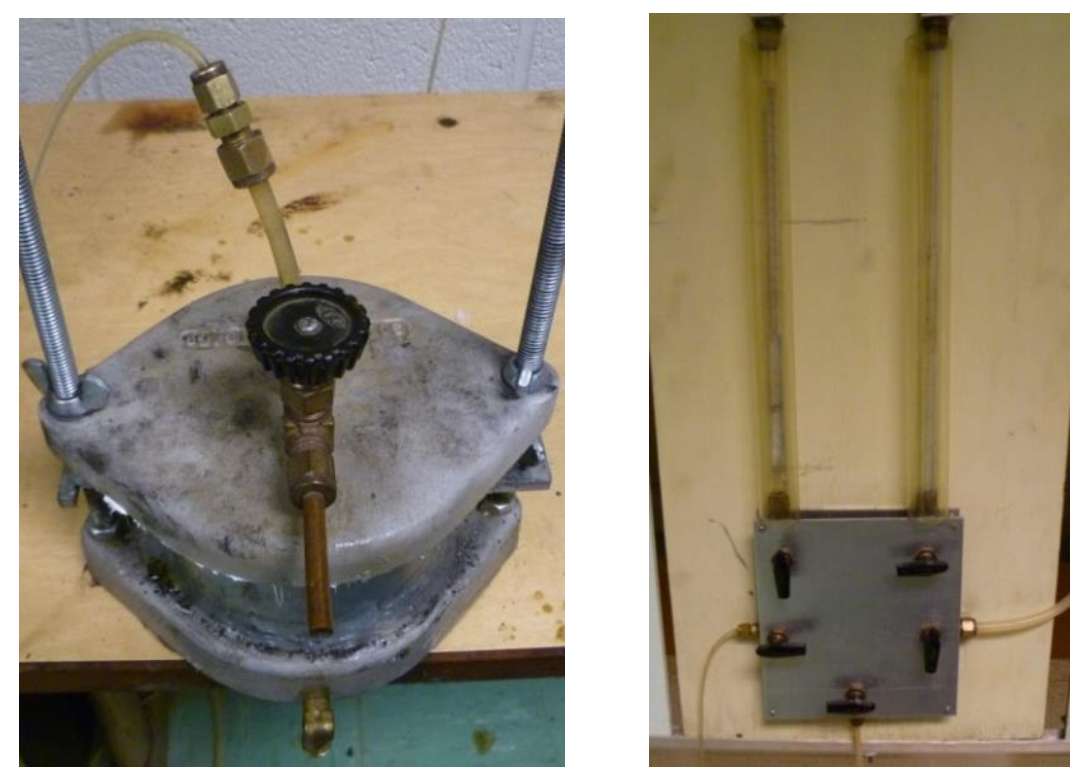

Figure 2-18 Falling-head permeability test apparatus

Since the hydraulic conductivity is related to the viscosity of the fluid which is affected by the temperature, the hydraulic conductivity is thereby standardized at $20^{\circ} \mathrm{C}$ as $k_{20}$ by using the following equation:

$$
\mathrm{k}_{20}=\mathrm{k}_{\mathrm{T}}\left(\boldsymbol{\eta}_{\mathrm{t}} / \boldsymbol{\eta}_{20}\right)
$$

Where $\eta_{\mathrm{t}}$ and $\eta_{20}$ are viscosities of water at test temperature $\mathrm{T}$ and at $20^{\circ} \mathrm{C}$, respectively. The test temperature was recorded as $23^{\circ} \mathrm{C}$. The coefficient $\alpha$ could therefore be defined as $\alpha=\eta_{\mathrm{t}} / \eta_{20}=0.9313$. 


\section{$\underline{\text { Test Results }}$}

A graphical representation of how hydraulic conductivities of the two coal refuse samples vary with void ratio or initial water content was presented in Figure 2-19. It was found that the hydraulic conductivity decreased with the reduction of void ratio or water content. The standardized hydraulic conductivity at $20^{\circ} \mathrm{C}$ ranged from $10^{-4}$ to $10^{-8} \mathrm{~cm} / \mathrm{s}$ for KY sample and from $10^{-5}$ to $10^{-9} \mathrm{~cm} / \mathrm{s}$ for WV sample.

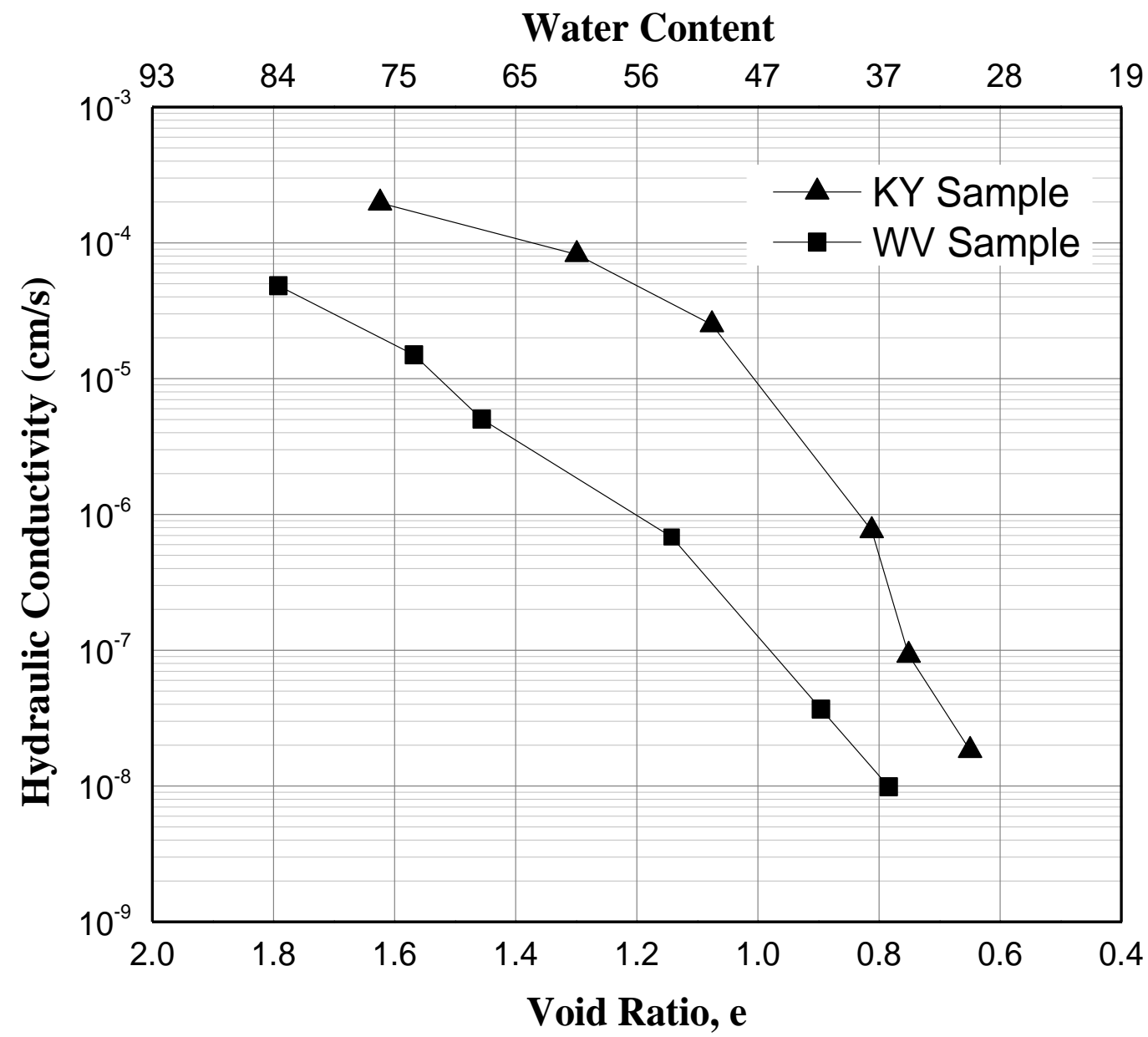

Figure 2-19 Comparison of permeability test results of two samples 
Table 2-6 Typical ranges of permeability for various soils

\begin{tabular}{|c|c|c|}
\hline Soil & $\begin{array}{c}\text { Hydraulic Conductivity, } \mathbf{k} \\
(\mathbf{c m} / \mathbf{s e c})\end{array}$ & Relative Permeability \\
\hline Coarse gravel & Exceeds $10^{-1}$ & High \\
\hline Sand & $10^{-5}$ to $10^{-1}$ & Low - Medium \\
\hline Silt & $10^{-5}$ to $10^{-7}$ & Very low \\
\hline Clay & Less than $10^{-7}$ & Impervious \\
\hline
\end{tabular}

The typical range of hydraulic conductivity for common soils was listed in Table 2-6 (Lewis, 1989; West, 1995). The fine coal refuse was classified as low-plasticity silt in terms of the particle size distribution and index properties. The measured hydraulic conductivities of both samples are consistent with the listed range between $10^{-5}$ and $10^{-7}$ $\mathrm{cm} / \mathrm{sec}$ for silt soils which is considered to have very low to impervious relative permeability.

As seen from the permeability test results, the hydraulic conductivity of coal refuse is strongly dependent on the void ratio and decreased from $10^{-4}$ to $10^{-9}$ as the void ratio was compressed from 1.8 to 0.65 . A number of empirical relationships have been established in order to represent hydraulic conductivity by other physical properties, such as: $k=(1+e)(A+$ Be) (Monte and Krizek, 1976); $k=C e^{D}$ (Somogyi, 1979); and $k=E e^{F} /(1+e)$ (Carrier, Bromwell, and Somogyi, 1983), where e is the void ratio and A, B, C, D, E, and F are empirical constants (Krizek, 2004). However, the values determined by these empirical formulas exhibited significant variation with soil classification and other physical properties. Chen et al. (1967) performed laboratory permeability tests on the coal refuse samples and indicated several applicable equations that can be used to describe the empirical relationships between the 
permeability and both void ratio and grain size (such as $D_{10}$ and $D_{50}$ ). They also drew a conclusion that void ratio is the most important among all factors influencing the permeability of coal refuse.

Permeability is considered as one of the most significant parameters in the design of tailings dam infrastructure and flow behavior of coal refuse. Hydraulic conductivity is directly related to the time required for the consolidation of impounded coal refuse and therefore has great impact on the strength buildup of coal refuse as well as the stability of tailings dams. The permeability of silt-like fine coal refuse is identified as very low to impervious and the length of the drainage path is long, so that the duration of primary consolidation will take quite a long time especially when the void ratio is reduced to a low level. In general, a new constructed coal waste impoundment needs to take many years to finish the primary consolidation due to the low permeability.

\subsubsection{Triaxial Tests}

\section{$\underline{\text { Introduction }}$}

The triaxial test is used to determine the stress-strain-strength characteristics of soils under undrained and drained conditions. This test, when performed well in the laboratory, reproduces the state of initial effective stress and change of soil stress in the field. The shear strength parameters of a soil including cohesion $\mathrm{c}$ and friction angle $\phi$ are mechanical parameters that have profound influence on the ultimate bearing capacity, slope stability and flowability.

The shear strength of a soil could be characterized by Mohr-Coulomb failure criterion which is shown as the following: 


$$
\tau_{f}=c+\sigma \tan \phi
$$

Where

$$
\begin{aligned}
& \tau_{f}=\text { the shear strength at failure } \\
& \mathrm{c}=\text { the cohesion of the soil } \\
& \sigma=\text { normal stress on the plane of shearing } \\
& \phi=\text { internal friction angle }
\end{aligned}
$$

The effective shear strength can be defined in terms of effective stress, $c^{\prime}$ and $\phi^{\prime}$. The cohesion for sands and normally consolidated clay soils is equal to zero.

The shear strength parameters $\mathrm{c}$ and $\phi$ either in the undisturbed or remolded conditions are usually determined by the following two laboratory tests:
a) Direct shear test
b) Triaxial compression test

In the direct shear test as shown in Figure 2-20, the soil sample is placed in the shear box and subjected to the known normal load. The shearing force is thereafter applied from the direction perpendicular to the normal load. During the shear process, the normal load is held constant but the shearing force is applied at a constant rate of strain. The normal pressure and the shear strength at failure of soil can be obtained by dividing the normal load and the maximum applied shear force by the cross-sectional area of the specimen at the shear plan. The Mohr-Coulomb failure criterion can be developed from the results of at least three shear tests. 


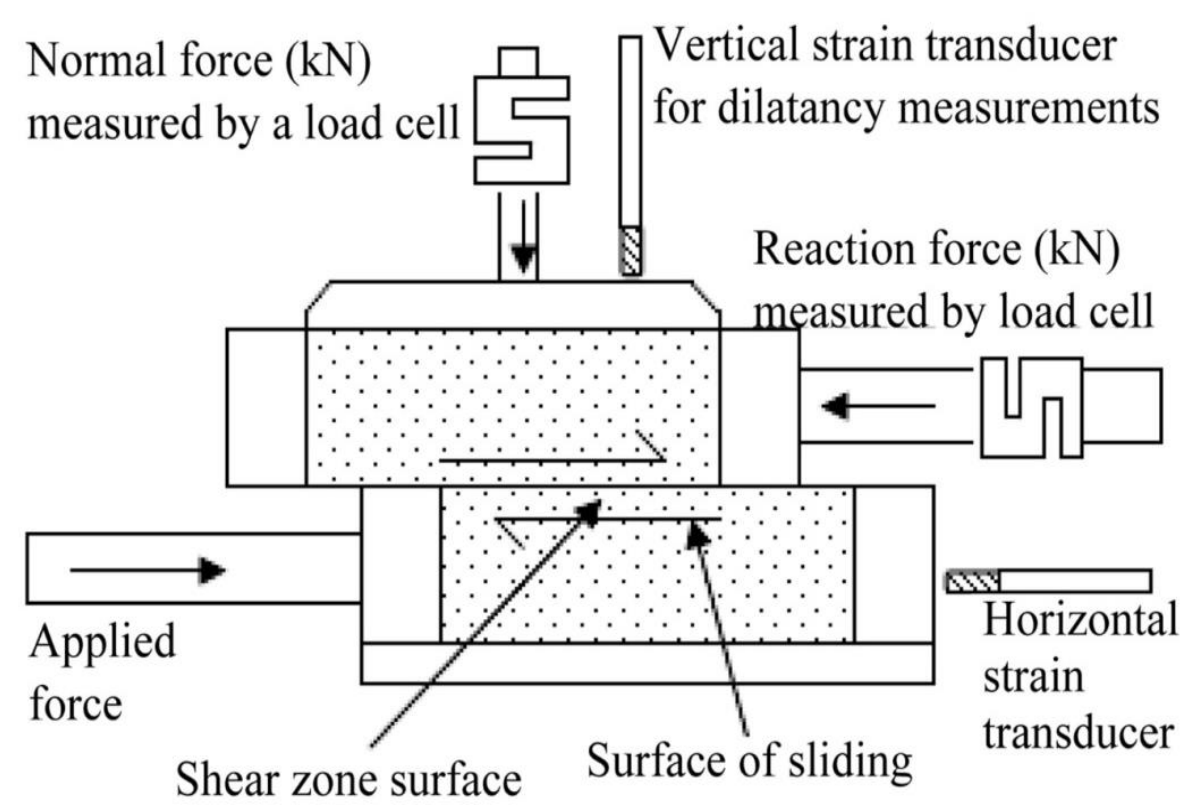

Figure 2-20 Direct shear apparatus

A schematic diagram of a triaxial test apparatus is shown in Figure 2-21. In the triaxial test, the cylindrical soil specimen is encased within a rubber membrane inside a pressure chamber. The lower and upper loading platens have porous disks connected to the drainage system for saturating and draining the soil specimen. The confining pressure $\sigma_{3}$ is applied before the axial compression. When the soil specimen is fully consolidated under the confining pressure, the axial stress $\sigma_{1}$ is applied to the soil until it fails. Although only compressive load is applied to the soil specimen, it fails by shear on the internal shear plane. Depending on whether the drainage is allowed during the consolidation phase and shearing phase, the triaxial tests could be categorized into three main types: UnconsolidatedUndrained (UU), Consolidated-Undrained (CU), and Consolidated-Drained (CD) test. The detailed information about these three tests can be found in Bardet (1997). The Mohr circle can be drawn in terms of the applied confining pressure and the recorded axial load at 
failure. At least three triaxial tests are required for one soil specimen under different confining pressures so that three Mohr circles can be obtained. The Mohr-Coulomb failure criterion can thereafter be defined as the tangent of the three Mohr circles. As shown in Figure 2-22, the slope of the tangent gives the angle of friction and the intercept on the ordinate gives the cohesion of soil specimen.

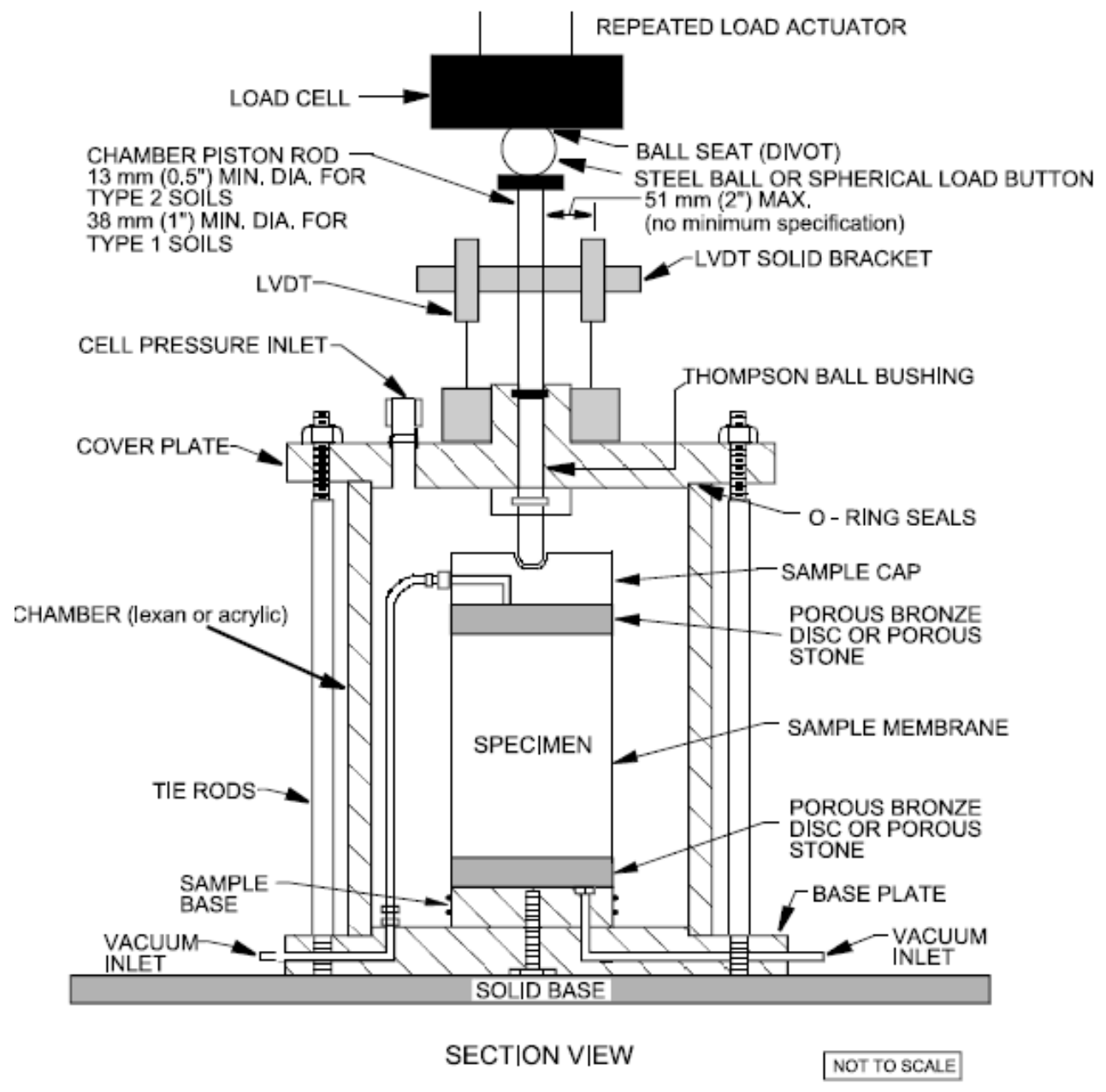

Figure 2-21 Triaxial chamber with external LVDT and load cell (FHWA, 2007) 


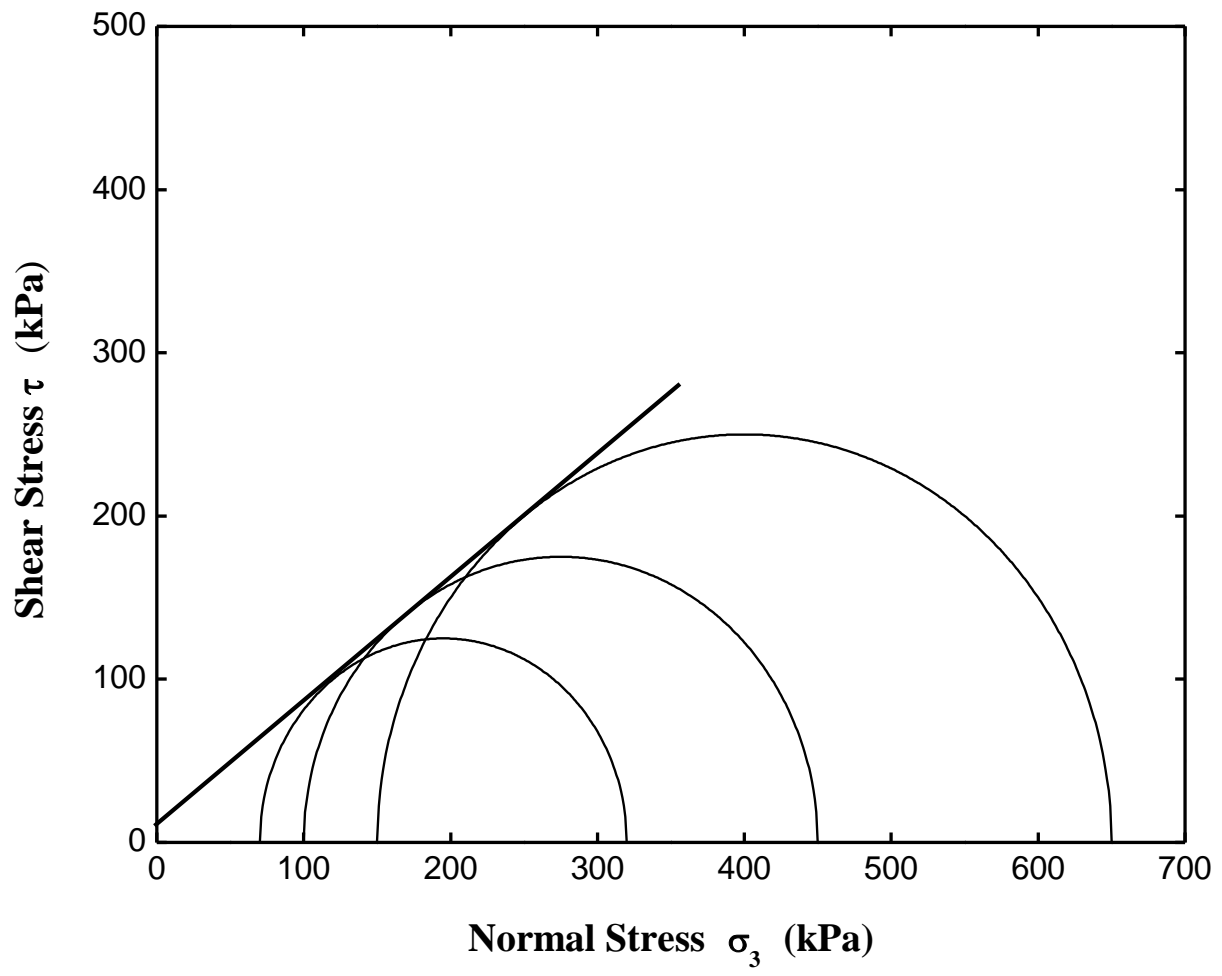

Figure 2-22 Mohr stress circles and developed strength envelope.

The direct shear and triaxial devices have been used for over 70 years to determine the shear strength parameters of soils (Saada and Townsend, 1981). As introduced above, the two testing methods have pronounced differences in the stress condition developed in the soil specimen. Although some of previous laboratory tests achieved the same shear strength of soil by comparing the direct shear and triaxial apparatuses (Skempton, 1964; Casagrande and Poulos, 1964; Moon, 1984; Thomson and Kjartanson, 1985; and AbdelGhaffar, 1990), the triaxial test is considered as a more reliable and accurate method due to the uniform distribution of stress, accurate measurement of volume change, the known state of stress during all stages of the test, and realistic plane of failure (Murthy, 2002). 


\section{Testing Facilities and Procedures}

In this study, a group of triaxial tests were conducted on the coal refuse samples with different initial void ratio under unconsolidated-undrained (UU) and consolidateddrained (CD) conditions in order to establish the relationship between the void ratio (water content) and shear strength. The preparation of samples and setup of the experiment device were graphically shown in Figure 2-23. The coal refuse specimen was encased by a thin rubber membrane and placed in a cylindrical chamber filled up with oil for the purpose of air isolation. Before starting the test, the specimen was flushed using the de-aired distill water which would increase the degree of saturation by extruding the air bubble from inside the soil specimen. Since the permeability of coal refuse is very low, a small amount of pressure was applied on the top of the buret to accelerate saturation process. However, the applied pressure can not be too high in case that the excessive uplift seepage force would induce soil liquefaction. The specimen was considered fully saturated as the Skempton's pore pressure parameter $B=\frac{\Delta u}{\Delta \sigma_{3}}>0.95$, where $\Delta u$ is the change in pore water pressure due to any incremental increase in confining pressure $\Delta \sigma_{3}$. The confining pressures were thereafter applied with $70 \mathrm{kPa}, 100 \mathrm{kPa}$, and $150 \mathrm{kPa}$, respectively. The loading rate applied during shearing was set at $0.5 \mathrm{~mm} / \mathrm{min}$ for UU tests and $0.015 \mathrm{~mm} / \mathrm{min}$ for CD tests. During the test, failure of the specimens was defined at $20 \%$ of strain. The shear strength of each sample could be developed by drawing the failure envelope based on the three Mohr stress circles. 


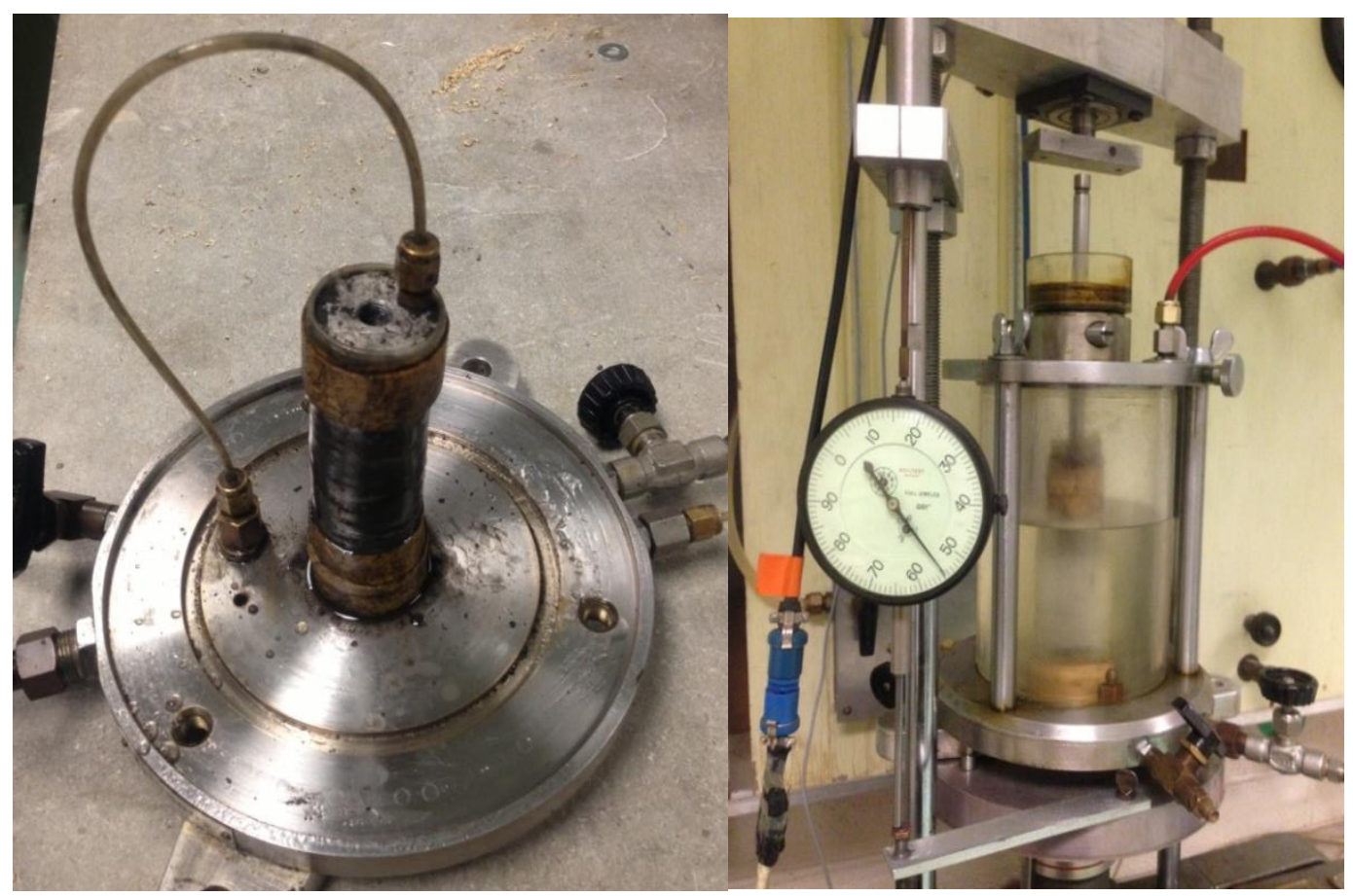

Figure 2-23 Prepared test sample and triaxial chamber for triaxial tests

\section{Test Results}

\section{Unconsolidated-Undrained Tests}

In the unconsolidated-undrained (UU) condition, drainage is not allowed

throughout the experiment. For saturated coal refuse, the voids in the specimen are full of water which is incompressible. The increment of confining pressure would be completely carried by pore water instead of causing any increase of effective stress of coal refuse. Therefore, the value of deviator stress $\bar{q}=\sigma_{1}-\sigma_{3}$ is a constant, irrespective of the change of confining pressure. A trial test results were exhibited in Figure 2-24 under confining pressure of $100 \mathrm{kPa}, 150 \mathrm{kPad}$ and $200 \mathrm{kPa}$ respectively. The procedures and data processing of the UU test could be found in ASTM D2850. Accordingly, the three Mohr's circle obtained under different confining pressure had the identical diameter $\left(\sigma_{1}-\sigma_{3}\right)$. 
The tangent to the three Mohr's circles was therefore a horizontal line with internal friction angle $\Phi=0$. The intercept on the ordinate was defined as the undrained shear strength $c_{u}$. Undrained shear strength is a quite significant engineering parameter used in the design and stability analysis of coal waste embankments and impoundments as well as the flow behavior of the impounded coal refuse.

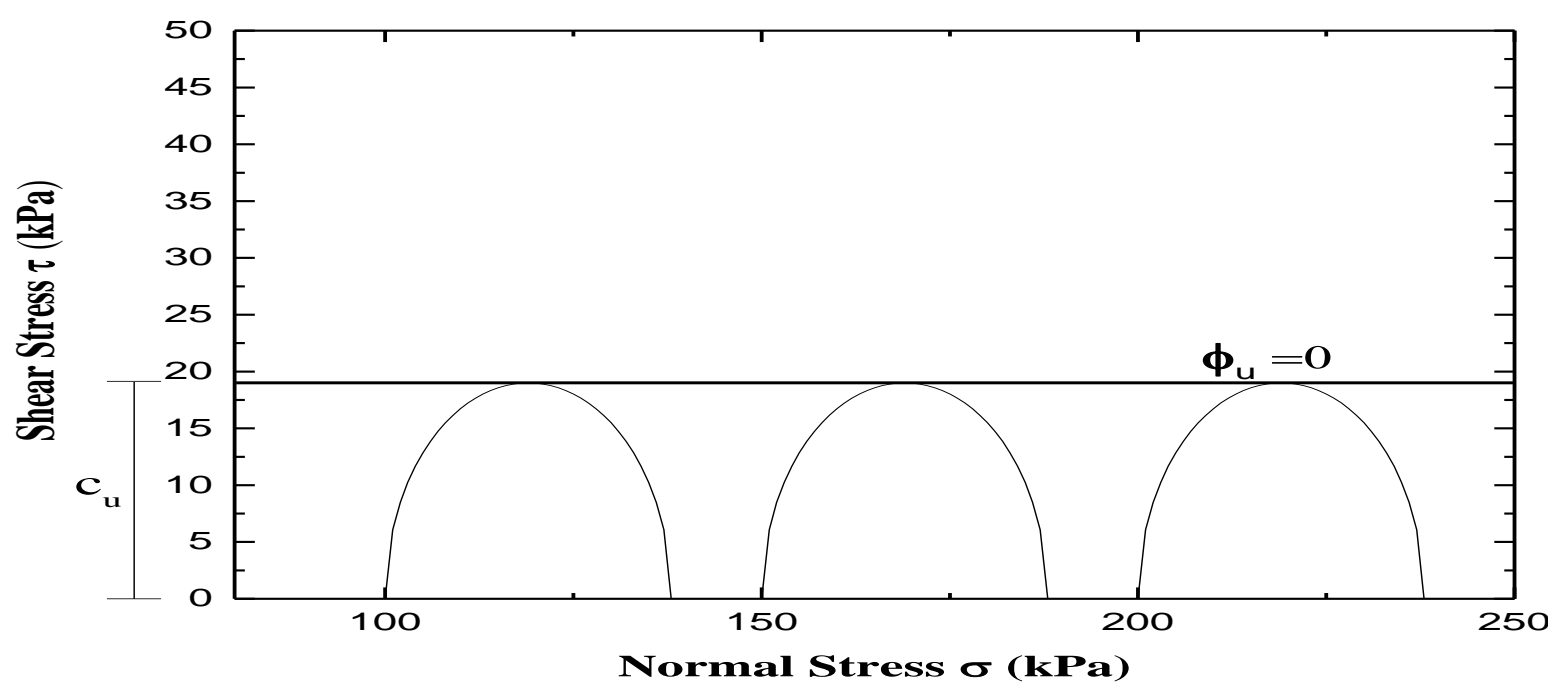

Figure 2-24 Example of Mohr stress circles for UU triaxial test

The variations of undrained shear strength $c_{u}$ with initial water content or void ratio for KY sample and WV sample were shown in Figure 2-25. It was found that the measured undrained shear strengths of both samples exhibited consistent results and were increased with the reduction of initial water content. Both of the two coal refuse samples had extremely low undrained shear strength less than $10 \mathrm{kPa}$ at water content above the corresponding liquid limits (38.1 for KY sample and 42.5 for WV sample). As the water 
content decreased below the liquid limit, significant buildup of undrained shear strength was observed.

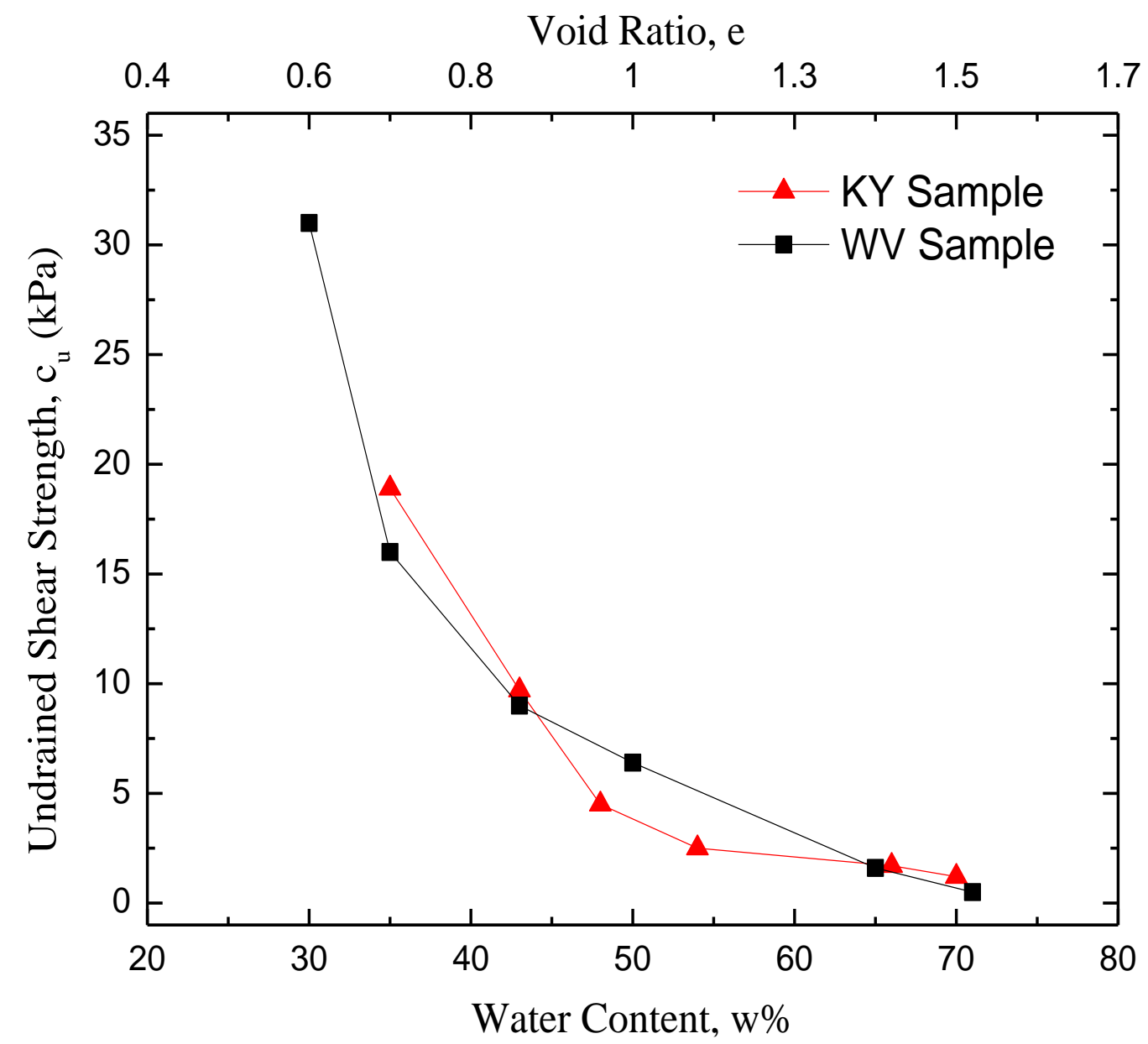

Figure 2-25 Variation of undrained shear strength with water content

\section{Consolidated-Drained Tests}

In the consolidated-drained (CD) condition, the saturated coal refuse sample was first consolidated to an initial effective stress under the applied confining pressure. Consolidation is an important step in testing the frictional materials whose elastic properties and shear strength depend largely on the effective stress (Bardet, 1997). The 
time required to complete consolidation was quite long for the fine grained coal refuse with low permeability. After the completion of consolidation, the shearing stress was applied until the sample failed with the drainage open. In the CD test, the coal refuse sample was sheared at a much slower rate of $0.015 \mathrm{~mm} / \mathrm{min}$ than $0.5 \mathrm{~mm} / \mathrm{min}$ in UU test in order to allow for pore pressure equalization throughout the sample and to obtain more accurate effective strength. Time required to failure for CD tests were approximately several hours with the failure criterion defined as $20 \%$ of axial strain. Since the drainage is opened, the excess pore water pressure remains equal to zero throughout the $\mathrm{CD}$ test. The measured total shear strength is also the effective shear strength (c' and $\left.\phi^{\prime}\right)$.

Typically impounded coal refuse, behaving similar to silt soils, is primarily frictional in nature. When the coal refuse is subjected to an external load in the drained condition, vast majority of the load will be carried out by the friction between internal particles rather than the cohesion. The coal refuse is found to have small cohesion value with the order of less than $30 \mathrm{kPa}$ and relatively prominent angles of internal friction in the drained tests (Zook et al., 1974; Sweigard et al., 1997; Zeng et al., 1998a and 1998b; Krizek, 2004; Hegazy et al., 2004; and Agarwal, 2009). However, the effective strength of coal refuse is quite sensitive to the water content. The reduction of internal friction angle with water content has been observed by (Sweigard et al., 1997; and Burns et al., 2010). 


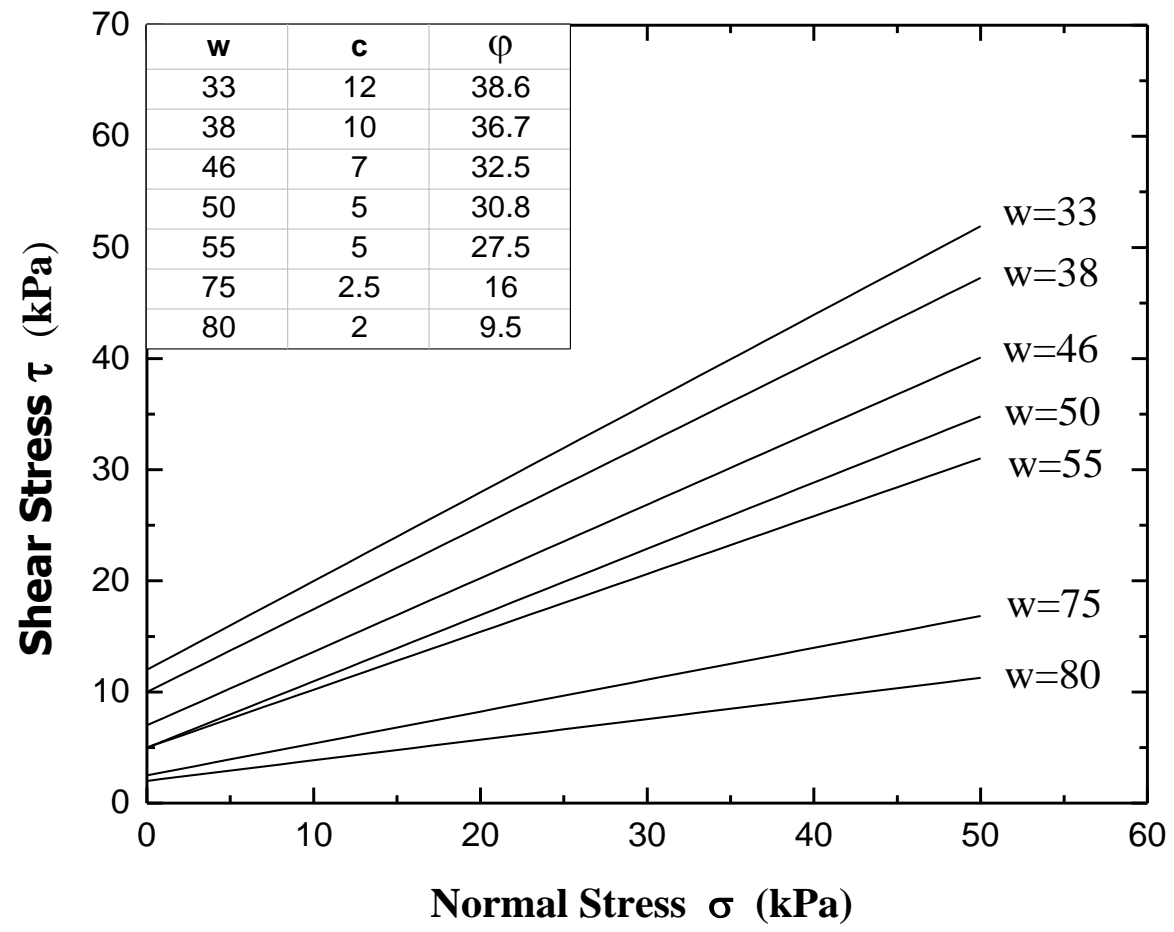

Figure 2-26 Results of consolidated-drained (CD) tests for KY sample

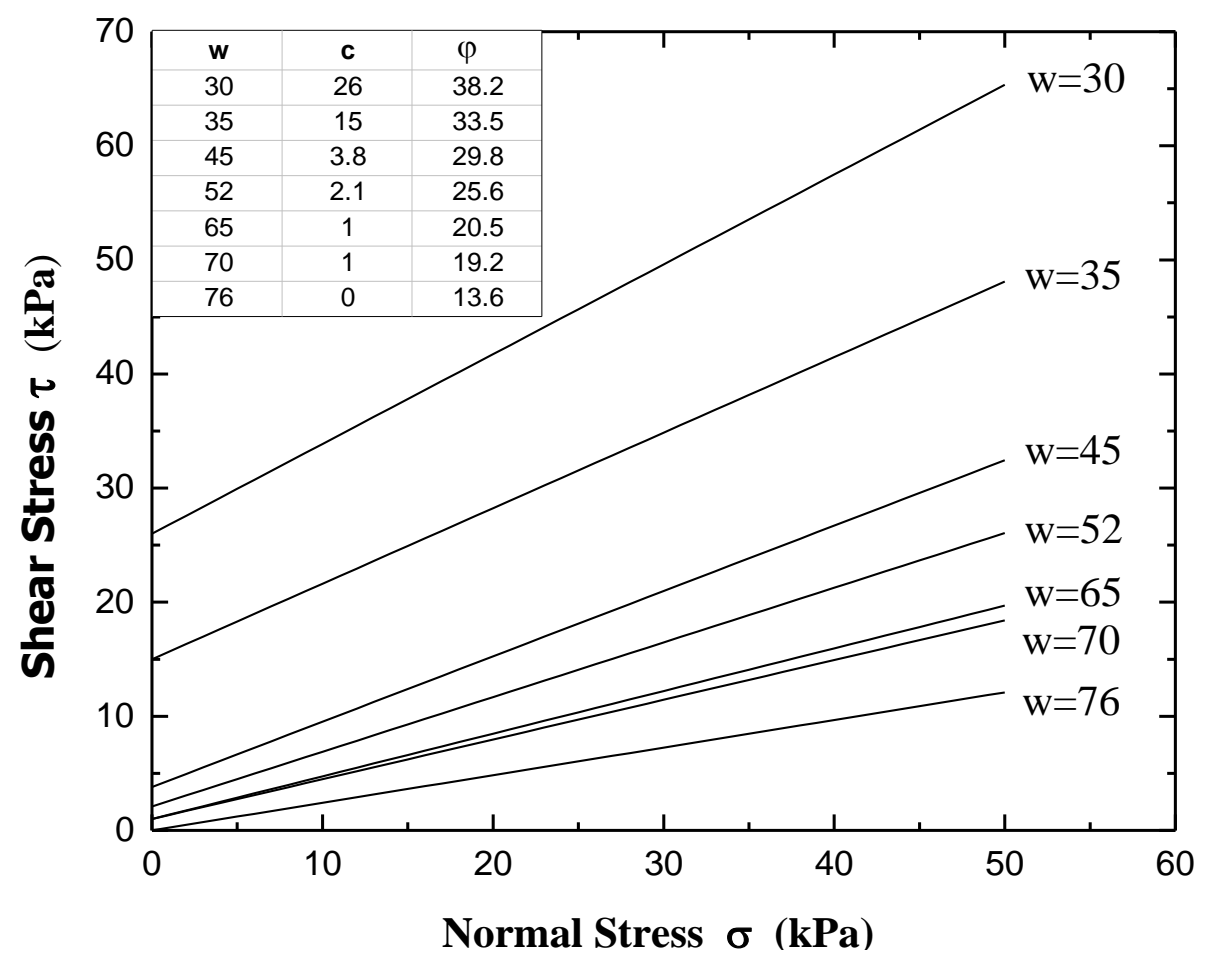

Figure 2-27 Results of consolidated-drained (CD) tests for WV sample 


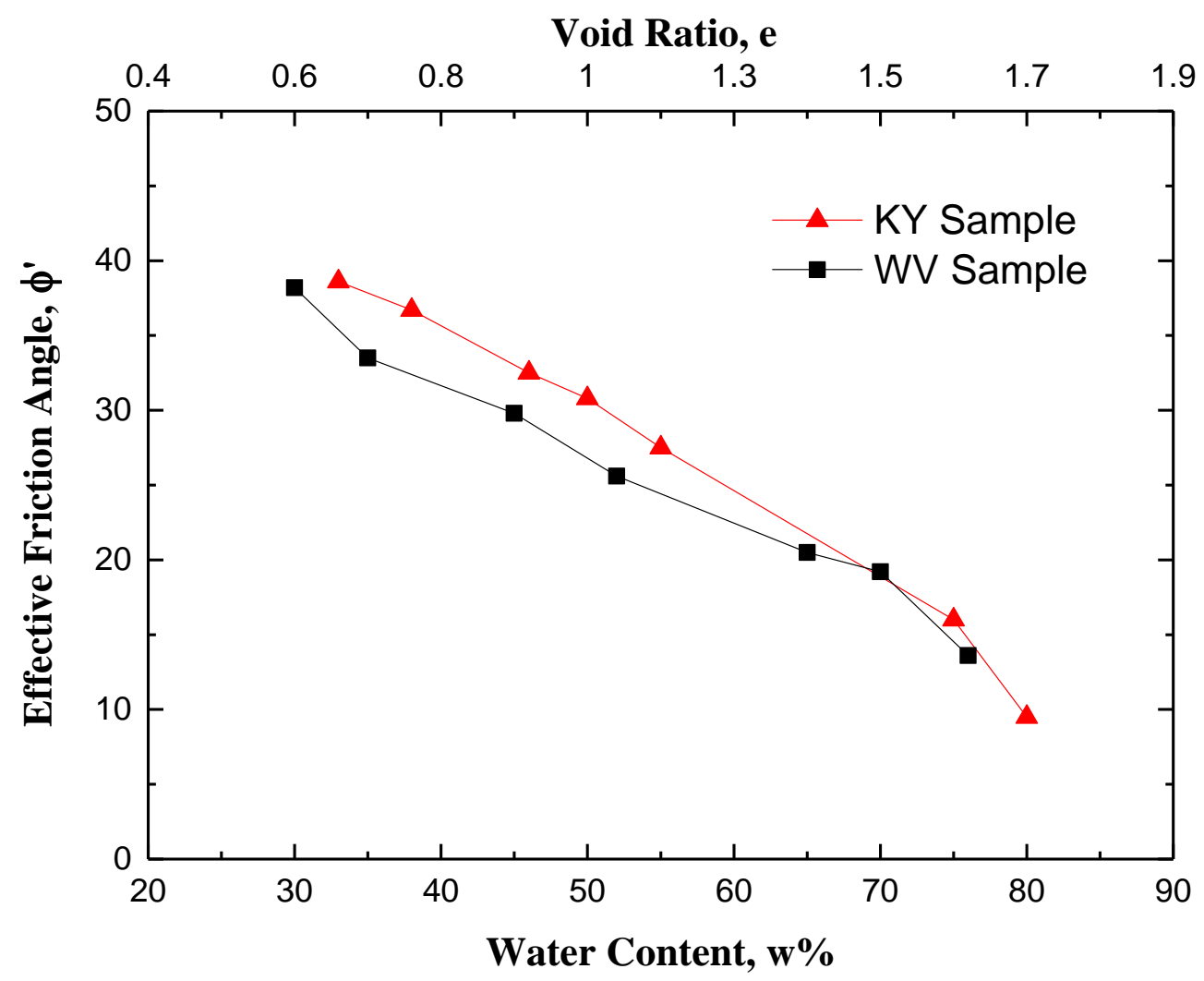

Figure 2-28 Variation of $\Phi$ ' with water content for two samples

In this test, both KY and WV coal refuse samples were prepared with different initial water content ranging approximately from $80 \%$ to $30 \%$. The developed $\sigma-\tau$ relationships with different water contents were displayed in Figure 2-26 for KY sample and Figure 2-27 for WV sample. Coincided with the previously reviewed results, the measured effective cohesion c' was in the extremely low range of $2-12 \mathrm{kPa}$ for KY sample and of $0-26 \mathrm{kPa}$ for WV sample. Lindeburg (2003) summized the typical cohesion values for different soil groups. As shown in Table 2-7, the cohesion of fine grained silty soil is 9 $\mathrm{kPa}$ which consists with the measured results. The change of effective internal angle of friction with water content was shown in Figure 2-28. A linear variation indicated that the 
effective friction angles decreased from larger than $35^{\circ}$ to less than $10^{\circ}$ as initial water content gradually increased from $30 \%$ below the liquid limit to approximately $80 \%$ above the limit liquid.

Table 2-7 Typical cohesion value for different soil groups (after Lindeburg, 2003)

\begin{tabular}{|c|c|}
\hline USCS Soil Group & $\begin{array}{c}\text { Cohesion (saturated) } \\
(\mathbf{k P a})\end{array}$ \\
\hline SM & 20 \\
\hline SC & 11 \\
\hline ML & 9 \\
\hline ML-CL & 22 \\
\hline CL & 13 \\
\hline MH & 20 \\
\hline CH & 11 \\
\hline
\end{tabular}

Zook et al. (1974) indicated that "the shear strength of coal refuse would be affected by its composition, moisture content, degree of compaction, amount and grain size of fines present". According to the results in this study, the initial water content (void ratio or consolidation degree) seemed to be the dominating factor controlling the shear strength of coal refuse. Although the KY and WV slurry samples have a bit different engineering properties such as grain-size distribution, Atterberg limits, compression index, and hydraulic conductivity, less variation of shear strength was observed between the two specimens. At high water content (typically above the liquid limit), the friction angle of fine refuse was extremely small, which made it vulnerable to the static or dynamic disturbance. In the event of impact loading, excess pore water pressure in the material would quickly build up and cause a further reduction in the shear strength or, in the worst 
case, a total loss of strength due to the liquefaction of the fine grained coal refuse. In the construction process, especially for upstream construction method, it is necessary to provide enough time for the consolidation of fine refuse in order to develop sufficient shear strength.

In the construction of upstream and center line tailings dams, the additional embankment material is often placed right upon the consolidated fine coal refuse. The engineering concern was therefore related to the long term impacts of consolidation on the shear strength of impounded coal refuse. A comprehensive literature review was performed on the work by Huang et al. (1987), Suthaker and Scott (1994), Suthaker et al. (1997), Sweigard et al. (1997), and Jones and Uckert (2006). Based on a number of laboratory tests on the impounded fine coal refuse, the internal angle of friction was found to be slightly increased as the water content dipped below the liquid limit. However, the rate of consolidation was extremely slow due to the low permeability and long drainage paths. A high void ratio was observed even after the full consolidation (Zeng et al, 1998b). Suthaker et al. (1997) conducted the large scale consolidation tests on the oil-sand tailings and found no development of effective strength after more than 14 years.

\subsubsection{Viscosity Tests \\ Introduction}

For all flowing fluids, the molecules are having relative movement between each other, and this movement is typically accompanied with the internal frictional forces which may be determined in terms of the viscosity (sometimes the terms dynamic viscosity or shear viscosity are used). Therefore, the viscosity is defined as the internal friction in a 
fluid that opposes the motion of one portion of a fluid relative to another, in other words, it represents the resistance to the shearing flow.

The Two-Plates-Model is usually used to explain the mechanism of shear flow as well as define the fundamental concept of viscosity. As shown in Figure 2-29, two plates are placed on the top and bottom of fluid. The distance between two plates is h. The upper plate with the shear area A starts to move under the drag force (shear force) $\mathrm{F}$ and the resulting flow velocity $\mathrm{v}$ on the surface is measured. The plate on the bottom is stationary with flow velocity equal to zero. The fluid is sheared in the shear gap h. However, this model is only applicable to the laminar flow and is based on the assumptions that the fluid adheres to both plates without slide or slip.

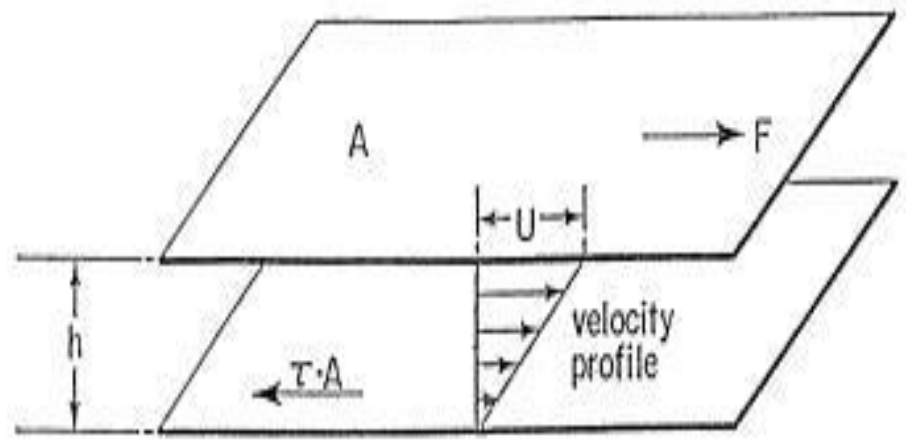

Figure 2-29 Shear flow by using Two-Plates-Model (after Vlachopoulos, 2003)

The shear stress $\tau$ varies linearly from zero on the bottom to the maximum value on the top surface which could be defined as:

$$
\tau=\frac{F}{A}
$$


Shear rate $\dot{\gamma}$ is the rate at which a progressive shearing deformation is applied to fluid. It is also named as shear gradient or velocity gradient. In terms of the Two-PlatesModel, the shear rate could be defined as:

$$
\dot{\gamma}=\frac{v}{h}
$$

The viscosity of fluid $\eta$ is thereafter defined as the ratio of the imposed shear stress and the shear rate:

$$
\eta=\frac{\text { Shear Stress }}{\text { Shear Rate }}=\frac{\tau}{\dot{\gamma}}=\frac{F / A}{v / h}
$$

The unit of the viscosity is named as Pascalseconds - "Pas" or poise - "P" and 1P $=100 \mathrm{cP}$ (centipoise).The typical values of viscosity for different materials are listed in Table 2-8.

Table 2-8 Typical viscosity values of various materials (after Mezger, 2002)

\begin{tabular}{|c|c|}
\hline Material & Shear Viscosity $\eta$ (cP) \\
\hline Gas / Air & $0.01-0.02 / 0.018$ \\
\hline Water at $0^{\circ} \mathrm{C} / 20^{\circ} \mathrm{C} / 100^{\circ} \mathrm{C}$ & $1.79 / 1.0 / 0.282$ \\
\hline Mercury & 1.55 \\
\hline Milk, Coffee cream & $2-10$ \\
\hline Glycerine & 1480 \\
\hline Silicone polymers & $10^{7}-10^{8}$ \\
\hline Bitumen at $80^{\circ} \mathrm{C} / 20^{\circ} \mathrm{C}$ & $2 \times 10^{5} / 5 \times 10^{8}$ \\
\hline
\end{tabular}


The viscosity of a fluid could be measured by using viscometer or rheometer. Strictly, the viscometer is an instrument only measuring viscosity under one flow condition while the rheometer could measure varying viscosity of a liquid with flow conditions. Most of the time, the rheometer is also called viscometer.

There are several different types of viscometers available to measure the viscosity of fluid. Some of standard viscometers for liquids are introduced as the following:

U-Tube viscometer: is also known as Ostwald viscometer or glass capillary viscometer. As shown in Figure 2-30(a), A U-tube viscometer consists of a U-shaped glass tube held vertically in a controlled temperature bath (Anonymous, 2013). The liquid is poured into the upper bulb by suction, and then allowed to flow down through the capillary into the lower bulb. Two marks A and B would indicate the volume of measured liquid. The time taken for the level of the liquid to pass between these two marks is proportional to the kinematic viscosity $v=\frac{\eta}{\rho}$. By multiplying the time taken by the factor of the viscometer, the kinematic viscosity is obtained.

Falling sphere viscometer: is based on the Stoke's law in which the fluid is stationary in a vertical glass tube. As shown in Figure 2-30(b), a sphere ball of known size and density is allowed to descend through the liquid. The time is taken for the sphere passing two marks on the tube in the terminal velocity. The viscosity can be calculated by using Stoks' law given the terminal velocity, the size and the density of the sphere as well as the density of the liquid. The resulting viscosity is given by (Lamb, 1879): 


$$
\eta=\frac{2}{9} \frac{\left(\rho_{p}-\rho_{f}\right)}{v_{s}} g r^{2}
$$

Where

$\rho_{p}=$ mass density of the sphere or particles

$\rho_{f}=$ mass density of the fluid

$v_{s}=$ terminal velocity

$\mathrm{g}=$ gravitational acceleration

$\mathrm{r}=$ radius of the sphere

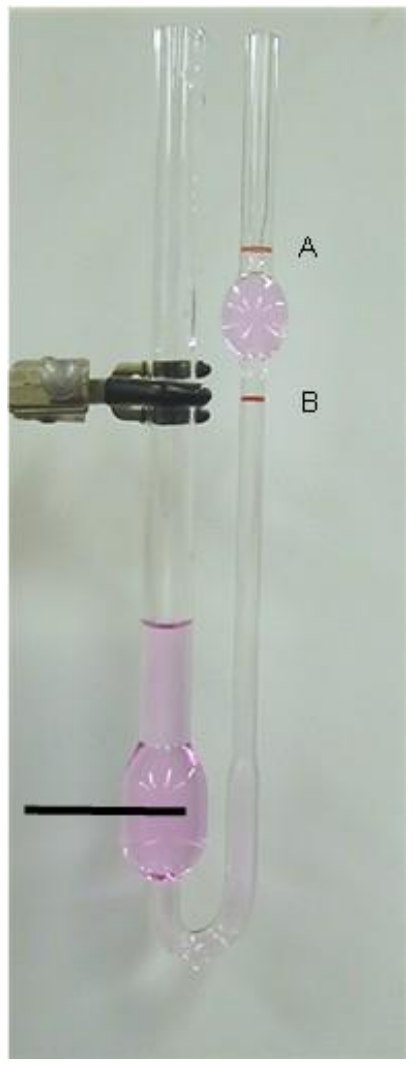

(a)

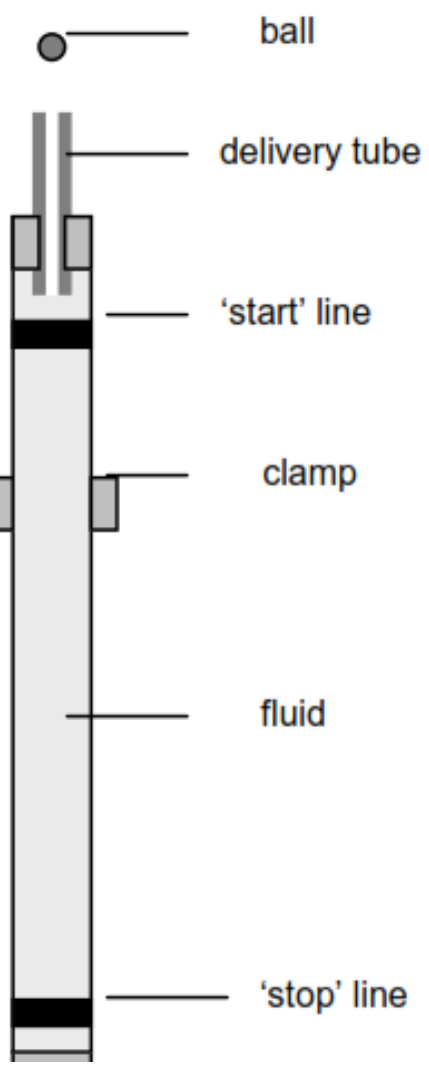

(b)

Figure 2-30 a) U-tube viscometer; b) Falling sphere viscosity 
Rotational viscometer: uses the idea that the torque required to turn an object in a fluid is a function of the viscosity of the fluid. It measures the torque required to rotate a disk or bob in a fluid at a given speed and collect data on a fluid's viscosity under different conditions. As shown in Figure 2-31, a rotational viscometer typically consists of two parts - a head unit with a motor and a spindle that is driven by the motor. The viscosity is determined by measuring the resistance of a spindle rotating in the sample.

The greatest advantage of rotational viscometer is that it can be used for the accurate measurement of viscosity for both Newtonian and non-Newtonian fluids. Newtonian fluids are affected by temperature, such as water, kerosene, mineral oils etc. Non-Newtonian fluids are those that change viscosity when stirred, shaken or otherwise agitated which includes paint, gels, inks, milk, ketchup etc. (Elcometer, 2006). The detailed information of rotational viscometer will be introduced in the following.

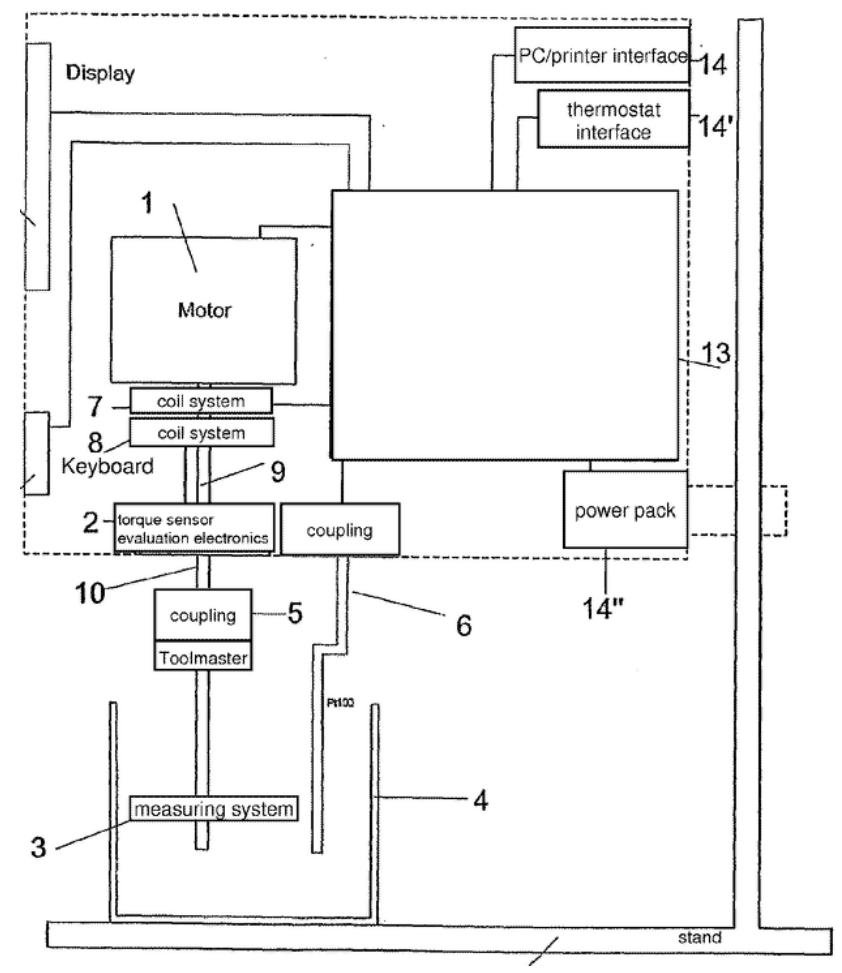

Figure 2-31 Schematic diagram of rotational viscometer (after Anonymous, 2012) 
Other types of viscometers which are commonly used in the measurement of fluid's viscosity include oscillating piston viscometer, vibrational viscometers, stabinger viscometer, etc. Since different types of viscometer are based on different theories and principles, the applicability of these instruments in measuring viscosity of various fluids would be different (Singh, 2012; and Anonymous, 2014).

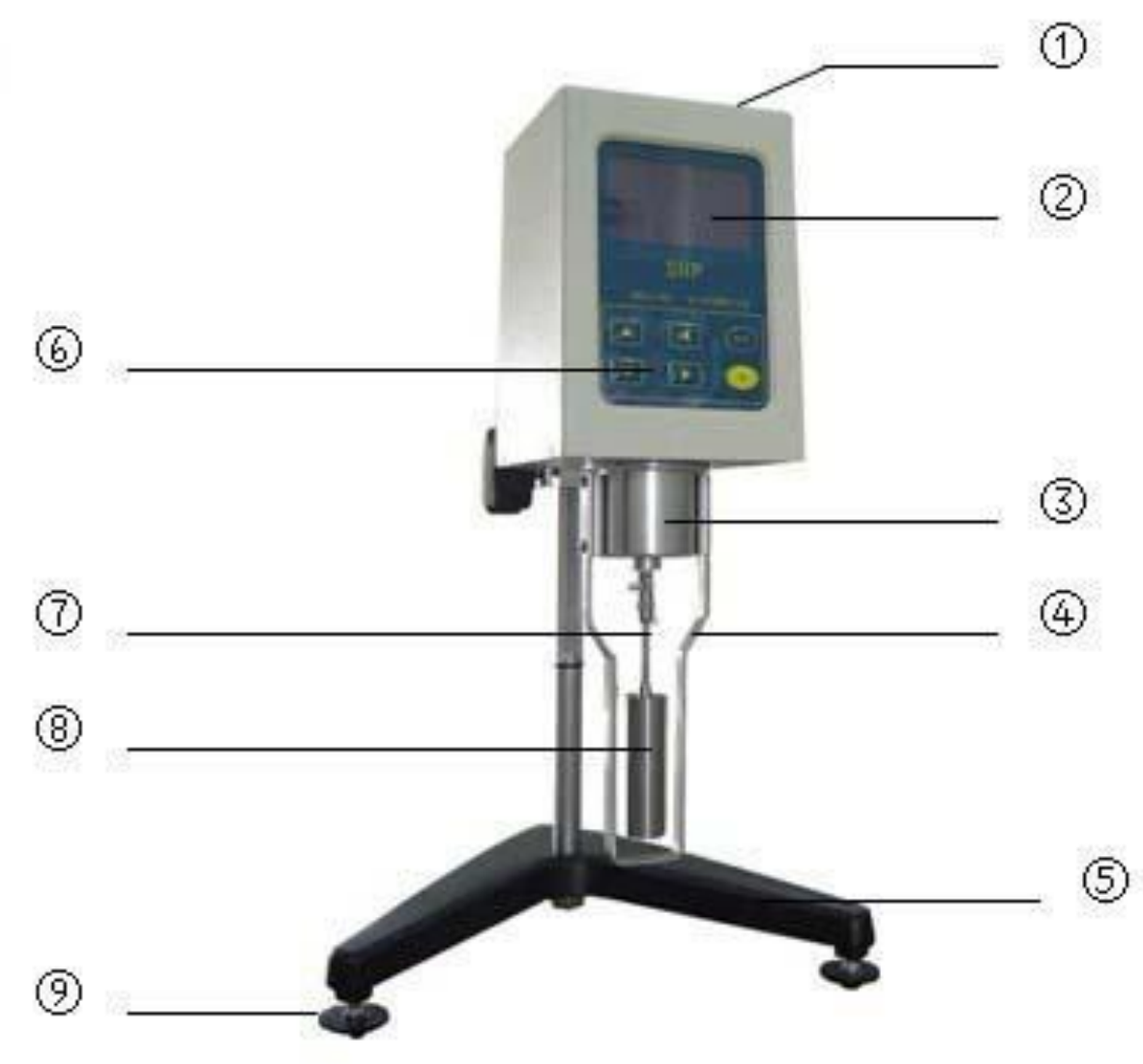

Figure 2-32 Structure of NDJ-8S digital rotary viscometer: (1) Level indicator (2) LCD

(3) Housing (4) Protection bracket (5) Base (6) Operation key (7) Rotor connector (8) Rotor (9) Level adjustment knob

$\underline{\text { Testing facilities and procedures }}$ 
In this study, the viscosities of coal slurry samples were measured by using NDJ$8 \mathrm{~S}$ digital rotary viscometer (Figure 2-32). NDJ-8S has been widely used in the measurement and determination of viscose capacity and the absolute viscosity of various liquid such as grease, painting, pharmacy and adhesives. Comparing with other similar products, the advantages of this instrument include the high measuring accuracy, stability in measured display, easy operation and read-out, and the prominent anti-interference.

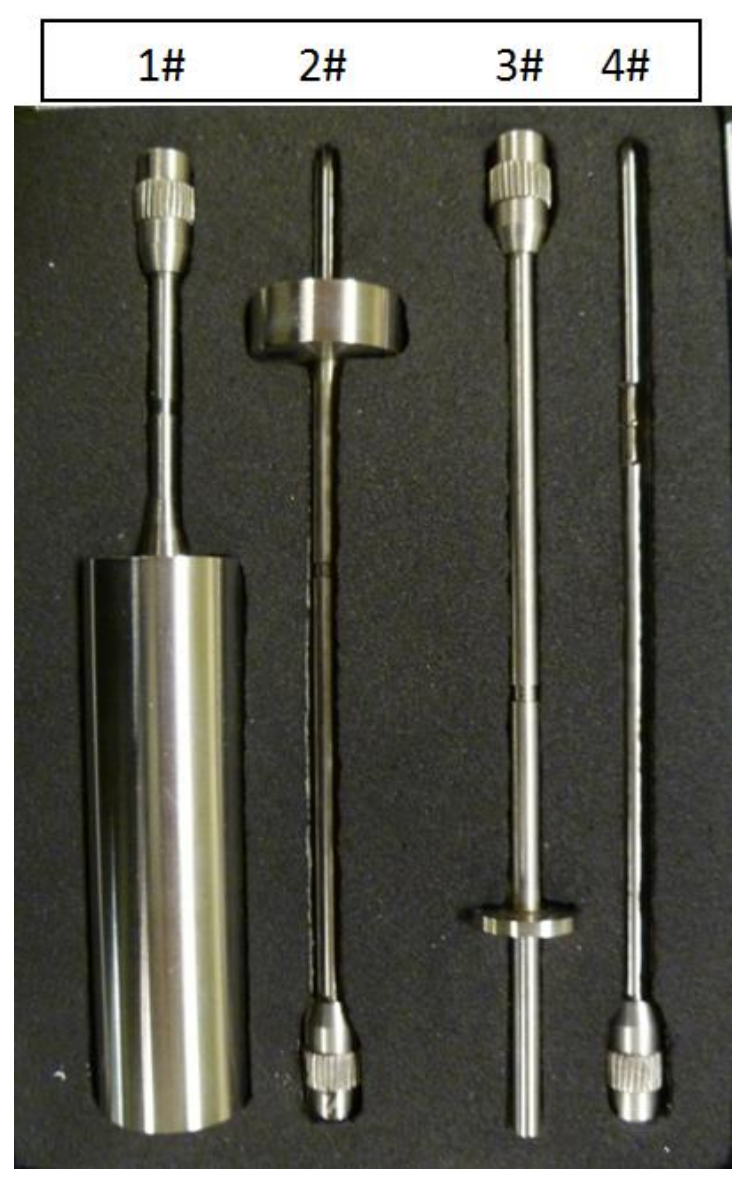

Figure 2-33 Four types of spindles of NDJ-8S digital rotary viscometer 
The rotor of the rotary viscometer can be rotated constantly by a variable speed motor. During the rotation, the rotor will be subject to a torque moment which is proportional to the viscosity of liquid due to the liquid viscose hysteresis. The torque is thereafter measured by the sensors and processed into the viscosity and shown on the display.

The NDJ-8S digital rotary viscometer was designed and manufactured with four different spindles shown in Figure 2-33 (1\#, 2\#, 3\#, 4\#) and 8 different velocities $(0.3,0.6$, $1.5,3,6,12,30,60 \mathrm{rpm})$, which enable it to measure any viscosity value in the given range. The measuring ranges of each spindle under different rotate speed were listed in Table 29. The instrument adopts micro computer technology so that the data determined by sensor can be conveniently processed. In addition, the spindle number; rotate speed; and the absolute value of viscosity can be displayed clearly on the LCD screen.

Table 2-9 Range table of each spindle under different velocities (unit: cp)

\begin{tabular}{|c|c|c|c|c|}
\hline & $\mathbf{1 \#}$ & $\mathbf{2 \#}$ & $\mathbf{3 \#}$ & $\mathbf{4 \#}$ \\
\hline $\mathbf{0 . 3}$ & $2 \times 10^{4}$ & $10 \times 10^{4}$ & $40 \times 10^{4}$ & $200 \times 10^{4}$ \\
\hline $\mathbf{0 . 6}$ & $1 \times 10^{4}$ & $5 \times 10^{4}$ & $20 \times 10^{4}$ & $100 \times 10^{4}$ \\
\hline $\mathbf{1 . 5}$ & $4 \times 10^{3}$ & $2 \times 10^{4}$ & $8 \times 10^{4}$ & $40 \times 10^{4}$ \\
\hline $\mathbf{3}$ & $2 \times 10^{3}$ & $10 \times 10^{3}$ & $4 \times 10^{4}$ & $20 \times 10^{4}$ \\
\hline $\mathbf{6}$ & $1 \times 10^{3}$ & $5 \times 10^{3}$ & $2 \times 10^{4}$ & $10 \times 10^{4}$ \\
\hline $\mathbf{1 2}$ & 500 & $2.5 \times 10^{3}$ & $1 \times 10^{4}$ & $5 \times 10^{4}$ \\
\hline $\mathbf{3 0}$ & 200 & $1 \times 10^{3}$ & $4 \times 10^{3}$ & $2 \times 10^{4}$ \\
\hline $\mathbf{6 0}$ & 100 & 500 & $2 \times 10^{3}$ & $1 \times 10^{4}$ \\
\hline
\end{tabular}




\section{Sample Preparation}

Two groups of KY and WV coal refuse specimens were prepared with different initial water content. The viscosity tests were conducted by referring to manufacturer's procedures, ASTM D1084, D2556, D4402, and D5018 standards. The saturated coal slurry samples were prepared at the same temperature of $23{ }^{\circ} \mathrm{C}$, and thoroughly stirred before each measurement. In order to increase the accuracy of measurement, the spindle was located in the center of the specimen and immerged in the liquid for enough time to achieve the same temperature as the tested specimen. The viscometer was calibrated before each measurement by using the calibration fluids provided by CANNON Instrument Company.

The impounded coal slurry is typically considered as a non-Newtonian fluid especially at low water content whose viscosity becomes thinning with rotational speed or shear rate (Botsaris and Glazman, 1988; Deng et al., 1989; Boger et al., 2006; Chhabra, 2010; and Bilbao et al., 2011). In the testing, 4\# spindle was selected in order to keep the recordings in the sufficient and accurate range, and the test was conducted from slow to high rotational speeds. The viscosity of coal refuse specimen at specific initial water content and rotational speed could be read directly from the LCD screen. Two rounds of tests were performed for each sample with specific water content in order to check the repeatability of the results.

\section{$\underline{\text { Test Results }}$}

A trial test was performed in order to study the variation of viscosity with time. As shown in Figure 2-34, the tested sample was subject to a constant shear rate for more than five minutes. The viscosity of coal refuse decreased with time and gradually converged to 
a constant. As mentioned by Chhabra (2010), the internal structures of coal refuse were progressively broken down at a constant value of shear rate. As the number of such structural linkages capable of being broken down reduced, the rate of change of viscosity with time would approach zero. However, such result might also be caused by the sinking of coal refuse particles (Aktas and Woodburn, 2000). Therefore, the viscosity readings in the test were recorded as soon as they displayed on the screen.

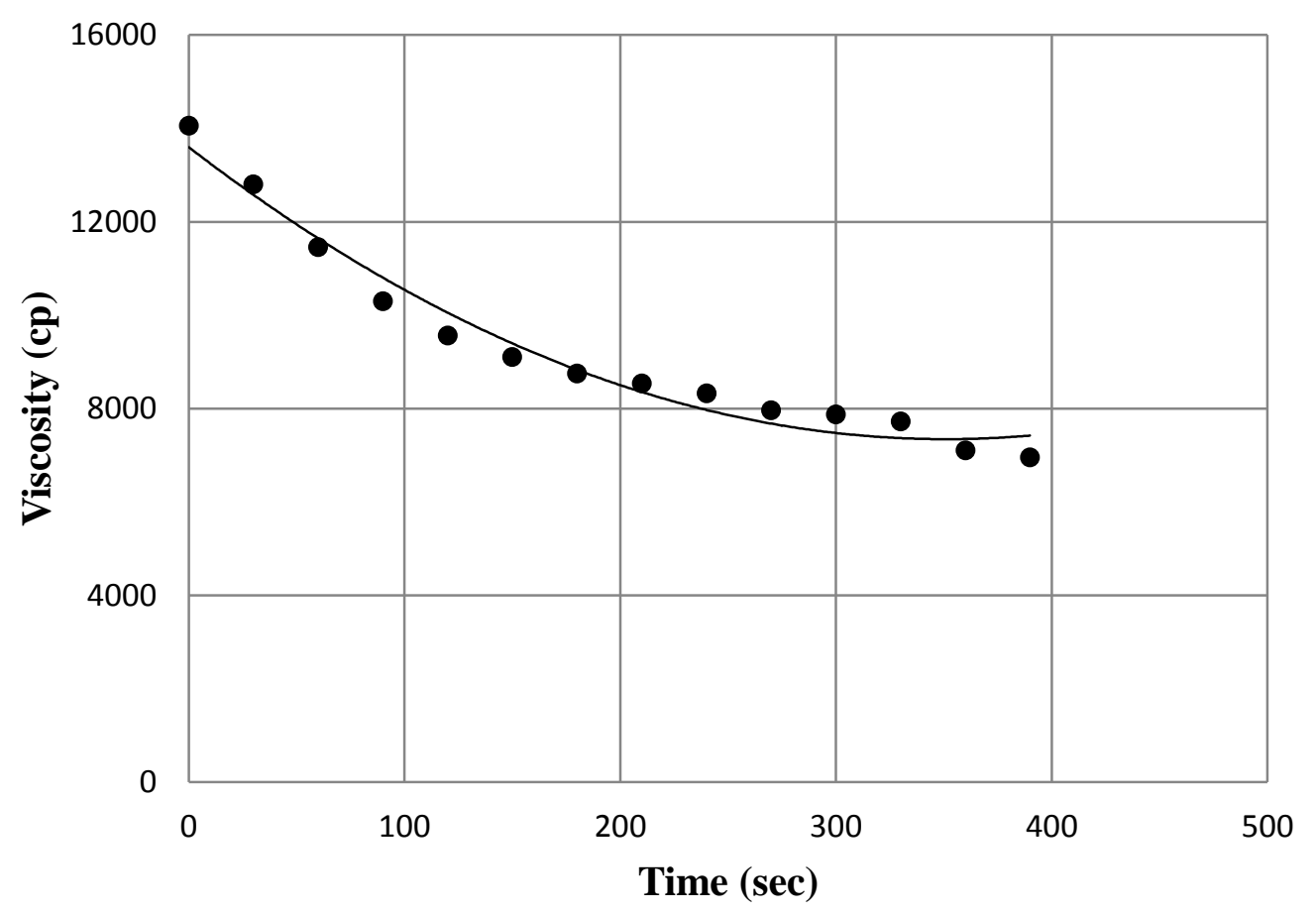

Figure 2-34 Example plot of viscosity vs. time (water content $=40 \%$, rotational speed $=6 \mathrm{rpm})$

The relationship between initial water content and viscosity of fine coal refuse at any specific rotational speed were listed in Table 2-10 for KY sample and Table 2-11 for WV sample. The results were also presented graphically in Figure 2-35 for KY sample and 
Figure 2-36 for WV sample. For both samples, the viscosity was found to decrease with the initial water content at the same rotational speed. This might be due to the fact that the pore water mitigates the interactions between the coal refuse particles. In addition, the decreasing of viscosity with rotational speed at the same water content was observed for both of the coal refuse samples because of the "shear-thinning" characteristics of coal refuse. Other shear thinning materials include polymer solutions, paints, glues, and shampoos. During the shearing, the particles of such material are more likely to orient to the shear direction and disentangle to a certain extent, which lowers their flow resistance (Mezger, 2002). When comparing viscosities of the two samples at the same water content and rotational speed, the recorded values were in the same order of magnitude. However, the WV sample exhibited more viscos than KY sample since the WV sample had higher content of clay particles with the size smaller than $0.075 \mathrm{~mm}$ (Figure 2-2).

A number of researches (Round and Hessari, 1985; Kaji et al., 1986; Woskoboenko et al., 1989; Leong and Boger, 1990; Kawatra et al., 1995; Aktas and Woodburn, 2000; and Atesok et al., 2002) have studies the effects of coal properties on the viscosity of coal slurry. It was found that the viscosity of coal slurry had relationship to various factors such as particle size distribution, microstructure, temperature, $\mathrm{pH}$, presence of electrolytes and chemical additives. However, the percent of coal particles, or in other words the initial water content, was considered the most significant factor influencing the viscosity of coal slurry and thereafter its flow behavior. Kawatra and Bakshi (1995) performed viscosity test on the coal slurry and observed apparent non-Newtonian flow behavior when the solid content was greater than 20 percent.

Table 2-10 Recorded viscosities of KY samples with different water content (unit: $\mathrm{cp}$ ) 


\begin{tabular}{|c|c|c|c|c|c|c|}
\hline $\begin{array}{c}\text { Rotate Speed } \\
(\mathrm{rpm})\end{array}$ & $\mathrm{w}=38 \%$ & $\mathrm{w}=43 \%$ & $\mathrm{w}=50 \%$ & $\mathrm{w}=64 \%$ & $\mathrm{w}=70 \%$ & $\mathrm{w}=80 \%$ \\
\hline 0.6 & 248000 & 98500 & 38250 & 15000 & 12500 & 5760 \\
\hline 1.5 & 97600 & 36200 & 16200 & 8000 & 4200 & 2080 \\
\hline 3 & 44400 & 17800 & 8800 & 3000 & 2235 & 1050 \\
\hline 6 & 25400 & 9700 & 4450 & 1700 & 1270 & 560 \\
\hline 12 & 14650 & 5325 & 2300 & 1100 & 771 & 346 \\
\hline 30 & 8140 & 2940 & 1285 & 880 & 415 & 258 \\
\hline 60 & 4280 & 2080 & 790 & 570 & 267 & 175 \\
\hline
\end{tabular}

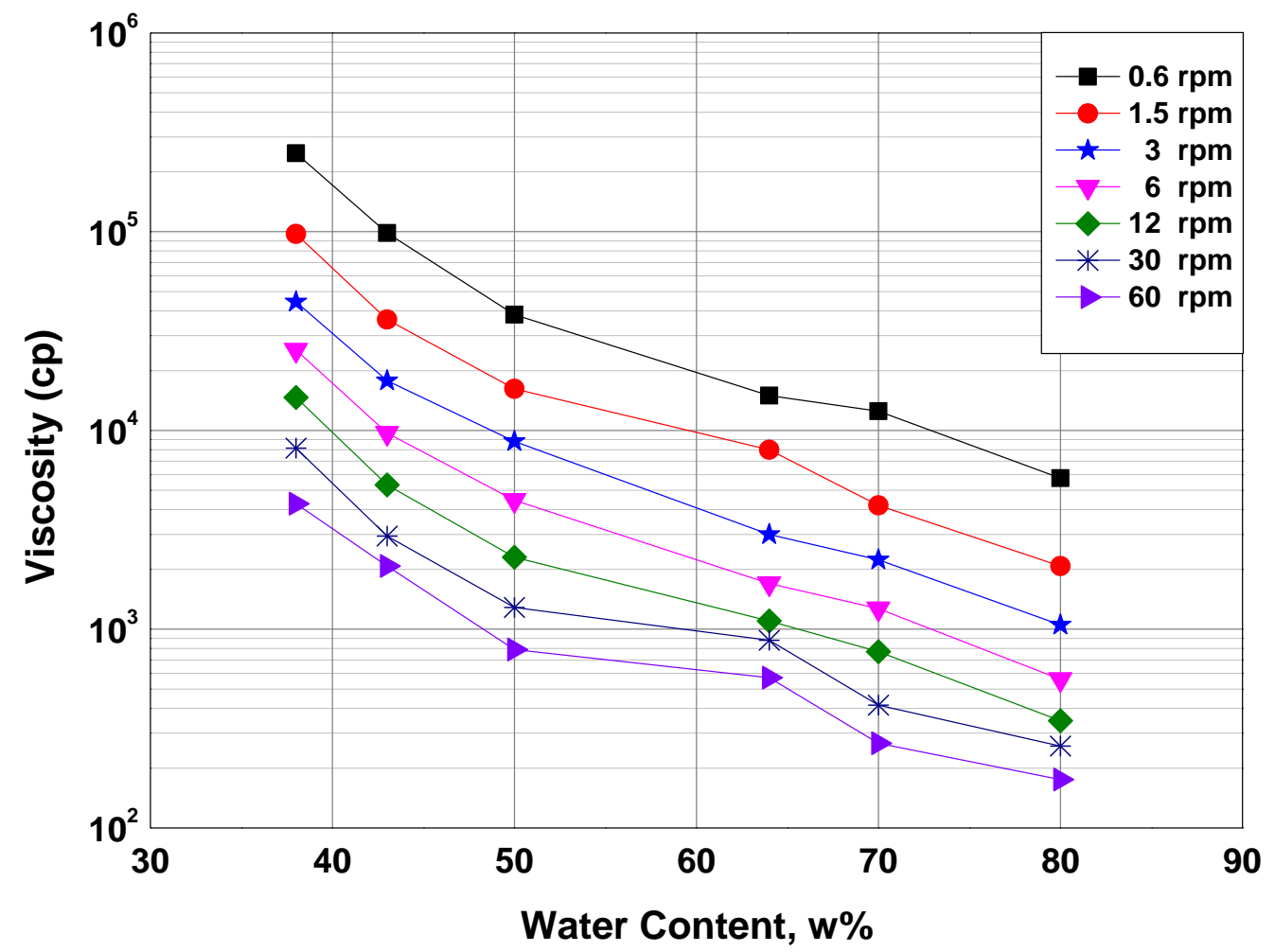

Figure 2-35 Water content vs. viscosity of KY sample under different rotational speeds 
Table 2-11 Recorded viscosities of WV samples with different water content (unit: cp)

\begin{tabular}{|c|c|c|c|c|c|c|c|}
\hline $\begin{array}{c}\text { Rotate Speed } \\
(\mathrm{rpm})\end{array}$ & $42 \%$ & $50 \%$ & $56 \%$ & $64 \%$ & $71 \%$ & $75 \%$ & $80 \%$ \\
\hline 0.6 & 128960 & 42300 & 26100 & 14235 & 11310 & 8188 & 6500 \\
\hline 1.5 & 54210 & 20856 & 12280 & 5970 & 4728 & 3605 & 3120 \\
\hline 3 & 28335 & 13744 & 6700 & 3240 & 2473 & 1978 & 1540 \\
\hline 6 & 15323 & 6430 & 3910 & 1800 & 1350 & 1050 & 976 \\
\hline 12 & 7980 & 3050 & 2500 & 1135 & 936 & 715 & 688 \\
\hline 30 & 3298 & 1986 & 1584 & 846 & 680 & 540 & 420 \\
\hline 60 & 2960 & 1140 & 977 & 668 & 525 & 438 & 340 \\
\hline
\end{tabular}

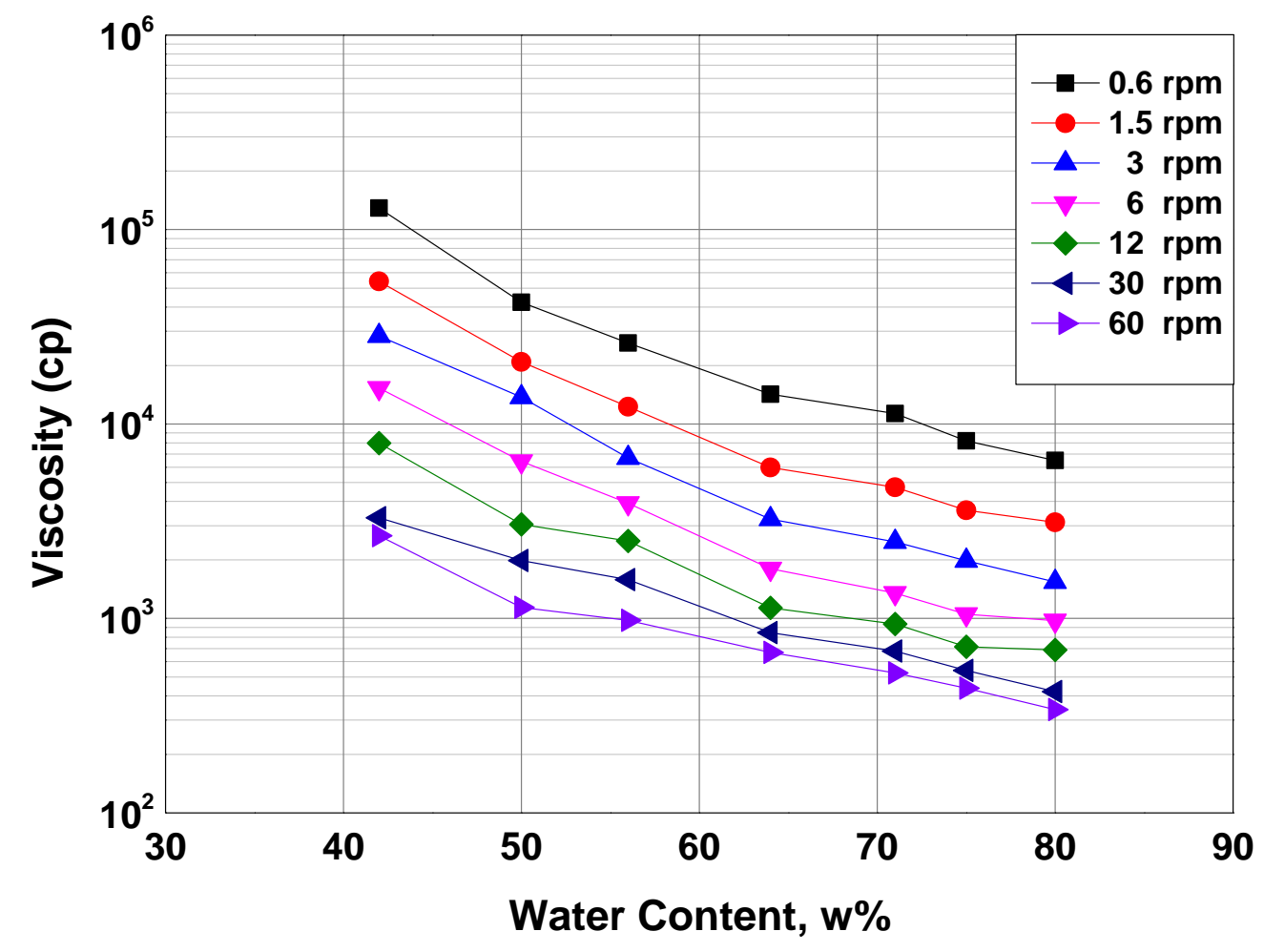

Figure 2-36 Water content vs. viscosity of WV sample under different rotational speeds 
Viscosity is considered as one of the most significant factors governing the flow behavior of coal slurry. Once a flow starts, the speed of flow and distance the flow will go is dependent on the viscosity of the slurry. Therefore, the measurement of viscosity of coal refuse can, to a great extent, evaluate the potential damage caused by the flow failure of tailings dams. The influence of viscosity on the flow behavior of coal refuse will be introduced in the following chapters.

\subsection{Conclusion}

In this chapter, a range of geotechnical laboratory tests have been performed on the coal refuse samples obtained from two representative impoundments in Kentucky and West Virginia respectively. The measurements of geotechnical properties of impounded fine coal refuse include the particle size distribution, specific gravity, soil index properties, consolidation coefficient and compression index, hydraulic conductivity, shear strength, and viscosity. The relationships between some of the geotechnical properties and initial water content (or initial void ratio) were thereafter established. In terms of the test results, the following conclusions can therefore be drawn:

1) For both KY and WV samples, more than $80 \%$ of fine particles pass the No. $200(0.075 \mathrm{~mm})$ sieve. The particle size of WV sample is even finer than KY sample.

2) In terms of the measured particle size distribution and soil index properties (liquid limit and plasticity index), the impounded fine coal refuse is classified as a silt with low plasticity (ML).

3) The measured specific gravity of fine refuse is 2.03 for KY sample and 2.14 for WV sample, which is smaller than other typical soils. Therefore, it creates a lower 
level of effective stress and lower shear strength. The formed loose structure after consolidation would be more susceptible to disturbance by dynamic loading.

4) The liquid limits for KY and WV coal refuse samples are 38.1 and 42.5 respectively. The liquid limit might be considered as the critical water content at or around which some geotechnical properties of coal refuse exhibit apparent change (such as shear strength and viscosity) or the flow behave of coal slurry would be affected.

5) The coefficient of consolidation $C_{v}$ increases with the compressive pressure while decreases with the initial water content. The value of $C_{v}$ would help to determine the time required for water content to drop below liquid limit in the coal waste impoundment. However, the variation of coefficient of consolidation with applied pressure is affected by many factors such as clay mineralogy, soil type and some mechanical and physicochemical parameters.

6) Both compression index $C_{c}$ and swelling index $C_{s}$ increase with initial water content. Compared with other types of soils and tailings, the impounded coal refuse with large amount of fine particles has a higher degree of compressibility.

7) The results of permeability tests by using falling-head method were corrected to the constant temperature of $20^{\circ} \mathrm{C}$. The recorded hydraulic conductivity of coal refuse $\mathrm{k}$ is found to decrease as the reduction of initial void ratio and is in a ranger of $10^{-9}$ to $10^{-4} \mathrm{~cm} / \mathrm{sec}$. The hydraulic conductivity is directly related to the time needed for the consolidation of coal refuse, the flow of water in the coal waste impoundment, and therefore the stability of tailings dams.

8) The permeability of silt-like fine refuse is identified as very low to impervious and the length of the drainage path is long, so that the duration of primary 
consolidation will take quite a long time. In general, a new constructed coal waste impoundment needs to take many years to finish the primary consolidation due to the low permeability.

9) The variation of undrained shear strength $c_{u}$ with initial water content was developed by conducting unconsolidated-undrained (UU) tests. It was found that the undrained shear strength increase with the reduction of the water content. In addition, significant buildup of strength is observed as the water content drops below the liquid limit.

10) The relationship between effective shear strength of fine coal refuse and initial water content was developed based on the results of consolidated-drained (CD) tests. The increasing of water content results in the gradually reduction of effective shear strength.

11) As the initial water content changes from $80 \%$ to $30 \%$, the effective cohesion c' of coal refuse is in the extremely low range of $0-26 \mathrm{kPa}$ and the effective internal angle of friction is between $10^{\circ}$ and $30^{\circ}$. It should notice that the impounded coal refuse exhibits quite low shear strength even though the water content is below the liquid limit. Accordingly, the coal waste impoundment would have a great failure potential when subject to static and dynamic disturbance.

12) The viscosity of coal refuse is measured by using a rotational viscometer. According to the measured results, the coal slurry is considered as a "shear-thinning" nonNewtonian fluid whose viscosity decreases with the rotational speed.

13) The percent of coal particles, in other words the initial water content, is considered the most significant factor influencing the viscosity of coal slurry.

14) At the same rotational speed, the viscosity of coal slurry is found to decrease with initial water content which might due to the factor that the increasing amount of pore 
water mitigates the interactions between the coal refuse particles and therefore reduce the resistance to the flow.

15) The measured geotechnical properties are quite important in studying the flow behavior of coal refuse and evaluating the flow failure of coal waste impoundment. 


\section{Chapter 3 ANALYSIS OF FLOW BEHAVIOR OF COAL REFUSE BY SMALL SCALE MODEL TESTS}

\subsection{Introduction}

Flow failure of tailings dams can cause significant property damage and environmental issues. In the past few decades, a number of tailings impoundments have failed, and have released a huge quantity of coal waste refuse which was usually mixed with water and flowed like viscous fluid. A typical example of such flow failure includes the failure of EL Cobre Dam in Chile in 1965 when 2 million tons of tailings traveled 12 $\mathrm{km}$ in minutes and killed more than 200 people (Jeyapalan et al, 1983). For a few of regions where the underground mine workings are adjacent to or beneath the impoundment, the impounded coal refuse slurry might break through into the underground mine works and therefore endangers the life of mine workers and groundwater resources (Michael et al. 2010).

In order to evaluate the hazards and damages caused by flow failure of coal waste tailings dams as well as the failure potential of impoundment under static and impact loading, it is necessary to be able to identify the flow characteristics of coal refuse in different initial states and the possible velocity and extent of the flow. Unfortunately, only a limited number of investigations on the flow failure of tailings dams were reported in the past few years. The flow behavior of coal waste under static and impact loading as well as its relationship to geotechnical properties have not been well studied.

In terms of the literature review of existing studies on the flow properties of coal refuse and other viscous fluid, a number of different approaches are available to predict the flow characteristics. Jeyapalan et al. (1983) performed a series of laboratory flume flow 
tests on the tailings slurries and similar materials. The measured results were thereafter compared with the theoretical analysis and the computation by using program TFLOW. The laboratory flume tests were also conducted by Kwak et al. (2005) in order to investigate the effect of water content on the flow behavior and depositional geometry of tailings and kaolinite pastes. Brisson et al. (2002) proposed instantaneous profile method to estimate the unsaturated flow characteristics in the nickel mine tailings based on the measurements of volumetric water content and matric suction. Sawyer et al. (2012) triggered mudflow using the dam-break method in order to explore how the difference between shear stress and shear strength controls the dynamic mudflow and the morphology of the deposit. The results indicated that a flow with high flow factor $F_{f}$ (defined as the ratio of the shear stress to the yield strength) would produce a rapid collapse of the impoundment (approximately $70 \%$ of volume) with an accelerating, long run-out flow within 10 second from flow initiation.

\subsubsection{Review of Rheological Models}

Under the static or impact disturbance, the saturated and loosely deposited coal refuse might flow as a viscous fluid. In order to study the flow characteristics associated with the measured results from laboratory flume test, it is necessary to use a suitable rheological model to represent the behavior of coal refuse flow.

In Equation 2-15, the term $\frac{v}{h}$ is the velocity gradient (or change in velocity with h), and can be expressed in the differential form of $\frac{d v}{d h}$. The Equation 2-16 can therefore be rewritten as: 


$$
\tau=\eta \frac{d v}{d h}
$$

This equation is known as Newton's law of viscosity. It has been known that the fluid can exhibit quite different behavior under the applied stress. Depending on whether the Newton's law is complied with, the fluids can be divided into Newtonian fluids and non-Newtonian fluids.

Newtonian fluids obey Newton's law and have constant value of viscosity $\eta$ which does not depend on the stress state and velocity of the flow (Anonymous, 2014). As shown in Figure 3-1, the viscous stress arising from its flow is linearly proportional to the shear rate. Newtonian fluid is considered as the simplest mathematical model of fluid accounting for the viscosity. However, it is hardly to find an ideal Newtonian fluid in the practice. Some of commonly used fluid such as water and air can be assumed to be Newtonian under the ordinary conditions.

In contrast, the non-Newtonian fluids do not obey Newton's law and the value of viscosity is not constant which is typically dependent on the shear rate or shear rate history. In a non-Newtonian fluid, the relationship between the shear stress and the shear rate is changing and can even be various with time which is called "time - dependent" viscosity. Therefore, a constant value of viscosity cannot be defined in the non-Newtonian fluid. (Anonymous, 2014). According to the variation of shear stress with the shear rate (or velocity gradient) in the fluid, the non-Newtonian fluids can be divided into several categories as Pseudoplastic fluid, Pseudoplastic with yield fluid, Bingham Plastic fluid, and Dilatant fluid. The relationships between $\tau-\dot{\gamma}$ of these categories are graphically shown in Figure 3-1. 


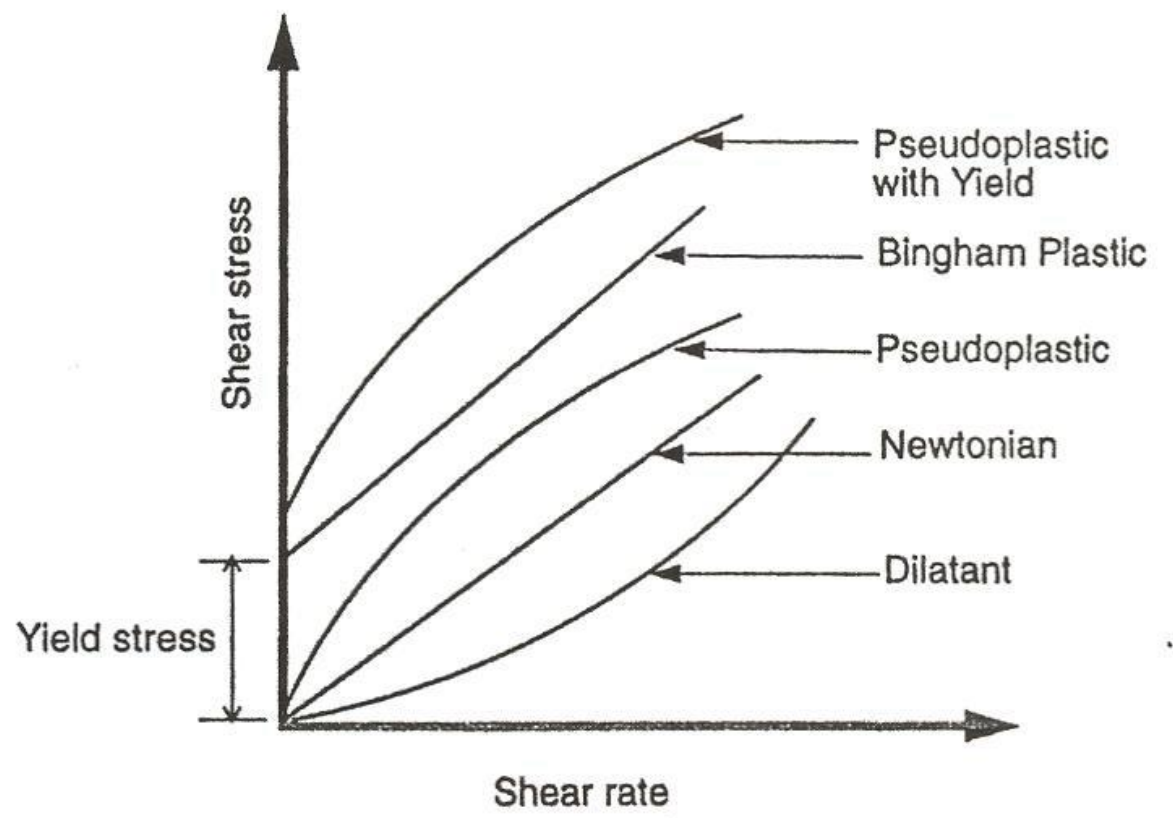

Figure 3-1 Basic models of rheological behavior (after Kawatra et al., 1995)

In general, the shear stress increases with the shear rate (or velocity gradient). The difference between each rheological model is associated with the variation of viscosity with the shear rate (the slope of each curve shown in Figure 3-1). When the viscosity decreases with the shear rate, the fluid is called "shear-thinning" fluid. Otherwise, the fluid is called "shear-thickening" fluid with the viscosity increases with the shear rate. In practice, shearthinning behavior is more common than shear-thickening. In terms of the different types of flow behaviors shown in Figure 3-1, the brief descriptions of the physical properties of each rheological model are listed as the following:

- Pseudoplastic Fluid: is a type of shear-thinning fluid with the viscosity decreases with shear rate. No minimum shear stress (yield stress) is necessary to initiate the 
flow. The examples of pseudoplastic fluid include milk and cement. The mathematical representation can be expressed as:

$$
\tau=m(\dot{\gamma})^{n}=m(\dot{\gamma})^{n-1} \dot{\gamma}
$$

where $\mathrm{m}$ and $\mathrm{n}$ are coefficients. Comparing with Equation 3-1, the viscosity of pseudoplastic is considered as a function of shear rate with $\mathrm{n}<1$.

- Pseudoplastic with Yield Fluid: is a type of shear-thinning fluid. It is quite similar to the pseudoplastic fluid with the decreasing viscosity with shear rate. However, the shear stress must reach a certain minimum value, yield stress, before flow commences. The mathematical representation of pseudoplastic with yield fluid can be expressed as:

$$
\tau=\tau_{y}+m(\dot{\gamma})^{n}=\tau_{y}+m(\dot{\gamma})^{n-1} \dot{\gamma}
$$

- Bingham Plastic Fluid: is a type of shear-thinning fluid. Similar to the pseudoplastic with yield fluids, the Bingham plastic fluids must achieve certain shear stress above the yield stress before they begin to flow. The ideal Bingham plastic fluid is an elastic solid at low shear stress below the yield stress and a Newtonian fluid once the shear stress exceeds the yield stress. As the flow starts, a linear relationship between the shear stress and the shear rate is exhibited in Figure 3-1 with a constant plastic viscosity $\eta_{p}$. Several examples of Bingham plastic fluid include clay suspensions, sewage sludge, drilling mud, toothpaste, mayonnaise, chocolate, and mustard 
(Anonymous, 2014). The mathematical representation of Bingham plastic fluid can be expressed as:

$$
\tau=\tau_{y}+\eta_{p} \dot{\gamma}
$$

Where the yield stress $\tau_{y}$ is also called Bingham yield stress. $\dot{\gamma}=0$ if the applied shear stress is less than Bingham yield stress.

- Dilatant Fluid: is type of shear-thickening fluid. As shown in Figure 3-1, the viscosity of dilatant fluid increases with shear rate and the yield stress is negligible. The most common dilatant fluid is the corn starch dissolved in water. The mathematical representation of dilatant fluid is the same as that of pseudoplastic fluid which is expressed as:

$$
\tau=m(\dot{\gamma})^{n}=m(\dot{\gamma})^{n-1} \dot{\gamma}
$$

Dilatant behavior occurs where the coefficient $\mathrm{n}$ is greater than 1 .

\subsubsection{Determine Rheological Parameters of Bingham Plastic Flow}

The flow characteristics of coal refuse has not been well known due to the limited data measured in the practical field and the complex flowability of coal refuse. The flow behavior of such viscous flow is influenced by the interrelationship among a number of factors. Based on the existing studies on the flow characteristics of impounded coal refuse, the "Bingham Plastic" was considered as the most suitable rheological model to represent the flow of coal refuse (Jeyapalan, 1980; Krizek, 2004; and Michael et al., 2010). Although the Bingham Plastic is the simplest rheological model among the non-Newtonian fluids as shown in Figure 3-1, it could be used to represent a wide range of flow behavior. In addition, 
the two primary parameters of Bingham Plastic fluid plastic viscosity $\eta_{p}$ and yield stress $\tau_{y}$ can be easily determined and incorporated in the flow analysis. Blight (1969), Bishop (1973), Whitney et al. (1977), Castillo and Williams (1979), Deysarkar and Turner (1980), and Jeyapalan, (1980) performed laboratory tests on the mine tailings and other natural debris materials and all reported the approximated flow behavior and probable plastic viscosity with reasonable accuracy by using the Bingham Plastic model.

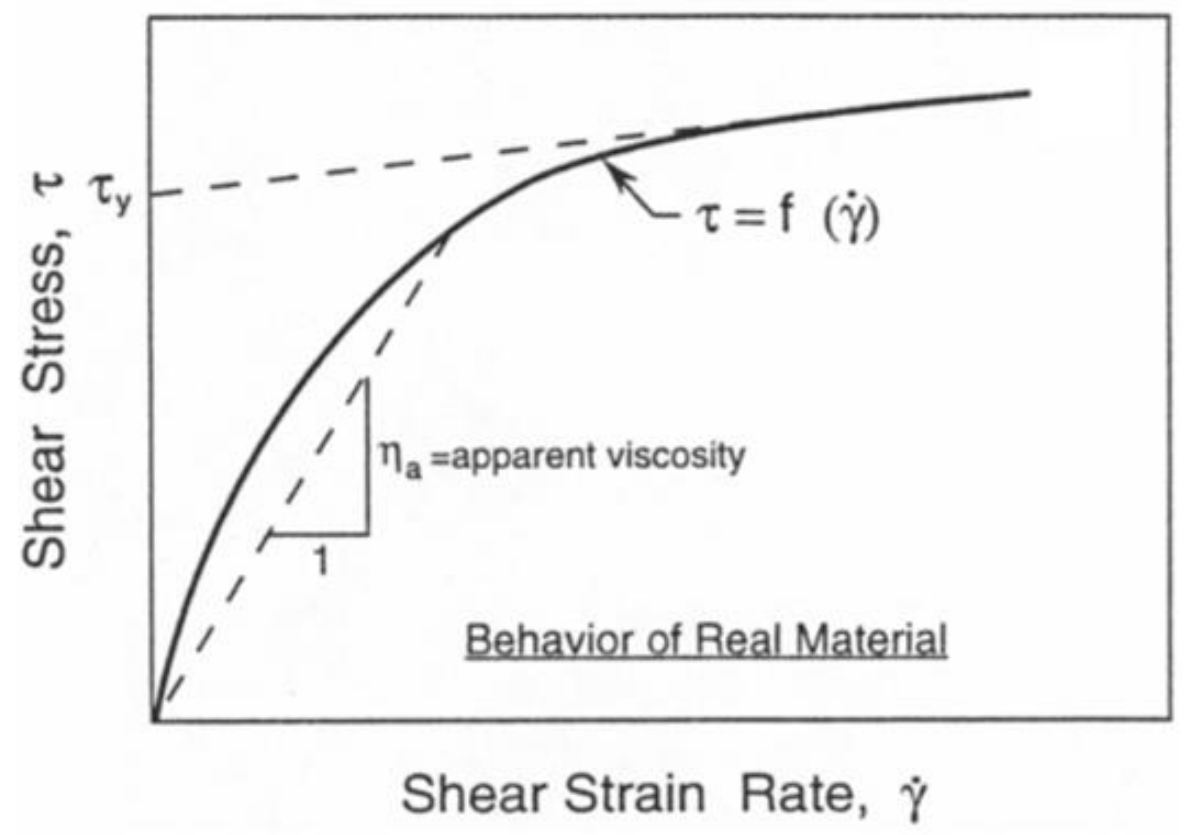

Figure 3-2 Pseudo-Bingham Plastic Model (after Krizek, 2004)

In order to represent the coal refuse by using Bingham Plastic model, It is necessary to determine the two governing parameters plastic viscosity $\eta_{p}$ and yield stress $\tau_{y}$. The characteristics of Bingham Plastic fluid has already been introduced in the previous section which is expressed as a sloped straight line starting at some yield stress. However, the 
actual flow of coal refuse might behave more likely as a Pseudo-Bingham Plastic fluid (or Herschel-Bulkley fluid). As shown in Figure 3-2, the slope of the tangent to the curve stands for the viscosity of Pseudo-Bingham Plastic fluid. It indicates that the viscosity decreases at the low shear rate and gradually becomes a constant as the shear rate continues increasing. However, such behavior is hardly to be expressed by using single mathematical representation, which might increase the complexity of flow analysis. In order to simplify the analysis nu using the simple Bingham Plastic model, Krizek (2004) recommended that "the plastic viscosity is taken as the slope of the more-or-less linear portion of the curve for high strain rates; and the yield stress is taken as the point where the projection of this linear portion of the curve intersects the shear stress axis".

\subsection{Model Preparations and Test Procedures}

In order to evaluate the influence of important parameters on the flowability of impounded coal refuse and to provide physical data for the rheological analysis, a group of small-scale flume tests were conducted under both static loading and impact loading. The measured data is also compared with the results obtained from centrifuge tests which are shown in the following chapter.

\subsubsection{Flume Tests under Static Loading}

The test setup for flow failure under static loading is shown in Figure 3-3. A pond with internal dimension of $30 \mathrm{~cm}$ (length) $\times 30 \mathrm{~cm}$ (width) $\times 60 \mathrm{~cm}$ (height) is at the top of a slope 2 meters tall. The flume is $5 \mathrm{~m}$ long and $35 \mathrm{~cm}$ wide, and has red lines on the surface 
of the slope marking the traveling distance of slurry sample from the top. The space of every two successive mark lines is $30 \mathrm{~cm}$.

A total of 12 gallons fine coal refuse samples were contained in the pond. The coal refuse samples were prepared with different initial water content and thoroughly agitated before pouring into the pond. Before starting each test, the viscosity and shear strength of the tested slurry sample would be measured in the laboratory in order to determine the rheological parameters of the slurry flow under different water content.

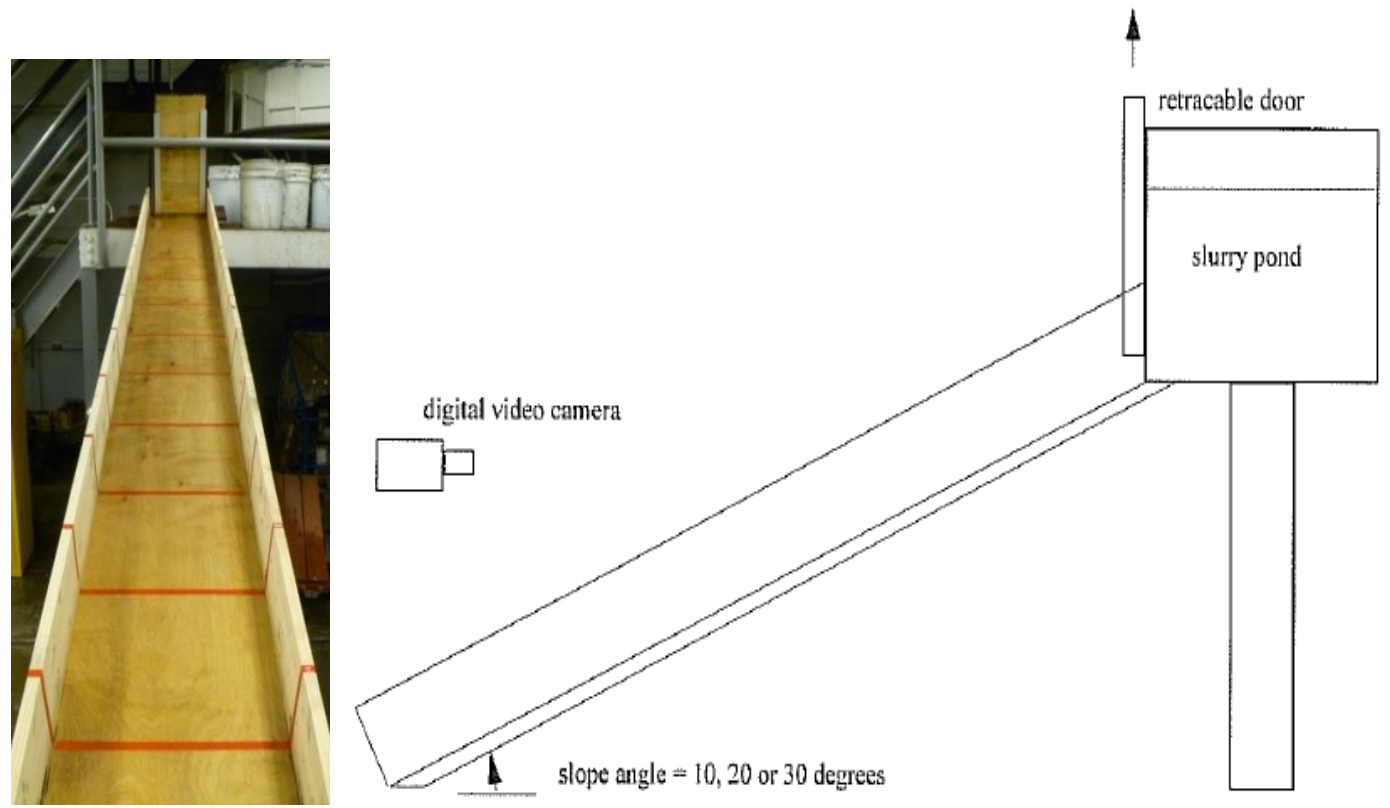

Figure 3-3 Small-scale model for flow study under static loading

The flume tests were conducted at different slope angle: $10^{\circ}, 20^{\circ}$, and $30^{\circ}$ respectively. Therefore, the coal refuse sample would subject to different driving shear stresses. The maximum shear stress would be induced at the maximum slope angle of $30^{\circ}$ in the beginning of the flow. The loss of impoundment was simulated by rapidly pulling 
the gate upwards. The coal refuse would flow down along the slope if a flow failure was initiated. As shown in Figure 3-3, a high-speed digital video camera was placed in front of the slope and recorded the movements of the flow failure including the free surface velocity and the travel distance of the flow at different initial water content. The time interval between two successive frames recorded by video camera was $1 / 25$ second. The flow velocity could thereby be determined in every marked distance of $30 \mathrm{~cm}$.

\subsubsection{Flume Test under Impact Loading}

The coal refuse samples were initially tested under static load with water content gradually decreasing from about $80 \%$ until the flow ceased at certain lower water content. After that, the tests under impact loading were conducted in order to study whether a blasting disturbance in the field can trigger liquefaction and flow of impounded coal refuse in the relatively lower water content. 


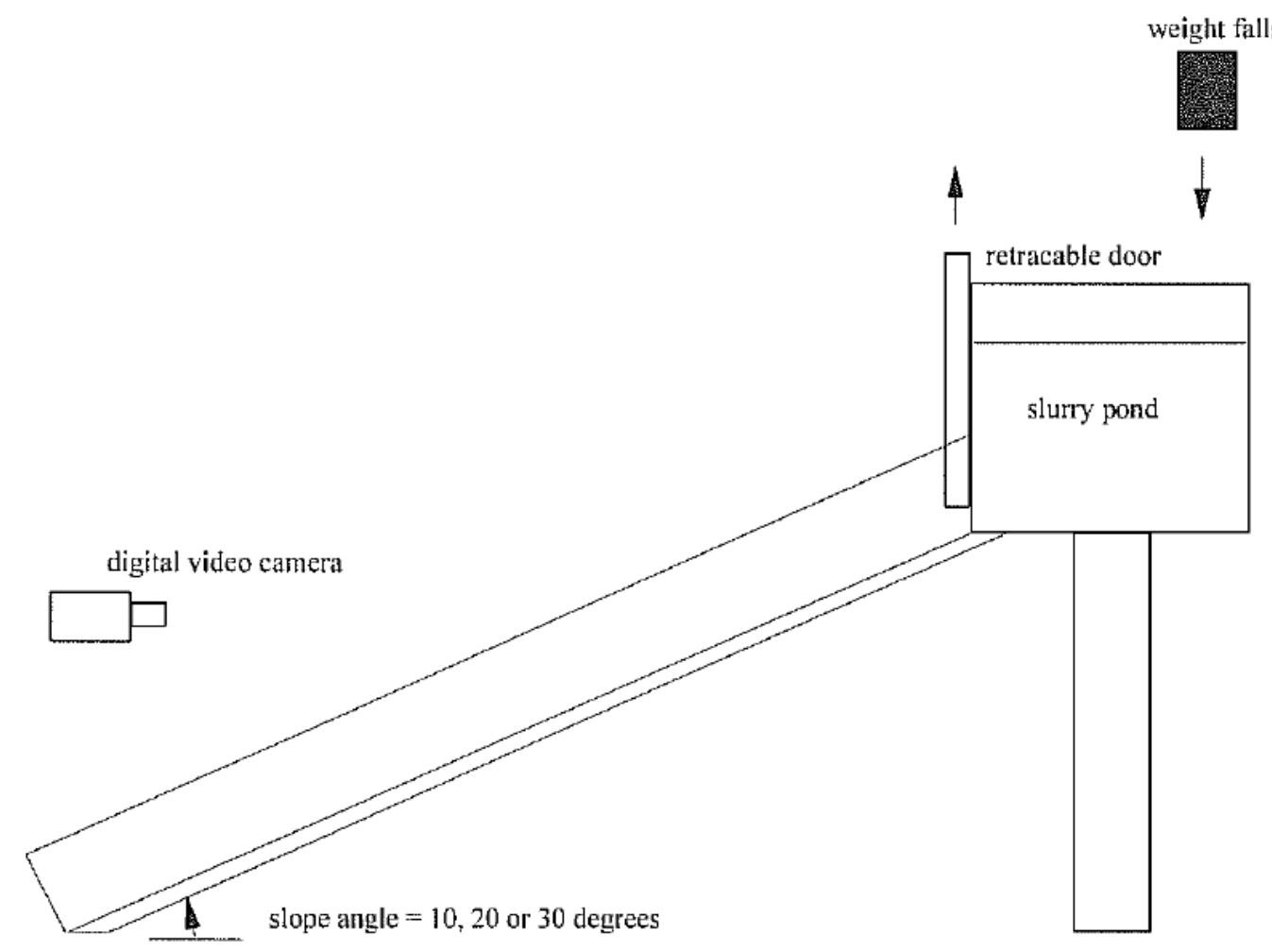

Figure 3-4 Small-scale model test for flow study under impact loading

The configuration of model test under impact loading is shown in Figure 3-4. A lumped mass was dropped down from the designed height to the surface of the slurry sample. It would generate $\mathrm{P}$ waves propagating through the coal refuse sample, similar to that of a monotonic blasting event in the practical coal mining field. At the time of weight drop, the gate of the container was opened quickly. It could therefore measure whether the flow of coal refuse at lower water content would be triggered by the impact loading. 
Table 3-1 Reference summary of published researches on the impact loading (after Charlie, 1988)

\begin{tabular}{|c|c|c|c|c|}
\hline $\begin{array}{l}\text { Author of } \\
\text { Article }\end{array}$ & $\begin{array}{l}\text { Loading } \\
\text { Type }\end{array}$ & $\begin{array}{l}\text { Soil Type } \\
\text { and } \\
\text { Density }\end{array}$ & $\begin{array}{c}\text { Degree } \\
\text { of } \\
\text { Saturation }\end{array}$ & Comments \\
\hline Kok (1977) & $\begin{array}{l}\text { Hammer } \\
\text { on } \\
\text { cylinder }\end{array}$ & Loose sand & $100 \%$ & $\begin{array}{l}\text { Compaction decreases with } \\
\text { increase in number of } \\
\text { impacts }\end{array}$ \\
\hline $\begin{array}{c}\text { Van Der } \\
\text { Kogel et al. } \\
(1980)\end{array}$ & $\begin{array}{l}\text { Falling } \\
\text { weight }\end{array}$ & $\begin{array}{c}\text { Sand } \\
\text { Dr }=8-93 \%\end{array}$ & $85-97 \%$ & $\begin{array}{l}\text { Transient negative pwp* } \\
\text { some liquefaction observed }\end{array}$ \\
\hline $\begin{array}{l}\text { Vesic et al. } \\
\quad(1967)\end{array}$ & $\begin{array}{l}\text { Impact } \\
\text { weight }\end{array}$ & $\begin{array}{c}\text { Dense Sand } \\
\text { Dr }=80 \%\end{array}$ & $100 \%$ & $\begin{array}{l}\text { Positive pwp only if soil } \\
\text { densifies }\end{array}$ \\
\hline $\begin{array}{l}\text { Florin \& } \\
\text { Ivanov } \\
(1961)\end{array}$ & $\begin{array}{l}\text { Surface } \\
\text { impact }\end{array}$ & Loose Sand & $100 \%$ & Liquefaction observed \\
\hline $\begin{array}{l}\text { Tanimoto } \\
(1967)\end{array}$ & Pendulum & $\begin{array}{l}\text { Loose fine } \\
\text { sand }\end{array}$ & $100 \%$ & $\begin{array}{l}\text { Settlement is the result of } \\
\text { the impact and the } \\
\text { dissipation of pwp }\end{array}$ \\
\hline
\end{tabular}

(*pwp: pore water pressure)

There are different approaches available to simulate the dynamic impact loading. A comprehensive literature review has been performed by Charlie (1988) on the published laboratory and field tests by impact loading (see Table 3-1). In this study, the reason to choose the "dropping weight" method to simulate a blast loading is because firstly, the dynamic load it generates is very similar to that of a monotonic blast event; and secondly, any test in a lab using explosives will require a number of strict safety procedures and the cost will be quite high.

A number of existing testing on saturated soil deposits indicates that the soil liquefaction would take place under single compressive strains greater than $0.01 \%$ for soils with low effective stresses and low relative densities and $1 \%$ for soils with high effective 
stresses and high relative densities (Charlie et al. 1982; Veyera 1985). Therefore, in this study, the lumped masses with different weights were dropped from the height of $80 \mathrm{~cm}$ in order to induce the compressive strain of $0.1 \%, 1 \%$, and $5 \%$, respectively. The analysis was based on the recorded flow behaviors by the high-speed video camera.

\subsection{Test Results and Analysis under Static Loading}

In this group of tests, the flow of coal refuse slurry was driven by the component of self-weight in the direction parallel to the slope. The KY samples and WV samples were prepared at different initial water content and flowed down at three different slope angles. Their movements were recorded by high-speed video camera and thereafter analyzed frame by frame using film processing software in order to determine the velocity and travel distance of coal refuse flow at specific water content and slope angle.

An example of variation of flow velocity after the loss of impoundment for the KY samples at initial water content of $80 \%$ was exhibited in Figure 3-5. It was found that the flow velocity increased along the slope in the beginning and thereafter kept a relatively stable value in the midstream. In addition, the slurry flow under the maximum initial shear stress (at the maximum slope angle of $30^{\circ}$ ) had the fastest velocity and took the least time to reach the peak velocity. The tendency of slowing down at the end of flow was more evident to the samples at lower water content. 


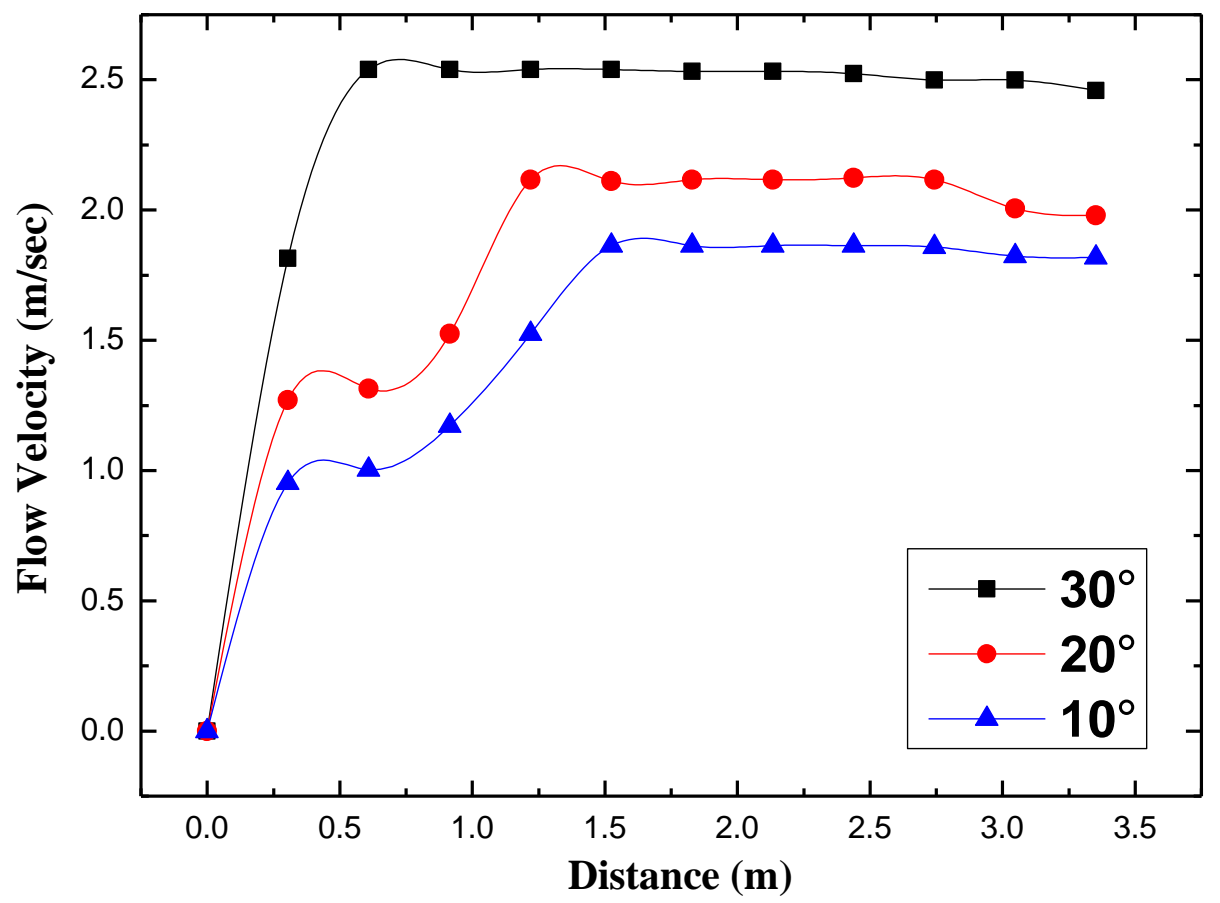

Figure 3-5 Example of the variation of flow velocity with distance for KY sample at initial water content of $80 \%$

In order to simplify analysis and provide more conservative results to the design of coal waste impoundment, the representative flow velocity in this study is selected from maximum velocity on the free surface in the midstream of the flow and could be considered as a constant in the steady state. Accordingly, the recorded flow velocities of two representative coal refuse samples at different initial water content and slope angles were summarized in Table 3-2 and Table 3-3. In addition, the travel distance of the coal slurry and the depth of flow normal to the slope in the midstream were also recorded. The flow depth of midstream was measured by using several clean and thin nails placed in the centerline of the slope. The depth could be determined from the dyed length of nails. The 
summarized results were listed in Table 3-4 and Table 3-5 and graphically illustrated in Figure 3-6 and Figure 3-7.

Table 3-2 Variation of flow velocities of KY sample with water content and slope angle (Unit: $\mathrm{m} / \mathrm{sec})$

\begin{tabular}{|c|c|c|c|}
\hline Water Content & $\mathbf{3 0}^{\circ}$ & $\mathbf{2 0}^{\circ}$ & $\mathbf{1 0}^{\circ}$ \\
\hline 80 & 2.541 & 2.116 & 1.863 \\
\hline 75 & 2.177 & 1.715 & 1.347 \\
\hline 70 & 1.465 & 0.896 & 0.635 \\
\hline 63 & 1.385 & 0.747 & 0.544 \\
\hline 57 & 0.692 & 0.381 & 0 \\
\hline 51 & 0.401 & 0.265 & 0 \\
\hline 48 & 0 & 0 & 0 \\
\hline
\end{tabular}

Table 3-3 Variation of flow velocities of WV sample with water content and slope angle (Unit: $\mathrm{m} / \mathrm{sec})$

\begin{tabular}{|c|c|c|c|}
\hline Water Content & $\mathbf{3 0}^{\circ}$ & $\mathbf{2 0}^{\circ}$ & $\mathbf{1 0}^{\circ}$ \\
\hline 82 & 2.291 & 1.742 & 1.525 \\
\hline 76 & 1.824 & 1.329 & 1.114 \\
\hline 72 & 1.389 & 0.847 & 0.701 \\
\hline 65 & 0.862 & 0.635 & 0.423 \\
\hline 55 & 0.398 & 0.227 & 0 \\
\hline 52 & 0 & 0 & 0 \\
\hline
\end{tabular}


Table 3-4 Recorded travel distance and flow depth in the midstream of KY sample

\begin{tabular}{|c|c|c|c|c|c|c|}
\hline & \multicolumn{2}{|c|}{$\mathbf{3 0}^{\circ}$} & \multicolumn{2}{c|}{$\mathbf{2 0}^{\circ}$} & \multicolumn{2}{c|}{$\mathbf{1 0}^{\circ}$} \\
\hline $\begin{array}{c}\text { Water content } \\
(\boldsymbol{\%})\end{array}$ & $\begin{array}{c}\mathbf{L} \\
(\mathbf{m})\end{array}$ & $\begin{array}{c}\mathbf{D} \\
(\mathbf{c m})\end{array}$ & $\begin{array}{c}\mathbf{L} \\
(\mathbf{m})\end{array}$ & $\begin{array}{c}\mathbf{D} \\
(\mathbf{c m})\end{array}$ & $\begin{array}{c}\mathbf{L} \\
(\mathbf{m})\end{array}$ & $\begin{array}{c}\mathbf{D} \\
(\mathbf{c m})\end{array}$ \\
\hline 80 & $>5$ & 2 & $>5$ & 3 & $>5$ & 3.4 \\
\hline 75 & $>5$ & 3 & 2.5 & 5 & 1.4 & 7.8 \\
\hline 70 & $>5$ & 3.6 & 1.6 & 5.8 & 0.6 & 10 \\
\hline 63 & 2.7 & 6 & 1.2 & 9 & 0.4 & 17 \\
\hline 57 & 1.2 & 7.6 & 0.8 & 9.2 & N/A & N/A \\
\hline 51 & 0.5 & 13 & 0.3 & 15 & N/A & N/A \\
\hline
\end{tabular}

(L: extent of the flow; D: depth of the flow in the midstream)

Table 3-5 Recorded travel distance and flow depth in the midstream of WV sample

\begin{tabular}{|c|c|c|c|c|c|c|}
\hline & \multicolumn{2}{|c|}{$\mathbf{3 0}^{\circ}$} & \multicolumn{2}{c|}{$\mathbf{2 0}^{\circ}$} & \multicolumn{2}{c|}{$\mathbf{1 0}^{\circ}$} \\
\hline $\begin{array}{c}\text { Water content } \\
(\%)\end{array}$ & $\begin{array}{c}\mathbf{L} \\
(\mathbf{m})\end{array}$ & $\begin{array}{c}\mathbf{D} \\
(\mathbf{c m})\end{array}$ & $\begin{array}{c}\mathbf{L} \\
(\mathbf{m})\end{array}$ & $\begin{array}{c}\mathbf{D} \\
(\mathbf{c m})\end{array}$ & $\begin{array}{c}\mathbf{L} \\
(\mathbf{m})\end{array}$ & $\begin{array}{c}\mathbf{D} \\
(\mathbf{c m})\end{array}$ \\
\hline 82 & $>5$ & 2 & $>5$ & 2.8 & $>5$ & 3.5 \\
\hline 76 & $>5$ & 2.5 & 3.4 & 3 & 2.6 & 4.5 \\
\hline 72 & $>5$ & 3.8 & 1.4 & 5 & 0.7 & 12 \\
\hline 65 & 1.1 & 8 & 0.8 & 11 & 0.5 & 19 \\
\hline 55 & 0.6 & 10 & 0.5 & 13 & N/A & N/A \\
\hline
\end{tabular}

(L: extent of the flow; D: depth of the flow in the midstream) 


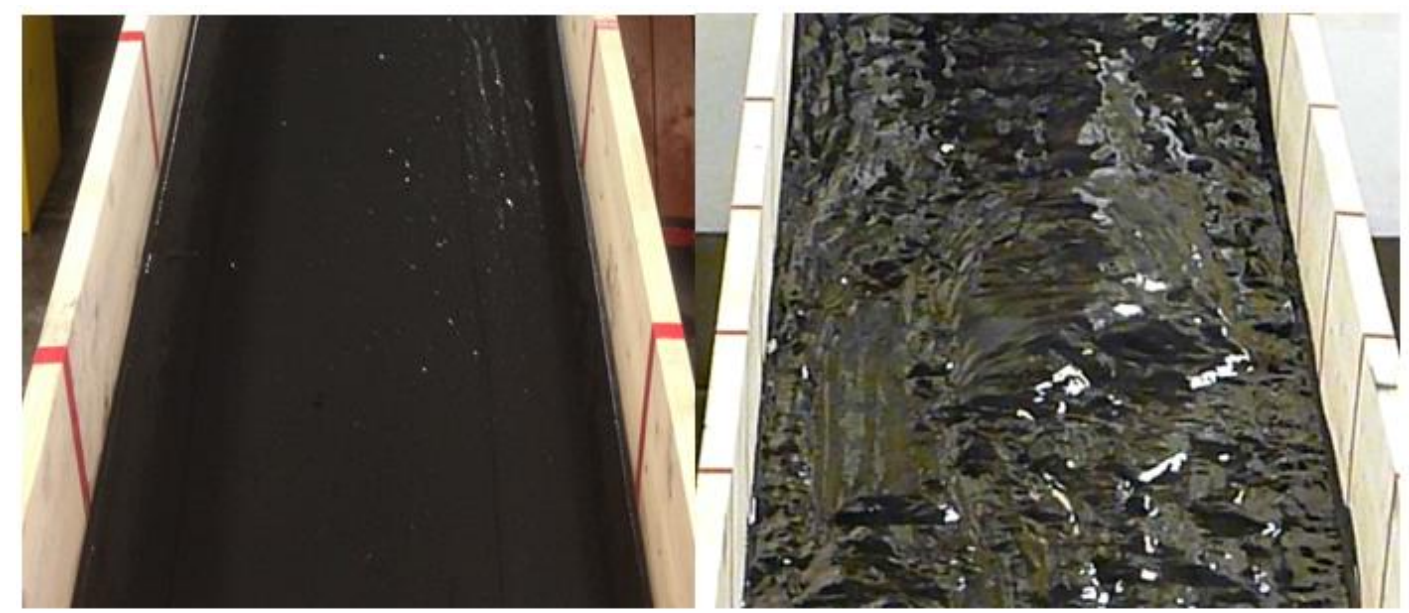

$$
\mathbf{w}=80 \quad \alpha=30^{\circ} \quad \mathbf{w}=80 \quad \alpha=10^{\circ}
$$

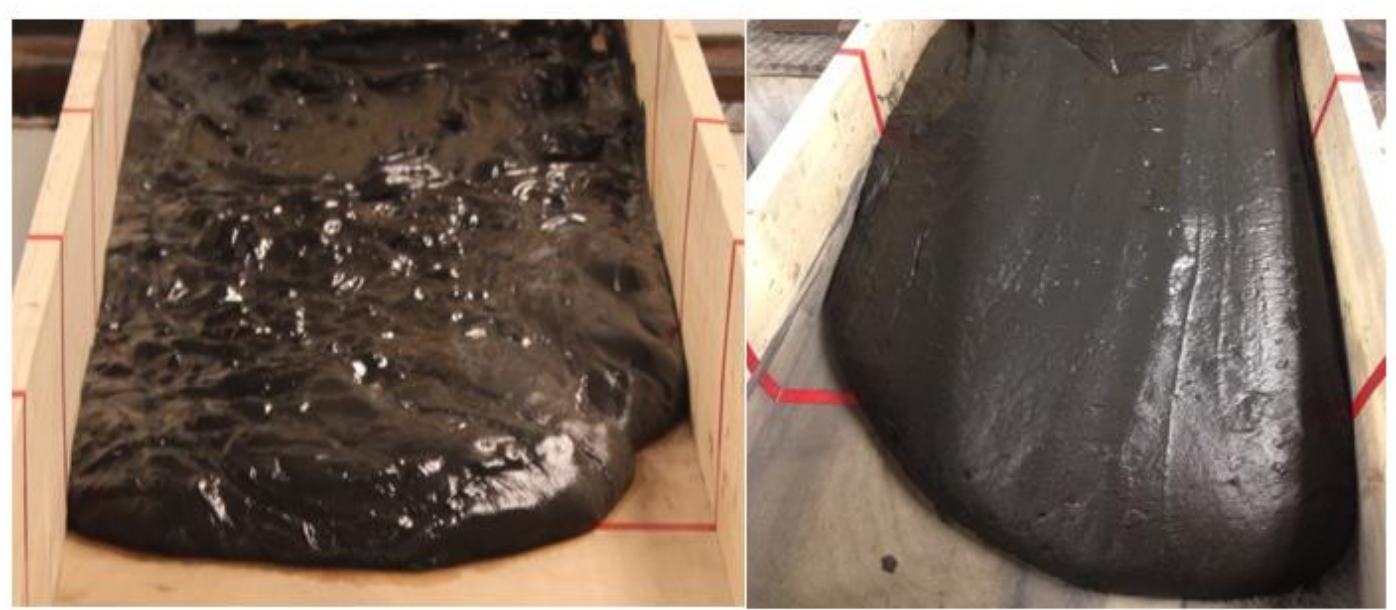

$$
\mathbf{w}=\mathbf{5 7} \alpha=\mathbf{3 0} \quad \mathbf{w}=\mathbf{5 1} \alpha=\mathbf{3 0}
$$

Figure 3-6 The flows of KY sample at different water content (w) and slope angle $(\alpha)$ 


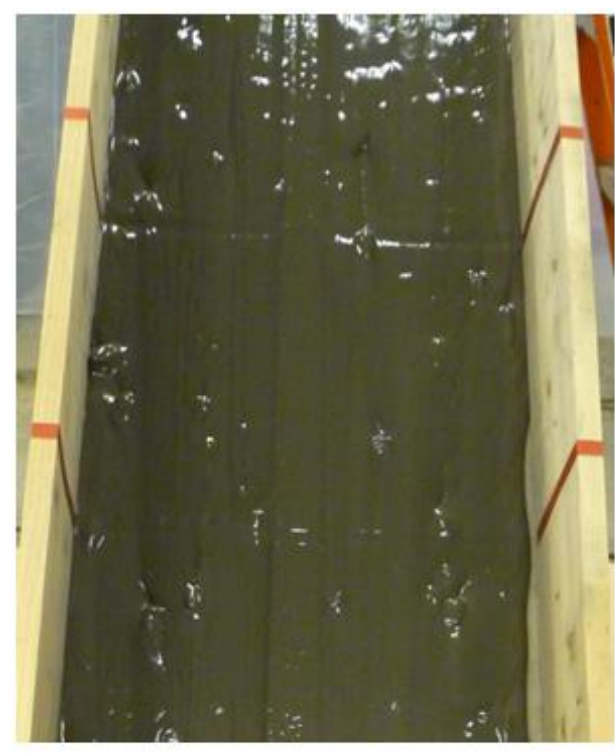

$\mathbf{w}=82 \alpha=30^{\circ}$

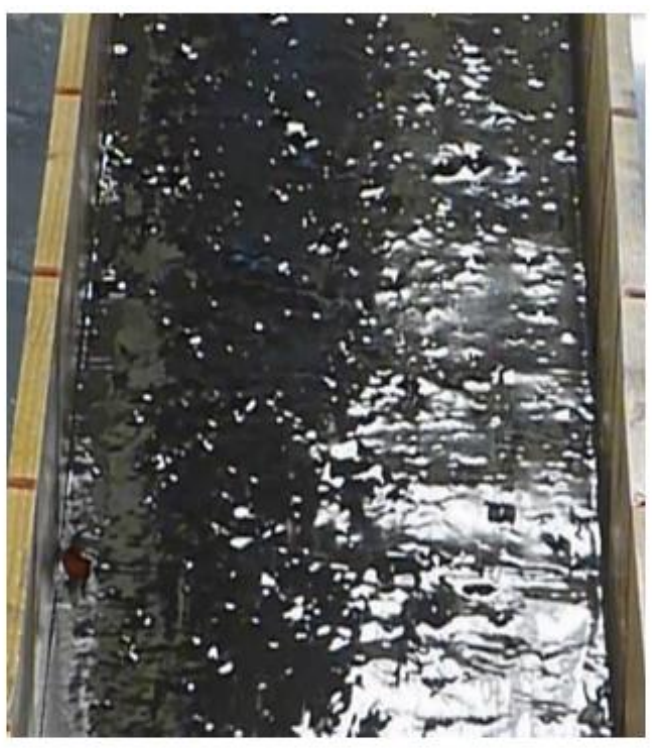

$\mathrm{w}=82 \alpha=10^{\circ}$

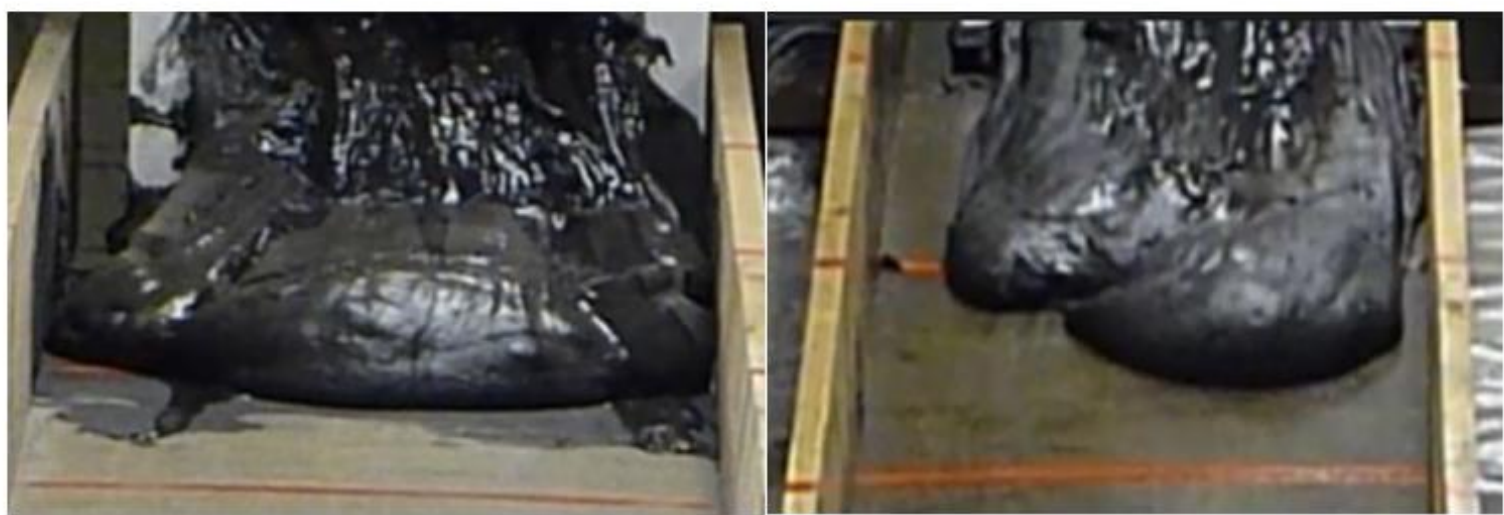

$$
\mathbf{w}=65 \alpha=30^{\circ}
$$$$
\mathbf{w}=55 \alpha=30^{\circ}
$$

Figure 3-7 The flows of WV sample at different water content (w) and slope angle $(\alpha)$ 
Although the samples had a slight difference in the initial water content, quite consistent results were obtained from the flume tests on the KY samples and WV samples. The flow velocities of coal refuse was within the range of $2.55 \mathrm{~m} / \mathrm{sec}$ as the water content changes from approximately $80 \%$ to $50 \%$. In addition, it was clearly noted that the velocity and travel distance of coal refuse flow gradually decreased as the initial water content and applied shear stress (or slope angle) reduced. At lower water content of about 55\%, the flow became quite slow and traveled less than $1 \mathrm{~m}$. The measured results were also graphically exhibited in Figure 3-6 and Figure 3-7. It was found that the coal slurry gradually switched from smooth flow at higher water content to quite viscous flow at lower water content. The observed plastic area on top of the flow became thicker as the water content reduced.

The comparisons of flow behaviors were also performed between KY sample and WV sample. As previously discussed, the percent of fine coal particles is one of the most significant factors influencing the viscosity of coal slurry (Kawatra and Bakshi, 1995). As shown in Figure 3-8, the WV coal refuse sample was therefore exhibited more viscous behavior than KY sample at the same water content. Once the flow start, the flow velocity of viscous coal refuse would be largely dependent on the viscosity. The viscosity could be considered as a resistance or frictional force acting within the moving flow of coal refuse. This might explain the phenomenon shown in Figure 3-9 that KY coal refuse sample had slightly faster flow velocity than WV sample at the same water content and slope angle, even though the values of flow velocities for both samples were in the same order of magnitude. 


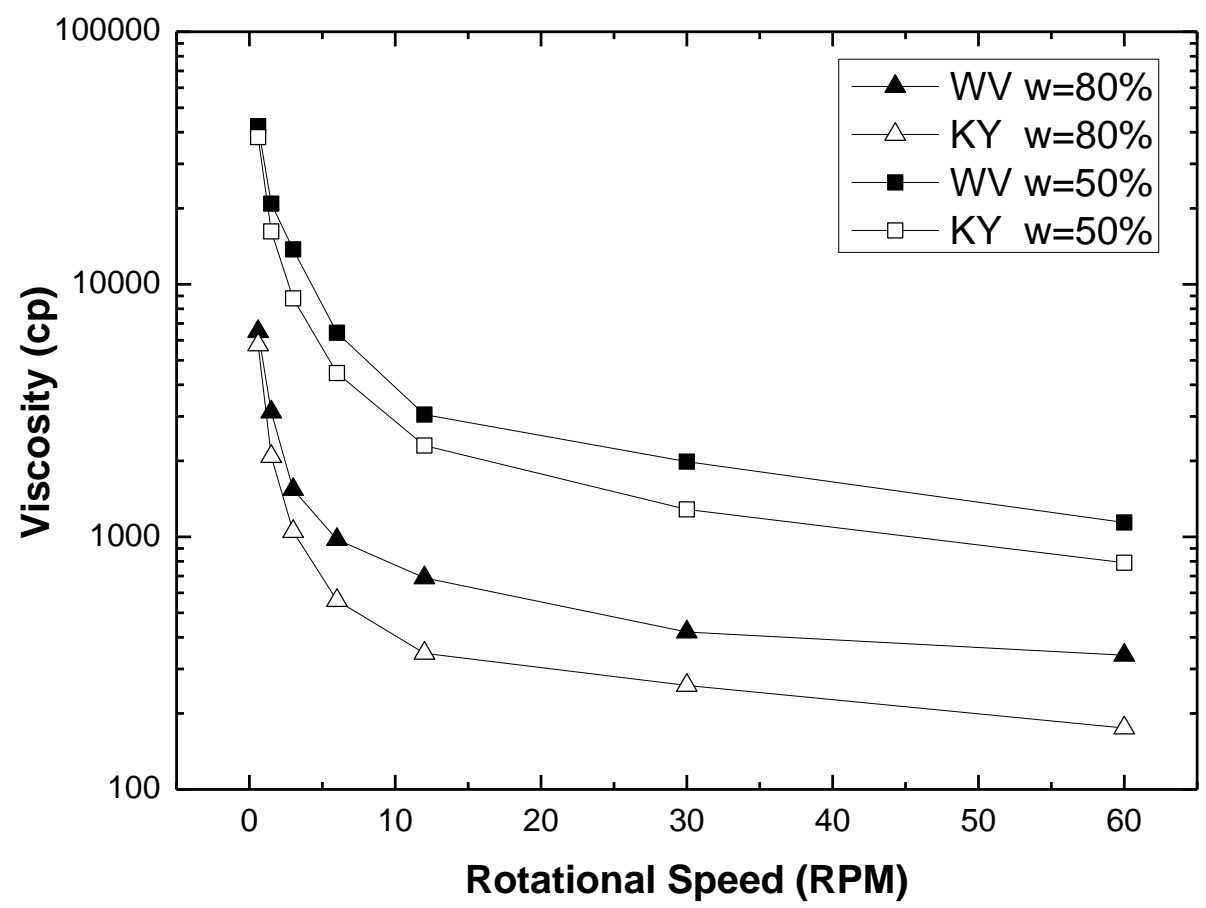

Figure 3-8 Comparison of variations of viscosities with rotational speed at $50 \%$ and $80 \%$ example water content

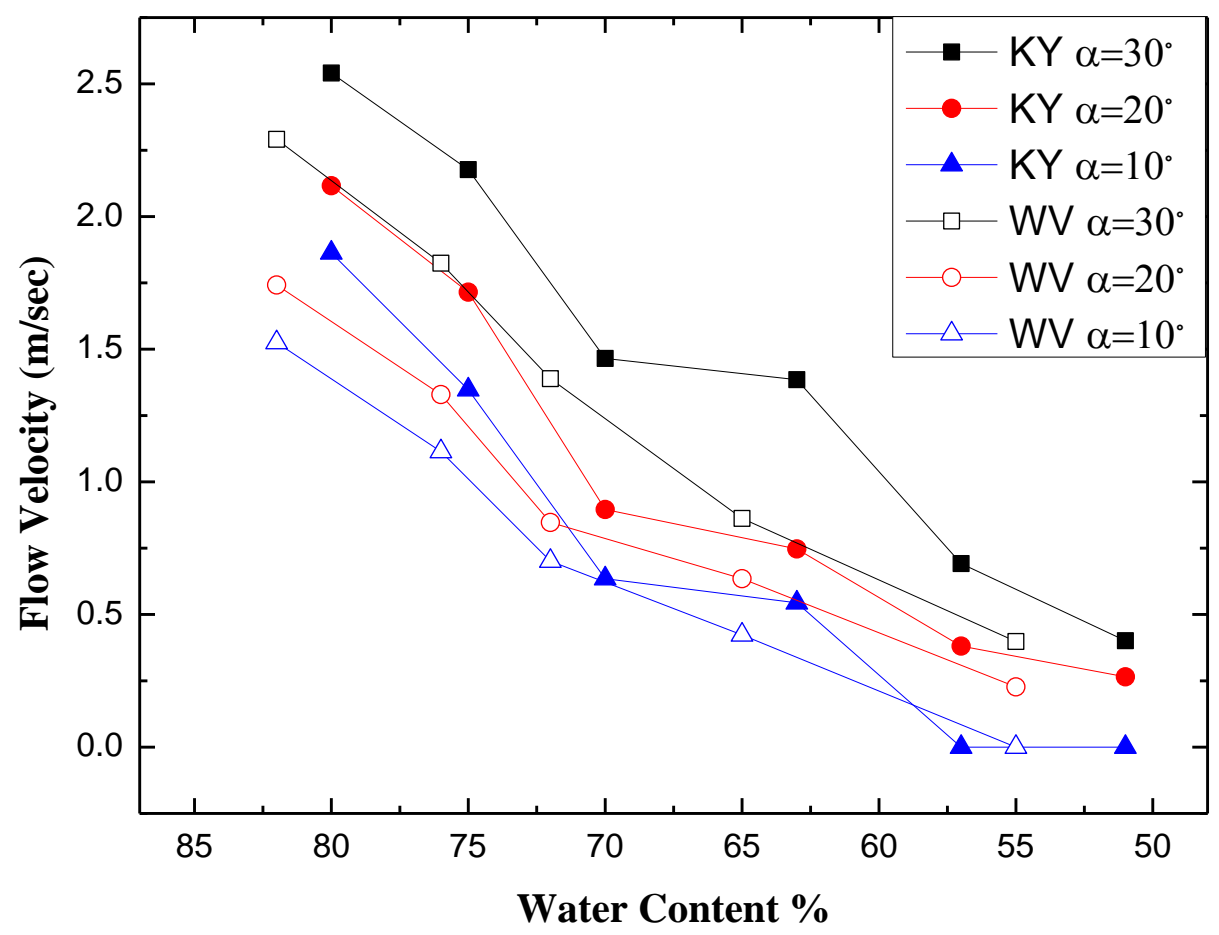

Figure 3-9 Comparison of flow velocity of two coal refuse samples varying with initial water content and slope angle 
The liquid limits $w_{L}$ of the two samples have been measured in the laboratory tests as 38.1 for KY sample and 42.5 for WV sample (see Table 2-3). As shown in Table 3-2 and Table 3-3, the flows of two coal refuse samples at $30^{\circ}$ slope angle ceased at water content of $48 \%$ and $52 \%$, which is about $10 \%$ higher than the corresponding liquid limit. The critical water content could be considered as the dividing line between flowable and non-flowable of impounded coal refuse. However, regarding the liquid limit of coal refuse as the critical water content would be more conservative in the practical design and construction of tailings dams.

\subsubsection{Representation of Coal Refuse by Bingham Plastic Model}

The behavior of Bingham plastic fluid is dominated by plastic viscosity $\eta_{p}$ and yield stress $\tau_{y}$. It has already been illustrated in Section 3.1.2 how to determine these two significant parameters in terms of the relationship between viscosity and shear rate. First of all, it is necessary to determine the variation of viscosity with the shear rate. Some of the advanced digital viscometers can directly give out the value of shear rate based on the internal processing and converting. However, the NDJ-8S digital rotary viscometer can only develop the relationship between the measured viscosity and rotational speed. Referring to the manual provided by Brookfield (2009), the shear rate applied in the rotational viscometer could be considered as a function of rotational speed. 


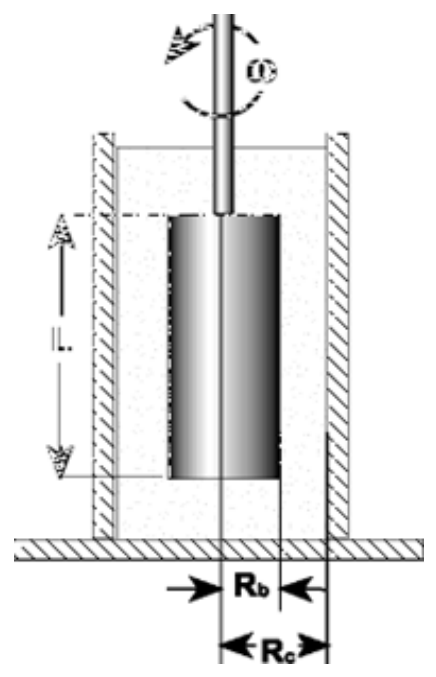

Figure 3-10 Sketch of cylindrical spindle rotating in the tested fluid

For cylindrical spindles with diameter of $\mathrm{R}$ and length of $\mathrm{L}$, the side contact area with fluid can be determined as $\pi \mathrm{R}^{2} \mathrm{~L}$. Torque is computed as the force acting on the outer surface of the spindle times the radius ("lever arm"). Therefore, the following relationship is derived:

$$
\dot{\gamma}=\frac{2 \omega R_{c}^{2} R_{b}^{2}}{x^{2}\left(R_{c}^{2}-R_{b}^{2}\right)}
$$

Where

$$
\begin{aligned}
& \dot{\gamma}=\text { shear rate }\left(\mathrm{sec}^{-1}\right) \\
& \omega=\text { angular velocity of spindle }(\mathrm{rad} / \mathrm{sec}) \\
& \mathrm{R}_{\mathrm{c}}=\text { radius of container }(\mathrm{cm}) \\
& \mathrm{R}_{\mathrm{b}}=\text { radius of spindle }(\mathrm{cm}) \\
& \mathrm{x}=\text { radius at which shear rate is being measured }
\end{aligned}
$$


As mentioned in the Section 2.3.7, \#4 spindle was used in the viscosity test (Figure 2-33). The parameters could thereby be determined as:

$$
\begin{aligned}
& \mathrm{R}_{\mathrm{b}}=1.683 \mathrm{~mm} \\
& \mathrm{R}_{\mathrm{c}}=42.437 \mathrm{~mm} \\
& \mathrm{x}=\mathrm{R}_{\mathrm{b}}=1.683 \mathrm{~mm}
\end{aligned}
$$

Accordingly, the shear rate could be obtained in terms of the corresponding rotational speed which is expressed in the following equation and listed in Table 3-6:

$$
\left.\dot{\gamma}=\frac{2 \omega R_{c}^{2} R_{b}^{2}}{x^{2}\left(R_{c}^{2}-R_{b}^{2}\right.}\right)=2.0032 \times \omega
$$

Table 3-6 Determination of shear rate from rotational speed

\begin{tabular}{|c|c|c|}
\hline rpm & Rad/sec & Shear rate \\
\hline 0.6 & 0.0628 & 0.1258 \\
\hline 1.5 & 0.1571 & 0.3147 \\
\hline 3 & 0.3142 & 0.6294 \\
\hline 6 & 0.6283 & 1.2586 \\
\hline 12 & 1.2566 & 2.5172 \\
\hline 30 & 3.1416 & 6.2933 \\
\hline 60 & 6.2832 & 12.5865 \\
\hline
\end{tabular}


A small amount of coal slurry sample was collected from the middle depth of the pond before starting each flume test. The viscosities of these samples were measured at different rotational speeds by using NDJ-8S digital rotary viscometer. The initial water content was considered the same as that in the small-scale model test. Based on the provided equation and coefficients by Brookfield (2009) and Brookfield Engineering Laboratories (2005), the variations of viscosity with the shear rate and initial water content were established in Table.3-7 for KY sample and in Table 3-8 for WV sample.

Table 3-7 Recorded viscosities of KY sample at different water content and shear rate

\begin{tabular}{|c|c|c|c|c|c|c|c|}
\hline \multirow{2}{*}{$\begin{array}{c}\text { Rotationa } \\
\text { I Speed } \\
\text { (rpm) }\end{array}$} & \multirow{2}{*}{$\begin{array}{c}\text { Shear } \\
\text { Rate } \gamma \\
\left(\sec ^{-1}\right)\end{array}$} & \multicolumn{6}{|c|}{ Viscosity $\eta(c p)$} \\
\hline & & $\begin{array}{c}\mathrm{w}=80 \\
\%\end{array}$ & $\begin{array}{c}\mathrm{w}=75 \\
\%\end{array}$ & $\begin{array}{c}\mathrm{w}=70 \\
\%\end{array}$ & $\begin{array}{c}\mathrm{w}=\mathbf{6 3} \\
\%\end{array}$ & $\mathrm{w}=57 \%$ & $\begin{array}{c}\mathrm{w}=51 \\
\%\end{array}$ \\
\hline 0.6 & 0.1258 & 5360 & 8700 & 12500 & 15000 & 25000 & 38250 \\
\hline 1.5 & 0.3147 & 2180 & 3380 & 4700 & 6400 & 10500 & 16200 \\
\hline 3.0 & 0.6294 & 1050 & 1700 & 2350 & 3100 & 5600 & 8800 \\
\hline 6.0 & 1.2586 & 530 & 850 & 1270 & 1700 & 2700 & 4450 \\
\hline 12 & 2.5172 & 346 & 470 & 680 & 1100 & 1700 & 2300 \\
\hline 30 & 6.2933 & 258 & 310 & 375 & 880 & 1020 & 1285 \\
\hline 60 & 12.5865 & 175 & 206 & 267 & 570 & 680 & 790 \\
\hline
\end{tabular}


Table 3-8 Recorded viscosities of WV samples at different water content and shear rate

\begin{tabular}{|c|c|c|c|c|c|c|c|c|}
\hline \multirow{2}{*}{$\begin{array}{l}\text { Rotational } \\
\text { Speed } \\
\text { (rpm) }\end{array}$} & \multirow{2}{*}{$\begin{array}{c}\text { Shear } \\
\text { Rate } \gamma \\
\left(\sec ^{-1}\right)\end{array}$} & \multicolumn{7}{|c|}{ Viscosity $\eta(c p)$} \\
\hline & & $\begin{array}{c}\mathrm{w}=\mathbf{8 0} \\
\%\end{array}$ & $\begin{array}{c}\mathrm{w}=75 \\
\%\end{array}$ & $\begin{array}{c}\mathrm{w}=71 \\
\%\end{array}$ & $\begin{array}{c}\mathrm{w}=64 \\
\%\end{array}$ & $\begin{array}{c}\mathrm{w}=56 \\
\%\end{array}$ & $\begin{array}{c}\mathrm{w}=\mathbf{5 0} \\
\%\end{array}$ & $\begin{array}{c}\mathrm{w}=42 \\
\%\end{array}$ \\
\hline 0.6 & 0.1258 & 6500 & 8188 & 11310 & 14235 & 26100 & 42300 & 128960 \\
\hline 1.5 & 0.3147 & 3120 & 3605 & 4728 & 5970 & 12280 & 20856 & 54210 \\
\hline 3.0 & 0.6294 & 1540 & 1978 & 2473 & 3240 & 6700 & 13744 & 28335 \\
\hline 6.0 & 1.2586 & 976 & 1050 & 1350 & 1800 & 3910 & 6430 & 15323 \\
\hline 12 & 2.5172 & 688 & 715 & 936 & 1135 & 2500 & 3050 & 7980 \\
\hline 30 & 6.2933 & 420 & 540 & 680 & 846 & 1584 & 1986 & 3298 \\
\hline 60 & 12.5865 & 340 & 438 & 525 & 668 & 977 & 1140 & 2960 \\
\hline
\end{tabular}

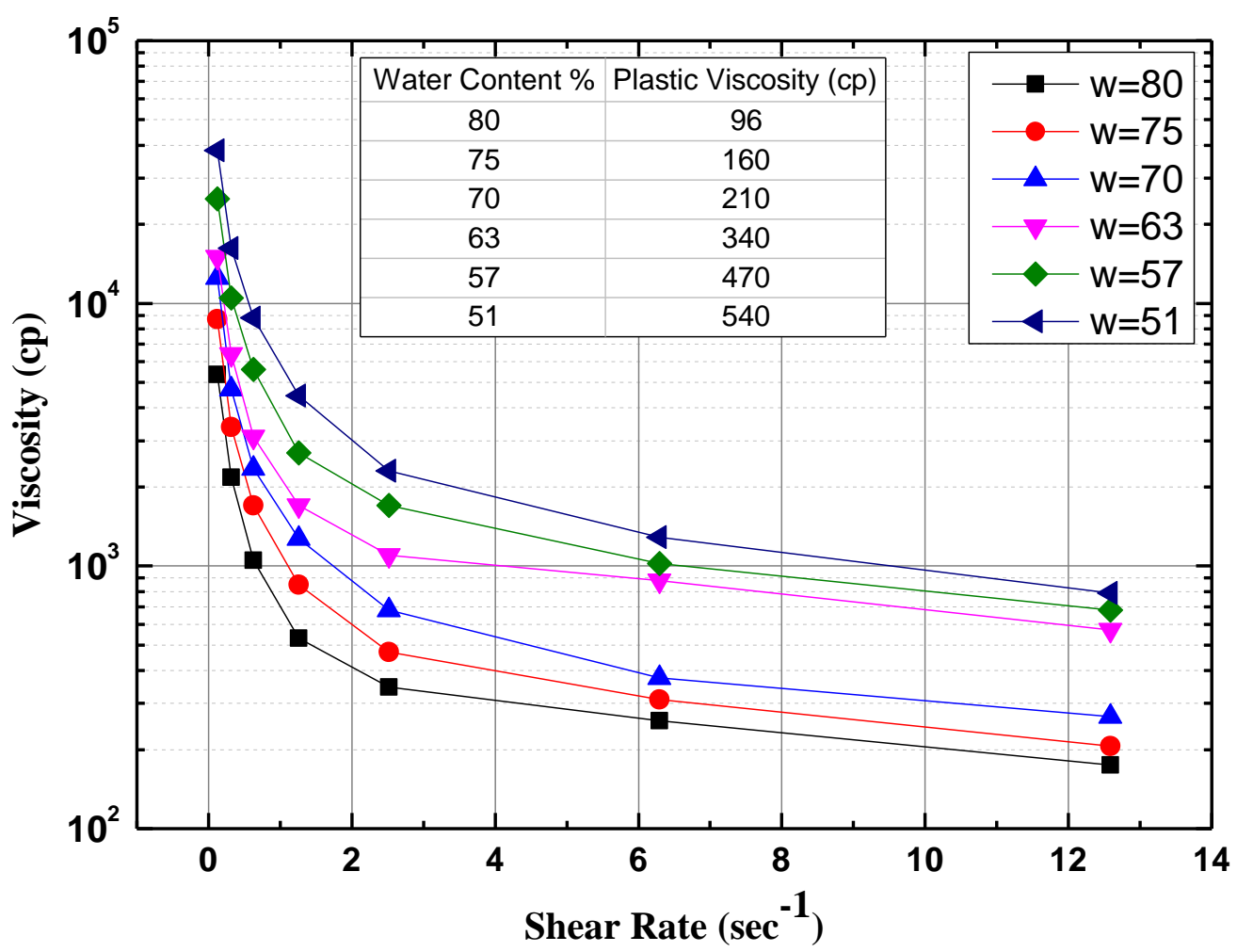

Figure 3-11 Variation of viscosity with shear rate for $\mathrm{KY}$ coal refuse sample $\left(23^{\circ} \mathrm{C}\right)$ 


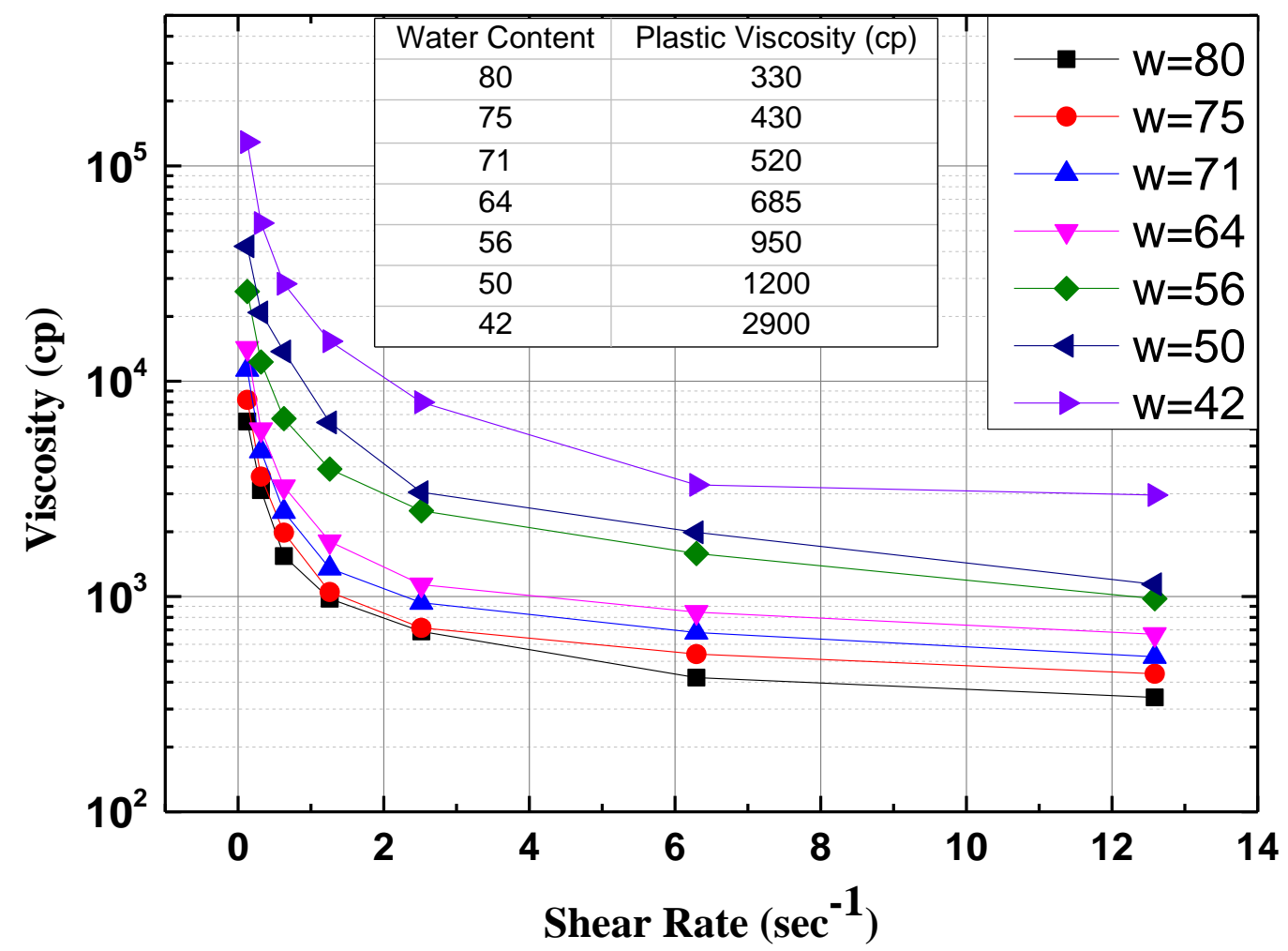

Figure 3-12 Variation of viscosity with shear rate for WV coal refuse sample $\left(23^{\circ} \mathrm{C}\right)$

The variations of recorded viscosity with shear rate were also graphically exhibited in Figure 3-11 and Figure 3-12 for the two representative coal refuse samples. It could be clearly observed that the viscosity of coal refuse decreased with the shear rate. However, the dramatic reduction of viscosity took place in the lower shear rate approximately between 0 and $2 \sec ^{-1}$. While only slight change of viscosity was observed as the shear rate greater than $6 \mathrm{sec}^{-1}$. The relationship between shear stress $(\tau=\eta \gamma)$ and shear rate could be developed with the known viscosity. The plastic viscosity and yield stress could therefore be determined based on the simplified method mentioned in Section 3.1.2. An example of conversion from $\eta-\dot{\gamma}$ to $\tau-\dot{\gamma}$ and determination of plastic viscosity and 
yield stress was shown in Figure 3-13. The plastic viscosity was determined from the slope of the linear portion of the curve at high shear rate, and the yield stress was taken as the intersection of the slope and the shear stress axis.

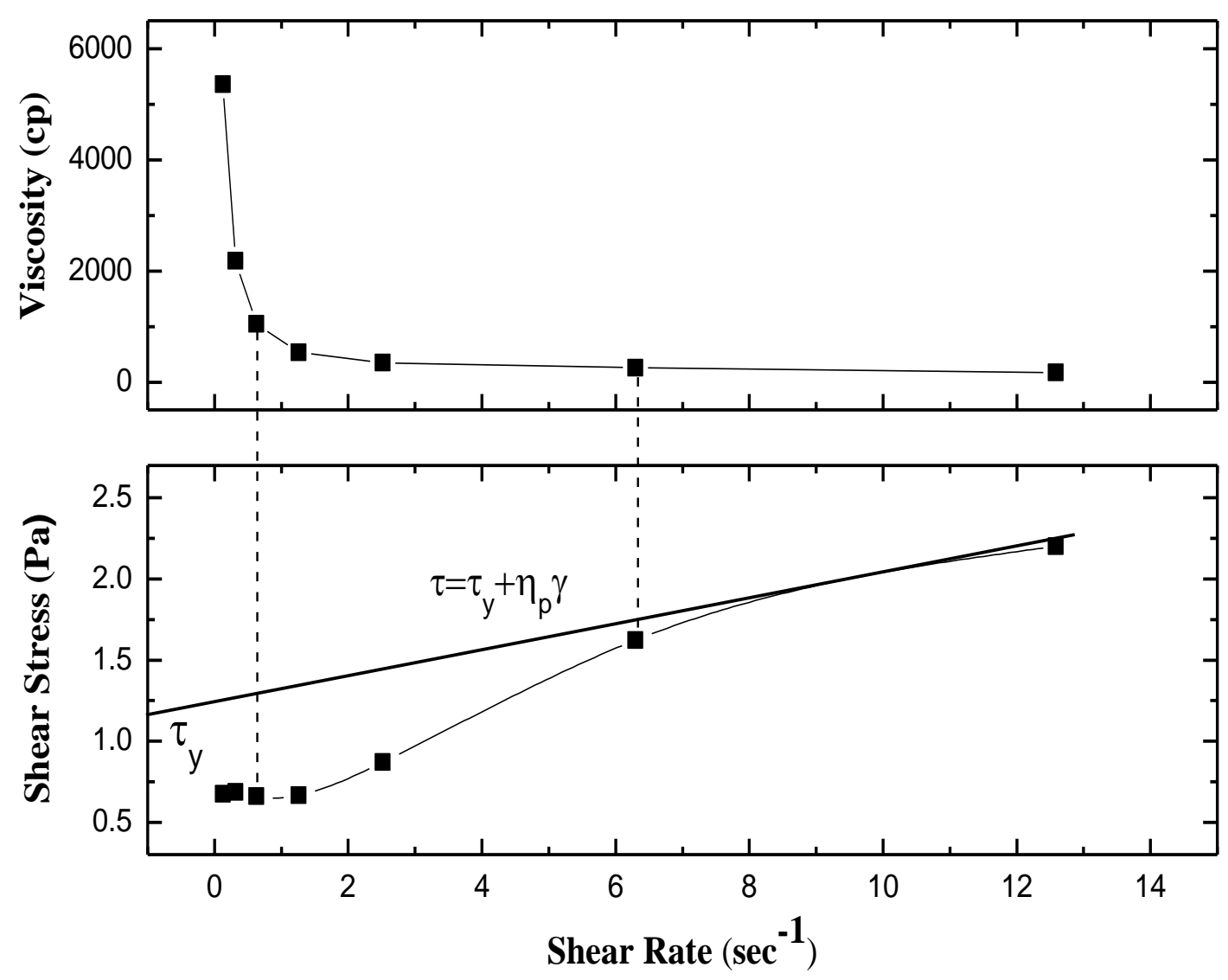

Figure 3-13 Determination of flow parameters of Bingham Plastic model (KY coal refuse sample, $\mathrm{w}=80 \%$ ) 


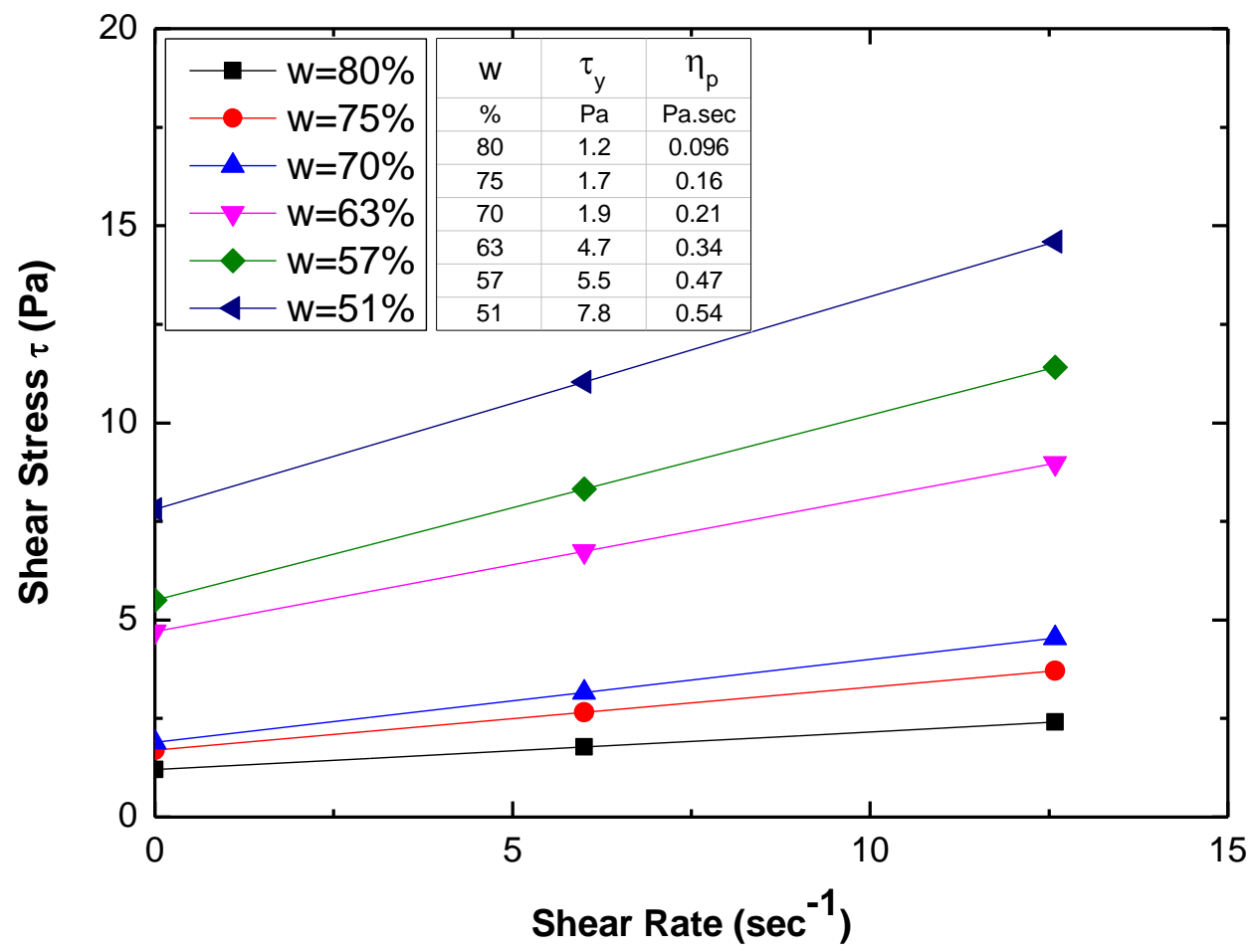

Figure 3-14 Bingham Plastic model for KY samples at different water content

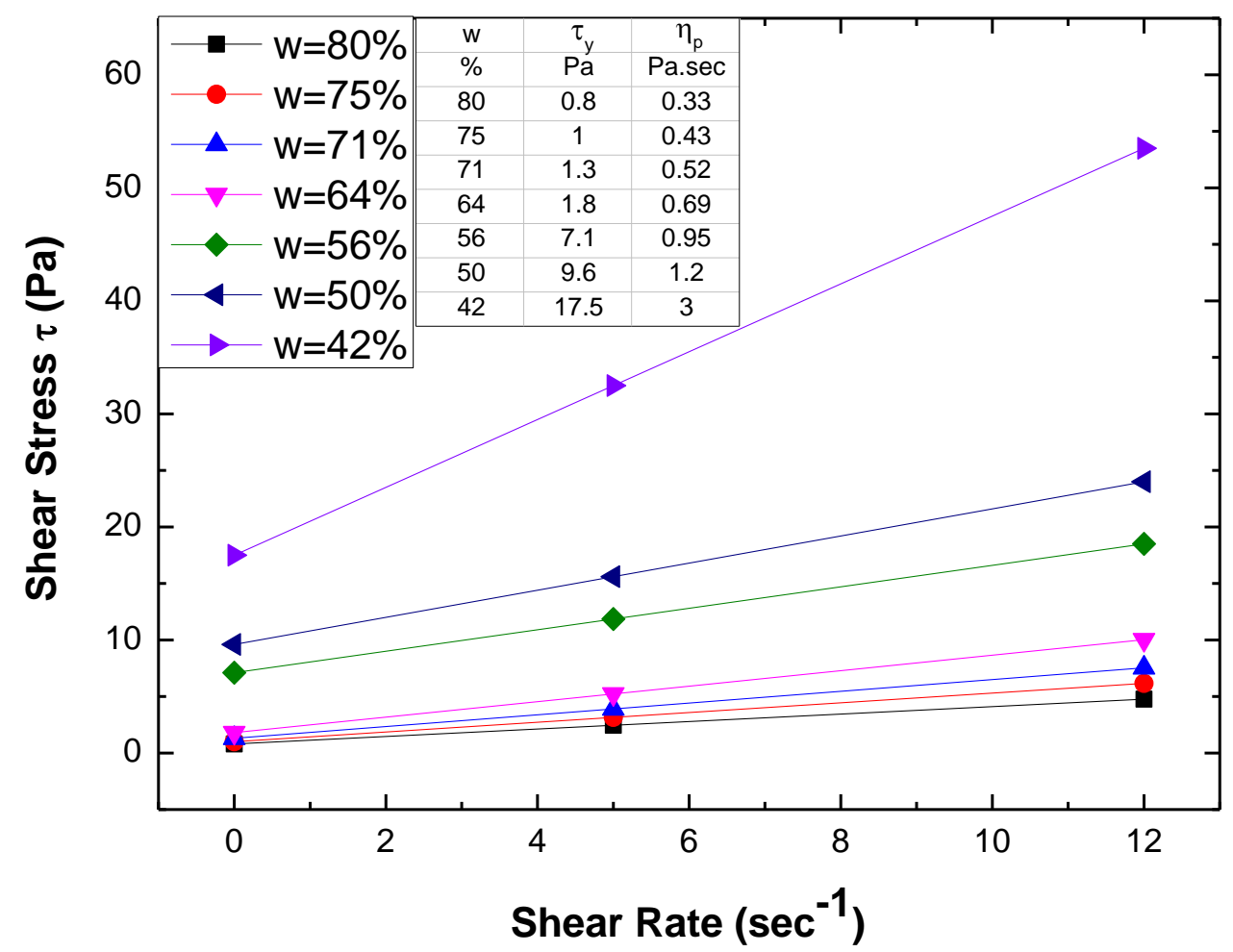

Figure 3-15 Bingham Plastic model for WV samples at different water content 113 
The developed Bingham Plastic models at different initial water content were graphically summarized in Figure 3-14 for KY sample and in Figure 3-15 for WV sample. It was found that the yield stress increased with the reduction of initial water content. Accordingly, larger shear force is needed to trigger the flow of coal slurry. However, the yield stress measured at higher water content was in the extremely low level which could be neglected. The same magnitude of results was also obtained by Krizek (2004). Thereby, the coal slurry might be roughly considered as Newtonian fluid whose flow behavior is governed primarily by the viscosity. Such approximation was also performed by Logos and Nguyen (1996), Boylu et al. (2004), and Sawyer et al. (2012). In addition, the obtained result of negligible yield stress could also demonstrate the susceptibility to the flow failure of impounded coal refuse under even slight disturbance. The plastic viscosity was also found to increase as the initial water content reduced. An apparent increase of yield stress and plastic viscosity was observed at water content lower than $60 \%$.

Regarding the method used in this study to determine the yield stress of coal refuse, some of the researchers have indicated that the yield stress might not be well defined due to the break-down of particle structures under the applied shear rate (Terzaghi, 1931; TerStepanian, 1963; and Phillips and Davis, 1991). Palmer and Krizek (1987), and Vallejo and Scovazzo (2003) studied the properties of mudflow and assumed the yield stress equaled to the undrained shear strength $c_{u}$. However, the obtained yield stress and undrained shear strength measured in this study exhibited a sharp discrepancy, which was probably due to the fact that the thoroughly agitation before the viscosity measurement had broken the particles structure. 


\subsubsection{Estimation of Flow Regime}

It is known that the characteristics of flow are greatly influenced by the flow velocity. Two types of flow have been well identified and studied according to the velocity of the fluid, i.e., laminar flow and turbulent flow. The laminar flow occurred when flow velocity is below a certain critical value while turbulent flow occurred above the value. The flow regime is typically estimated by comparing Reynolds number at certain velocity (which gives a measure of the ratio of inertial forces to viscous forces) to the critical Reynolds number. In the case of open channel flow, the Reynolds number for Newtonian fluid is defined as:

$$
\operatorname{Re}=\frac{\rho v R}{\eta}
$$

Where

$$
\begin{aligned}
& \mathrm{Re}=\text { Reynolds number } \\
& \rho=\text { density of the fluid } \\
& v=\text { mean flow velocity } \\
& \mathrm{d}=\text { hydraulic radius in the open channel } \\
& \eta=\text { the viscosity of fluid }
\end{aligned}
$$

However, the definition of the Reynolds number for non-Newtonian fluid has not been clearly proposed even though quite a number of researches have been performed by Chhabra and Richardson (2008) and Haldenwang et al. (2010). The calculation of Reynolds numbers in this report were referred to the equation shown above for the Newtonian fluid. 
In practical, it is also quite difficult to find an apparent transition from laminar to turbulent for Bingham Plastic fluid. A lower critical Reynolds number $\operatorname{Re}_{c}$ was proposed by Hanks and Pratt (1967). Below this value, almost all the disturbances would be damped. Hanks and Pratt (1967) and Swamee and Aggarwal (2011) expressed the critical Reynolds number for transition from laminar to turbulent flow as a function of the Hedstrom number:

$$
H e=\frac{\rho R^{2} \tau_{y}}{\eta^{2}}
$$

Where $\mathrm{R}$ is the hydraulic radius in the open channel which equals to the crosssectional area of the flow divided by the wetted perimeter $\left(R=\frac{A}{\mathrm{X}}=\frac{B D}{B+2 D}, \mathrm{~B}\right.$ is the width of the slope and $\mathrm{D}$ is the flow depth).

The critical Reynolds number can thereafter be defined as:

$$
\begin{array}{ll}
\operatorname{Re}_{c}=2100\left(1+\frac{H e}{3600}\right)^{0.35} & \text { for } \quad 1 \leq H e \leq 10^{8} \\
\operatorname{Re}_{c}=161 H e^{0.334} & \text { for } 10^{8} \leq \mathrm{He} \leq 10^{12}
\end{array}
$$

Based on the dimension of flume channel and measured flow parameters shown through Table 3-2 to Table 3-5, the Hedstrom number and critical Reynolds number were determined and listed in Table 3-9 and Table 3-10 for the two coal refuse samples. 
Table 3-9 Determination of critical Reynolds number for KY sample

\begin{tabular}{|c|c|c|c|c|c|c|c|c|}
\hline $\begin{array}{c}\text { Water } \\
\text { Content }\end{array}$ & $\boldsymbol{\rho}$ & $\mathbf{B}$ & $\mathbf{D}$ & $\mathbf{R}$ & $\eta_{p}$ & $\tau_{y}$ & $\mathbf{H e}$ & $\mathrm{Re}_{c}$ \\
\hline$\%$ & $\mathrm{~kg} / \mathrm{m}^{\wedge} 3$ & $\mathrm{~m}$ & $\mathrm{~m}$ & $\mathrm{~m}$ & $\mathrm{~Pa} \cdot \mathrm{sec}$ & $\mathrm{Pa}$ & & \\
\hline 80 & 1393 & 0.3 & 0.02 & 0.02 & 0.10 & 1.2 & 56 & 2111 \\
\hline 75 & 1408 & 0.3 & 0.03 & 0.03 & 0.16 & 1.7 & 58 & 2112 \\
\hline 70 & 1425 & 0.3 & 0.04 & 0.03 & 0.21 & 1.9 & 52 & 2111 \\
\hline 63 & 1452 & 0.3 & 0.06 & 0.04 & 0.34 & 4.7 & 108 & 2122 \\
\hline 57 & 1477 & 0.3 & 0.08 & 0.05 & 0.47 & 5.5 & 94 & 2119 \\
\hline 51 & 1506 & 0.3 & 0.13 & 0.07 & 0.54 & 7.8 & 195 & 2139 \\
\hline
\end{tabular}

Table 3-10 Determination of critical Reynolds number for WV sample

\begin{tabular}{|c|c|c|c|c|c|c|c|c|}
\hline $\begin{array}{c}\text { Water } \\
\text { Content }\end{array}$ & $\boldsymbol{\rho}$ & $\mathbf{B}$ & $\mathbf{D}$ & $\mathbf{R}$ & $\eta_{p}$ & $\tau_{y}$ & $\mathrm{He}$ & $\mathrm{Re}_{c}$ \\
\hline$\%$ & $\mathrm{~kg} / \mathrm{m}^{\wedge} 3$ & $\mathrm{~m}$ & $\mathrm{~m}$ & $\mathrm{~m}$ & $\mathrm{~Pa} \cdot \mathrm{sec}$ & $\mathrm{Pa}$ & & \\
\hline 82 & 1413 & 0.3 & 0.02 & 0.02 & 0.33 & 0.8 & 3 & 2100 \\
\hline 76 & 1434 & 0.3 & 0.03 & 0.02 & 0.43 & 1.0 & 4 & 2100 \\
\hline 72 & 1448 & 0.3 & 0.04 & 0.03 & 0.52 & 1.3 & 6 & 2101 \\
\hline 65 & 1476 & 0.3 & 0.08 & 0.05 & 0.69 & 1.8 & 15 & 2103 \\
\hline 55 & 1523 & 0.3 & 0.1 & 0.06 & 0.95 & 7.1 & 43 & 2109 \\
\hline
\end{tabular}


Table 3-11 Determination of flow regime for KY sample

\begin{tabular}{|c|c|c|c|c|c|c|l|}
\hline $\begin{array}{c}\text { Water } \\
\text { Content }\end{array}$ & $\boldsymbol{\rho}$ & $\mathbf{v}$ & $\mathbf{R}$ & $\boldsymbol{\eta}$ & $\mathbf{R e}$ & $\operatorname{Re}_{c}$ & Regime \\
\hline$\%$ & $\mathrm{~kg} / \mathrm{m}^{\wedge} 3$ & $\mathrm{~m} / \mathrm{sec}$ & $\mathrm{m}$ & $\mathrm{Pa} \cdot \mathrm{sec}$ & & & \\
\hline 80 & 1393 & 2.541 & 0.02 & 0.10 & 650 & 2111 & Laminar \\
\hline 75 & 1408 & 2.177 & 0.03 & 0.16 & 479 & 2112 & Laminar \\
\hline 70 & 1425 & 1.465 & 0.03 & 0.21 & 289 & 2111 & Laminar \\
\hline 63 & 1452 & 1.385 & 0.04 & 0.34 & 253 & 2122 & Laminar \\
\hline 57 & 1477 & 0.692 & 0.05 & 0.47 & 110 & 2119 & Laminar \\
\hline 51 & 1506 & 0.401 & 0.07 & 0.54 & 78 & 2139 & Laminar \\
\hline
\end{tabular}

Table 3-12 Determination of flow regime for WV sample

\begin{tabular}{|c|c|c|c|c|c|c|l|}
\hline $\begin{array}{c}\text { Water } \\
\text { Content }\end{array}$ & $\boldsymbol{\rho}$ & $\mathbf{v}$ & $\mathbf{R}$ & $\boldsymbol{\eta}$ & $\mathbf{R e}$ & $\mathrm{Re}_{c}$ & Regime \\
\hline $\boldsymbol{\%}$ & $\mathrm{kg} / \mathrm{m}^{\wedge} 3$ & $\mathrm{~m} / \mathrm{sec}$ & $\mathrm{m}$ & $\mathrm{Pa} \cdot \mathrm{sec}$ & & & \\
\hline 82 & 1413 & 2.29 & 0.02 & 0.33 & 173 & 2100 & Laminar \\
\hline 76 & 1434 & 1.82 & 0.02 & 0.43 & 130 & 2100 & Laminar \\
\hline 72 & 1448 & 1.39 & 0.03 & 0.52 & 117 & 2101 & Laminar \\
\hline 65 & 1476 & 0.86 & 0.05 & 0.69 & 97 & 2103 & Laminar \\
\hline 55 & 1523 & 0.4 & 0.06 & 0.95 & 38 & 2108 & Laminar \\
\hline
\end{tabular}


Since the velocity of coal refuse was found to increase with the slope angle, the flow regime analysis was only performed on the flow at the largest slope angle of $30^{\circ}$. The flow regimes of two representative coal refuse were summarized in Table 3-11 and Table $3-12$, respectively. It was found that the Reynolds numbers at different water content were much lower than the corresponding critical Reynolds numbers. Therefore the flow of coal refuse could be considered as a steady uniform laminar flow in the open channel. The laminar regime of coal slurry was also observed by Schaflinger et al. (1990), Coussot (1994), Cooke (2002), Spelay (2007), and Xia et al. (2009). However few data are available on the flow failure of tailings dams, most of the rheological researches are performed based on the slurry flow in the pipeline.

\subsubsection{Velocity Profile}

As discussed in the previous section, the approximation of uniform, steady, fully developed laminar flow has provided great convenience in studying the rheological characteristics of the impounded coal refuse slurries. Velocity profile could intuitively exhibit the features of Bingham Plastic fluid which is governed by both yield stress and the shear rate. As shown in Figure 3-16, an ideal Bingham Plastic fluid flow down an inclined plane. Due to the effect of yield stress $\tau_{y}$, a plug-like region is formed near the free surface of flow $\left(X \leq X_{0}\right)$. In this region, the applied shear stress is below the yield stress. Therefore, the solid plug moves with the flow without a velocity gradient. When the driving shear stress is larger than the yield stress at $X>X_{0}$, the fluid will behave close to the viscous liquid with a parabolic distribution of flow velocity. From a microscopic point of view, the shear stresses would be developed during the movement of a fluid as long as the particles 
of the fluid move relative to one another. When this happens, the particles on the different layers along the flow depth would have different velocities. However, there would be no shear stress if the flow velocity is the same at every point and thereby the particles have zero relative velocity.

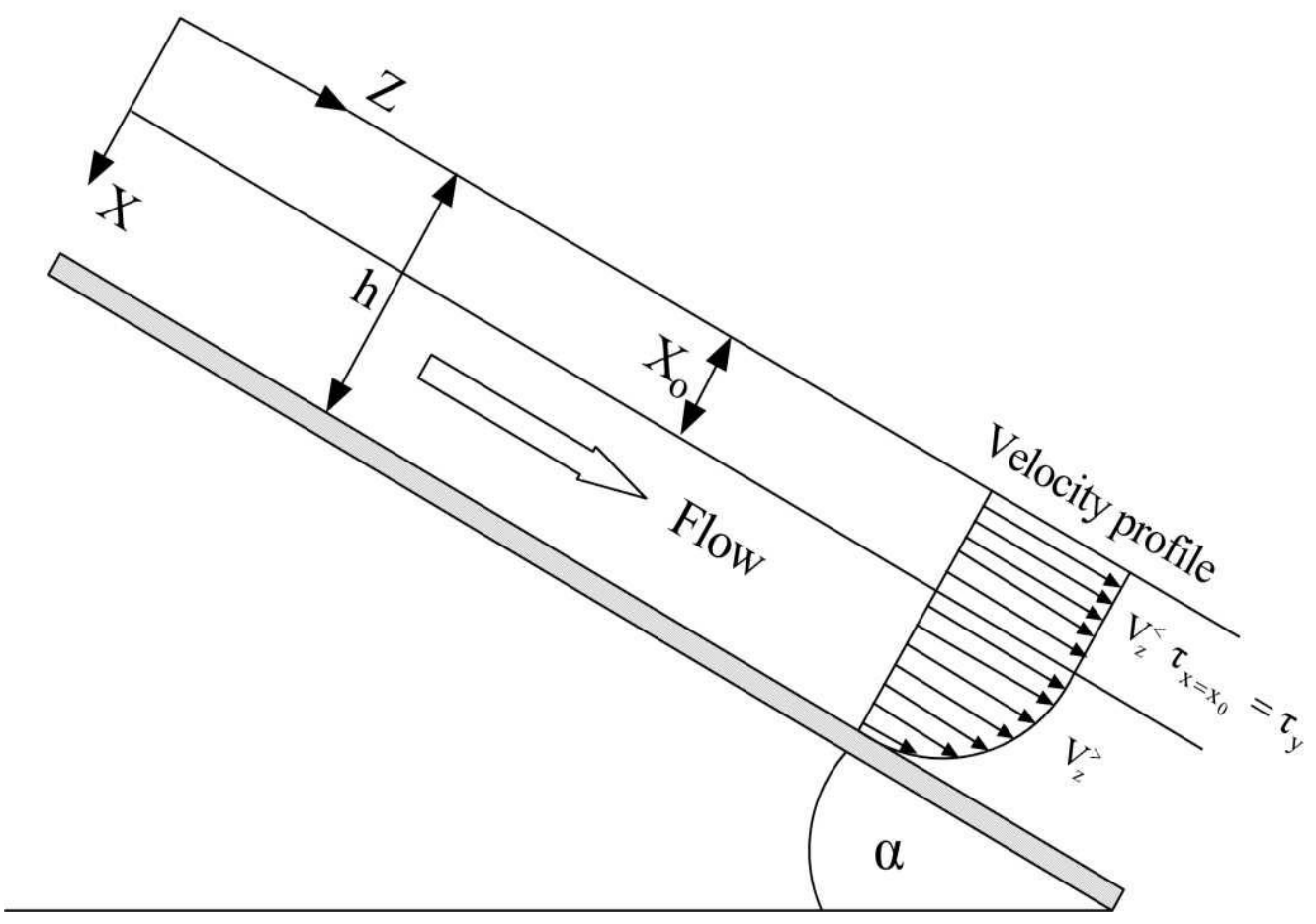

Figure 3-16 Schematic of flow configuration (De Kee et al., 1990) 


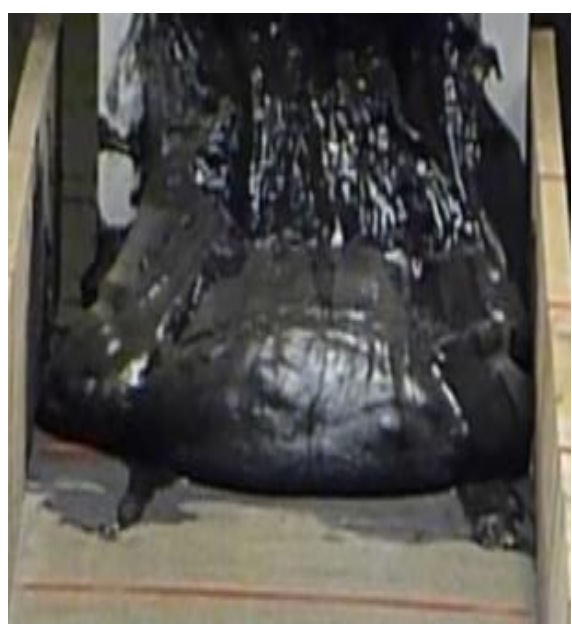

$\mathbf{w}=65 \quad \alpha=30^{\circ}$

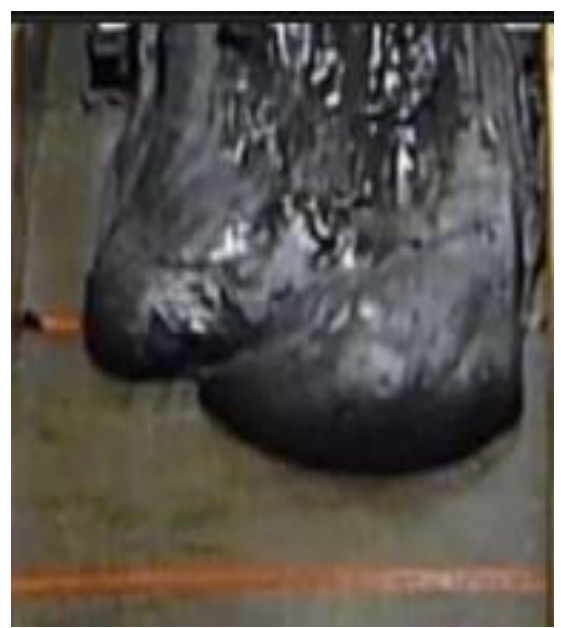

$\mathbf{w}=\mathbf{5 5} \alpha=\mathbf{3 0}^{\circ}$

Figure 3-17 Comparison of flow profile at different water content (WV sample)

In the process of deriving the velocity profile, the thickness of the solid plug needs to be determined at different water content. As mentioned before, the coal slurry at higher water content could be considered as Newtonian fluid due to the negligible yield stress. Therefore, the plug-like region as shown in Figure 3-7 (at water content of 82\%) can hardly be observed. As water content decreasing, the coal slurry gradually became more viscous and thicker. The solid region on the top part of the flow was clearly observed. As shown in Figure 3-17, the thickness of solid plug increased as the water content reduced. In reality, however, the determination of velocity distribution of non-Newtonian fluid is quite complicated due to various affecting factors. In addition, identification of yield surface as the flow evolves is one of the most complicated problems associated with the Bingham plastic fluid (Liu, 2003). In the past few decades, quite a lot of studies have been conducted associating with the velocity distribution of non-Newtonian fluid. Different analytical and numerical models have been built by Oldroyd (1947), De Kee et al. (1990), Abdali et al. (1992), Mitsoulis et al. (1993), Wilson and Taylor (1996) and Balmforth et al. (2002). The 
flow behavior was also studied based on the experimental observation (Kozicki and Tiu 1986; Chhabra and Richardson 2008; Haldenwang et al. 2010). Haldenwang et al. (2012) and Kotze (2007) obtained the extensive experimental results on the velocity profile of non-Newtonian fluid by using Ultrasonic Velocity Profiling (UVP) technique. However, significant variations were observed in the results of these models and experiments.

\subsubsection{Relationship between Flow Velocity and Viscosity}

As mentioned in the previous sections, the viscosity of coal refuse behaves as a resistant force during the movement of the flow and therefore largely influences the flow velocity. In terms of the Bingham Plastic model in this study, the representative flow velocity in this study is selected from maximum velocity on the free surface during the midstream of the flow which could be considered as a constant. At lower water content, the flow velocity became quite slow and only short travel distance was observed. It was difficult to clearly identify the acceleration, lasting, and deceleration processes of slurry flow. The mean velocity was thereby used as an alternative of the representative flow velocity at the lower water content.

In general, the flow failure of coal tailings impoundments occurs at extremely high shear rate. The representative viscosities at different initial water content were thereafter determined based on the measured viscosities at high shear rate which were found to approach constant values (see Figure 3-11 and Figure 3-12). The defined representative viscosities were used as the plastic viscosities in the Bingham Plastic model. 


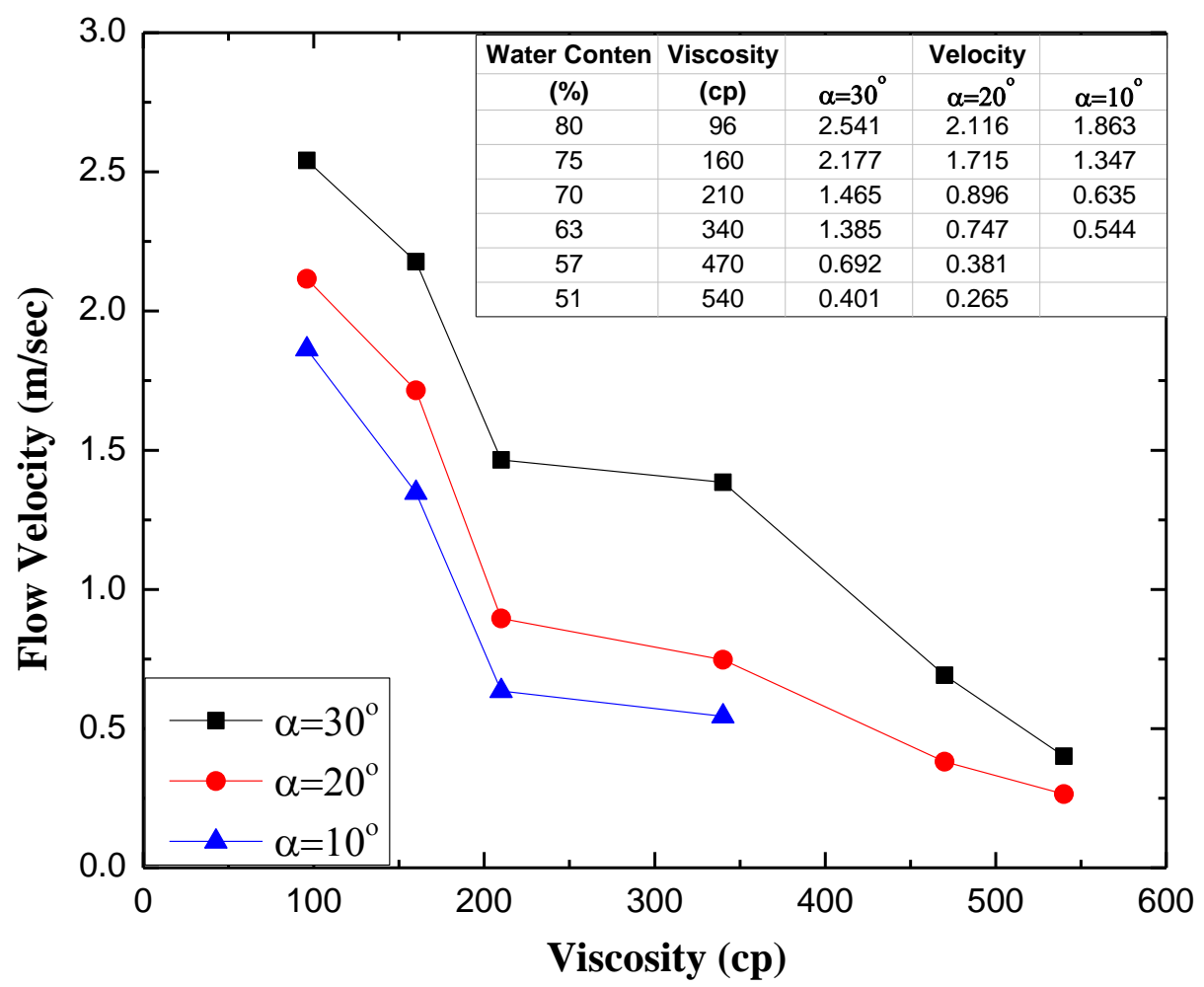

Figure 3-18 The relationship between flow velocity and viscosity of KY sample

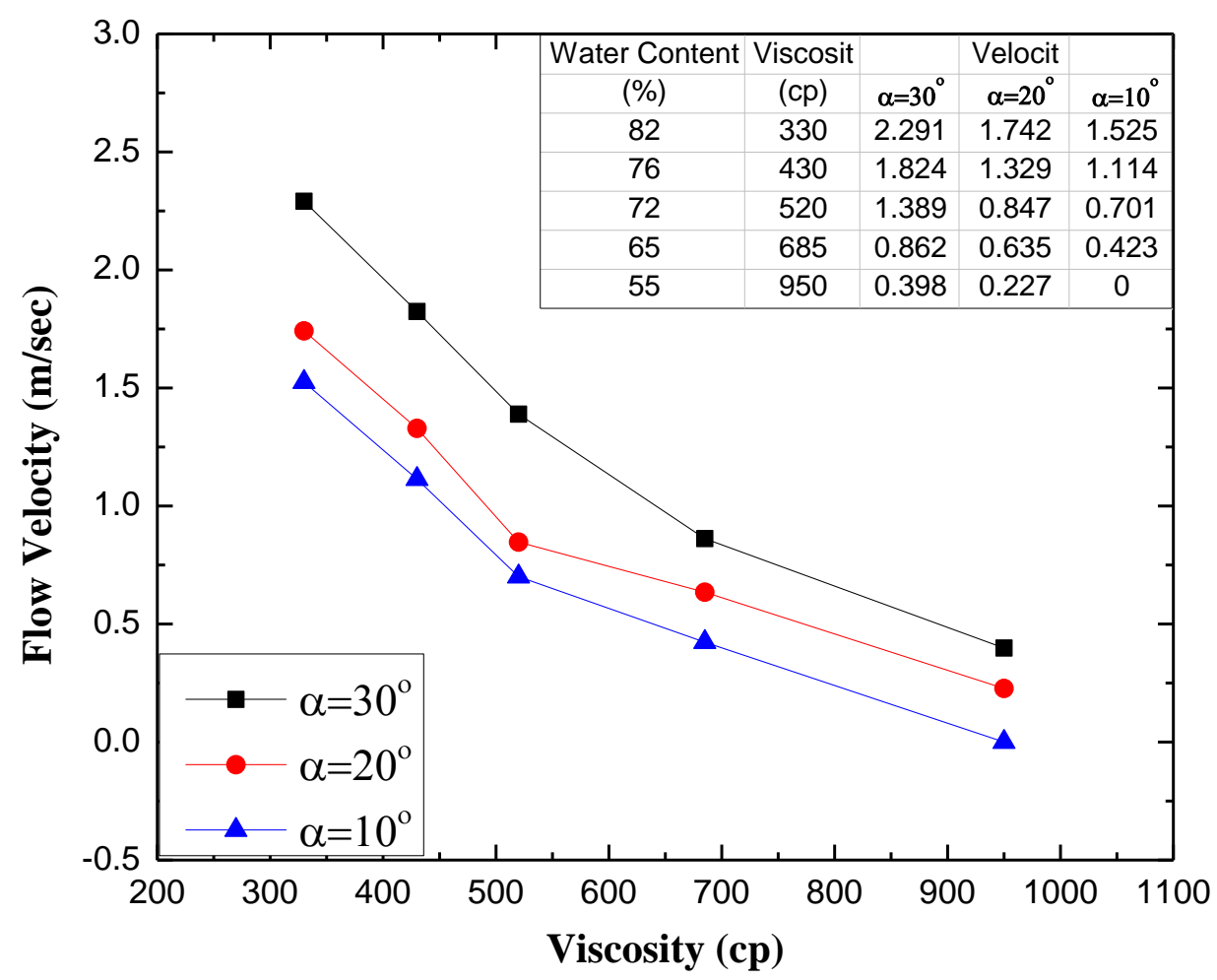

Figure 3-19 The relationship between flow velocity and viscosity of WV sample 
The relationships between flow velocity and viscosity of two representative coal refuse samples were established in Figure 3-18 and Figure 3-19 respectively. It was apparently found that the flow velocity decreased with viscosity and varied from approximately $2.5 \mathrm{~m} / \mathrm{sec}$ to less than $0.5 \mathrm{~m} / \mathrm{sec}$ at the slope angle of $30^{\circ}$. In addition, the WV coal refuse sample exhibited more linear relationship between flow velocity and viscosity. Providing sufficient flow test data, an empirical equation might be established between flow velocity and viscosity so that the degree of damage caused by the flow failure of the tailings dams could be estimated according to the known viscosity of the impounded coal refuse.

In addition to the properties of coal refuse itself, many other factors also have evident impact on the flow velocity. For example, the volume (or weight) of impoundment would also influence the flow velocity of coal refuse. The peak flow velocity was found to increase with the gravitational stress by Kailey et al., 2011. However, the peak velocity would not increase infinitely and would remain a constant as the weight of flowable coal refuse continues increasing. In addition, the effect of increased volume of coal refuse was far less significant than that of increased water content (Kailey et al., 2011). Jeyapalan et al. (1983) indicated that the flow velocity would be different when the fluid flows across the planes and prismatic valleys with different cross sections. The shape factors were defined in the open channel investigations by Straub et al. (1958) and Kozicki and Tiu (1967). The velocity profile of laminar Bingham plastic fluids was found to be affected by the presence of surface roughness when the fluid flowing through channels (Tani, 1969; Mekle et al., 1974; and Engin et al., 2004). Due to the limited quantity of coal refuse 
samples, the effects of these factors on the flow velocity of coal refuse did not included at this stage of study.

\subsection{Test Results and Analysis under Impact Loading}

The impact loading such as the blast loading has inverse effects on the stability of tailings dams. A single blast will generate a high frequency and high intensity compressive stress wave in quite short duration. In the event of impact loading, excess pore water pressure in the fine refuse can quickly build up and cause a severe reduction in the strength of the material. In practical, the duration and magnitude of blast loading could be considered as a function of the charge size, embedded depth of charge and the distance from the charge (Lyakhov, 1961; Melzer, 1978; and Fragaszy et al., 1983). The effects of blast loading on the surrounding soil also depends on the soil properties such as degree of saturation, particle size and shape, compressibility, permeability, and initial effective stress of ground soils (Florin and Ivanov, 1961; Kurzeme, 1971; Studer and Prater, 1977; Damitio, 1977; Rischbieter, 1977; Studer and Kok, 1980; Ivanov et al., 1981; and Hubert, 1986). In the worst scenario, liquefaction of the fine coal refuse would change the material into a heavy viscous fluid producing a large pressure increase on the embankment. Therefore, it can be clearly seen that the tailings dams impounding fine refuse are susceptible of flow failure under the impact loading.

A group of small-scale model tests were performed in order to investigate the influence of impact loading on the flow behavior of coal refuse. The configuration of model test was shown in Figure 3-4 and the test procedures were introduced in detail in Section 3.2.2. The test started at lower initial water content at which the flow of coal refuse ceased 
under static loading. The flow parameters under impact loading were only measured at the slope angle of $30^{\circ}$ regarding to the weak flowability at lower water content. Since the range of pore pressure transducer was not suitable for 1-g test, the liquefaction of coal refuse was considered to occur when the single compressive strains greater than $0.01 \%$ for soils with low effective stresses and low relative densities and $1 \%$ for soils with high effective stresses and high relative densities (Charlie et al. 1982; Veyera 1985). In this study, the coal refuse samples were also tested at $5 \%$ compressive strain in order to observe more evident flow behavior under impact loading. A thin plate was placed on top of the coal refuse so that the mass dropping on the plate can generate uniformly distributed stress wave. A series of trial tests have been conducted by dropping masses with different weight from $80 \mathrm{~cm}$ above the contained coal slurry surface in order to achieve the designed compressive strains. The slight discrepancy caused by different water content could be neglected.

Table 3-13 The summarized test results of KY sample under impact loading $\left(\alpha=30^{\circ}\right)$ 


\begin{tabular}{|c|c|c|c|}
\hline Compressive Strains $\varepsilon$ & $\mathbf{0 . 1 \%}$ & $\mathbf{1 \%}$ & $\mathbf{5 \%}$ \\
\hline Weight & $0.3 \mathrm{~kg}$ & $0.8 \mathrm{~kg}$ & $1.5 \mathrm{~kg}$ \\
\hline Height & $80 \mathrm{~cm}$ & $80 \mathrm{~cm}$ & $80 \mathrm{~cm}$ \\
\hline & \multicolumn{3}{|c|}{ Water Content $\mathbf{w}=\mathbf{4 8 \%}$} \\
\hline Extent of Flow & 0 & $0.2 \mathrm{~m}$ & $0.34 \mathrm{~m}$ \\
\hline Flow Velocity & 0 & $0.007 \mathrm{~m} / \mathrm{s}$ & $0.026 \mathrm{~m} / \mathrm{s}$ \\
\hline & \multicolumn{4}{|c|}{ Water Content $\mathbf{w}=\mathbf{4 3 \%}$} \\
\hline Extent of Flow & 0 & 0 & $0.15 \mathrm{~m}$ \\
\hline Flow Velocity & 0 & 0 & $0.005 \mathrm{~m} / \mathrm{s}$ \\
\hline & \multicolumn{3}{|c|}{ Water Content $\mathbf{w}=\mathbf{3 8 \%}$} \\
\hline Extent of Flow & 0 & 0 & 0 \\
\hline Flow Velocity & 0 & 0 & 0 \\
\hline
\end{tabular}

Table 3-14 The summarized test results of WV sample under impact loading $\left(\alpha=30^{\circ}\right)$

\begin{tabular}{|c|c|c|c|}
\hline Compressive Strains $\varepsilon$ & $\mathbf{0 . 1 \%}$ & $\mathbf{1 \%}$ & $\mathbf{5 \%}$ \\
\hline Weight & $0.3 \mathrm{~kg}$ & $0.8 \mathrm{~kg}$ & $1.5 \mathrm{~kg}$ \\
\hline Height & $80 \mathrm{~cm}$ & $80 \mathrm{~cm}$ & $80 \mathrm{~cm}$ \\
\hline Extent of Flow & \multicolumn{3}{|c|}{ Water Content w=52\% } \\
\hline Flow Velocity & 0 & $0.15 \mathrm{~m}$ & $0.45 \mathrm{~m}$ \\
\hline \multirow{2}{*}{ Extent of Flow } & 0 & $0.005 \mathrm{~m} / \mathrm{s}$ & $0.048 \mathrm{~m} / \mathrm{s}$ \\
\hline Flow Velocity & 0 & 0 & $0.1 \mathrm{~m}$ \\
\hline & \multicolumn{3}{|c|}{ Water Content w=45\% } \\
\hline Extent of Flow & 0 & 0 & $\approx$ \\
\hline Flow Velocity & 0 & 0 & 0 \\
\hline
\end{tabular}




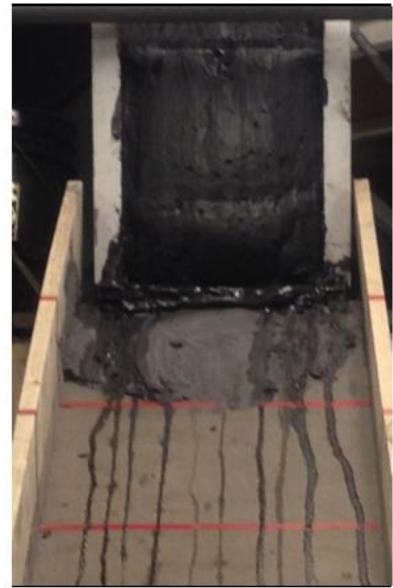

$\varepsilon=0.1 \%$

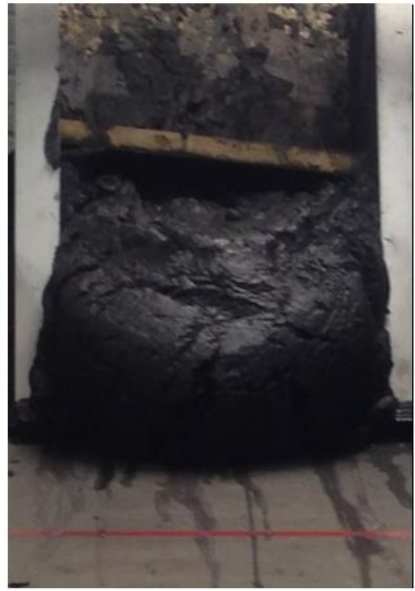

$\varepsilon=1 \%$

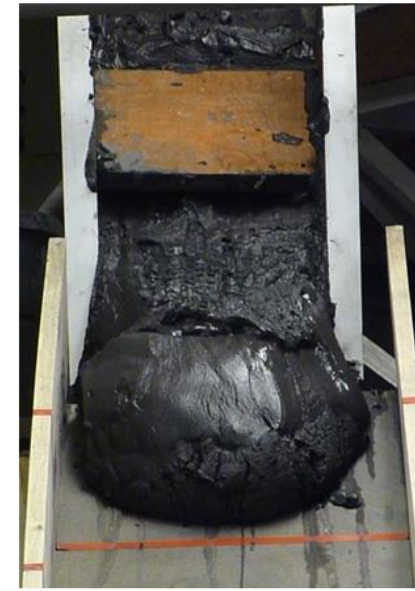

$\varepsilon=5 \%$

Figure 3-20 Results of impact loading tests on KY sample under different compressive strains $\left(\alpha=30^{\circ}, \mathrm{w}=48 \%\right)$
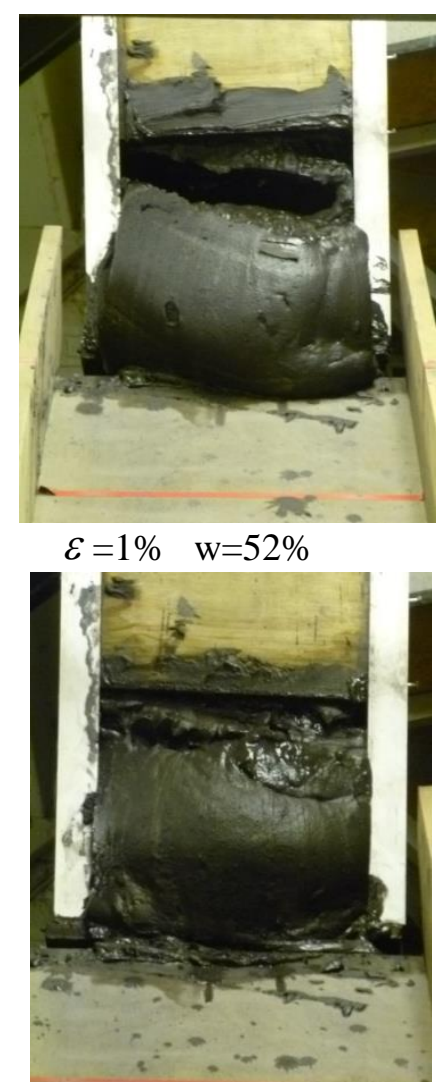

$\varepsilon=5 \% \quad \mathrm{w}=45 \%$

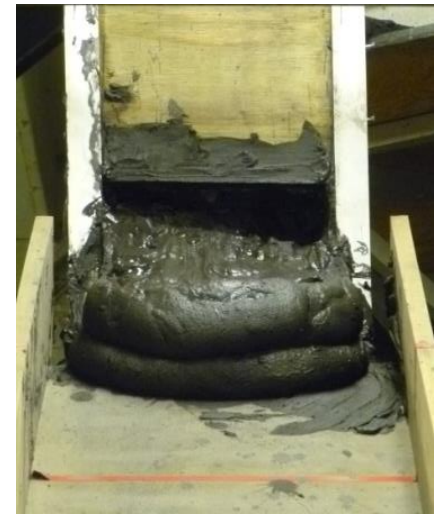

$\varepsilon=5 \% \quad \mathrm{w}=52 \%$

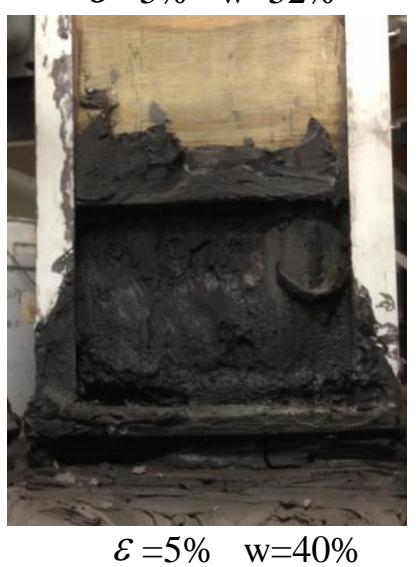

Figure 3-21 Results of impact loading tests on WV sample under different compressive strains $\left(\alpha=30^{\circ}\right)$ 
The results were summarized in Table 3-13 and Table 3-14 and graphically exhibited in Figure 3-20 and Figure 3-21 for the two coal refuse samples. For KY sample, the flow under static loading ceased at water content of $48 \%$ which was $10 \%$ higher than the liquid limit of 38.1. Under impact loading, no flow was observed at $0.1 \%$ compressive strain. Although small amount of water seeping out, the coal refuse sample still behaved as a solid. As shown in Figure 3-20, the flow was triggered when compressive strain reached $1 \%$. The solid coal refuse changed into very thick and viscous flow but travelled quite short distance of less than $0.3 \mathrm{~m}$. At $5 \%$ compressive strain, more significant liquefaction was observed. The flow seemed much thinner and smoother than that at $1 \%$ compressive strain. In addition, the flow travelled farther distance than under lower compressive strain. The effect of impact loading became insignificant as the water content lower than $43 \%$ with no apparent flow observed.

In terms of WV coal refuse sample, the flow under static loading ceased at $52 \%$ water content which was also approximately $10 \%$ higher than the liquid limit of 42.5 . The same as the results of KY sample, no flow took place under $0.1 \%$ compressive strain. The coal refuse sample seemed quite stiff under $1 \%$ compressive strain with a mass block slowly snapped and slipped down. As shown in Figure 3-21, more apparent flowability was observed at $5 \%$ compressive strain. The flow ceased when water content lower than $45 \%$ with only a slight plastic deformation at $5 \%$ compressive strain.

The small scale model tests under impact loading on the two representative coal refuse samples exhibited consistent results. More evident liquefaction and flow behavior of coal refuse was observed at the highest compressive strain of $5 \%$. However, it was difficult to estimate whether the saturated coal refuse sample was fully liquefied at $1 \%$ or 
$5 \%$ compressive strain without the using of pore pressure transducer. These results would be verified by comparing with the results of centrifuge model tests which was shown in the following chapter. Both samples exhibited sufficient resistance in impact loading at water content approximately $5 \%$ higher than the corresponding liquid limits. Based on the results under impact loading, it is recommended to keep the initial water content under the liquid limit in the design and construction of coal waste impoundment in order to improve the stability of impoundment under blast loading.

\subsection{Conclusion}

In this chapter, a group of small-scale model tests have been performed on the two representative coal refuse samples. The flow behaviors of coal refuse were studied under both static loading and impact loading. Based on the recorded results, the following conclusions could be drawn:

1) Quite consistent results were obtained from the two representative coal refuse samples.

2) Flow of coal refuse is a type of non-Newtonian fluid. Although there are many different non-Newtonian rheological models, the Bingham plastic model is considered to be the most suitable to represent the flow of impounded fine coal refuse.

3) The behavior of Bingham plastic flow is primarily governed by yield stress $\tau_{y}$ and plastic viscosity $\eta_{p}$. In terms of shear stress - shear rate curve, the plastic viscosity is taken as the slope of linear portion of curve at high shear rate while the yield stress is taken as the point where the projection of this linear portion of the curve intersects the shear stress axis. 
4) At higher water content, the yield stress was extremely small. Therefore, the flow of coal refuse at high water content could be considered as Newtonian fluid whose flow properties are largely dependent on the viscosity.

5) The coal refuse flow under the maximum initial shear stress (or at the maximum slope angle) had the fastest velocity.

6) Under the static loading, the flow velocities and travel distance of coal refuse gradually decreased as the initial water content and slope angle reduced. The flow of two coal refuse samples ceased at water content approximately $10 \%$ higher than the corresponding liquid limits.

7) By studying the flow regime, the coal refuse flow (in the midstream where the flow velocity of coal refuse keeps a constant value) could be considered as a uniform, steady, laminar flow.

8) The obtained profile of coal refuse flow could be described as a solid plug region near the free surface of the flow and underlain by a viscous fluid with a parabolic distribution of flow velocity. As initial water content reduced, the solid plug region near the free surface of flow became more evident.

9) The viscosity could be considered as a resistance or frictional force within the moving flow which would greatly influence the flow velocity. The higher viscosity at lower water content resulted in slower flow velocity.

10) The blast loading was simulated by dropping a mass from designed height. Without pore pressure transducer, the liquefaction was assumed to take place according to the compressive strain. 
11) The coal refuse flow was triggered by impact loading as the compressive strain greater than $1 \%$. The liquefied coal refuse was changed into a heavy viscous fluid.

12) The coal waste impoundment with initial water content below liquid limit should have sufficient resistance to the static loading and dynamic impact disturbance. This conclusion would provide a significant criterion to the design and construction of tailings dams. 


\section{Chapter 4 ANALYSIS OF FLOW BEHAVIOR OF COAL REFUSE BY CENTRIFUGE MODEL TESTS}

\subsection{Introduction}

As flow failure of tailings dams takes place, million tons of impounded coal refuse flow into the valley or break through into nearby underground mine workings and subsequently breakout into surface waterways. The viscous flow under high stress field would travel several kilometers distance in just a few minutes and result in significant loss of lives, property damages, and environmental and eco-system issues.

A number of laboratory tests related to the rheological properties of coal tailings and other non-Newtonian fluids have been performed in the past decades (Zhang and Ren, 1982; Jeyapalan, 1983; Shook and Roco, 1991; Coussot, 1994; Haldenwang, 2003; Henriquez et al., 2009). However, the measured results were found to exhibit significant discrepancy and might only qualitatively reflect the flow characteristics of coal refuse due to the limited quantity of specimen and low stress field. Although quite a few of flow failure of tailings dams have been reported since the instability problem of mining waste was first realized by Casagrande (1950), there is not enough data recorded about the flow behavior of the coal refuse. Therefore, it is quite difficult to analyze the realistic mechanical properties and flow behavior of this material.

The geotechnical centrifuge provide an effective solution to the scale modeling of any large-scale nonlinear problem for which gravity is a primary driving force. The centrifuge enables a small model to be subject to the same effective stress as a full scale prototype and makes it possible to obtain accurate data to solve complex problems such as 
seismic-induced liquefaction; strength, stiffness, and bearing capacity of foundations and other geo-infrastructures; and rheological characteristics of different types of fluids.

In this chapter, a group of centrifuge model tests have been performed on the two coal refuse samples collected from Kentucky and West Virginia in order to study their flow properties under the prototype stress field and to generate realistic physical data to verify an engineering countermeasure by using coarse refuse build "slurry cell". A special container was designed to conduct flow tests under static loading and dynamic impact loading. The results would also be compared with those measured in the small-scale model tests to identify whether the stress field (or the volume of impoundment) would greatly influence the flow behavior of coal refuse.

\subsubsection{Review of Geotechnical Centrifuge Test}

Centrifuge modeling provides a useful and powerful experimental tool for the study of complex geotechnical problems. The original idea of performing geotechnical centrifuge tests, proposed in 1869 by Phillips in Paris, France (Craig, 1995), is to increase self-weight of a small scale model. Phillips derived the similitude relationship between prototype and small scale model by using the equilibrium differential equations for elastic solids, and suggested using inertial forces and more particularly the centrifugal force in the case that the gravity is a major factor in the equilibrium of those solids (Taylor, 1995). The centrifuge modelling was not widely studied until Bucky (1931), who first performed centrifuge model tests in the United States on the integrity of mine roof structures in rock, and Pokrovsky and Davidenkov (Ng, 2014), who investigated the instability of embankment and slope through centrifuge modelling in 1933. Between 1940s and 1960s, a number of 
geotechnical centrifuges have been developed in the Union of Soviet Socialist Republics (USSR) and applied to the geotechnical problems and stress analysis in the soils and rocks. In 1969, the International Society for Soil Mechanics and Foundation Engineering held its seventh conference in Mexico. Technical papers related to the centrifuge modelling were first published since 1936 (Avgherinos and Schofield, 1969; Mikasa et al., 1973; and TerStepanian and Goldstein, 1969). A rapid advance was commenced right after the conference in the knowledge of the technology of centrifuge modelling as well as the development of modeling techniques with associated instruments (Taylor, 1995). The first geotechnical centrifuge in the UK was developed by Professor Andrew N. Schofield at Cambridge University in 1966 (Schofield, 1980). Prof. Schofield also played a key role in modern development of centrifuge modeling. Four international special conferences (Centrifuge $88,91,94,98$ ) and eight international physical modeling conferences (ICPMG) have been organized so far and provided useful source of references for the state of the art and information on the application of geotechnical centrifuge modeling and the advancement of the techniques and instruments.

In the past four decades, considerable progress has been made on the centrifuge modelling technique. Nowadays, centrifuge modeling has been widely recognized and used in many countries. There are now over 50 geotechnical centrifuges in operation in the world. Recent development in modeling technique and the results of many research projects using centrifuge testing were reported by Craig (1984), Corte (1988), Ko and McLean (1991), Leung et al. (1994), Taylor (1995), Kimura et al. (1998), and Phillips et al. (2002). Data from centrifuge tests can be used to study the mechanism of complex problems in 
geotechnical engineering, to validate numerical procedures when field data is lacking, and verify new design concepts when existing standard design procedures are inadequate.

\subsubsection{Scaling Law}

The centrifuge applies an increased gravitational acceleration to the physical models in order to produce identical self-weight stress in the model and prototype. In other words, the small scale model and full scale prototype should have the same stress and strength at the corresponding positions. This objective can be mathematically stated as:

$$
\sigma^{*}=\frac{\sigma_{\text {model }}}{\sigma_{\text {prototype }}}=1
$$

where the asterisk on a quantity denotes a scaling factor for that quantity, i.e. the ratio of the quantity in the model to the quantity in the full scale prototype.

In soil mechanics, the total vertical stress at a depth of $\mathrm{H}$ in a uniform soil layer could be calculated by:

$$
\sigma_{\mathrm{t}}=\rho g \mathrm{H}
$$

Where

$$
\begin{aligned}
& \sigma_{t}=\text { total vertical stress at depth } \mathrm{H} \\
& \rho=\text { mass density of the layer } \\
& g=\text { gravity acceleration }
\end{aligned}
$$

In the conventional form of centrifuge modeling (Garnier et al., 2007), the same materials are prepared at the same mass density $\rho^{*}=1$ so as to ensure the similar behavior in the model and prototype. 
The equivalence relationship illustrated in Figure 4-1 could thereafter be established based on Equation 4-1 and Equation 4-2:

$$
\rho g \mathrm{H}_{\mathrm{p}}=\rho g \mathrm{NH}_{\mathrm{m}}
$$

Where

$\mathrm{H}_{\mathrm{p}}=$ corresponding height in the prototype

$\mathrm{H}_{\mathrm{m}}=$ corresponding height in the model

$\mathrm{N}$ = scaling factor

The subscript $\mathrm{p}$ and $\mathrm{m}$ represent prototype and model, respectively.

By cancelling the identical items in Equation 4-3, the scaling factor for linear dimension could be obtained as:

$$
\mathrm{L}^{*}=\frac{\mathrm{H}_{\mathrm{m}}}{\mathrm{H}_{\mathrm{p}}}=\frac{1}{\mathrm{~N}}
$$

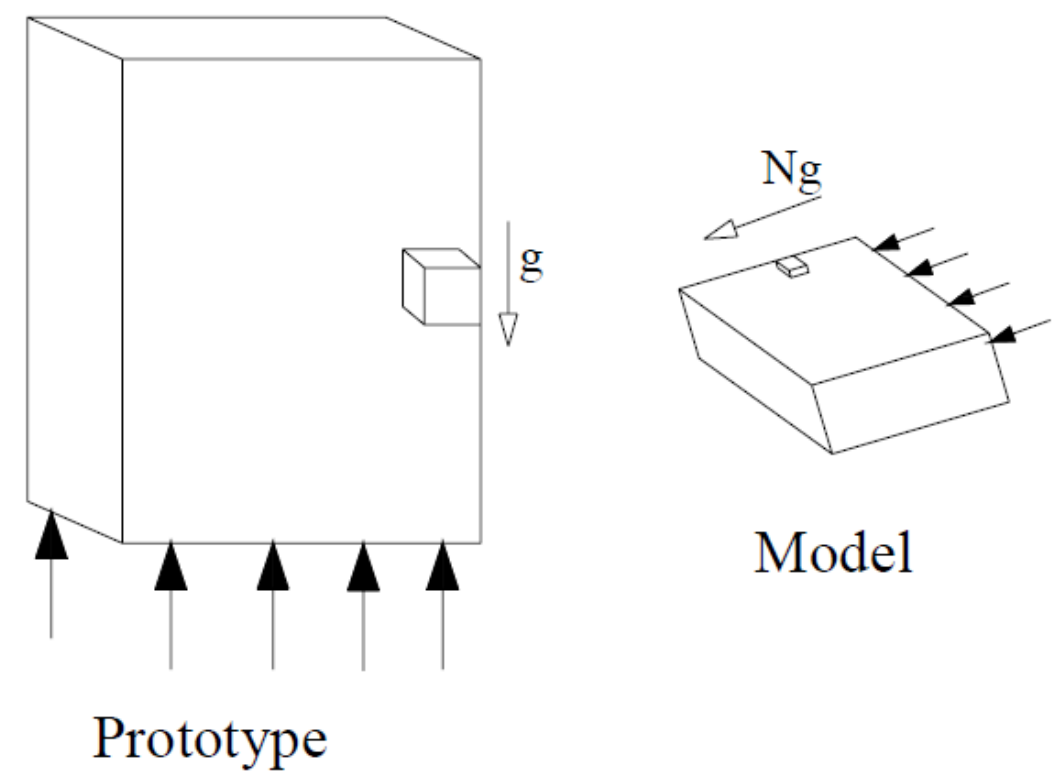

Figure 4-1 Gravity effects in prototype and model (after Schofield, 1980) 
Scaling factors for many other quantities can be derived from the above relationships. The commonly-used scaling factors for centrifuge testing have been summarized in Table 4-1 (Kutter, 1992).

Table 4-1 Scaling relationship for centrifuge test ( $\mathrm{N}$ : scaling factor)

\begin{tabular}{|c|c|c|}
\hline Quantity & Prototype & Model \\
\hline Length & $\mathrm{N}$ & 1 \\
\hline Area & $N^{2}$ & 1 \\
\hline Volume & $N^{3}$ & 1 \\
\hline Velocity & 1 & 1 \\
\hline Acceleration & 1 & $\mathrm{~N}$ \\
\hline Mass & $N^{3}$ & 1 \\
\hline Force & $N^{2}$ & 1 \\
\hline Stress & 1 & 1 \\
\hline Strain & 1 & 1 \\
\hline Mass Density & 1 & 1 \\
\hline Time (Dynamic) & $\mathrm{N}$ & 1 \\
\hline Time (Diffusion) & $N^{2}$ & 1 \\
\hline Frequency & 1 & $\mathrm{~N}$ \\
\hline
\end{tabular}


There might be ambiguity related to the different scaling factors of time in the consolidation situation and dynamic situation. Considering the basic equation in the dynamic problem:

$$
\mathrm{L}=\frac{1}{2} \mathrm{at}^{2}
$$

Where

$\mathrm{L}=$ distance of an accelerating mass moved within certain time

$\mathrm{a}=$ acceleration

$\mathrm{t}=$ time

Therefore, the scaling factor of time in the dynamic situation is:

$$
\mathrm{t}^{*}=\sqrt{\frac{\mathrm{L}^{*}}{\mathrm{a}^{*}}}=\sqrt{\frac{1 / \mathrm{N}}{\mathrm{N}}}=\frac{1}{\mathrm{~N}}
$$

The duration of the dynamic event in the model is $\mathrm{N}$ times less than that in the full scale prototype.

While in the case of consolidation event, the time factor is given that:

$$
\mathrm{T}_{\mathrm{V}}=\frac{\mathrm{C}_{\mathrm{v}} \mathrm{t}}{\mathrm{H}_{d r}{ }^{2}}
$$

Where

$\mathrm{T}_{\mathrm{V}}=$ time factor

$\mathrm{C}_{\mathrm{V}}=$ coefficient of consolidation

$H_{d r}=$ maximum drainage path

The scaling factor of time could be obtained as:

$$
\mathrm{t}^{*}=\frac{\mathrm{T}_{\mathrm{V}}{ }^{*} \mathrm{H}^{* 2}}{\mathrm{C}_{\mathrm{V}}{ }^{*}}=\frac{\mathrm{H}^{* 2}}{\mathrm{C}_{\mathrm{V}}{ }^{*}}
$$


If the specimen and pore fluids used in the model tests are the same as those in the prototype, the coefficient of consolidation equals to one. And the scaling factor of time thereafter becomes:

$$
\mathrm{t}^{*}=\mathrm{H}^{* 2}=\frac{1}{\mathrm{~N}^{2}}
$$

The duration of the consolidation in the model is $N^{2}$ times less than that in the full scale prototype, which conflict with the scaling factor of time in the dynamic situation. Regarding to the centrifuge model tests under dynamic loading (such as earthquake, ice, wind and blast), both dynamic and consolidation (including the dissipation of generated excess pore water pressure under dynamic loading) events play significant roles in determining the dynamic soil responses. In some case, the built-up of pore water pressure may not be observed due to the rapid diffusion.

It is impossible to separate the dynamic effect and diffusion effect in one dynamic centrifuge modeling test. The most common solution is to slow down the rate of diffusion by reducing coefficient of consolidation $\mathrm{C}_{\mathrm{v}}$ by $\mathrm{N}$ times. Recalling the expression of $C_{v}=\frac{k}{m_{v} \gamma_{w}}$ in Equation 2-1, the value of coefficient of consolidation is proportional to the hydraulic conductivity of soils. According to the equation given by Taylor D.W.:

$$
k=D_{s}^{2} \frac{\gamma_{w}}{\eta} \frac{e^{3}}{1+e} \frac{c_{s}}{36}
$$

Where

$$
\begin{aligned}
& D_{s}=\text { effective grain diameter } \\
& \eta=\text { viscosity of pore fluid } \\
& \mathrm{e}=\text { void ratio of soil }
\end{aligned}
$$




$$
c_{s}=\text { shape factor }
$$

Provided that same soil used in the model test as in the prototype, the reduction of coefficient of consolidation could be realized by increasing the viscosity of pore fluid by $\mathrm{N}$ times.

Liu (2009) performed comprehensive literature review on the viscous fluids used as the alternative of water in the centrifuge modeling tests. The commonly used viscous fluids include silicone oil, Glycerin-water mixture and Methycellulose. The advantages and limitations of these pore fluids have been discussed by Kutter (1995), Zeng et al. (1998) and Ko and Dewoolkar (1998). The silicone oil was first used at Cambridge University twenty years ago (Steedman and Zeng, 1990; and Madabhushi, 1994). At present, silicone oil is not widely used due to its deleteriousness and difficulties in cleaning and disposal. Glycerin-water mixture have been used by Whitman and Lambe (1988), Whitman and Ting (1993), and Liu and Dobry (1994). Zeng et al. (1998) found the clogging of such fluid in the soil deposit with relatively high density. In addition, the density of Glycerin-water mixture is quite different from the pure water, which makes the hydraulic conductivity in Equation 4-10 not only depend on the viscosity. The Methylcellulose water mixture is considered to be one of the most popular viscous fluids in the centrifuge tests (Kimura, 1993; Ko et al., 1998; and Stewart et al., 1998). Its suitability is largely attributed to its easy preparation and cleaning, identical density as pure water, and ready availability.

In this study, pure water rather than other viscous fluids was used in the centrifuge modeling test under the impact loading. The primary concern is associated with the factor that the flow behavior would be greatly changed if viscous fluid be employed. In addition, the development and dissipation of pore pressure under dynamic impact loading could be 
clearly observed in the centrifuge tests without using the viscous fluids. The centrifuge modeling tests were conducted at $50 \mathrm{~g}$ centrifugal acceleration. If a viscous fluid is employed with viscosity 50 times of pure water, the duration of pore pressure dissipation would be prolonged by 50 times. The existing data acquisition in the centrifuge may not record that huge number of data points so that it would hardly observe and analyze the whole process of excess pore pressure (buildup-maintaining-dissipation).

\subsection{Facilities and Instrumentation}

\subsubsection{Centrifuge}

The centrifuge modeling tests were conducted on the geotechnical centrifuge at Case Western Reserve University (CWRU) which is shown in Figure 4-2. The centrifuge has been used in various projects associated with earthquake analysis, environmental hazard mitigation and advanced infrastructure geo-technology. As shown in Figure 4-3, the CWRU centrifuge has dual platforms with a radius of $1.37 \mathrm{~m}$. The payload capacity is $20 \mathrm{~g}$ ton with a maximum acceleration of $200 \mathrm{~g}$ for static tests and $100 \mathrm{~g}$ for dynamic tests. The centrifuge arm is balanced by adjusting the counterbalance weights on the opposite swing

platform. The centrifuge has a 16 channels data acquisition system. The laboratory is equipped with transducers such as LVDTs, accelerometers, and pore pressure transducers. The rigid modeling container (see Figure 4-4) has been commonly used in many centrifuge tests with the inside dimensions of $53.3 \mathrm{~cm}($ length $) \times 24.1 \mathrm{~cm}($ width $) \times 17.7 \mathrm{~cm}($ height $)$. 


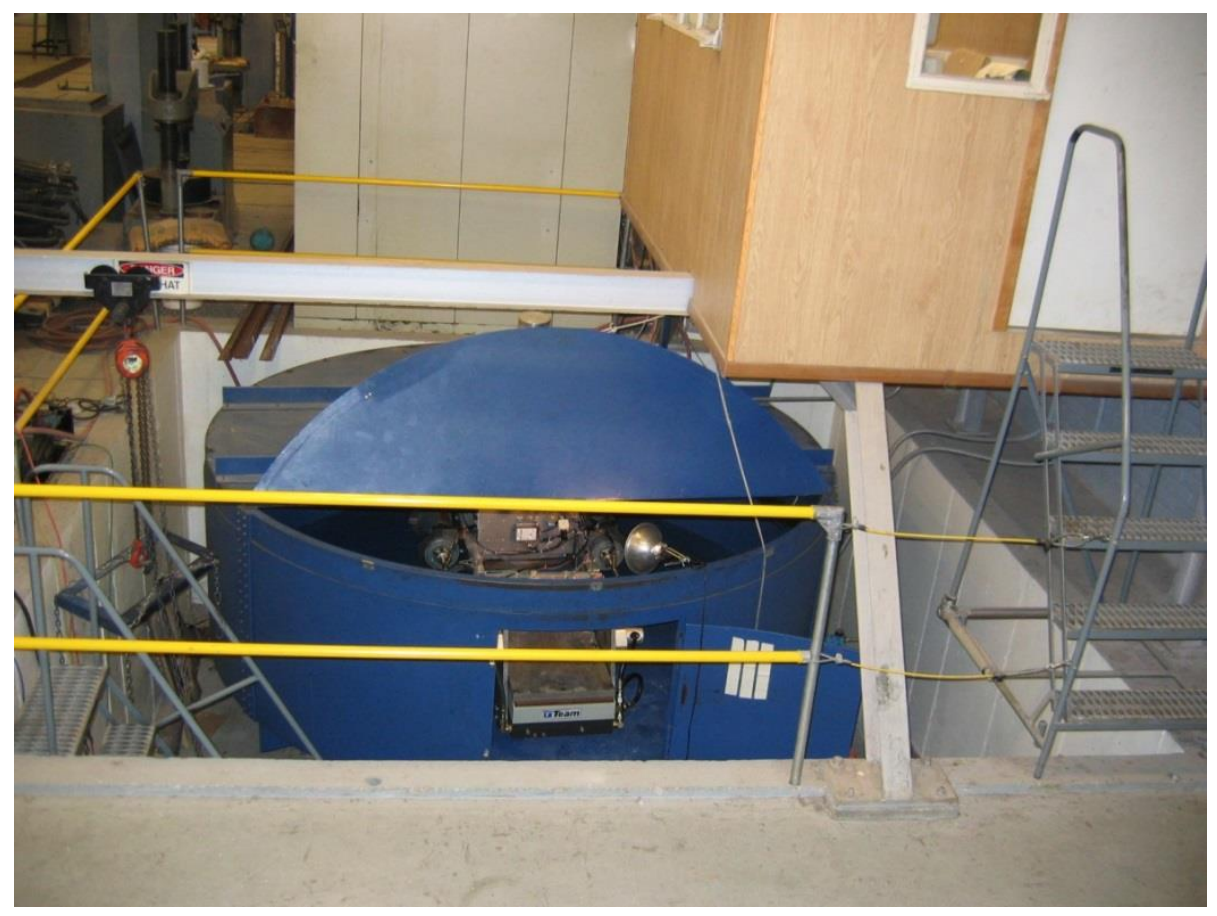

Figure 4-2 CWRU geotechnical centrifuge lab

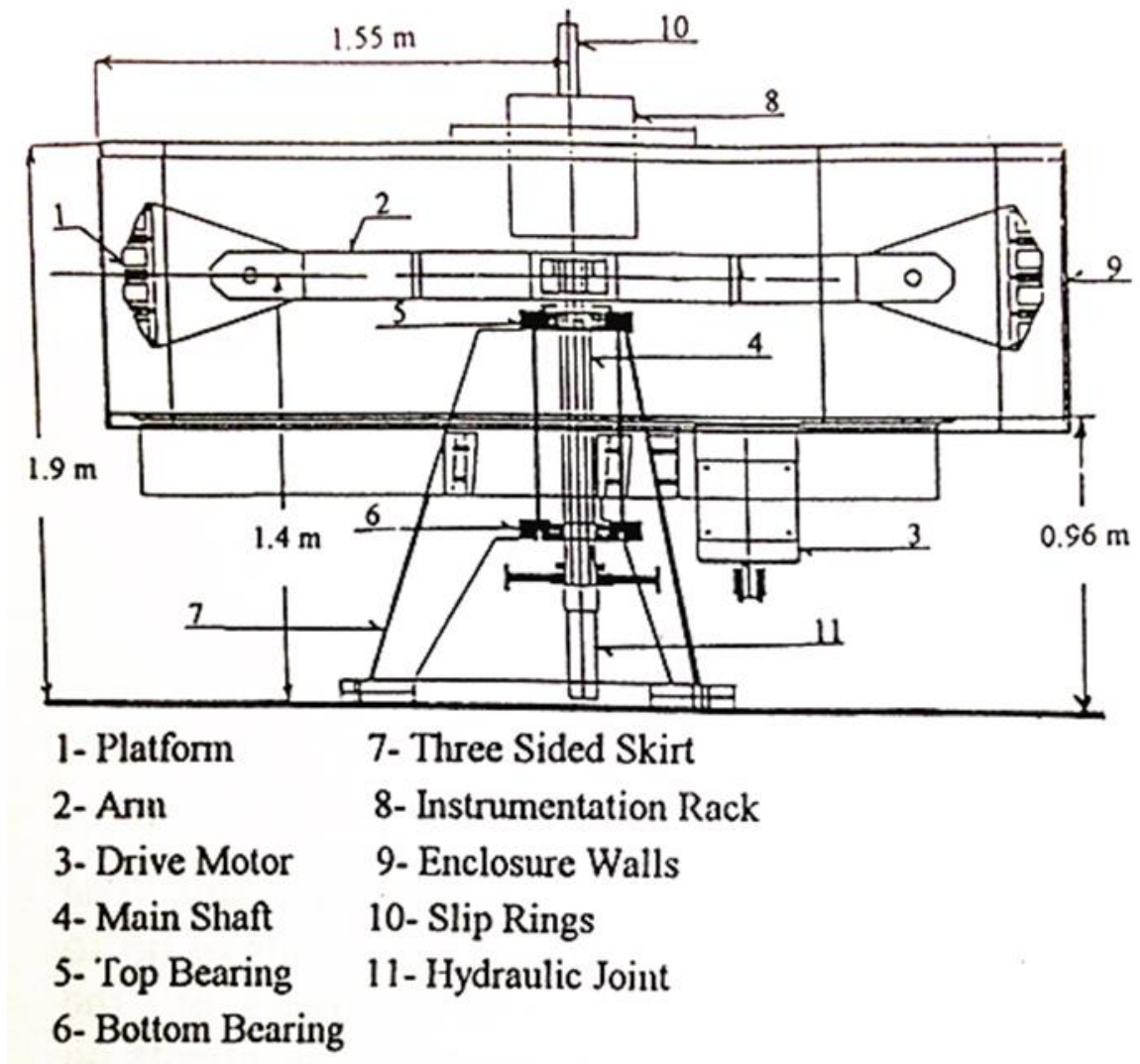

Figure 4-3 Cross-sectional view of CWRU centrifuge (after Figueroa et al., 1998) 


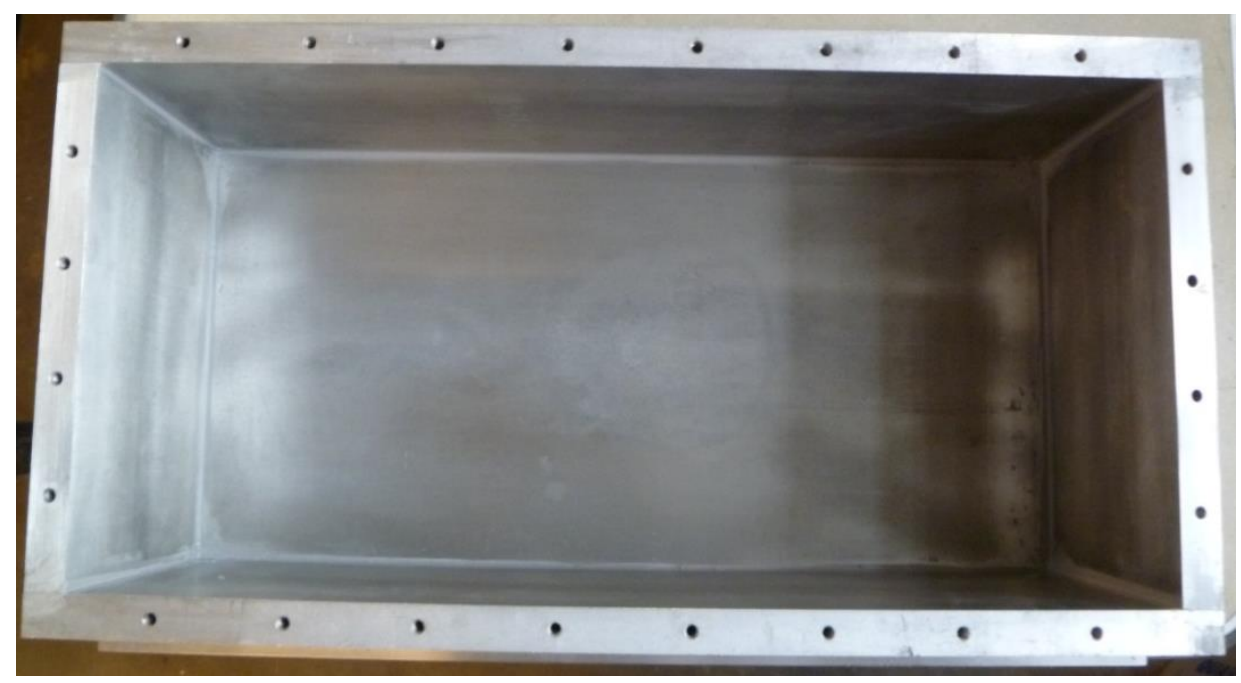

Figure 4-4 Rigid box on the CWRU geotechnical centrifuge

\subsubsection{Pore Pressure Transducers}

The pore pressure transducer used in CWRU centrifuge modeling test are Druck model PDCR81. They are cylindrical with a diameter of $5.8 \mathrm{~mm}$ and a length of $11.4 \mathrm{~mm}$. The transduction is performed by a silicon diaphragm with a strain gauge bridge diffused into the surface. Pore pressure reaches the diaphragm through a porous stone with a 2 micron filter grade. The specifications are listed as Table 4-2.

Table 4-2 Pore Pressure Transducer PDCR81 (Source: GE Sensing)

\begin{tabular}{|c|c|}
\hline Model No. & PDCR81 \\
\hline Mechanical Shock & $1000 \mathrm{~g}$ for $1 \mathrm{~ms}$ \\
\hline Resolution & Infinitely small \\
\hline Sensitivity & $0.16 \mathrm{mV} / \mathrm{V} / \mathrm{psi}$ \\
\hline Temperature Range & $-20^{\circ} \mathrm{C}-120^{\circ} \mathrm{C}$ \\
\hline Weight & $2 \mathrm{~g}$ \\
\hline Size (Length $\times$ Diameter) & $11.4 \times 5.8 \mathrm{~mm}$ \\
\hline
\end{tabular}




\subsubsection{Flow Container for Centrifuge Test}

As shown in Figure 4-5 and Figure 4-6, a special model container has been designed for the centrifuge flow tests with the dimensions of $44 \mathrm{~cm}$ (length) $\times 15 \mathrm{~cm}$ (width) $\times 44$ $\mathrm{cm}$ (height) so that the container could be put inside of the rigid box shown in Figure 4-4. About one gallon coal slurry sample was contained in the upper right part of the container. The slope and the camera mount could be adjusted with three different angles.
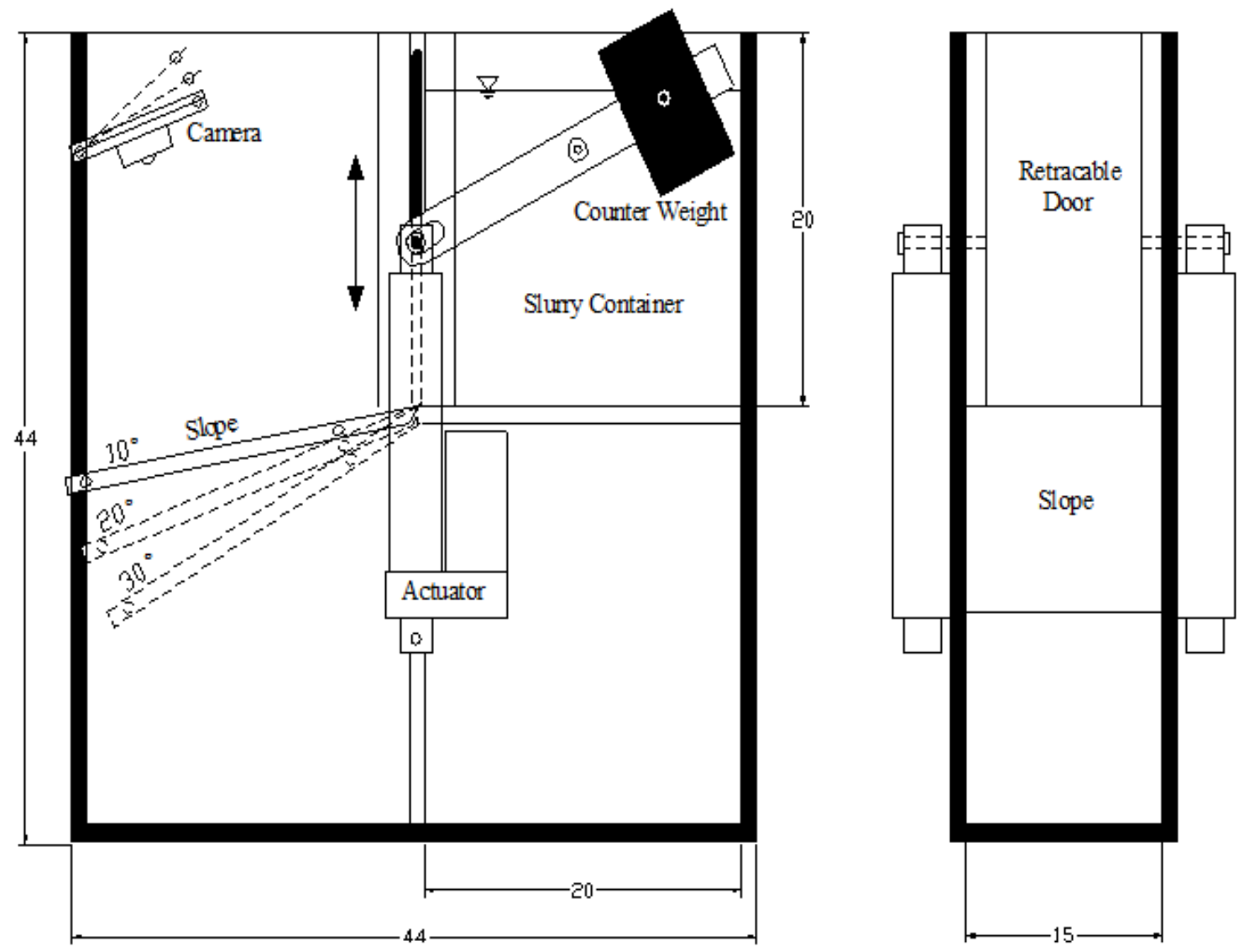

Figure 4-5 The design drawing of model container for centrifuge test (unit: $\mathrm{cm}$ ) 

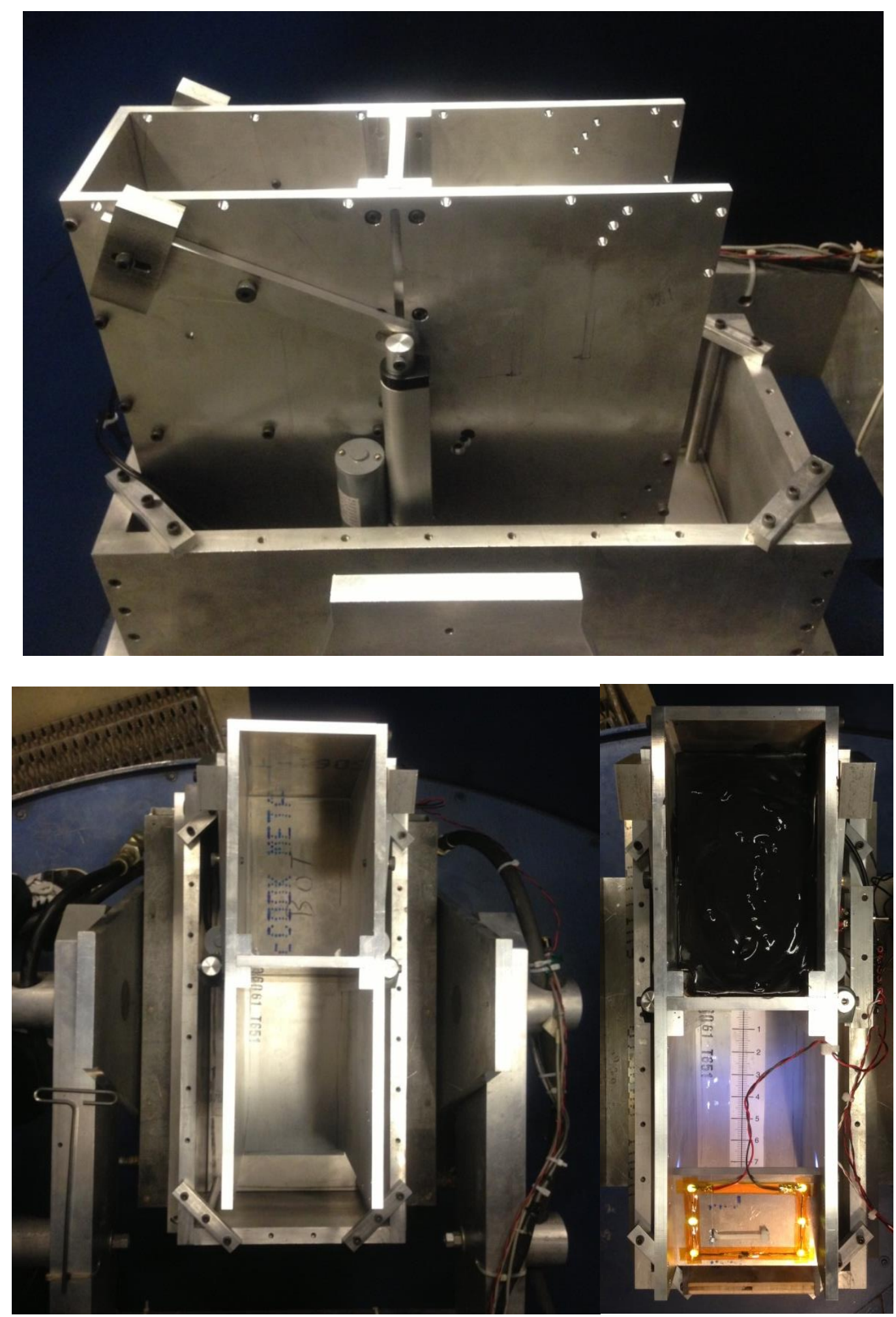

Figure 4-6 The flow container in the centrifuge test 
The procedures and measurements in the centrifuge test were the same as those in the small scale test. Since the centrifuge test was conducted under 50 gravitational acceleration, some detailed designs were concerned regarding to the potential issues under such a high stress field. The challenges were primarily related to the following three aspects: 1) How to open/close the door during the test and whether the door will be opened under high stress field; 2) How to prevent the leakage during the test; and 3) How to generate the impact loading.

Based on the rough estimation of static earth pressure exerted behind the door and the induced friction during opening, two actuators (FA-150-S-12-4) produced by Firgelli Automations were selected to lift the door. As shown in Figure 4-7, each actuator has 4" stroke length and can withstand 150lbs push/pull force. The speed can reach $0.5 \mathrm{in} / \mathrm{sec}$ under 12 VDC. The actuators are mounted on the two sides of the container and work at the same time. To ensure the door opening at $50 \mathrm{~g}$, a lumped mass is added on each side of the container to counter the weight of the door and some part of the friction force. The details are graphically shown in Figure 4-5.
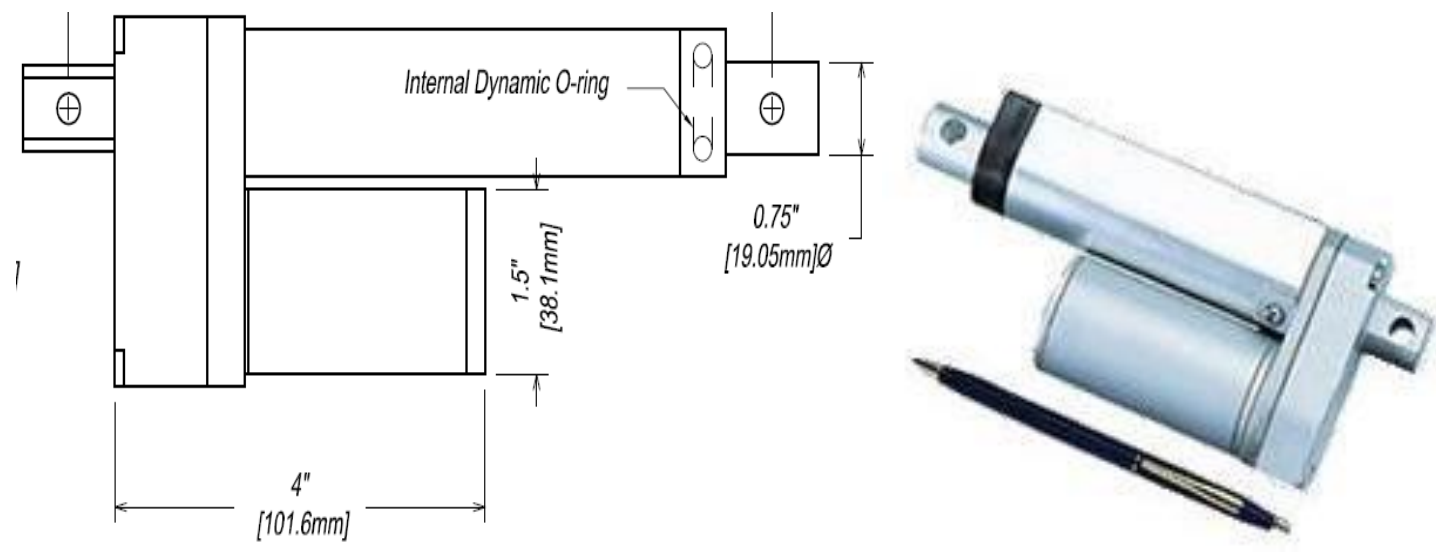

Figure 4-7 Actuator used in the centrifuge test 
In order to prevent the leakage under high stress filed, the connections and joints were all coated with silicone rubber adhesive sealant when assembling the model container. Besides, a thick layer of grease needs to be applied on the sides and bottom of the door before filling with slurry sample. By taking these approaches, a couple of trial tests were successfully conducted without any leakage under $50 \mathrm{~g}$. The door could be opened smoothly and then closed as the flow ceased.

One of the greatest challenges in designing the centrifuge model test was related to the generation of impact loading. Quite a number of issues have been encountered during the model container design which included how to hold the weight before dropping; how to release the weight; and how to let the weight fall down at the designed location. By comparing various techniques and methods, the electromagnet method was selected due to its safety and effectiveness. As centrifuge reaches designed gravitational acceleration, the mass is released by shutting the magnet power. The surface-contact of electromagnet has 2 inch diameter and $15 / 8$ inch height. It creates magnetic power as the power supply switch on, which can hold the maximum weight of $180 \mathrm{lbs}$. Magnets with spring-loaded release have a pin that quickly releases the held object when power is turned off. As shown in Figure 4-8, the electromagnet holding a mass is placed on top of a tube which mounted right above the slurry sample so that the mass can fall down from the designed heights. However, the mass and height of the dropping mass need to be determined by conducting a couple of trial tests. 


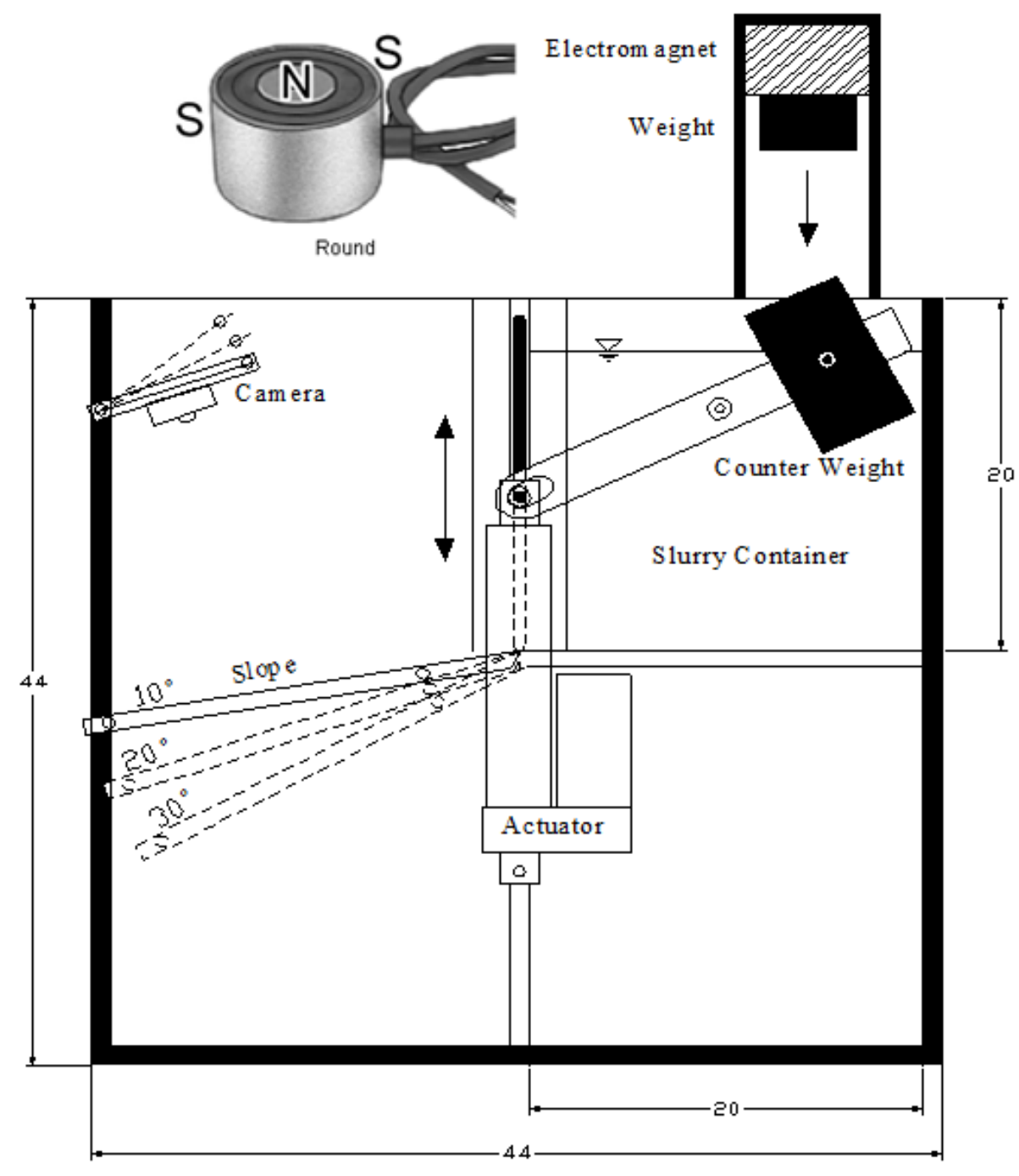

Figure 4-8 Design of centrifuge model test under impact loading

\subsection{Model Preparations and Test Procedures}

A group of centrifuge model tests were performed on the two representative samples collected from Kentucky and West Virginia, respectively. The design of model container for the flow tests has been introduced in the previous section. The door of the container was closed and grease was applied on the bottom and along each sides. As shown 
in Figure 4-5, approximately one gallon saturated slurry of fine coal refuse with different initial water content was contained to simulate a coal waste impoundment.

The container filled with coal refuse sample was thereafter placed on the centrifuge arm and the model was gradually spun up to a centrifugal acceleration of $50 \mathrm{~g}$ which was 50 times of gravitational acceleration. Centrifuge scaling laws shown in Table 4-1 were employed to evaluate corresponding prototype behaviors of the models. Since the stress field increases with the centrifugal acceleration, the slurry sample would speed up the consolidation (or drainage) process so that the water content of coal refuse sample at $50 \mathrm{~g}$ is lower than its initial water content. Based on the results of a few trial tests, it was found that the water content reduced 5\% - 7\% when initial water content higher than $65 \%$, and $3 \%$ when it lower than $65 \%$. Accordingly, the coal refuse samples in the centrifuge tests were intentionally prepared with the initial water content a little higher than the designed values.

In general, the procedures of centrifuge model tests were the same as those of smallscale model test. Due to the limited quantity of slurry sample, the centrifuge tests were only conducted at the slope angle of $10^{\circ}$ and $30^{\circ}$. The loss of impoundment was simulated by rapidly pulling the gate upwards, which could be remotely operated in the centrifuge control room. The coal refuse would flow down along the slope if a flow failure was initiated. A Gopro Hero3 high speed video camera was installed facing to the slope and recoded the whole processes of the test. The scale attached on the slope could help to indicate the travel velocity and distance of the flow. 


\subsection{Test Results and Analysis under Static Loading}

The centrifuge model tests were conducted under $50 \mathrm{~g}$ centrifugal acceleration and simulated the flow behavior of coal slurry from an impoundment containing $50^{3}$ gallon of fine coal refuse. In static loading test, the flow of coal refuse slurry is driven by the component of self-weight in the direction parallel to the slope. Using the same procedures as those in the small-scale model tests, the KY and WV fine coal refuse samples were prepared at different initial water content and flowed down at two different slope angles. Their movements were recorded by high-speed video camera and thereafter analyzed frame by frame using film processing software in order to determine the velocity and travel distance of coal refuse flow at specific water content and slope angle. According to the centrifuge scaling laws shown in Table 4-1, the scaling factor for velocity is one which means the velocity measure in the model equals to that in the prototype.

The variations of flow velocity with initial water content of coal refuse and slope angles were graphically exhibited in Figure 4-9. The flow velocities of the two representative coal refuse samples were found to decrease as the initial water content and slope angle reduced. This tendency agrees well with the recorded results from small-scale model tests. Eventually, the flow of KY coal refuse sample at $30^{\circ}$ slope ceased at water content of $40 \%$ and the flow of WV sample ceased at 50\%. As compared in Table 4-3, the increased stress field in the centrifuge has lowered the critical water contents of both samples. However, the critical water content was still above the corresponding liquid limit of each sample. Therefore, it is rational to recommend that the water content of impounded fine coal refuse should be lower than liquid limit during the design and construction phase in order to ensure the sufficient strength of tailings dams and impoundment. 

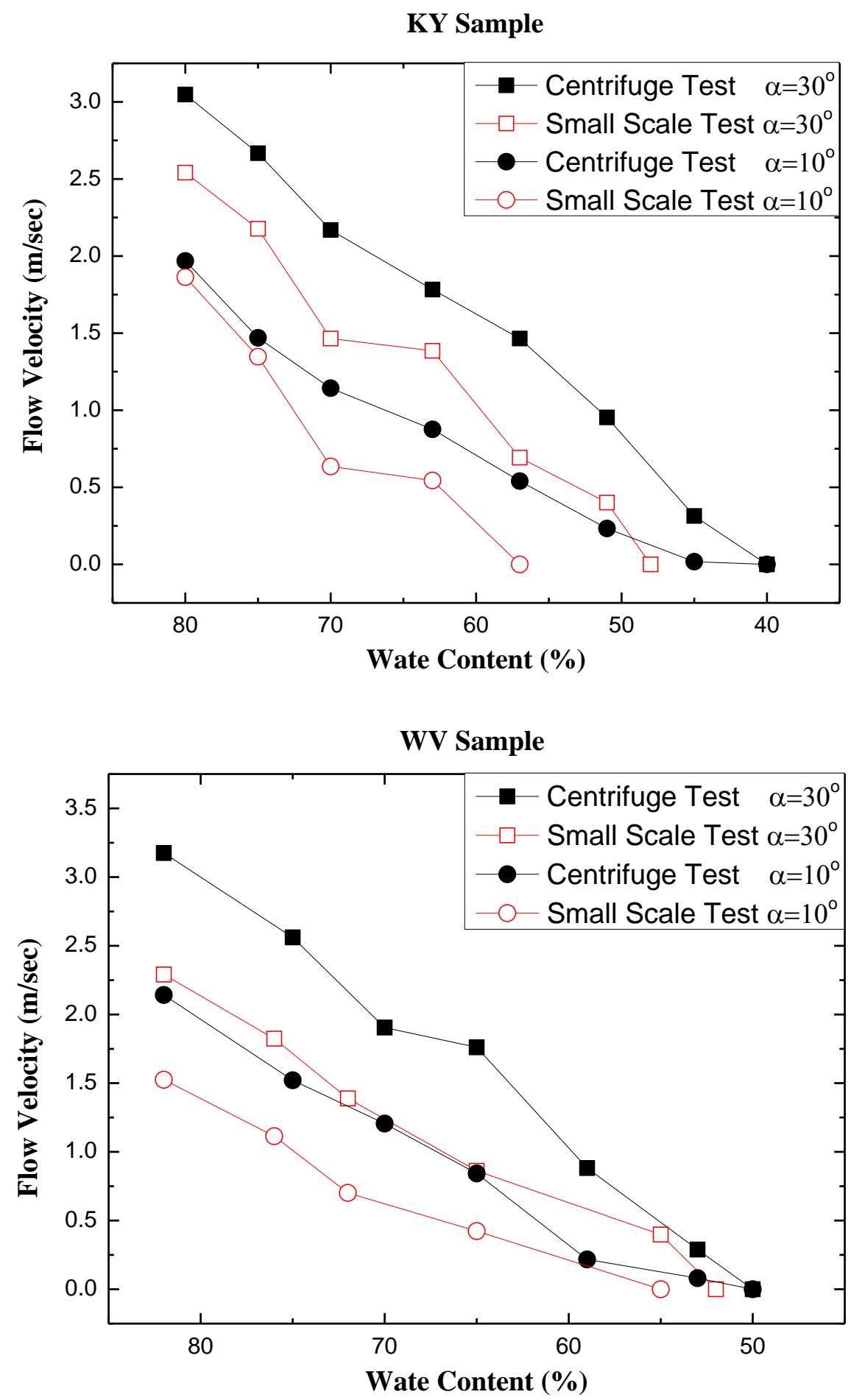

Figure 4-9 Centrifuge test results for two coal slurry samples

Table 4-3 Comparison of liquid limit with critical water content in centrifuge tests

\begin{tabular}{|l|l|l|}
\hline Critical Water Content & KY Samle & WV Sample \\
\hline
\end{tabular}




\begin{tabular}{|c|c|c|}
\hline Liquid Limit & $38.1 \%$ & $42.5 \%$ \\
\hline Small-Scale Tests & $51 \%$ & $52 \%$ \\
\hline Centrifuge Tests & $40 \%$ & $50 \%$ \\
\hline
\end{tabular}

In addition, the travel distance of the coal slurry and the depth of flow normal to the slope in the midstream were also recorded. As shown in Table 4-4, the impounded coal refuse traveled more than $80 \mathrm{~m}$ (in prototype scale) once the flow was initiated. At slope angle of $30^{\circ}$, the transition from flowable state to nonflowable state seemed quite sensitive to the water content. Only a slight increase of water content would trigger the extensive flow of coal refuse. Apparent increase of flow depth was observed from less than $0.05 \mathrm{~m}$ to more than one meter as the initial water content decreased from $80 \%$ to less than $50 \%$.

Table 4-4 Recorded travel distance and flow depth of two samples in the centrifuge tests

\begin{tabular}{|c|c|c|c|c|c|c|c|c|c|}
\hline \multirow{3}{*}{$\begin{array}{c}\text { Water } \\
\text { content } \\
(\%)\end{array}$} & \multicolumn{4}{|c|}{ KY Sample } & \multirow{3}{*}{$\begin{array}{c}\text { Water } \\
\text { content } \\
(\%)\end{array}$} & \multicolumn{4}{|c|}{ WV Sample } \\
\hline & \multicolumn{2}{|c|}{$30^{\circ}$} & \multicolumn{2}{|c|}{$10^{\circ}$} & & \multicolumn{2}{|c|}{$30^{\circ}$} & \multicolumn{2}{|c|}{$10^{\circ}$} \\
\hline & $\begin{array}{c}\mathrm{L} \\
(\mathrm{m})\end{array}$ & $\begin{array}{c}\mathrm{D} \\
\text { (m) }\end{array}$ & $\begin{array}{c}\mathrm{L} \\
\text { (m) }\end{array}$ & $\begin{array}{c}\mathrm{D} \\
(\mathrm{m})\end{array}$ & & $\begin{array}{c}\mathrm{L} \\
\text { (m) }\end{array}$ & $\begin{array}{c}\mathrm{D} \\
\text { (m) }\end{array}$ & $\begin{array}{c}\mathrm{L} \\
(\mathrm{m})\end{array}$ & $\begin{array}{c}\mathrm{D} \\
(\mathrm{m})\end{array}$ \\
\hline 80 & $>81.28$ & $<0.05$ & $>81.28$ & $<0.05$ & 80 & $>81.28$ & $<0.05$ & $>81.28$ & $<0.05$ \\
\hline 75 & $>81.28$ & $<0.05$ & $>81.28$ & 0.075 & 75 & $>81.28$ & $<0.05$ & $>81.28$ & 0.1 \\
\hline 70 & $>81.28$ & 0.075 & $>81.28$ & 0.175 & 70 & $>81.28$ & 0.125 & $>81.28$ & 0.25 \\
\hline 63 & $>81.28$ & 0.1 & $>81.28$ & 0.3 & 65 & $>81.28$ & 0.15 & $>81.28$ & 0.38 \\
\hline 57 & $>81.28$ & 0.2 & $>81.28$ & 0.425 & 59 & $>81.28$ & 0.3 & $>81.28$ & 0.43 \\
\hline 51 & $>81.28$ & 0.35 & $>81.28$ & 0.65 & 53 & $>81.28$ & 0.55 & 76.2 & 0.9 \\
\hline 45 & $>81.28$ & 1.25 & 60.96 & 1.75 & & & & & \\
\hline
\end{tabular}

(L: extent of flow; D: flow depth in the midstream; dimensions in prototype scale) 


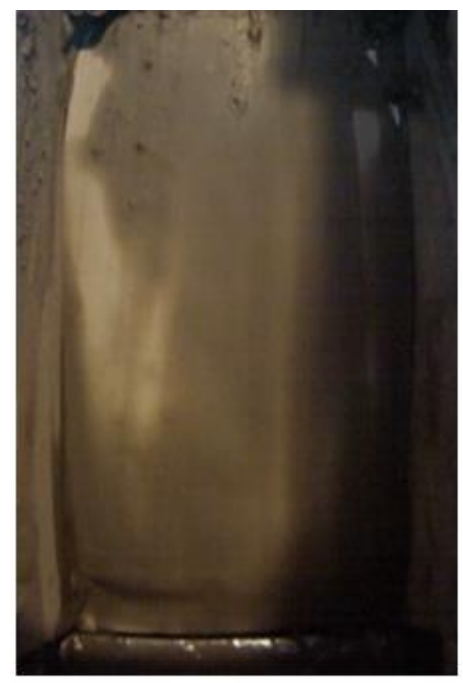

$\mathbf{w}=\mathbf{8 0} \quad \alpha=\mathbf{3 0}$

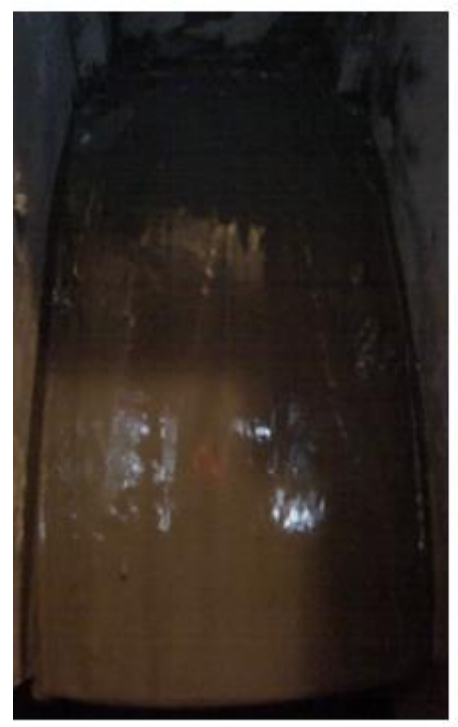

$\mathbf{w}=\mathbf{8 0} \quad \alpha=\mathbf{1 0}$

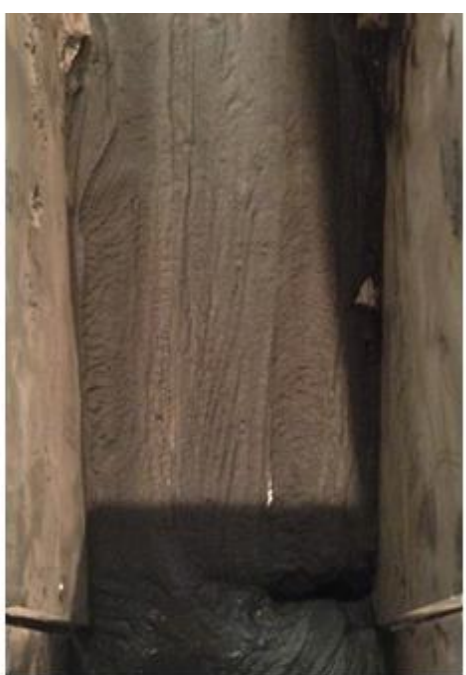

$\mathbf{w}=\mathbf{7 0} \quad \alpha=30^{\circ}$

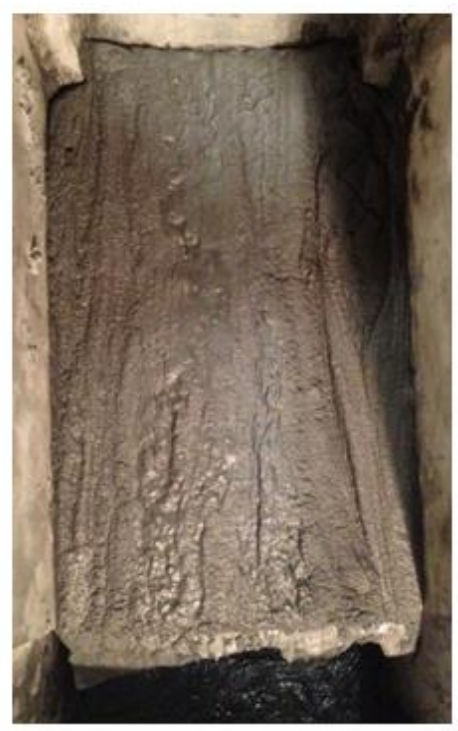

$\mathbf{w}=\mathbf{7 0} \quad \alpha=10^{\circ}$

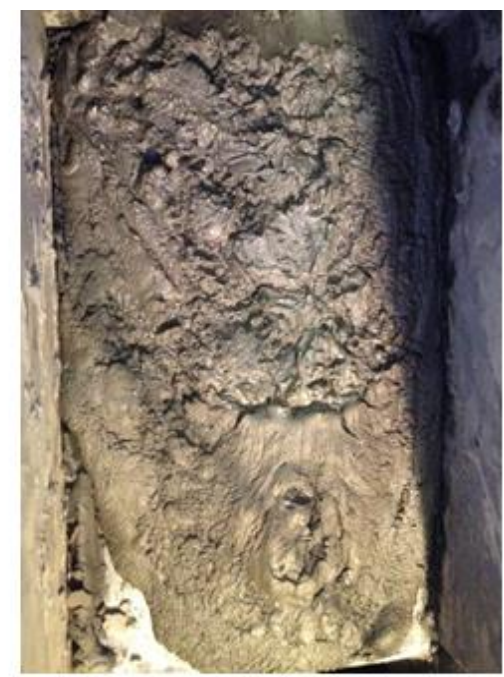

$\mathrm{w}=46 \quad \alpha=30^{\circ}$

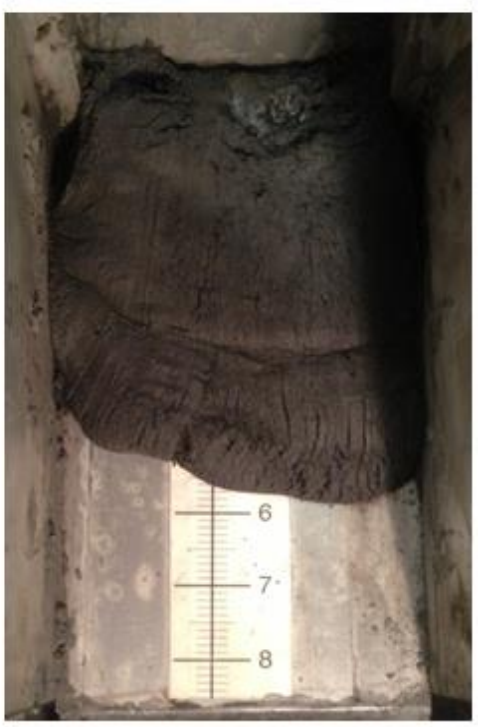

$\mathbf{w}=46 \quad \alpha=10^{\circ}$

Figure 4-10 Flow of KY coal refuse sample in the centrifuge tests

The flow behaviors of coal refuse in the centrifuge tests were graphically exhibited in Figure 4-10. At initial water content of $80 \%$, quite thin and smooth layer of slurry adhered on the slope surface with depth less than $5 \mathrm{~mm}$. As water content reduced, the flow of coal refuse gradually became heavier and more viscous. In addition, the solid plug on top of the flow, which had no velocity gradient, became thicker. As discussed in the small- 
scale model tests, the flow of coal refuse gradually transferred from Newtonian fluid at higher water content to non-Newtonian fluid (Bingham Plastic fluid) at lower water content.

The flow velocities measured in the centrifuge model tests were also compared with those measured in the small-scale model tests. As shown in Figure 4-9, the solid dot line represented the measured data from centrifuge model tests while the hollow dot line represented the data from small-scale model tests. Although the measured data were in the same order of magnitude, the flow velocities in the centrifuge tests were faster than those in the small-scale model tests due to the increased stress field. The small centrifuge model in the high stress field was equivalent to the sample with larger mass and volume in the prototype. The effect of mass and water content on the debris flow velocity have been studied by Kailey et al. (2011). They performed a series of flume tests in the geotechnical centrifuge on the debris samples with variable volumes and water content. They found that the increase of mass and water content increased the peak flow velocity. However, the effect of increased water content was much more pronounced than that of increased mass.

The study of flow regime followed the identical procedures as those stated in the small-scale model tests in Section 3.3.2 and was performed in the prototype scale. The determination of Reynolds number and critical Reynolds number employed the Equations 3-8, 3-10, and 3-11 shown in the small scale tests. As shown in Table 4-5, the flows of both representative coal refuse samples were measured as laminar flow with Reynolds number smaller than the corresponding critical Reynolds number at different initial water content. The measured Reynolds numbers in the centrifuge model tests were larger than those in the small-scale model tests due to the increased stress field and thereafter the flow velocity. In addition, the Reynolds numbers of WV sample were found smaller than those of KY 
samples due to its larger viscosity. It also demonstrated the significant effect of viscosity of coal refuse on the flow velocity and flow regime.

Table 4-5 Determination of flow regime in the centrifuge tests

\begin{tabular}{|c|c|c|c|c|c|c|c|}
\hline \multicolumn{8}{|c|}{ Kentucky Sample } \\
\hline $\begin{array}{c}\text { Water Content } \\
\%\end{array}$ & $\begin{array}{c}\boldsymbol{\rho} \\
k g / m^{3}\end{array}$ & $\begin{array}{c}\mathrm{v} \\
\mathrm{m} / \mathrm{sec}\end{array}$ & $\begin{array}{l}\mathbf{R} \\
\mathbf{m}\end{array}$ & $\begin{array}{c}\eta \\
\text { Pa·sec }\end{array}$ & $\mathbf{R e}$ & $\operatorname{Re}_{c}$ & Regime \\
\hline 80 & 1393 & 3.05 & 0.05 & 0.1 & 2094 & 2180 & Laminar \\
\hline 75 & 1408 & 2.67 & 0.05 & 0.16 & 1158 & 2145 & Laminar \\
\hline 70 & 1425 & 2.17 & 0.07 & 0.21 & 1082 & 2166 & Laminar \\
\hline 63 & 1451 & 1.78 & 0.1 & 0.34 & 741 & 2209 & Laminar \\
\hline 57 & 1477 & 1.47 & 0.19 & 0.47 & 874 & 2343 & Laminar \\
\hline 51 & 1506 & 0.95 & 0.32 & 0.54 & 850 & 2743 & Laminar \\
\hline \multicolumn{8}{|c|}{ West Virginia Sample } \\
\hline $\begin{array}{c}\text { Water Content } \\
\%\end{array}$ & $\begin{array}{c}\boldsymbol{\rho} \\
k g / m^{3}\end{array}$ & $\begin{array}{c}v \\
\mathrm{~m} / \mathrm{sec}\end{array}$ & $\begin{array}{l}\mathbf{R} \\
\mathbf{m}\end{array}$ & $\begin{array}{c}\eta \\
\text { Pa·sec }\end{array}$ & $\operatorname{Re}$ & $\operatorname{Re}_{c}$ & Regime \\
\hline 80 & 1420 & 3.18 & 0.05 & 0.33 & 674 & 2105 & Laminar \\
\hline 75 & 1438 & 2.56 & 0.05 & 0.43 & 422 & 2104 & Laminar \\
\hline 70 & 1456 & 1.91 & 0.12 & 0.52 & 645 & 2121 & Laminar \\
\hline 65 & 1477 & 1.76 & 0.14 & 0.69 & 548 & 2124 & Laminar \\
\hline 53 & 1534 & 0.29 & 0.48 & 0.95 & 224 & 2565 & Laminar \\
\hline
\end{tabular}

\subsection{Test Results and Analysis under Impact Loading}

The configuration of centrifuge model tests under impact loading was shown in

Figure 4-11. An alumina tube was installed right above the slurry sample with an 
electromagnet attached on the top. The electromagnet can generate magnetic power to hold a one pound mass and drop it under 50g by turning off the magnet power. The height of the mass could be adjusted in order to generate different energy. Each impact loading test represents a single-cycle event such as a sudden failure of mine barriers or subsidence events. A pore water pressure transducer was buried in the middle depth of slurry sample. The recorded development of excess pore water pressure would be helpful in evaluating whether the sample was liquefied under impact loading.

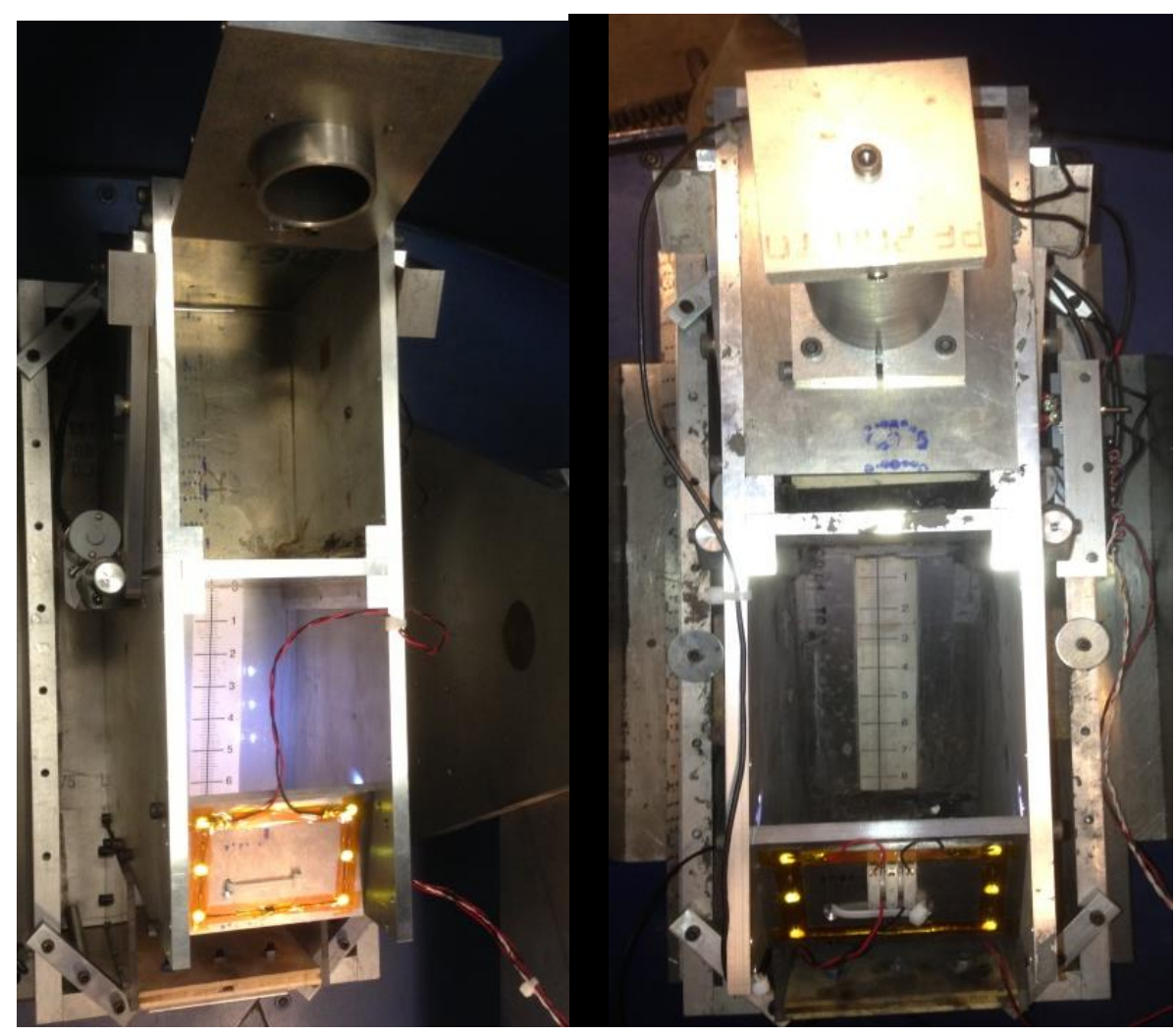

Figure 4-11 The centrifuge model test under impact loading

The samples were tested from the water content at which the flow ceased under static loading. The results of centrifuge tests under impact loading were summarized in Table 4-6 and graphically exhibited in Figure 4-12. Figure 4-13 illustrated the development 
of excess pore water pressure when the mass dropped down. The vertical axis represented the pore water pressure ratio which was the ratio of buildup excess pore water pressure to the effective stress at the measuring point $\frac{\square \mathrm{u}}{\sigma^{\prime}}$. The liquefaction would take place as pore pressure ratio equals to one.

Different compressive strains were induced by dropping the mass from different heights. As seen from Table 4-6, no flow was triggered under 3\% compressive strain. For KY sample at $40 \%$ water content, the flow was initiated under $5 \%$ compressive strain with extremely slow velocity. The flow was quickly stopped when traveled less than one meter (see Figure 4-12). The recorded pore water pressure in Figure 4-13 indicated that the liquefaction of KY coal refuse sample occurred as compressive strain increased up to $8 \%$. Although the existing Data Acquisition System in the centrifuge can not collect sufficient data to display the entire development of pore water pressure, the peak value at the end of the curve was pretty close to one, when the coal refuse lost its effective stress and the liquefied fine particles behaved as a suspension. Accordingly, the flow velocity and the extent of flow were greatly increased at this water content. When initial water content lower than the liquid limit, the flow could hardly be triggered. At $36 \%$ water content, the recorded pore pressure ratio was smaller than 0.5 under $10 \%$ compressive strain. The value of flow velocity was too small to be measured.

For WV coal refuse sample, the centrifuge tests started at $50 \%$ water content. Although the flow was ceased under static loading, still a large amount of pore water existing in the WV sample. At slope angle of $30^{\circ}$, the fine refuse was liquefied when compressive strain reached $6 \%$ with the recorded pore pressure ratio in Figure 4-13 equal to one. As shown in Figure 4-12, the solid sample was changed into a heavy viscous fluid 
and flowed down the slope at the velocity of $0.176 \mathrm{~m} / \mathrm{sec}$. The initiated flow under impact loading traveled more than 10 meters (see Table 4-6). At $45 \%$ water content, more evident flow was observed in Figure 4-12 under 10\% compressive strain than under 6\% with the pore pressure ratio was as high as 0.8 . Even though the coal refuse was not liquefied, the flow travelled more than 5 meters at the speed of $0.061 \mathrm{~m} / \mathrm{sec}$. No flow was observed as the initial water content lower than its liquid limit of $42.5 \%$.

In conclusion, the results of centrifuge model tests were consistent well with those obtained from the small scale tests although the flow velocity was 20 percent higher in the centrifuge tests due to the increased stress field. Some minor discrepancies might exist resulting from the control of initial water content or density.

The results also demonstrate that the void ratio of fine refuse is still high even after the material is fully consolidated. In the event of impact loading or other similar dynamic disturbances (i.e. seismic loading, stress waves from blast, construction process, subsidence events, and other sources), excess pore water pressure in the material would quickly build up and cause severe reduction in the effective strength of the material. Liquefaction of the fine refuse could be induced at higher water content which would produce a large pressure increase on the embankment. The results from both small-scale model tests and centrifuge model tests indicate that the impounded fine coal refuse would have sufficient resistance to the dynamic impact loading as long as its initial water content lower than liquid limit.

Table 4-6 The summarized results of centrifuge tests under impact loading $\left(\alpha=30^{\circ}\right)$

\section{Kentucky Sample}




\begin{tabular}{|c|c|c|c|c|}
\hline $\begin{array}{c}\text { Water Content } \\
(\%)\end{array}$ & $\begin{array}{l}\text { Compressive } \\
\text { Strains } \varepsilon(\%)\end{array}$ & $\begin{array}{c}\text { Drop Height } \\
\text { (m) }\end{array}$ & $\begin{array}{l}\text { Extent of Flow } \\
\text { (m) }\end{array}$ & $\begin{array}{c}\text { Flow Velocity } \\
(\mathrm{m} / \mathrm{s})\end{array}$ \\
\hline 40 & 3 & 2.5 & 0 & 0 \\
\hline 40 & 5 & 4 & 0.64 & 0.0047 \\
\hline 40 & 8 & 5 & 3.56 & 0.02 \\
\hline 36 & 10 & 7.5 & $\approx 0$ & $\approx 0$ \\
\hline 33 & 10 & 8 & 0 & 0 \\
\hline 33 & 13 & 9.5 & 0 & 0 \\
\hline \multicolumn{5}{|c|}{ West Virginia Sample } \\
\hline $\begin{array}{c}\text { Water Content } \\
(\%)\end{array}$ & $\begin{array}{l}\text { Compressive } \\
\text { Strains } \varepsilon(\%)\end{array}$ & $\begin{array}{c}\text { Drop Height } \\
\text { (m) }\end{array}$ & $\begin{array}{l}\text { Extent of Flow } \\
\text { (m) }\end{array}$ & $\begin{array}{c}\text { Flow Velocity } \\
(\mathrm{m} / \mathrm{s})\end{array}$ \\
\hline 50 & 3 & 2 & 0 & 0 \\
\hline 50 & 6 & 4 & $>10$ & 0.176 \\
\hline 45 & 6 & 4 & 1.27 & 0.0013 \\
\hline 45 & 10 & 6 & 5.1 & 0.061 \\
\hline 40 & 10 & 7.5 & 0 & 0 \\
\hline 40 & 13 & 9 & 0 & 0 \\
\hline
\end{tabular}

(Dimensions in prototype scale under $50 \mathrm{~g}$ ) 


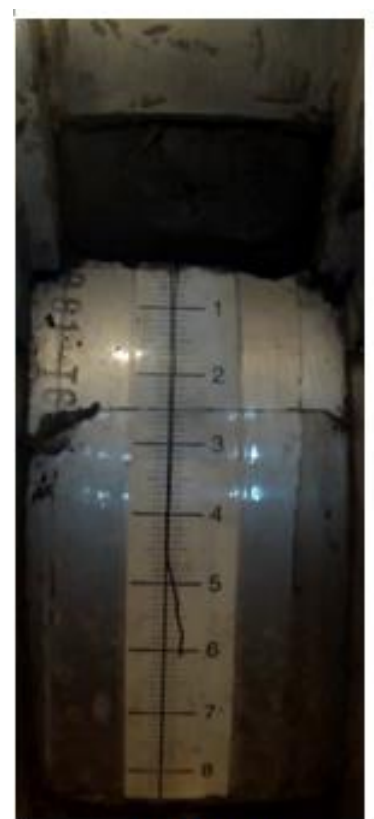

$\varepsilon=5 \% w=40 \%$

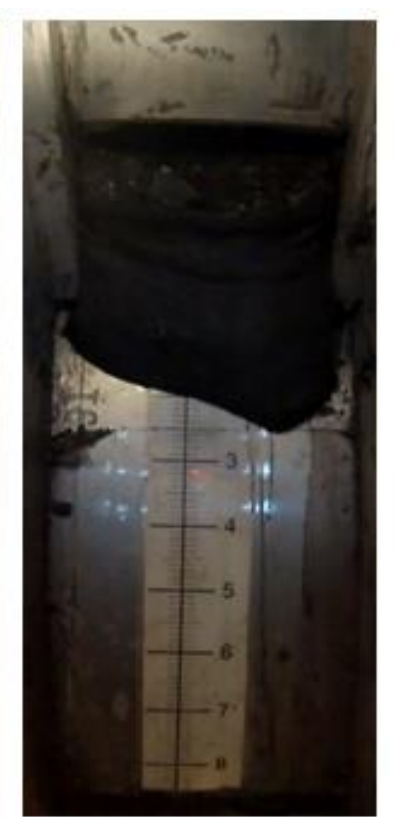

$\varepsilon=8 \% \mathrm{w}=\mathbf{4 0} \%$

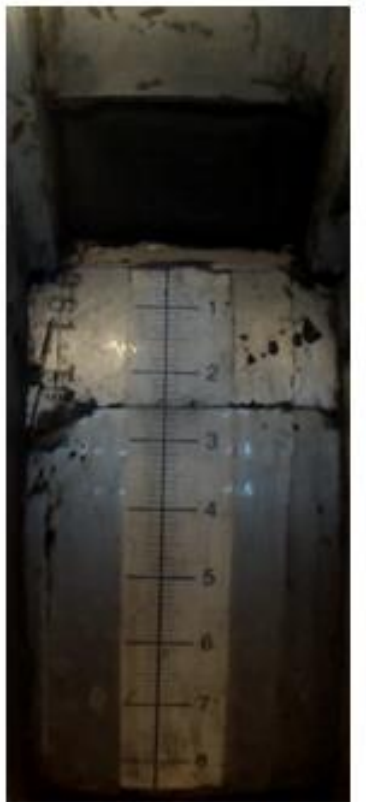

$\varepsilon=10 \% \mathrm{w}=36 \%$

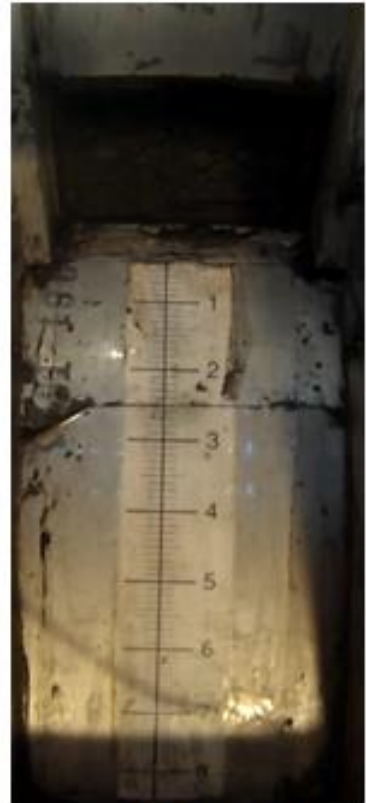

$\varepsilon=10 \% \quad w=36 \%$

Kentucky Sample

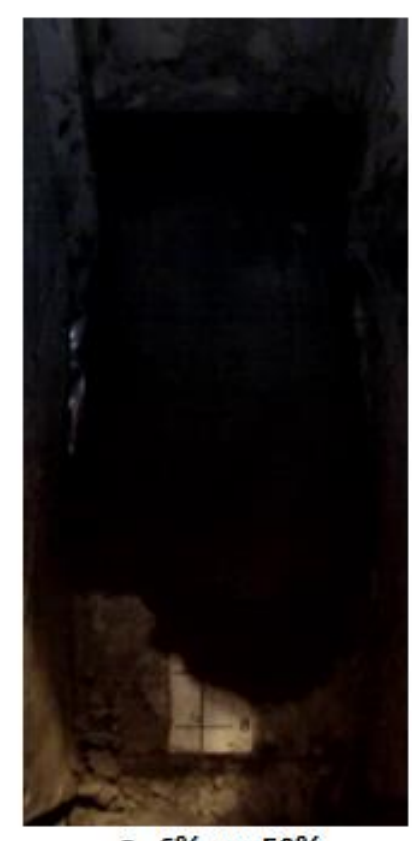

$\varepsilon=6 \% \mathrm{w}=50 \%$

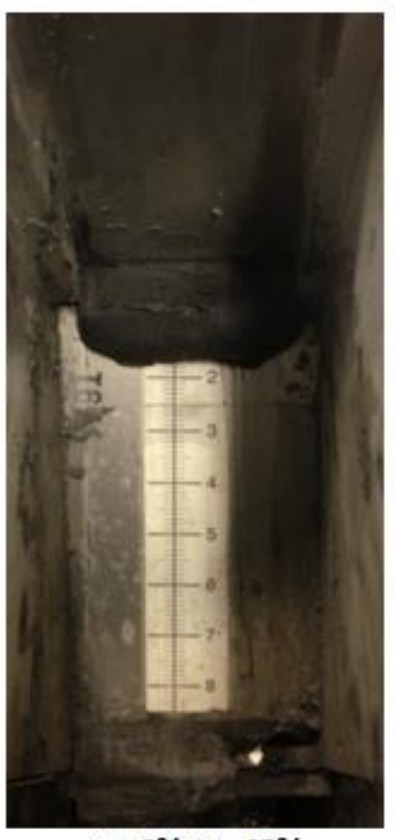

$\varepsilon=6 \% \mathrm{w}=45 \%$ West Virginia Sample

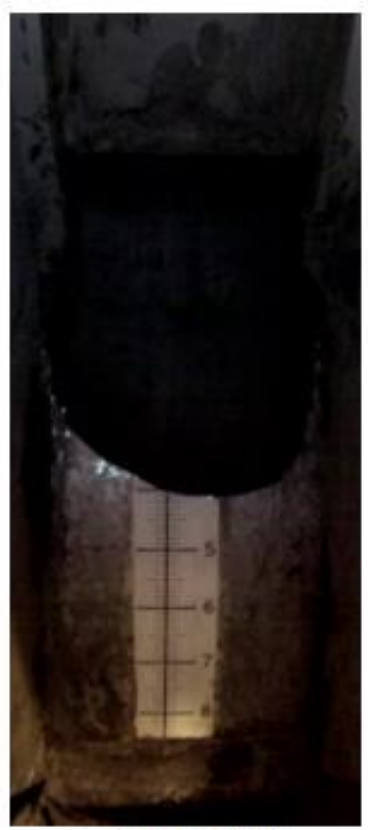

$\varepsilon=10 \% \mathrm{w}=45 \%$

Figure 4-12 Flow of coal refuse in the centrifuge tests under impact loading $\left(\alpha=30^{\circ}\right)$ 

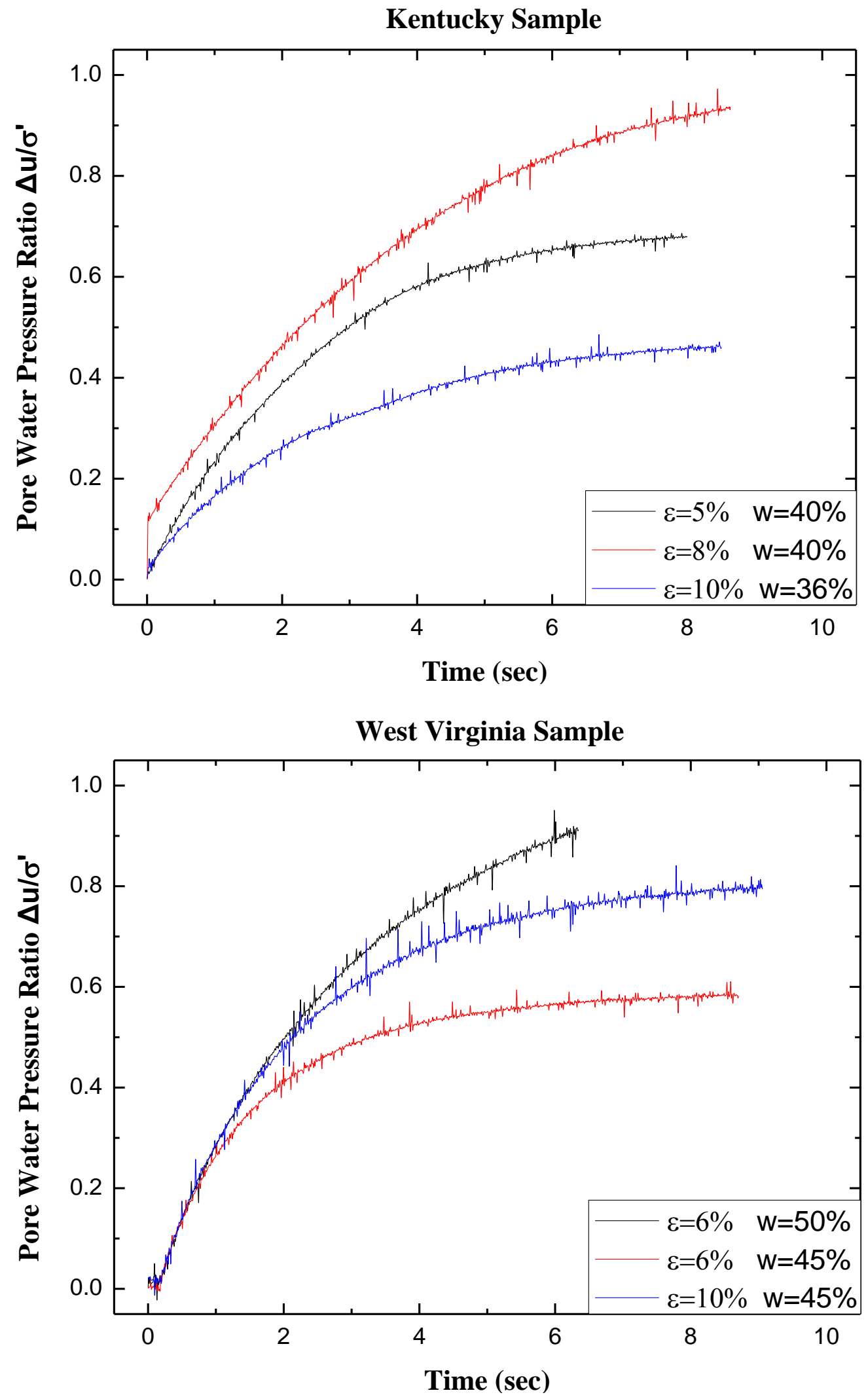

Figure 4-13 Recorded pore water pressure under impact loading 162 


\subsection{Evaluation of Slurry Cell as a Countermeasure}

\subsubsection{Review of Coal Refuse Slurry Cells}

Slurry cell is considered as one of the viable alternatives to coal slurry impoundment with increasing popularity. Slurry cells are designed to small impound typically less than 20 acre-feet of coal slurry (Committee on Coal Waste Impoundments, 2002; and Craynon, 2013) and have been used successfully in some cases regardless of the higher cost. The small impounding structures are built from compacted coarse refuse and constructed in layers. In practice, the first layer of cells is quickly filled and capped with coal slurry and overtopped by a new layer of cells. The total depth of slurry cells could equal or even exceed that of the original impoundments (Michael et al., 2010). Unlike the conventional coal waste impoundment, the construction of slurry cells is quite sensitive to the site specific condition which is more suitable for the mining area with flat land rather than the sites consisting of steep slopes and narrow valleys (Gardner et al., 2003). As shown in Figure 4-14, each cell is small and self-contained so that it would limit the potential for flow failure by holding much less coal slurry at one time. In addition, each independent cell can be designed according to the strength properties of the coarse refuse. However, Michael et al. (2010) found the slurry cells would not mitigate the breakthrough potential of the coal refuse into the underground mine. They indicated that the surcharge from the stacked slurry cells will adversely increase the hydrostatic pressure in the fine refuse slurry below the impoundment cap.

In this study, the design of slurry cell was proposed as a potential countermeasure to reduce the risk of flow failure under impact loading. In practice, slurry cells are constructed by compacted and high strength coarse refuse so that the impoundment would 
be reinforced. In addition, coarse refuse also has much higher permeability so the coarse particles would not liquefy under dynamic impact loading. Moreover, it would be used as drains for fine coal refuse and hence speed up the consolidation of the slurry and the dissipation of excess pore water pressure induced by dynamic impact loading. Regarding to the supply of coarse refuse, it is a by-product of coal mining and is available locally at the site of the tailings dam. Given the above positive evaluations, the slurry cell would be an effective and economical solution.
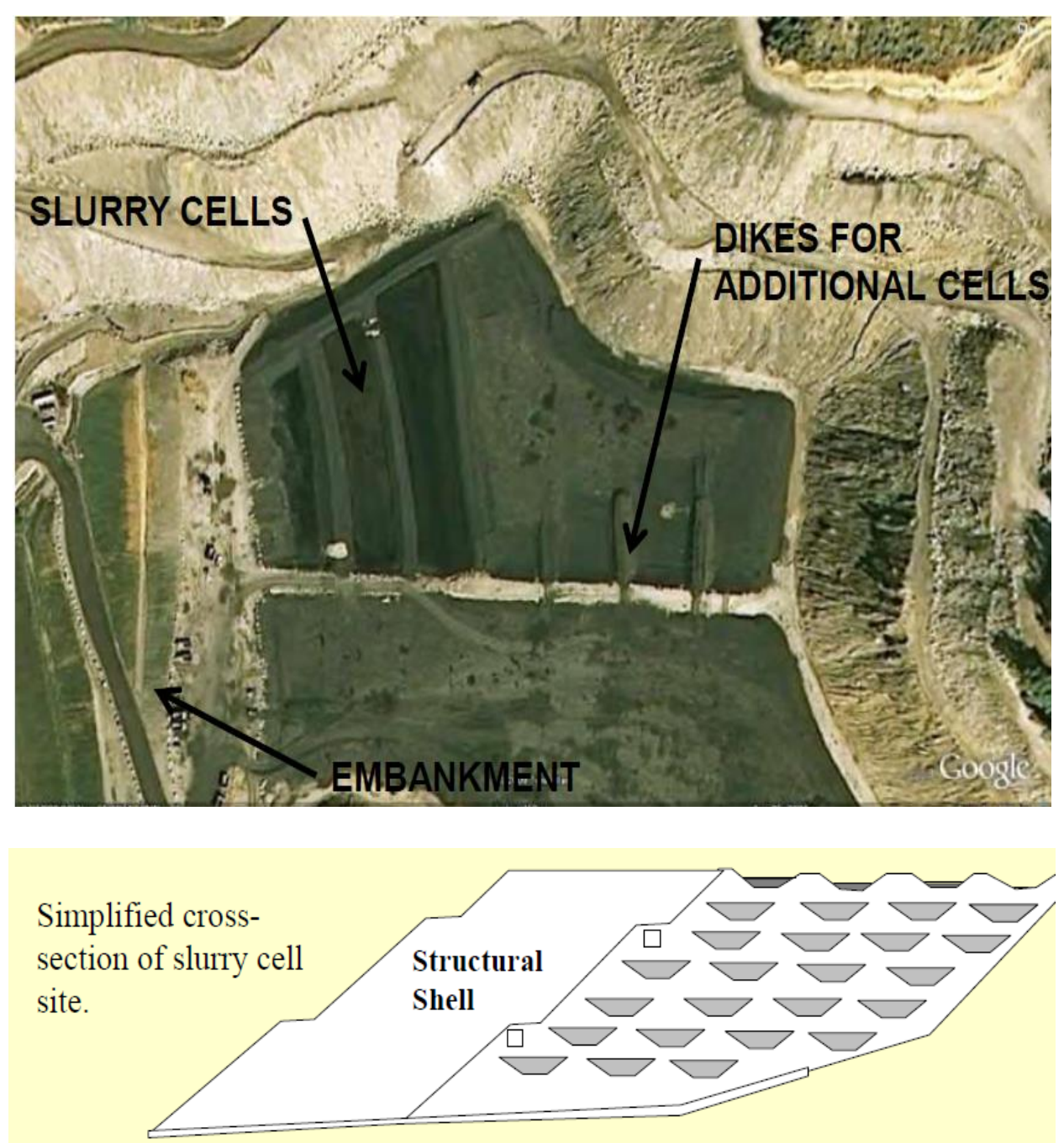

Figure 4-14 Coal refuse slurry cells (after Wu et al., 2003; and Michael et al. 2010) 


\subsubsection{Centrifuge Model Preparations}

A group of centrifuge model tests were performed in order to validate the effectiveness of the design of slurry cell. The simplified model of an impoundment was shown in Figure 4-15. The slurry cells were constructed with crushed stone with particle size between $2 \mathrm{~mm}$ and $4.75 \mathrm{~mm}$. The sample was prepared in two layers. A cross shape columns were built along the depth of the impoundment with the thickness of $2 \mathrm{~cm}$. As the first layer of cell was filled up to $8 \mathrm{~cm}$, it was overtopped by a $2 \mathrm{~cm}$ thickness of coarse refuse build cell and thereafter the other layer of slurry pond. The procedures were identical with those described in the centrifuge model tests under impact loading in Section 4.3.
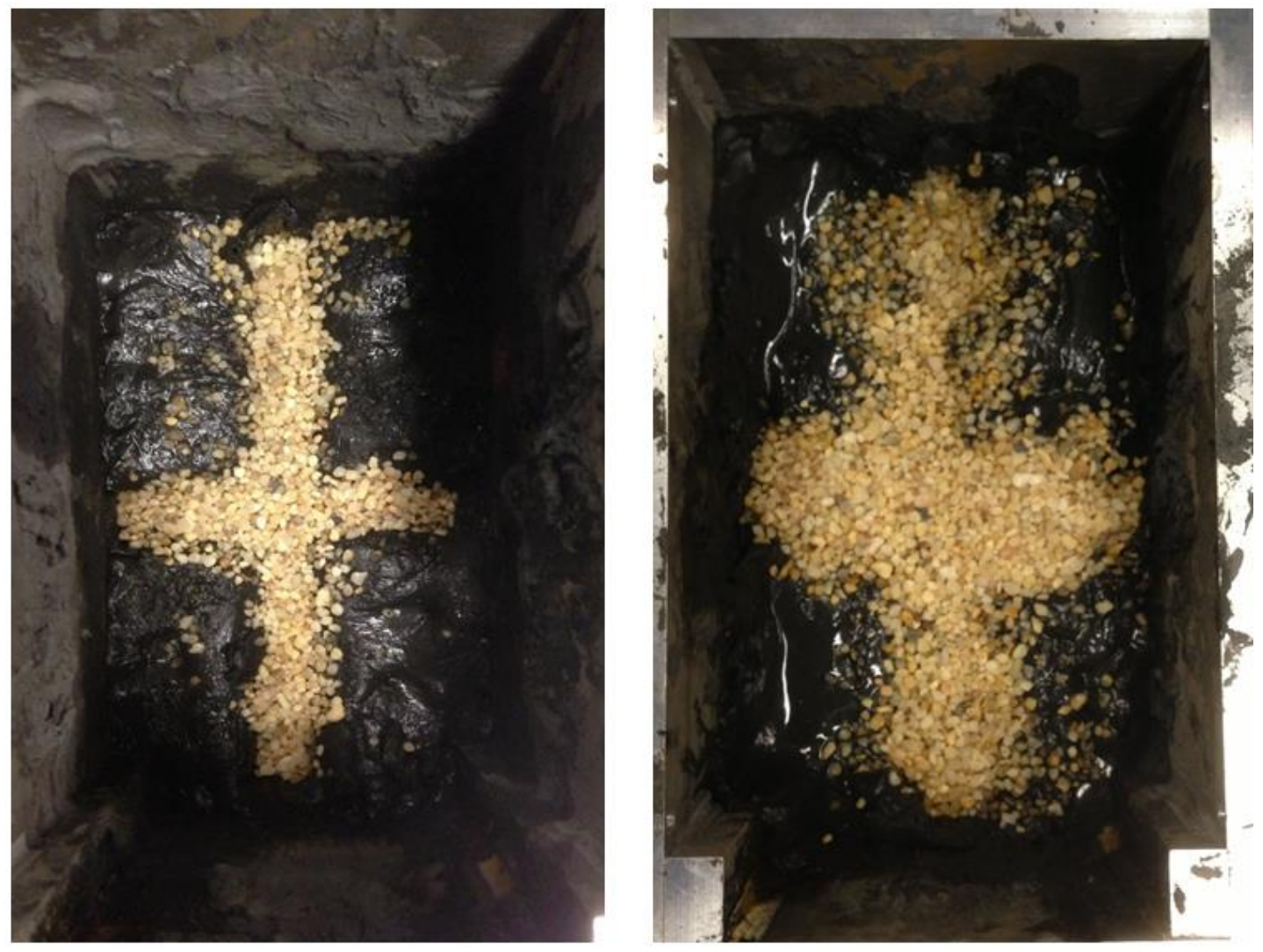

Figure 4-15 Centrifuge model with coarse refuse build cells 
Since no flow was observed under impact loading when water content lower than liquid limit, the centrifuge model tests by applying slurry cells were therefore performed at the initial water content of $40 \%$ and $50 \%$ and, and in the meantime, under the highest compressive strains of $10 \%$ for KY sample and WV sample, respectively. The pore pressure transducer was embedded on the bottom of the upper layer to record the development of excess pore water pressure under impact loading.

\subsubsection{Test Results and Analysis}

The summarized results were listed in Table 4-7. The mass was dropped from $7 \mathrm{~m}$ height (in prototype scale) to induce 10\% compressive strain. No flow was triggered for both of the representative samples. Only some stone particles and small amount of water streamed down the slope as the door lifted. The flow was neither observed in two repeated tests with the same initial water content and configuration.

As shown in Figure 4-16, the generated pore pressure ratio of both samples under impact loading were less than 0.5 , which were quite less than those recorded in the centrifuge tests without coarse refuse build cells. Comparing with the development of pore water pressure in Figure 4-13, apparent dissipation of pore water pressure was observed in Figure 4-16 after the peak value. It demonstrated the increased permeability of impoundment by using the coarse particle build cells. The water flowing down during the test was believed to drain through the slurry cells as pore water pressure dissipated. Also, quite insignificant pore water pressures were developed in the repeated tests. Based on the obtained results, the technique by using slurry cells is considered to be effective in improving the stability of impoundment under dynamic impact loading. 
Table 4-7 The summarized results of centrifuge tests with slurry cells ( $\alpha=30^{\circ}$ )

\begin{tabular}{|c|c|c|c|c|}
\hline \multicolumn{5}{|c|}{ Kentucky Sample } \\
\hline $\begin{array}{c}\text { Water } \\
\text { Content } \\
(\%)\end{array}$ & $\begin{array}{c}\text { Compressive Strains } \\
(\%)\end{array}$ & $\begin{array}{c}\text { Drop } \\
\text { Height } \\
(\mathrm{m})\end{array}$ & $\begin{array}{c}\text { Extent of Flow } \\
(\mathrm{m})\end{array}$ & $\begin{array}{c}\text { Flow Velocity } \\
(\mathrm{m} / \mathrm{s})\end{array}$ \\
\hline 40 & 10 & 7 & 0 & 0 \\
\hline \multicolumn{2}{|c|}{ West Virginia Sample } \\
\hline $\begin{array}{c}\text { Water } \\
(\%)\end{array}$ & $\begin{array}{c}\text { Compressive Strains } \\
\varepsilon(\%)\end{array}$ & $\begin{array}{c}\text { Drop } \\
\text { Height } \\
(\mathrm{m})\end{array}$ & $\begin{array}{c}\text { Extent of Flow } \\
(\mathrm{m})\end{array}$ & Flow Velocity \\
$(\mathrm{m} / \mathrm{s})$
\end{tabular}

(dimensions in prototype scale under $50 \mathrm{~g}$ )

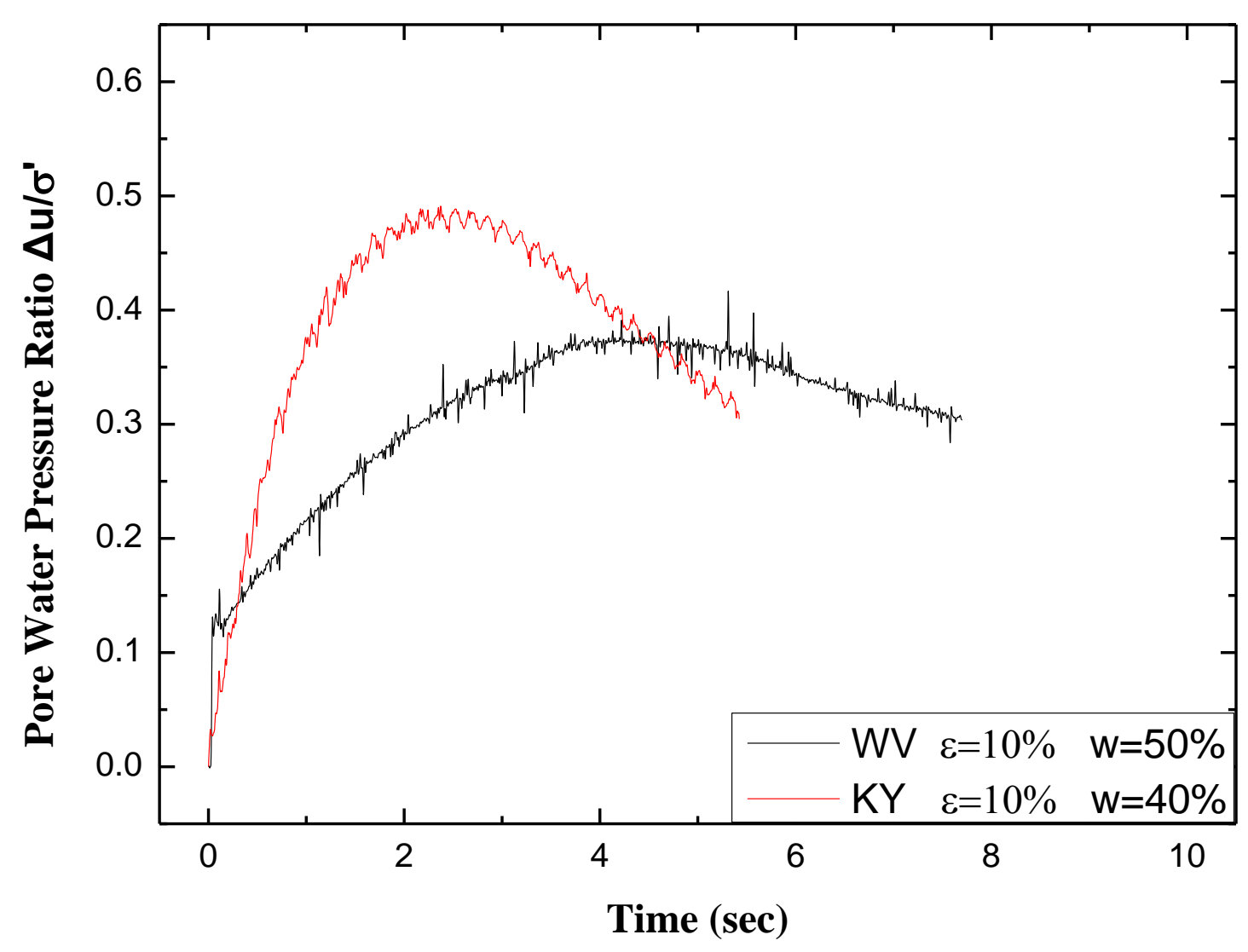


Figure 4-16 Recorded pore water pressure under impact loading by using slurry cells

\subsection{Conclusion}

In this chapter, a group of centrifuge model tests have been performed on the two representative coal refuse samples. The flow behaviors of coal refuse were studied under both static loading and impact loading. In addition, the results of centrifuge tests were used to compare and validate the results measured in the small-scale model tests. A potential countermeasure by using coarse refuse build slurry cells was proposed to reduce the risk of flow failure. Based on the recorded results, the following conclusions could be drawn:

1) Quite consistent results were obtained from the two representative coal refuse samples. In addition, the results matched well with those measured in small-scale model tests.

2) Centrifuge tests can generate realistic physical data to analyze flow behaviors of impounded coal refuse under prototype stress field.

3) A special model container has been designed for centrifuge flow tests under both static loading and impact loading.

4) By comparing the results of small scale model test and centrifuge test, it was found the increase of mass or volume of slurry sample would increase the flow velocity. However, the influence of mass was less important than the water content.

5) Under static loading tests, the flow velocities and travel distance of coal refuse gradually decreased as the initial water content and slope angle reduced. The flow of coal refuse ceased at water content higher than liquid limit. Although the flow ceased under static loading, still a large amount of pore water existed in the coal slurry. In addition, 
the critical water content was also a bit higher than that in the small-scale model test due to the increased stress field.

6) Although the recorded flow velocities and Reynolds number increased, the coal refuse flow could still be considered as a laminar flow.

7) Viscosity is considered to be one of the most important parameters influencing the flow behaviors of coal refuse.

8) According to the recorded pore water pressure, the liquefaction of coal refuse was observed under compressive strain larger than 5\%. The extensive flow was initiated as liquefaction occurred. However, it was found that the coal refuse would have sufficient resistance to the dynamic impact loading as long as the initial water content lower than its liquid limit.

9) The design of slurry cells were proposed as an effective and economical countermeasure, due to the higher strength and permeability as well as the local availability of coarse refuse, to improve the stability of impoundment under dynamic impact loading.

10) No flow was observed in the impact loading tests by using coarse refuse build slurry cells. The recorded pore water pressures were found to be greatly reduced compared with those in the centrifuge model test without slurry cells. In addition, the quick dissipation of pore water pressure was found after impact loading. 


\section{Chapter 5 CONCLUSIONS AND RECOMMENDATIONS}

\subsection{Introduction}

The flow failure of coal waste tailings dams has been a major concern for the federal agencies such as the Office of Surface Mining (OSM), the Mine Safety and Health Administration (MSHA), geotechnical engineers, and the coal industry. Failure of tailings dams has been reported many times in the recent few decades. Millions tones of tailings flowed into the valley with high speed and caused tremendous property damages. For quite a number of tailings dams located in the steep-slope topography, the impoundments are constructed on inclined slopes within narrow hollows and are in adjacent to numerous coal beds and underground coal mine workings. High breakthrough potential of impounded coal refuse into the underground mines would endanger the lives of mine workers and downstream inhabitants. In addition, the breakthroughs of coal refuse would result in significant environmental problems as the coal waste contaminant emerge into the groundwater resources and river ecosystems.

Failures of tailing dams as a result of soil liquefaction were also reported in the past 40 years. As concluded by Casagrande in as early as 1950, the flour-sized coal waste materials are usually deposited hydraulically in very loose condition and are extremely sensitive to the dynamic disturbance. The triggered flow slides would result in much loss of lives and property. However, there is no previous study on the influence of dynamic impact loading on the flow initiation and flow properties of coal refuse.

In this thesis, a comprehensive study was performed on the geotechnical properties and flow behavior of coal refuse under both static loading and impact loading by using laboratory tests, small-scale model tests, and centrifuge model tests. The relationships have 
been established between flow behaviors of coal refuse and its geotechnical properties. Some classic flow models have been studied in order to realistically represent the flow of coal slurry. The effectiveness of an engineering countermeasure - "slurry cells" was evaluated using centrifuge model tests. The results of this study will help to understand the flow behavior of impounded coal refuse and provide a tool to predict and prevent the flow failure of coal refuse. The resulting conclusions will lead to more effective and economical design procedures in practice.

\subsection{Summary of Conclusions}

This project carried out a comprehensive study on the geotechnical properties and flow behavior of coal refuse under static loading and dynamic impact loading. Several conclusions can be drawn regarding the obtained results of laboratory tests, small-scale model tests, and centrifuge model tests.

\subsubsection{Geotechnical Properties of Impounded Coal Refuse}

A group of laboratory tests was performed on two representative coal refuse samples from different impoundments in Appalachian regions. Comprehensive study were carried out on the geotechnical properties of coal refuse. The measured soil properties included particle size distribution, specific gravity, Atterberg limits, permeability, compressibility and coefficient of consolidation, shear strength, and viscosity. Based on the findings stated in Chapter 2, the following conclusions can be drawn:

1) More than $80 \%$ of the particles of impounded coal refuse passed No.200 sieve. In addition to the measured index properties, the fine coal refuse could be classified 
as low-plasticity silt (ML). The flour-sized fine particles are typically deposited in very loose state and quite susceptible to external disturbance.

2) The specific gravity of fine coal refuse was measured in the range of 2 to 2.15 which is typically smaller than other soils. It creates a low level of effective stress and hence lower shear strength. Also, the low specific gravity can cause an initially loose structure even after consolidation, increasing the flow failure of tailings dams.

3) The liquid limit of fine coal refuse measured is between 38.1 and 42.5 . According to the results of small scale model tests and centrifuge model tests, the flow of coal refuse ceased at water content higher than its liquid limit even under impact loading. However, to be conservative, it is still recommended that the liquid limit should be used as the critical water content above which the flow of coal refuse would be triggered.

4) It was found that the coal refuse with higher initial water content had higher compressibility and lower consolidation rate. More settlement and time are necessary to build up the consolidation strength in the coal refuse.

5) Consolidation is a complex process incorporating the pore water drainage, volume reduction, density increase, and buildup of effective strength. Therefore, the parameters obtained in the consolidation tests would be used in the design and construction phases to determine the time required for water content dropping below liquid limit and the initial density after consolidation. In addition, the results can help to estimate if sufficient shear strength has been developed as the coal refuse reach certain degree of consolidation. For tailings dams constructed using upstream and centerline methods, it is recommended to provide sufficient time for the consolidation of impounded coal refuse before adding a new layer of embankment. 
6) The hydraulic conductivity of impounded coal refuse was recorded in the range of $10^{-4}$ to $10^{-9} \mathrm{~cm} / \mathrm{s}$, which is classified as very low to impervious permeability. The low permeability (or insufficient drainage) might result in soil liquefaction during the consolidation process and under the dynamic impact loading.

7) The triaxial tests were conducted to measure the undrained shear strength and effective shear strength at different initial water content. The relationship had been established between water content and shear strength.

8) In general, the shear strength of coal refuse was at extremely low level. Apparent buildup of shear strength was observed as the water content dropped below the liquid limit. However, it would take quite long time for the strength development (or consolidation process).

9) Viscosity is the internal friction in a fluid that opposes the motion of one portion of a fluid relative to another. Once a flow failure of tailings dams take place, the viscosity of coal refuse would greatly influence the velocity of flow and the distance the flow will extend.

10) The viscosity of coal refuse was measured by NDJ-8S rotational viscometer under different initial water contents and rotational speeds. According to the measured results, the coal slurry is considered as a "shear-thinning" non-Newtonian fluid whose viscosity decreases with the rotational speed.

11) Viscosity of coal refuse was found to be quite sensitive to the water content.

At high rotational speed of $60 \mathrm{rpm}$, the viscosity varied from $10^{3}$ at about $40 \%$ water content to $10^{2}$ at $80 \%$ water content. The increased water content mitigates interactions between the coal refuse particles and thereby reduces the resistance to the slurry flow. 


\subsubsection{Flow Behavior of Impounded Coal Refuse under Static Loading}

The rheology properties and flow behavior of impounded coal refuse has been comprehensively investigated in this research. A group of small-scale model tests and centrifuge model tests were performed on the coal refuse samples under self-weight. The effects of initial water content, driving shear force, and other geotechnical parameters on the flow behavior of coal refuse have been studied. Based on the recorded results, the following conclusions can be drawn:

1) Due to the limited material, the flow velocity of coal slurry changes with distance. The maximum flow velocity measured in the midstream was selected as the representative flow velocity assuming the flow was steady. Accordingly, the recorded flow depth and travel distance in the midstream were used in the analysis.

2) It was found that the velocity and travel distance of coal refuse flow gradually decreased as the initial water content and applied shear stress (or slope angle) reduced. The flow consequently ceased at water content higher than its liquid limit.

3) Although the measured flow velocities in centrifuge model tests were greater than those in small-scale model tests due to the increased stress field (equivalent to the increased volume of impoundment), the obtained flow velocities were still in the same order of magnitude. In addition, the effect of coal waste impoundment volume on the flow velocity was found to be less significant than that of water content.

4) In comparison, the WV sample exhibited more viscous behavior (i.e. slower velocity and thicker flow depth) than KY sample which might be resulted from the higher percent of fine particles and higher viscosity. 
5) The relationships between shear stress and shear rate have been established at different water content by using the approximately constant viscosities at highest shear rate of $60 \mathrm{rpm}$.

6) Different rheological models have been studied in this research. In terms of the developed $\tau-\dot{\gamma}$ curves, it was found that the flow of coal slurry could be considered as Newtonian fluid at higher water content with negligible yield stress. As water content gradually decreased, the flow of coal refuse became heavier and viscous, and behaved as non-Newtonian flow. In order to simplify the investigation and to represent wider range of flow behavior, the flow of coal refuse was expressed as Bingham plastic fluid although the pseudo-Bingham Plastic fluid (Herschel-Bulkley fluid) also was a reasonable match with the shear stress-shear rate relationship of impounded coal refuse.

7) Plastic viscosity $\eta_{p}$ and yield stress $\tau_{y}$ are two primary parameters governing the flow behavior of Bingham Plastic fluid, which could be determined based on the established ${ }^{\tau-\dot{\gamma}}$ curve. Increase of yield stress and plastic viscosity was observed as water content reduced.

8) By studying the flow regime, the coal refuse flow (in the midstream where the flow velocity of coal refuse keeps a constant value) could be considered as a uniform, steady, laminar flow.

9) The obtained profile of coal refuse flow could be described as a solid plug region near the free surface of the flow and underlain by a viscous fluid with a parabolic distribution of flow velocity. As initial water content reduced, the solid plug region near the free surface of flow became more evident. 
10) The viscosity could be considered as a resistance or frictional force within the moving flow which would greatly influence the flow velocity. The higher viscosity at lower water content resulted in slower flow velocity.

11) Although the flow ceased under static loading, a large amount of pore water still existed in the coal refuse making it susceptible to the flow failure under dynamic disturbance.

\subsubsection{Flow Behavior of Impounded Coal Refuse under Impact Loading}

The impact loading such as the blast loading has inverse effects on the stability of tailings dams. The major cause of the failures was believed to be the overall slope stability failure as a result of soil liquefaction. A group of small-scale model tests and centrifuge model tests were performed on the impounded coal refuse samples under a single blast event. The main focus was on the samples that have initial water content below liquid limit to study whether a blasting can trigger flow in this kind of initial condition. Based on the recorded results, the following conclusions can be drawn:

1) Considering the cost, safety, and effectiveness, the monotonic blast loading was simulated by dropping a weight from the top of the pond.

2) The coal refuse samples with lower water content than liquid limit were tested under different compressive strains ranging from $0.1 \%$ to $5 \%$ in small-scale model tests and $3 \%$ to $13 \%$ in centrifuge model tests. Based on performed experiments by Veyera (1985), the soil liquefaction would take place under single compressive strains greater than $0.01 \%$ for soils with low effective stresses and low relative densities and $1 \%$ for soils with high effective stresses and high relative densities 
3) The coal refuse flow would not be triggered by impact loading until compressive strain greater than $1 \%$. As flow started, the solid coal refuse changed into very thick and viscous fluid flowing down the slope.

4) Centrifuge is an effective and economical tool to investigate the flow behavior of coal refuse by generating the realistic stress field and dynamic loading.

5) More evident flow under impact loading was observed in the centrifuge model tests. According to the recorded pore water pressure, soil liquefaction took place under compressive strain greater than 5\%, accompanied by extensive flow of viscous coal refuse.

6) The effect of impact loading became insignificant as water content reduced. No flow was observed at water content a bit higher than its liquid limit. It could be concluded that the coal waste impoundment with initial water content below liquid limit should have sufficient resistance to the dynamic impact disturbance.

\subsubsection{Effectiveness of Slurry Cells as a Countermeasure}

It was noted that the impounded coal refuse could be liquefied under dynamic impact loading. Soil liquefaction would change the coal refuse into heavy fluid producing a large pressure increase on the embankment. Once the failure of tailings dams takes place, the liquefied fine coal resufe with enhanced flowability would result in even more tremendous damages.

In this research, the design of slurry cells was proposed as a countermeasure to improve stability of impoundment under dynamic impact loading. Its effectiveness has 
been evaluated in the centrifuge model tests. Based on the recorded results, the following conclusions can be drawn:

1) Slurry cell is considered as one of the alternatives to coal refuse impoundment which is typically constructed with compacted coarse refuse. The construction of slurry cells is sensitive to the site specific condition which is more suitable for flat land.

2) The prominence of slurry cells is related to its great stiffness and strength, high permeability for consolidation and dissipation of pore water pressure, and availability of coarse refuse materials.

3) No flow was observed under compressive strain as high as $10 \%$. The measured pore water pressure indicated that coal refuse was not liquefied. In addition, the magnitude of pore water pressure recorded in the same location was much less than that in the centrifuge model test without slurry cells.

4) Since coarse refuse built cells improved the permeability of impoundment, apparent dissipation of pore water pressure was observed in the recorded results.

5) Although coal waste impoundment exhibited sufficient resistance to the dynamic impact loading, the influences of slurry cells on the breakthrough potential still need to be validated regarding the fact that the surcharge from the stacked slurry cells will adversely increase the hydrostatic pressure in the fine refuse slurry below the impoundment cap.

\subsection{Recommendations for Future Study}

Recommendations for future work in this research shall include but not limited to: 
1) One of the limitations in this research is the limited amount of impounded coal refuse samples. Although initial water content is considered to be more significant, the volume effect of impoundment on the flow behavior of coal refuse needs to be further validated. If sufficient coal refuse material provided in the physical model tests, the flow would be closer to steady flow making it easier to determine the characteristic flow velocity.

2) In this research, all the laboratory tests and physical model tests were conducted on coal refuse samples obtained from two impoundments. Additional samples from different places need to be tested in order to understand general properties and flow behavior of coal refuses as well as to establish a database for further studies and researches.

3) In the small-scale model tests, the soil liquefaction was estimated according to the measured compressive strain. The empirical approach derived from large number of in-situ and laboratory experiments on soil samples in specific locations may, however, not provide adequate accuracy and applicability on coal refuse samples from different impoundments. The pore pressure transducers suitable in 1-g test or other sensors are needed in order to identify the development of pore water pressure in the dynamic test.

4) The study of non-Newtonian flow of impounded coal refuse is quite complex. Some of the assumptions and approximations proposed in this research have simplified analysis. However, they might induce some discrepancies. The obtained flow behavior of coal refuse as well as rheological parameters needs to be further validated by using 1-g model test and numerical analysis.

5) Although the flow of coal refuse ceased at water content higher than its liquid limit, it is still conservatively recommended to set liquid limit as the critical water content in the design and construction of embankment and impoundment. 
6) It have been demonstrated that impounded coal refuse with initial water content higher than its liquid limit could be liquefied under dynamic impact loading. Particular attentions should be paid to construction of tailings dams (especially in upstream method) where blasting disturbance happens frequently in the adjacent field.

7) Considering the extremely low permeability of fine coal refuse and the fact that strength of impoundment may not be built up over many years, long-term monitoring is recommended for deformation of embankment (i.e. settlement of crest and sliding) and development of pore water pressure in the impoundment. If necessary, periodical in-site tests (i.e. SPT, CPT, seismic method) or laboratory tests (consolidation tests, direct shear tests, triaxial tests) could be conducted in order to determine if adequate strength is developed in the impoundment.

8) Slurry cell has been proven in this research to be an effective and economical countermeasure in resisting dynamic impact loading. However, the construction of slurry cells is dependent on the topography of site and may not be suitable for any place. In addition, the effectiveness of slurry cell on the breakthrough potential needs to be further investigated.

9) In order to mitigate flow failure potential of tailings dams, other alternatives in addition to slurry cells should be explored in the future studies. It may not be a redundant solution to place impoundments away from the mining area in order to prevent breakthrough of coal slurry into underground mines. Therefore, the investigations could also be in a multidisciplinary evaluation which incorporates mechanical, geotechnical, biochemical, and other techniques. 


\section{REFERENCES}

Abdali, S., Mitsoulis, E., \& Markatos, N. (1992). Entry and exit flows of Bingham fluids. Journal of Rheology, 36(2), 389.

Abdel-Ghaffar, M. (1990). The Meaning and Practical Significance of the Cohesion Intercept in Soil Mechanics. Thesis. University of Illinois, Urbana-Champaign, IL.

Administration, M. S. (2009). Engineering And Design Manual Coal Refuse Disposal Facilities. 2nd Edition, MSHA, United States Department of Labor.

Agarwal, V. (2009). Geotechnical investigation of coal mine refuse for backfill in mines. Department of Mining Engineering, National Institute of Technology.

Akayuli, C., \& Ofosu, B. (2013). Empirical Model for Estimating Compression Index from Physical Properties of Weathered Birimian Phyllites. The Electronic Journal of Geotechnical Engineering, 18, 6135-6144.

Aktas, K., \& Woodburn, E. (2000). Effect of addition of surface active agent on the viscosity of a high concentration slurry of a low-rank British coal in water. Fuel Processing Technilogy, 62, 1-15.

Aktas, Z., \& Woodburn, E. (2000). Effect of addition of surface active agent on the viscosity of a high concentration slurry of a low-rank British coal in water. Fuel Processing Technology, 62, 1-15.

Anonymous. (2007). Wikipedia exploration of the consolidation tests. Retrieved from http://en.wikipedia.org/wiki/Consolidation_(soil)\#mediaviewer/File:Consolidation_sprin g_analogy.jpg

Anonymous. (2012). ROTATIONAL VISCOMETER - diagram, schematic, and image 04. Retrieved from http://www.faqs.org/patents/imgfull/20120210774_04

Anonymous. (2013). Wikipedia: exploration of the viscometer. Retrieved from http://en.wikipedia.org/wiki/Viscometer.

Anonymous. (2014). Wikipedia exploration of Buffalo Creek Flood. Retrieved from http://en.wikipedia.org/wiki/Buffalo_Creek_Flood

Anonymous. (2014). Wikipedia exploration of the Newtonian Fluid. Retrieved from http://en.wikipedia.org/wiki/Newtonian_fluid 
Anonymous. (2014). Wikipedia exploration of the non-Newtonian Fluid. Retrieved from http://en.wikipedia.org/wiki/Non-Newtonian_fluid

Anonymous. (2014). Wikipedia: exploration of the Bingham Plastic. Retrieved from http://en.wikipedia.org/wiki/Bingham_plastic

ASTM. (1963). Test method of particle-size analysis of soils. D422. West Conshohocken, Pa: ASTM.

ASTM. (1985). Practice for dry preparation of soil samples for particle size analysis and determination of soil constants. D421. West Conshohocken, Pa.: ASTM.

ASTM. (1985). Standard test methods for Liquid Limit, Plastic Limit and Plasticity Index of soils. D4318. West Conshohocken, Pa: ASTM.

ASTM. (2004). Standard test methods for measurement of hydraulic conductivity of saturated porous materials using a flexible wall permeameter, ASTM D5084-03. West Conshohocken, PA.

ASTM. (2005). Standard Test Methods for One-Dimensional Consolidation Properties of Soils Using Incremental Loading. D2435. West Conshohocken, Pa: ASTM.

ASTM. (2006). Method for Consolidated Drained Triaxial Compression Test for Soils, ASTM D7181-11. West Conshohocken, Pa.

ASTM. (2006). Standard Test Method for Apparent Viscosity of Adhesives Having ShearRate-Dependent Flow Properties Using Rotational Viscometry, ASTM. West Conshohocken, PA.

ASTM. (2006). Standard Test Method for Permeability of Granular Soils (Constant Head), ASTM D2434-68. West Conshohocken, Pa.

ASTM. (2006). Standard Test Method for Shear Viscosity of Coal-Tar and Petroleum Pitches, ASTM. West Conshohocken, PA.

ASTM. (2006). Standard Test Method for Viscosity Determination of Asphalt at Elevated Temperatures Using a Rotational Viscometer, ASTM. West Conshohocken, PA.

ASTM. (2006). Standard Test Methods for Viscosity of Adhesives, ASTM D1084. West Conshohocken, $\mathrm{Pa}$.

ASTM. (2007). Standard Test Method for Unconsolidated-Undrained Triaxial Compression Test on Cohesive Soils, ASTM D2850-03a. West Conshohocken. 
Atesok, G., Boylu, F., Sirkeci, A., \& Dincer, H. (2002). The effect of coal properties on the viscosity of coal-water slurries. Fuel, 81, 1855-1858.

Avegherinos, P., \& Schofield, A. (1969). Drawdown failures of centrifuged models. Proceeding, Seventh International Conference on Soils Mechanics and Foundation Engineering, 2, 497-505.

Balmforth, N., Craster, R., \& Sassi, R. (2002). Shallow viscoplastic flow on an inclined plane. Journal of Fluid Mechanics, 470, 1-29.

Bardet, J. (1997). Experimental soil mechanics. Upper Saddle River, New Jersey 07458: Prentice Hall.

Bilbao, L., Lane, D., Michael, P., Richmond, M., Stoltz, J., Stump, D., \& Superfesky, M. (2011). POTENTIAL OF IMPOUNDED-COAL-WASTE-SLURRY BREAKTHROUGHS INTO UNDERGROUND MINES. U.S. Department of the Interior, Office of Surface Mining Reclamation and Enforcement.

Bishop, A. (1973). The stability of tips and spoil heaps. Quarterly Journal of Engineering Geology, 6, 335-376.

Blight, G. (1969). Waste gypsum as an emabnkment material. Proceedings of Seventh International Conference on Soil Mechanics and Foundation Engineering, 39-43.

Boger, D., Scales, P., \& Sofra, F. (2006). Rheological Concepts. In Paste and Thickened Tailings: a Guide. Australian Centre for Geomechanics, 25-37.

Botsaris, G., \& Glazman, Y. (1988). Interfacial Phenomena in Coal Technology. Marcel Dekker, Inc., New York.

Bowles, J. (1979). Physical and Geotechnical Properties of Soils. New York: McGraw Hill.

Bowles, J. (1992). Engineering properties of soils and their measurement (Fourth ed.). McGraw-Hill Companies.

Boylu, F., Dincer, H., \& Atesok, G. (2004). Effect of coal particle size distribution, volume fraction and rank on the rheology of coal-water slurries. Fuel Processing Technology, 85, 241-250.

Brisson, P., Garga, V., \& Vanapalli, S. (2002). Determination of Unsaturated Flow Characteristics in Mine Tailings. Retrieved from http://by.genie.uottawa.ca/ vanapall/papers/conference/2002/Pat_Sai_CGS2002.pdf 
Brookfield. (2009). Brookfield Viscometer Assignment. Retrieved from http://www.eng.auburn.edu/ drmills/mans382/Viscometer/Brookfield\%20Viscometer\%2 OAssignment.doc

Brookfield Engineering Labs Inc. (2005). More solutions to sticky Problems. Retrieved from http://www.viscometers.org/PDF/Downloads/More\%20Solutions.pdf

Bucky, P. (1931). Use of model for the study of mining problems. American Institution of Mining and Metallurgical Engineers, 425, 3-28.

Burns, C., Gauglitz, P., \& Russell, R. (2010). Shear strength correlations for Kaolin/Water slurries: A comparison of recent measurements with historical data. U.S. Department of Energy, Pacific Northwest National Laboratory, Richland, Washington.

Busch, R.A.; Backer, R.R.; Atkins, L.A.; Kealy, C.D. (1975). Physical Property Data on Fine Coal Refuse. Bureau of Mines, United States Department of The Interior. Spokane, Wash: Spokane Mining Research Center.

Carrier, W. D. (1983). Design Capacity of Slurried Mineral Waste Ponds. Journal of the Geotechnical Engineering Division, ASCE, 109(GT5), 699-716.

Casagrande, A. (1950). Notes on the design of earth dams. Journal of Boston Society of Civil Engineering, Oct., 231-255.

Casagrande, A., \& Poulos, S. (1964). Fourth report on investigation of stress-deformation and strength characteristics of compacted clays. Harvard Soil Mechanics Series No. 74.

Castillo, C., \& Williams, M. (n.d.). Rheology of very concentrated coal suspensions. University of California, Berkeley, Chemical Engineering Series.

Chan, A. (2003). Determination of the Coefficient of Consolidation Using a Least Squares Method. Geotechnique, 53(7), 673-678.

Charlie, W. (1988). Blast induced liquefaction of soils: laboratory and field tests. Research Grant AFOSR-85-0172.

Charlie, W., Veyera, G., \& Muzzy, M. (1982). Shock induced soil liquefaction: test facility development. 28th International Instrumentation Symposium, Instrument Society of America, Las Vegas, NV.

Chen, C., Bullen, A., Vitale, E., \& Elnaggar, H. (1967). Permeability and related properties of coal refuse. Wiley, New York: Engieneering Practice.

Chhabra, R. (2010). Non-Newtonian Fluids: An Introduction. SERC School-cumSymposium on Rheology of Complex Fluids. India: Indian Institute of Technology Madres. 
Chhabra, R., \& Richardson, J. (2008). Non-Newtonian Flow and Applied Rheology. 2nd edition, Oxford, Butterworth-Heinemann.

Chhabra, R., \& Richardson, J. (2008). Non-Newtonian Flow and Applied Rheology. 2nd edition, Oxford, Butterworth-Heinemann.

Committee on Coal Waste Impoundments. (2002). Coal Waste Impoundments: Risks, Responses, and Alternatives. National Academy of Sciences.

Cooke, R. (2002). Laminar flow setting: the potential for unexpected problems. Proceedings of 15th International Conference on Hydrotransport, Banff, Canada.

Corte, J. (1988). Proceedings of the International Conference on Geotechnical Centrifuge Modelling, Paris, April, Balkema.

Coussot, P. (1994). Steady laminar flow of concentrated mud suspension in open channels. Journal of hydraulic research, 32(4), 535-558.

Coussot, P. (1994). Steady, laminar, flow of concentrated mud suspensions in open channel. Journal of Hydraulic Research, 32(4), 535-559.

Craig, W. (1984). The application of centrifuge modelling to design. Proceedings of a Symposium, Manchester, April, Balkema.

Craig, W. (1995). Geotechnical centrifuge: past, present and future. Geotechnical Centrifuge Technilogy, 1-18.

Craynon, J. (2013). Environmental considerations in energy production. Society for Mining, Metallurgy, and Exploration, Inc. (SME).

Damitio, C. (1978). Field experience on blast-induced liquefaction. Int. Workshop on Blast-Induced Liquefaction, Dames and Moore, AFOSR, Maidenhead, U.K., 137-148.

De Kee, D., Chhabra, R., Powley, M., \& Roy, S. (1990). Flow of viscoplastic fluids on an inclined plane: evaluation of yield stress. Chemical Engineering Communications, 96, 229239.

Deng, C., Nio, T., Sanada, Y., \& Chiba, T. (1989). Relationship between swelling of coal particles and apparent viscosity of slurry during coal liquefaction for Akabira coal/creosote oil slurry system. Fuel, 68(9), 1134-1139.

Deysarkar, A., \& Turner, G. (1980). The effect of vibrations on the flow properties of a saturated paste of iron ore and water. International Journal of Mineral Processing, 257276. 
Dobry, R., \& Alvarez, L. (1967). Seismic failures of Chilean tailings dams. Journal of the Soil Mechanics and Foundations Division, ASCE, 93(SM6), 237-260.

Elcometer. (2006). Rotational viscometers. Retrieved from www.elcometer.com

Engin, T., Dogruer, U., Evrensel, C., Heavin, S., \& Gordaninejad, F. (2004). Effect of wall roughness on laminar flow of Bingham plastic fluids through microtubes. Journal of Fluids Engineering, 126, 880-883.

Engineers, U. A. (1982). Engineering and design stability for earth and rock-fill dams. Manual 1110-2-2300. Washington, DC.

Ferrrini, F., Battara, V., Donati, E., \& Piccinini, C. (1984). Optimization of particle grading for high concentration coal slurry. Proc. 9th Int. Conference Hydraulic Transport of Solids in Pipes. Roma.

FHWA. (2007). Pro46 Long Term Pavement Performance Project Laboratory Materials Testing and Handling Guide. United States Department of Transportation - Federal Highway Administration .

Figueroa, J., Saada, A., Dief, H., \& Dietz, C. (1998). Development of the geotechnical centrifuge at Case Western Reserve University. Centrifuge 98, Kimura, Kusakabe \& Takemura (eds). Balkema, Rotterdam, 3-8.

Florin, V., \& Ivanov, P. (1961). Liquefaction of saturated sandy soils. 5th International Conferene on Soil Mechanics and Foundation Engineering, Paris, France, 107-111.

Fragaszy, R., Voss, M., Schmidt, R., \& Holsapple, K. (1983). Laboratory and centrifuge modeling of blast-induced liquefaction. 8th Int. Symposium on Military Application of Blast Simulation, Spiez, Switzerland, Proceedings II, 1-20.

Freme, F., \& Hong, B. (2000). U.S. Coal Supply and Demand: 1999 Review. Energy Information Administration, 8.

Gardner, J., Houston, K., \& Campoli, A. (2003). Alternatives analysis for coal slurry impoundments. SME Annual Meeting, Feb. 24-26, Cincinnati, Ohio.

Garnier, J., Gaudin, C., Springman, S., Culligan, P., Goodings, D., Konig, D., . . Thorel, L. (2007). Catalogue of scaling laws and similitude questions in geotechnical centrifuge modelling. International Journal of Physical Modelling in Geotechnics, 7(3), 1-23.

Haldenwang, R. (2003). Flow of non-Newyonian fluids in open channels. Ph.D. Thesis, Department of Civil Engineering, Cape Technikon. 
Haldenwang, R., Kotze, R., \& Chhabra, R. (2012). Determining the viscous behavior of non-Newtonian fluids in a flume using a laminar sheet flow model and ultrasonic velocity profiling (UVP) system. J. Braz. Soc. Mech. Sci. \& Eng., 34(3), 276-284.

Haldenwang, R., Slatter, P., \& Chhabra, R. (2010). An experimental study of nonNewtonian fluid flow in rectangular flumes in laminar, transition and turbulent flow regimes. Journal of the South African Institution of Civil Engineering, 52(1), 11-19.

Haldenwang, R., Slatter, P., \& Chhabra, R. (2010). An experimental study of nonNewtonian fluid flow in rectangular flumes in laminar, transition and turbulent flow regimes. Journal of the South African Institution of Civil Engineering, 52(1), 11-19.

Hanks, R., \& Pratt, D. (1967). On the flow of Bingham plastic slurries in pipes and between parallel plates. Society of Petroleum Engineers Journal, 1, 342-346.

Hanson, A., DeMouche, L., Lesikar, B., \& Dreager, A. (2013). Onsite wastewater management: a manual for tribes. Las Cruces, NM.: New Mexico State University .

Hegazy, Y., Cushing, A., \& Lewis, C. (2004). Physical, Mechanical and Hydraulic Properties of Coal Refuse for Slurry Impoundment Design. D’Appolonia Engineering, Monroeville, PA .

Henriquez, J., Vandervoort, A., \& Simms, P. (2009). Imaging and modelling of flows of gold paste tailings during deposition - laboratory study and field scale predictions. Paste2009, Australian Centre for Geomechanics, Perth, 31-38.

Hough, B. (1957). Basic Soils Engineering. New York: The Ronald Press Company.

Huang, Y., \& Li, J. (1987). Strength and consolidation characteristics of fine coal refuse. Report to Office of Surface Mining, Department of Interior.

Huang, Y., Li, J., \& Gamini, W. (1987). Strength and consolidation characteristics of fine coal refuse. University of Kentucky Contract Report J5140126 prepared for U.S. Department of Interior Office of Surface Mining Reclamation and Enforcement, Lexington, KY.

Hubert, A. (1963). The behavior of sand in one-dimensional compression. Ph.D. Thesis, Dept. of Civil Engineering, University of Illinois at Urbana.

Idriss, I. (2003). Some considerations in the assessment of the performance of tailings dams during earthquakes. Proceedings o International Workshop on Earthquake Simulation in Geotechnical Engineering, Dept. of Civil Engineering, Case Western Reserve University, Cleveland, Ohio. 
Ishihara, K. (1992). Post-earthquake failure of a tailing dam due to liquefaction of the pond deposite. Proceedings of the Internaional Conference on Case histories in Geotechnical Engineering, University of Missouri, Rolla, Missouri, 3.

Ivanov, P., Sinitsyn, A., \& Musaelyan, A. (1981). Characteristics of soils at cyclic and shock loads. 10 Int. Conf. on Soil Mechanics and Foundation Engineering, Stockholm, Sweden, 3, 239-243.

Jeyapalan, J., Duncan, J., \& Seed, H. (1983). Investigation of Flow Failure of Tailings Dams. Journal of Geotechnial Engineering, 109(2), 172-189.

Jeyapalan, J., Duncan, M., \& Seed, B. (1983). Analyses of flow failures of mine tailings dams. Journal of Geotechnical Engineering, 109(2), 150-171.

Jeyapalan, K. (1980). Analyses of Flow Failures of Mine Tailings Impoundments. Ph.D. Thesis, University of California, Berkeley.

Jones, A., \& Uckert, R. (2006). The investigate of the use of coal mine refuse for subbase material and embankment fill in South Dakota. Billings Land Reclamation Symposium, 3134 Montavesta Rd., Lexington, KY.

Justice, C. (1997). Consolidation and Shear Strength of Coal Slurry. Kentucky: University of Kentucky.

Kailey, P., Bowman, E., Laue, J., \& Springman, S. (2011). Modelling debris flow processes with a geotechnical centrifuge. Italian Journal of Engineering Geology and Environment, 3, 339-349.

Kaji, R., Muranaka, Y., \& Hishinuma, Y. (1986). Effect of electrolyte on the rheological properties of coal-water mixtures. AIChE Spring National Meetings, C3-D1.

Kawatra, S., \& Bakshi, A. (1995). Determination of changes in rheologic properties of coal slurries in process streams. Coal Preparation, 15, 165-175.

Kimura, T. (n.d.). Lecture Presented at U.S. Japan Workshop on Liquefaction, Napa, CA, June . 1993.

Kimura, T., Kusakabe, O., \& Takemura, J. (1998). Centrifuge 98 - Proceedings of the International Conference, IS-Tokyo 98, Tokyo, Japan.

Ko, H., \& Dewoolkar, M. (1998). Modeling liquefaction in centrifuge. Proceedings, Physics Mechanics of Soil Liquefaction, 307-322.

Ko, H., \& McLean, F. (1991). Proceedings of the International Conference Centrifuge 1991, Boulder, Colorado, June, Balkema. 
Kok, L. (1977). The effect of blasting in water-saturated sands. 5th International Symposium on Military Application of Blast Simulation, Stockholm, Sweden, May, 1-10.

Koppula, S. (1978). Statistical Estimation of Compression Index. Geotechnical Testing J, $4(2), 68-73$.

Kotza, R. (2007). Rheological characterization of highly concentrated mineral suspensions using an ultrasonic velocity profiler. Thesis, CAPE PENINSULA UNIVERSITY OF TECHNOLOGY.

Kozicki, W., \& Tiu, C. (1967). Non-Newtonian flow through open channels. The Canadian Journal of Chemical Engineering, 45, 127-134.

Kozicki, W., \& Tiu, C. (1986). Parametric modelling of flow geometries in non-Newtonian flows. Encyclopedia of Fluid Mechanics, 7, 199-252.

Krizek, R. (2004). Slurries in geotechnical engineering. Evanston, Illinois: The Twelfth Spencer J. Buchanan Lecture.

Kurzeme, M. (1971). Liquefaction of saturated granular soils. 1st Australia-New Zealand Conference on Geomechanics, Australian Geomechanics Society, Melbourne, Australia, 1, 45-53.

Kutter, B. (1992). Dynamic Centrifuge Modeling of Geotechnical Structures. Transportation Research Record 1336, TRB, National Research Council, Washington D.C., 24-30.

Kutter, B. (1995). Recent Advances in Centrifuge Modeling of Seismic Shaking. Third International Conference on Recent Advances in Geotechnical Earthquake Engineering and Soil Dynamics, 2, 927-941.

Kwak, M., James, D., \& Klein, K. (2005). Flow behavior of tailings paste for surface disposal. International Journal of Mineral Processing, 77, 139-153.

Lamb, H. (1879). Hydrodynamics. Cambridge University Press. .

Leonards , G., \& Ramiah , B. (1959). Time effects in the consolidation of clays. ASTM STP, 254, 117-130.

Leong, \& Boger, D. (1990). Surface chemistry effects on concentrated suspension rheology. Journal of Colloid and Interface Science, 136(1), 249-258.

Leung, W., Ballard, R., \& Ledbetter, R. (1994). Proceedings of the International Conference Centrifuge 94, Singapore, Balkema. 
Lewis, M. (1989). Water in Earth Science Mapping for planning, development and conservation. (J. A. MCCALL, \& G. A. TROTMAN, Eds.)

Lingeburg, M. (2003). Civil Engineering Reference Manual for the PE Exam. Professional Publications Inc., Belmont, CA.

Liu, G. (2009). Verification of shear wave velocity based liquefaction criteria using centrifuge model. PH.D. Thesis, Department of Civil Engineering, Case Western Reserve University .

Liu, J. (2003). Stability of viscoplastic flow. Geophysical Fluid Dynamics, 232-252.

Liu, L., \& Dobry, R. (1994). Seismic settlement and pore pressure of shallow foundations. Centrifuge 94, Leung, Lee and Ten es, Balkema, Rotterdam, 227-232.

Logos, C., \& Nguyen, Q. (1996). Effect of particle size on the flow properties of a South Australian coal-water slurry. Power Technology, 88, 55-58.

Logos, C., \& Nguyen, Q. (1996). Effect of particle size on the flow properties of a South Australian coal-water slurry. Powder Technology, 88, 55-58.

Lyakhov, G. (1961). Shock waves in the ground and the dilution of water saturated sand. Zhurnal Prikladnoy Mekhaniki i. Tckhricheskoy, Fiziki, Moscow, USSR, 1, 38-46.

Madabhushi, S. (1994). Effect of pore fluid in dynamic centrifuge modeling. Centrifuge 94, Leung, Lee and Tan eds, Balkem, Rotterdam, 127-132.

Mekle, C., Kubota, T., \& Ko, D. (1974). 'An Analytical Study of the effects of surface roughness on boundary layer transition. AF Office of Scientific Res. Space and Missile Sys. Org., Report No. AD/A004786.

Melzer, L. (1978). Blast-induced liquefaction of materials. Nuclear Technology Digest, AFWL-TR-78-110, Air Force Weapons Lab., Kirkland, Air Force Base, Albuquerque, New Mexico, August, 21-38.

Mesri, G., Feng, T., \& Shahien, M. (1999). Coefficient of Consolidation by the Inflection Point Method. Journal of Geotechnical and Geoenvironmental Engineering, 125(GT8), 716-718.

Mezger, T. (2002). The Rheology Handbook: For Users of Rotational and Oscillatory Rheometers. Hannover, Germany .

Michael, P., \& Chavel, L. (2008). Environmental risks associated with coal refuse impoundment reclamation: an assessment of the possibility of an underground mine breakthrough occuring as a result of the impoundment reclamation process. U.S. Office of 
Surface Mining Appalachian Region Management Council Open-File Report, Pittsburgh, $P A, 14$.

Michael, P., Richmond, M., Lane, D., \& Superfesky, M. (2013). Preventing breakthroughs of impounded-coal-waste-slurry into underground mines. U.S. Department of the Interior, Office of Surface Mining Reclamation and Enforcement.

Michael, P., Richmond, M., Superfesky, M., Stump, D., \& Chavel, L. (2010). Potential of breakthroughs of impounded coal refuse slurry into underground mines. Environmental \& Engineering Geoscience, XVI(3), 299-314.

Michalek, S., Gardner, G., \& Wu, K. (1996). Accidental release of slurry and water from coal impoundments through abandoned underground coal mines. Pittsburgh, PA: Mine Safety and Health Administration, Safety and Health Technology Center.

Mikasa, M., \& Takada, N. (1973). Significance of centrifuge model test in soil mechanics. Proceedings, Eighth International Conference on Soil Mechanics and Foundations, 1, 273278.

Mitsoulis, E., Abdali, S., \& Markatos, N. (1993). Flow simulation of Herschel-Bulkley fluids through extrusion dies. Canadian Journal of Chemical Engineering, 71(1), 147-160.

Monte, J. L. (1976). One-Dimensional Mathematical Model for Large-Strain Consolidation. Geotechnique, 26(3), 495-510.

Moon, A. (1984). Effective shear strength parameters for stiff fissured clays. 4th AustraliaNew Zealand Conference on Geomechanics, (pp. 107-111).

Murthy, V. (2002). Geotechnical Engineering: Principles and Practices of Soil Mechanics and Foundation Engineering. New Delhi, DEL, India.

Nagase, A., Kusakabe, O., \& Wong, S.-F. (1984). Centrifuge model tests on bearing capacity of clay. J Geotech Eng Div, ASCE, 110, 1749-1765.

National Research Council. (2002). Coal waste impoundments: risks, responses, and alternatives. National Academy Press, Washington, D.C., 185.

$\mathrm{Ng}$, C. (2014). The state-of-the-art centrifuge modelling of geotechnical problems at HKUST. Journal of Zhejiang University-Science A (Applied Physics \& Engineering), 15(1), 1-21.

Oldroyd, J. (1947). A rational formulation of the equations of plastic flow for a Bingham solid. Mathematical Proceedings of the Cambridge Philosophical Society, 43(1), 100-105. 
Olson, R. (1986). State of Art: Consolidation Testing, Consoli-dation of Soils, Testing and Evaluation. (E. R. N.Yong and F. C. Townsend, Ed.) ASTM STP 892, 7-70.

Olson, R., \& Mesri, G. (1970). Mechanisms controlling the compressibility of clays. J Am Soc Civ Engrs, 96, 1853-1878.

Osborne, D. (1988). Coal Preparation Technology. Norwell, MA: Kluwer Academic Publishers.

Palmer, B., \& Krizek, R. (1987). Thickened slurry disposal method for process tailings. Proceedings of the ASCE Geotechnical Specialty Conference on Geotechnical Practice for Waste Disposal '87, Geotechnical Special Publication (13), ASCE, NY, 728-743.

Philips, C., \& Davis, R. (1991). Determination rheological parameters of debris flow material. Geomorphology, 4, 101-110.

Phillips, R., Guo, P., \& Popescu, R. (2002). Physical Modeling in Geotechnics - ICPMG'02, July, St.John, Canada.

Qiu, Y., \& Sego, D. (1998). Engineering properties of mine tailings. In Proceedings of the 51 st Canadian Geotechnical Conference: Canadian Geotechnical Society,, (pp. 149-154). Vancouver, B.C.

Qu, C., Zhang, X., Chen, S., Li, Y., Pan, F., \& Yao, Y. (2013). Characteristics of capillary sealing mechanism of late quaternary shallow biogenic gas in the hangzhou bay area. Advance in Earth Science, 28(2), 209-220.

Rendon-Herrero, O. (1980). Universal Compression Index Equation. Journal of Geotechnical Engineering Division,ASCE, GT11, 1179-1199.

Rischbieter, F. (1977). Soil liquefaction-a survey of research. Proceedings, 5th International Symposium on Military Application of Blast Simulation, Stockholm, Sweden, $1-24$.

Robinson, R., \& Allam, M. (1998). Effect of Clay Mineral-ogy on Coefficient of Consolidation. Clays and Clay Minerals, 46(5), 596-600.

Round, G., \& Hessari, A. (1985). The effect of size distribution and $\mathrm{pH}$ on the rheology of coal slurries. Part. Multiph. Process. 3, 329-340.

Round, G., \& Hessari, A. (1985). The effect of size distribution and pH on the rheology of coal slurries. Particular Multiphase Process, 3, 329-340.

Saada, A., \& Townsend, F. (1981). State of the art: laboratory strength testing of soils. (R. N. Towsend, Ed.) Laboratory shear strength of soil. ASTM STP 740, 7-77. 
Samarasinghe, A., Huang, Y., \& Drnevich, V. (1982). Permeability and consolidation of normally consolidated soils. J Geotech Eng, ASCE, 108, 835-850.

Sawyer, D., Flemings, P., Buttles, J., \& Mohrig, D. (2012). Mudflow transport behavior and deposit morphology: role of shear stress to yield strength ratio in subaqueous experiments. Marine Geology, 307-310, 28-39.

Schaflinger, U., Acrivos, A., \& Zhang, k. (1990). Viscous resuspension of a sediment within a laminar and stratified flow. International Journal of Multiphase Flow, 16(4), 567578.

Schofield, A. (1980). Cambridge geotechnical centrifuge operations. Geotechnique, 30(3), 227-268.

Shinavski, L. (2006). Overview of impoundment abandonment. Presentation at the U.S. Mine Safety and Healt Administration 2006 Annual Dam Safety Seminar: National Mine Health and Safety Academy, Beaver, WV.

Shook, C., \& Roco, M. (1991). Slurry flow: principles and practice. Butterworth and Heinemann.

Singh, A. (2012). RHEOLOGICAL INVESTIGATION OF COAL WATER SLURRIES WITH AND WITHOUT ADDITIVE, Thesis. Department of Mechnical Engineering, Thapar University, India .

Skempton, A. (1944). Notes on the Compressibility of Clays. Q. J. Geol. Soc. London, 100(1-4), 119-135.

Skempton, A. (1964). Long-term stability of clay slopes. Géotechnique, 14(2), 77-102.

Somogyi, F. (1979). Analysis and Prediction of Phosphatic Clay Consolidation: Implementation Package. Lakeland, Florida: Florida Phosphatic Clay Research Project.

Sowers. (1979). Introductory Soil Mechanics and Foundations: Geotechnical Engineering, 4th Ed. Macmillan, New York.

Spelay, R. (2007). Solids transportation in laminar, open channel flow of non-Newtonian slurry. Ph.D. Thesis, University of Saskatchewan, Saskatoon, Sakatchewan, Canada.

Sridharan, A., \& Nagaraf, H. (2004). Coefficient of Consolidation and its Correlationwith Index Properties of Remolded Soils. Geotechnical Testing Journal, 27(5).

Sridharan, A., \& Nagaraj , H. (2003). Coefficient of Consolidation and its Correlation with Index Properties of Remolded Soils. Geotechnical Testing Journal, 27(5). 
Sridharan, A., \& Prakash, K. (1985). Improved Rectangular Hyperbola Method for Determination of Coefficient of Consolidation. Geotechnical Testing Journal, 8(3), 37-40.

Sridharan, A., \& Prakash, K. (1995). Critical Appraisal of Labo-ratory Determination of cv. International Symposium on Com- pression and Consolidation of Clayey Soils (pp. 567572). Hiroshima, Japan: Balkema Publishers.

Sridharan, A., \& Rao, G. (1976). Mechanisms controlling volume change of saturated clays and the role of effective stress concept. G6otechnique, 32, 249-260.

Steedman, R. Z. (1990). The seismic response of waterfront retaining walls. Design and Performance of Earth Retaining Structures, ASCE Special Publication(25), 872-886.

Stewart, D., Chen, Y., \& Kutter, B. (1998). Experience with the use of Methylcllulose as a viscous pore fluid in centrifuge models. Geotechnical Testing Journal, 21(4), 365-369.

Stout, B., Papillo, J., McAteer, D., Childers, H., Hoover, J., Higginbotham, J., \& Quaranta, J. (2004). Coal slurry impoundment location and warning system. Tailings and Mine Waste, Taylor and Francis Group, London, 275-278.

Straub, L., Silberman, E., \& Nelson, H. (1958). Open channel flow at small Reynolds numbers. American Society of Civil Engineers, 123, 685-713.

Studer, J., \& Kok, L. (1980). Blast-induced excess porewater pressure and liquefaction: experience and application. Int. Symposium on Soils under Cyclic and Tranient loading, Swansea, UK, 581-593.

Studer, J., \& Prater, E. (1977). An experimental and analytical study of the liquefaction of saturated sands under blast loads. Int. Conf. on Numerical Methods in Soil and Rock Mechanics, Karsruhe, Germany, 2, 217-238.

Suthaker, N., \& Scott, J. (1994). Large scale consolidation testing of oil sand fine tails. In Proceedings of the International; Congress of Environmental Geotechnics: Geotechnical and Related Aspects of Waste Management Associated with Municipal, Mine, Industrial, and Nuclear Wastes: Canadian Geotechnical Society, Edmonton, AB (Canada), 149-154.

Suthaker, N., Scott, J., \& Miller, W. (1997). The first fifteen years of a large scale consolidation test. Proceedings of the 50th Canadian Geotechnical Conference: Canadian Geotechnical Society, Ottawa, Ontario, 476-483.

Swamee, P., \& Aggarwal, N. (2011). Explicit equations for laminar flow of Bingham plastic fluids. Journal of Petroleum Science and Engineering, 76, 178-184. 
Sweigard, R., Hopkins, T., Justice, C., Beckman, T., Thompson, E., \& Rohlf, R. (1997). Impact of consolidation on the shear strength of coal refuse impoundments. SME Annual Meeting, Denver, CO.

Tani, I. (1969). Boundary Layer Transition. Annual Reviews of Fluid Mechanics. Annual Reviews, Tiago, Palo Alta, CA, 1.

Taylor, D. (1948). Fundamentals of Soil Mechanics. New York: John Wiley and Sons.

Taylor, R. (1995). Centrifuges in Modelling: Principles and Scale effects. Geotechnical Centrifuge Technilogy, Blackie Academic and Professional, Glasgow, 19-33.

Ter-Stepanian, G. (1963). On the long-term stability of slopes. Norwegian Geotech. Institute, Publication, 52, 1-14.

Ter-Stepanian, G., \& Goldstein, M. (1969). Multistoreyed Landslides and the strength of soft clays. Proceedings, Seventh International Conference on Soil Mechanics and Foundation Engineering, 2, 693-700.

Terzaghi, K. (1931). The static rigidity of plastic clays. Journal of Rheology, 2(3), 253262.

Terzaghi, K., \& Peck, R. (1967). Soil Mechanics in Engineering Practice. New York: John Wiley and Sons.

Thacker, B., Ullrich, C., Athanasakes, J., \& Smith, G. (1988). Evaluation of a refuse impoundment built by the upstream method. ASCE Geotechnical Special Publication, No.21, 730-749.

Thomson, S., \& Kjartanson, B. (1985). Study of delayed failure in a cut slope in stiff clay. Canadian Geotechnical Journal, 22(2), 286-297.

U.S. Mine Safety and Health Administration. (2001). Report of Investigation: Noninjury Impoundment Failure/Mine Inundation Accident. Mine Safety and Health Administration, Arlington, VA, 71 pp. plus appendices.

Vallejo, L., \& Scovazzo, V. (2003). Determination of the shear strength parameters associated with mudflows. Soils and Foundations, 43(2), 119-133.

Van Der Kogel, H., Van Loon-Engels, C. H., \& Ruygrok, P. (1981). Wave propagation in porous media, shock tube experiments. 10th International Conference on Soil Mechanics and Foundation Engineering, Stockholm, Sweden, 253-256. 
Veyera, G. (1985). Transient porewater pressure response and liquefaction in a saturated sand. Ph.D. Thesis, Department of Civil Engineering, Colorado State University, Fort Collins, Colorado.

Vlachopoulos, J., \& Strutt, D. (2003). The Role of Rheology in Polymer Extrusion. In: Proceedings of New Technologies for Extrusion. Milan: SPIE, (pp. 1-25).

Volpe, R. (1979). Physical and engineering properties of copper tailings. Current Geotechnical Practice in Mine Waste Disposal, ASCE Monograph.

Wakeley, L., \& Peterson, R. (2004). comments to Peter Michael of the U.S. Office of Surface Mining Comments on the OSM Draft Report Entitled "The Flowabilityof Impounded Coal Refuse". Vicksburg, MS.: U.S. Army Engineer R\&D Center Geotechnical and.

West, T. (1995). Geology applied to engineering. Prentice Hall.

Whitman, R., \& Lambe, P. (1988). Earthquake like shaking of a structure founded on saturated sand. Centrifuge 88, Corte ed, Balkema, Rotterdam, 529-538.

Whitman, R., \& Ting, N. (1993). Experimental results for tilting wall with saturated backfill. Verification of Numerical Procedures for the Analysis of Soil Liquefaction Problems, 2, 1515-1528.

Whitney, E., Moudgil, B., \& Onoda, G. (1977). Dewatering of phosphatic clay wastes. Report of Department of Material Science and Engineering, University of Florida.

Widodo, S., \& Ibrahim, A. (2012). Estimation of Primary Compression Index (Cc) Using Physical Properties of Pontianak Soft Clay. International Journal of Engineering Research and, 2(5), 2232-2236.

Wilson, S., \& Marsal, R. (1979). Current trends in design and construction of embankment dams. prepared for International Commission on Large Dams and Geotechnical Division of the American Society of Civil Engineers. New York: American Society of Civil Engineers.

Wilson, S., \& Taylor, A. (1996). The channel entry problem for a yield stress fluid. Journal of Non-Newtonian Fluid Mechanics, 65, 165-176.

Worth, C., \& Wood, D. (1978). The correlation of Index Properties with Some Basic Engineering Properties of Soils. Canadian Geotechnical Journal, 15, 137-145.

Woskoboenko, F., Siemon, S., \& Creasy, D. (1989). The rheology of Victorian brown coal slurries: 2. Effect of pH. Fuel, 68, 120-124. 
Wu, K., Owens, H., \& Fredland, J. (2003). MSHA's Review of Impoundment Plans. Presentations, International Workshop on Seismic Stability of Tailings Dams.

Xia, Y., Wang, W., \& Xu, Z. (2009). Numerical Computation of Laminar Flow Pipeline Transport Axial Flow Field. Information Technology and Computer Science, 2, 196-199.

Zeng, X. (2003). Challenges in seismic stability analysis of tailings dams. International Workshop on Seismic Stability of Tailings Dams, Case Western Reserve University, Cleveland, $\mathrm{OH}$.

Zeng, X. W. (1998). Influence of viscous fluids on properties of sand. Geotechnical Testing Journal, 21(1), 45-51.

Zeng, X., Wu, J., \& Rohlf, R. (1998a). Modeling the seismic response of coal-waste tailings dams. Geotechnical News, 29-32.

Zeng, X., Wu, J., \& Rohlf, R. (1998b). Seismic stability of coal-waste tailings dams. Geotechnical Earthquake Engineering and Soil Dynamics III, 951-961.

Zeng, X., Wu, J., \& Rohlf, R. (1998c). Response of coal-waste tailings dams under simulated earthquake loading. Proceedings of Centrifuge 98, Tokyo, Japan, 255-260.

Zhang, H., \& Ren, Z. (1982). Discussion of resistance of hyperconcentrated flow in open channels. Scientia Sinica (Series A), 1332-1342.

Zook, R., Olup, B., \& Pierre, J. (1974). Engineering evaluation of coal refuse slurry impoundments. AIME Annual Meetingm Dallas, Texas. 